\title{
VALIDATION OF WIND-DRIVEN RAIN MODULE FOR HAM-TOOLS
}

\author{
by \\ Sam Siassi \\ BASc with Honours, York University, 2009 \\ A thesis \\ presented to Ryerson University \\ in partial fulfillment of the \\ requirements for the degree of \\ Master of Applied Science \\ in the Program of \\ Building Science
}

Toronto, Ontario, Canada, 2013

CSiassi, Sam 2013 


\section{Author's Declaration}

I hereby declare that I am the sole author of this thesis. This is a true copy of the thesis, including any required final revisions, as accepted by my examiners.

I authorize Ryerson University to lend this thesis to other institutions or individuals for the purpose of scholarly research.

I further authorize Ryerson University to reproduce this thesis by photocopying or by other means, in total or in part, at the request of other institutions or individuals for the purpose of scholarly research.

I understand that my thesis may be made electronically available to the public. 
Validation of Wind-Driven Rain Module for HAM-Tools

Sam Siassi, Master of Applied Science, 2013

Building Science, Ryerson University

\begin{abstract}
This study is a continuation of previous research carried out to improve the hygrothermal analysis capabilities of the readily available HAM-Tools building simulation software. Previous study intended to improve the program by adding a wind driven rain (WDR) module using the semi-empirical model from ASHRAE 160P. However, further verification of the model was needed. In this study, the WDR module's verification process was corrected and compared to WUFI simulation. The module was then validated by comparing its results with field measurements. The results indicated that the newly designed HAM-Tools WDR module have good agreement with field measurements. HAM-Tools with added WDR module is then used to study the hygrothermal responses of wood-frame wall with WDR amount calculated using different averaging techniques of high resolution meteorological data. It was concluded that in climates with high rainfall, it is best to use high resolution data (at least 10 minutes) for hygrothermal simulations.
\end{abstract}




\section{Acknowledgements}

I would like to express my appreciation to my supervisors, Dr. Miljana Horvat and Dr. Hua Ge. You have given me a great opportunity to work on this project that made me strive both personally and academically. Thank you for finding the time to help me complete this paper. Given the difficulties of long distance communication with Dr. Ge during the time she was in Concordia, and with Dr. Horvat when she was on sabbatical in Sweden, I was very pleased to have their support throughout my entire study period. Your encouragement and funding not only helped me complete my masters degree, but it also broadened my expertise and vision in building science and in life. I would also like to thank you for the extensive support that you gave me for reviewing my paper and its results, especially during the last couple of months.

I would also like to thank the members of my committee, Dr. Gorgolewski, Dr. Richman, and Professor Straka, who spent the time to read my paper and gave me advice and suggested the necessary corrections in order to complete my paper.

Finally, I would like to extend my gratitude towards my brother and my parents who believed in me, supported me every step of the way, and helped me achieve this wonderful goal. 


\section{Table of Contents}

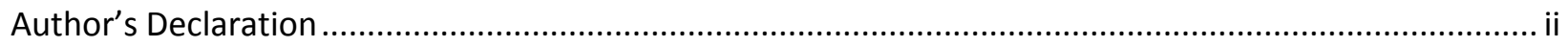

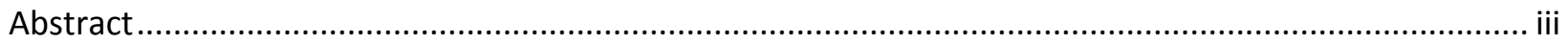

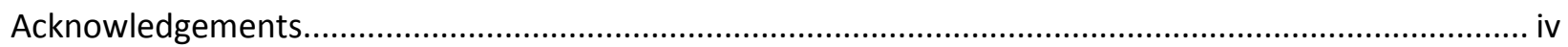

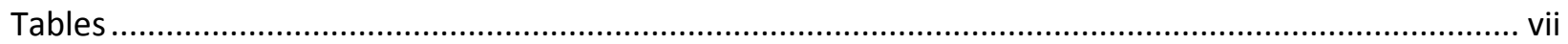

Figures

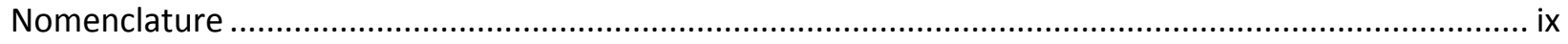

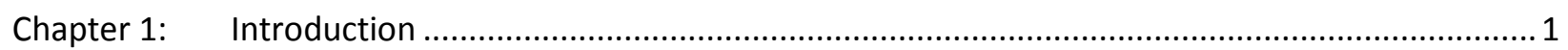

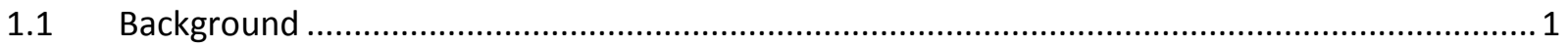

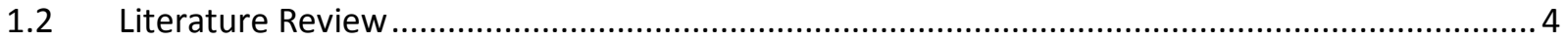

1.2.1 Moisture Storage and Transport in porous materials..................................................... 4

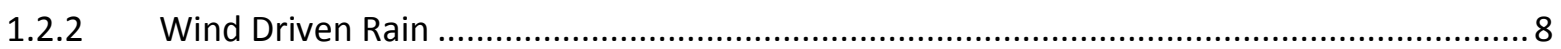

1.2.3 Impact of time resolution of WDR data on hygrothermal performance of building

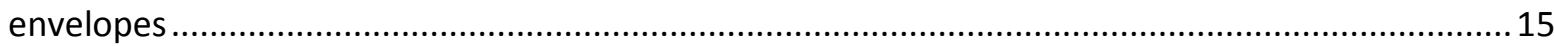

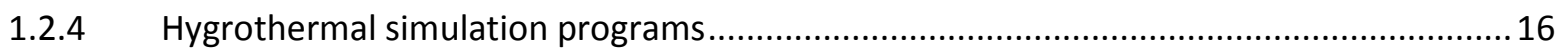

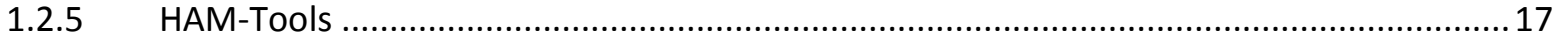

1.2.6 Integration of Wind-Driven-Rain module in HAM-Tools ............................................... 19

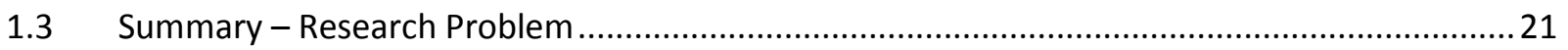

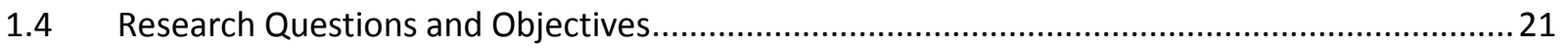

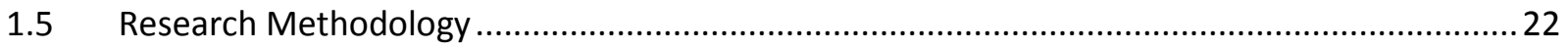

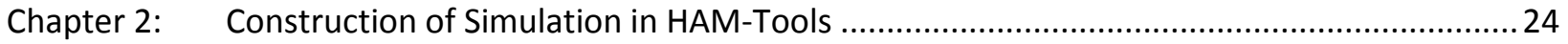

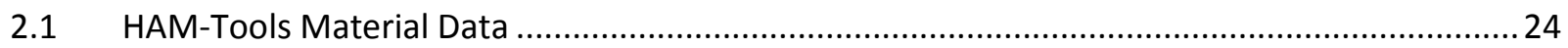

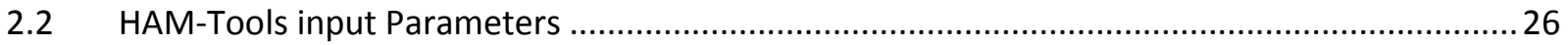

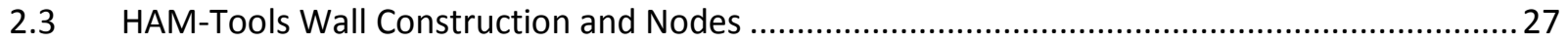

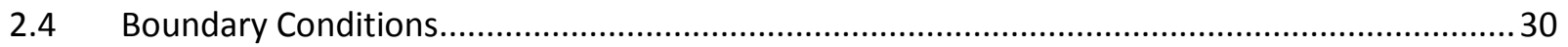

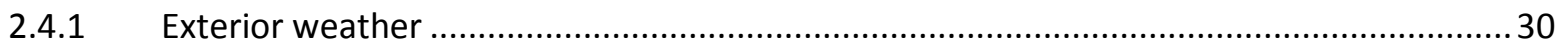

2.4.2 Software Input Requirements for weather data............................................................ 30

2.4.3 Formatting the weather data................................................................................... 32

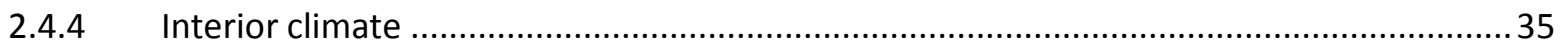

2.4.5 Development of Wind Driven Rain in HAM-Tools Software ............................................. 35

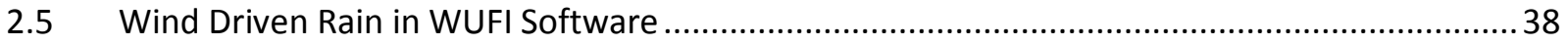




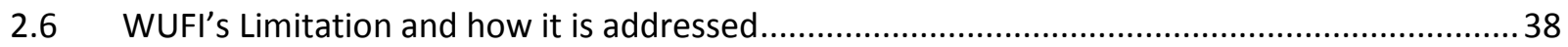

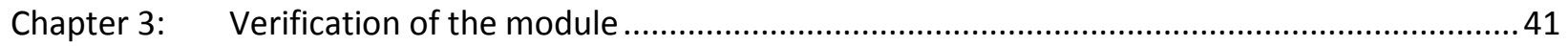

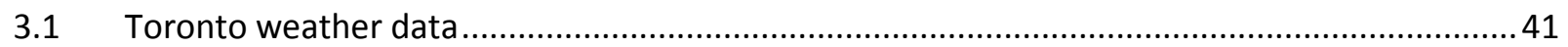

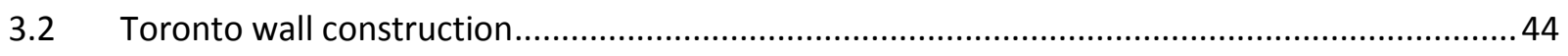

3.3 Water Transport properties Conversion .............................................................................. 47

3.3.1 Retention curve comparison between measured data and WUFI database.....................49

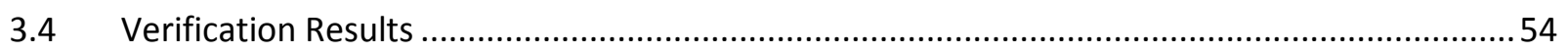

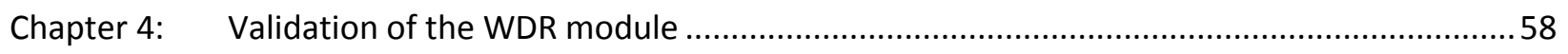

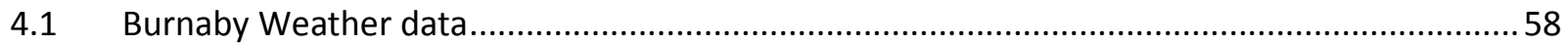

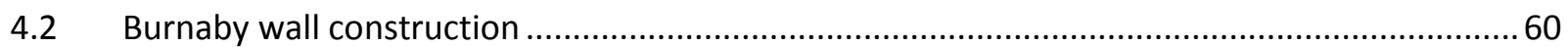

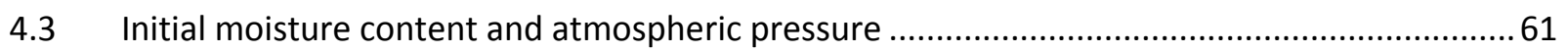

4.4 Sensor placements and results from field measurements ..................................................64

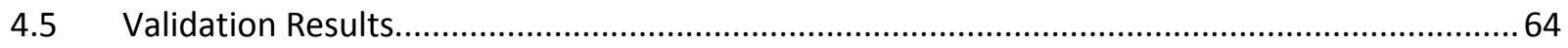

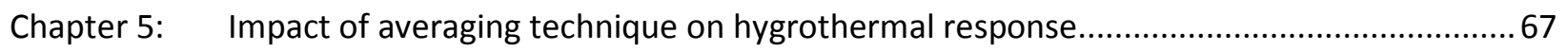

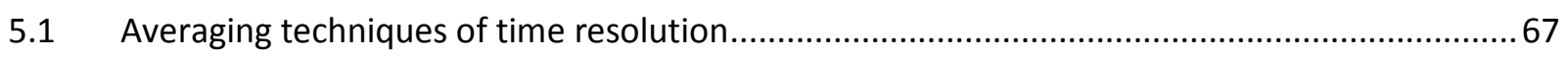

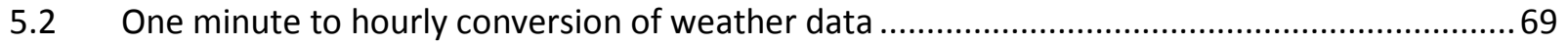

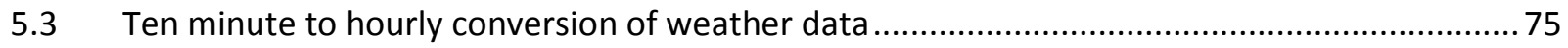

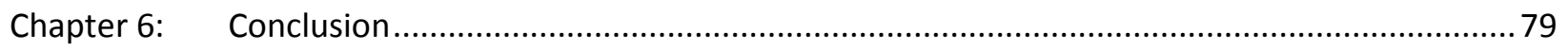

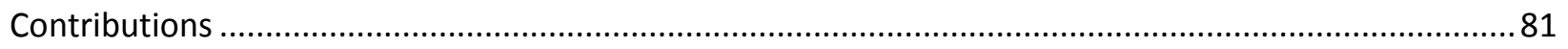

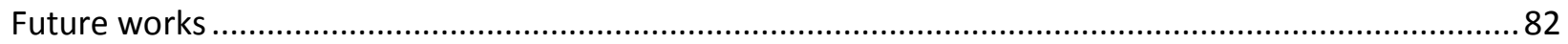

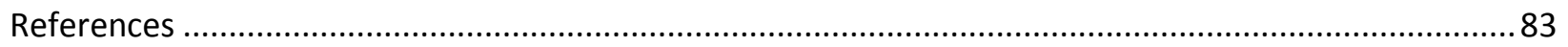

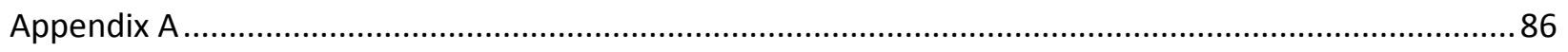

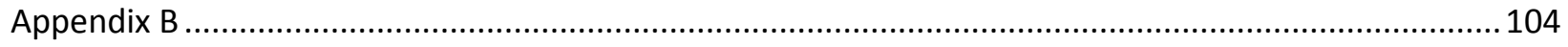

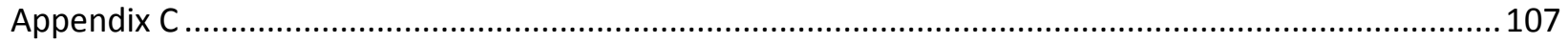

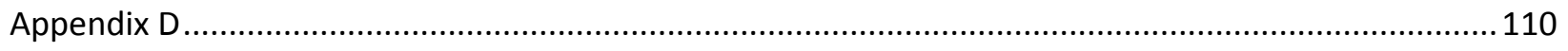

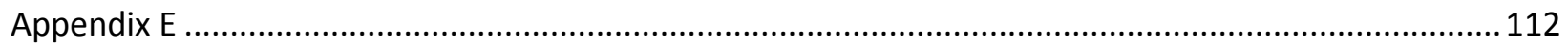

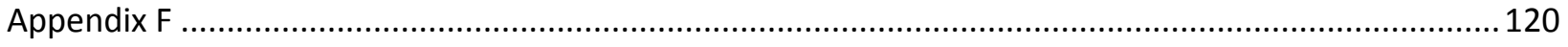

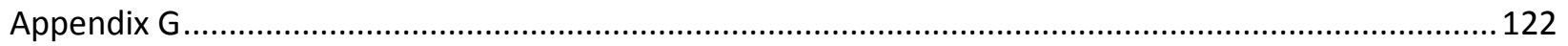




\section{Tables}

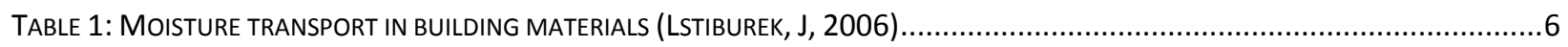

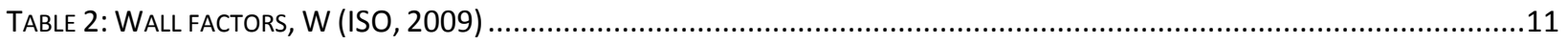

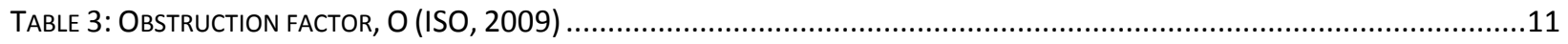

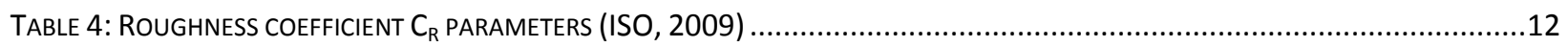

TAble 5: HAM-Tools Weather data format (Kalagasidis, Weitzmann, Nielsen, Peuhkuri, Hagentoft, \& Rode, 2007).......31

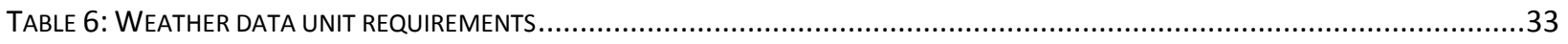

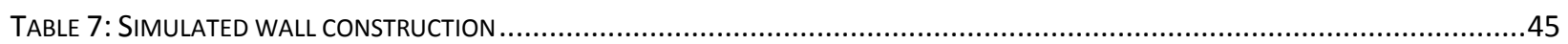

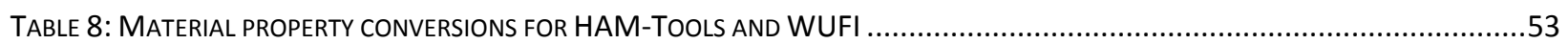

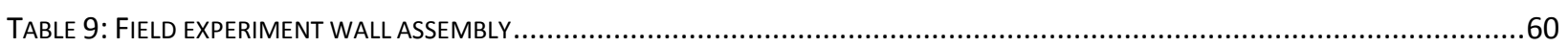

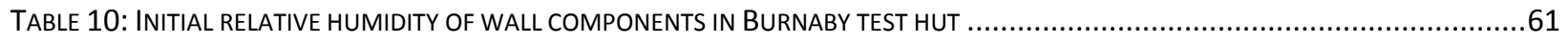

TABLE 11: SUMMARY OF HOURLY AVERAGING TECHNIQUES FOR EACH CALCULATED WEATHER DATASET........................................69

\section{Figures}

FIGURE 1: MOISTURE STORAGE FUNCTION OF A TYPICAL HYGROSCOPIC CAPILLARY-ACTIVE BUILDING MATERIAL (KÜNZEL, 1995) .............6 FIGURE 2: RAIN ADMITTANCE FACTORS (RAF) FOR (A) LOW-RISE BUILDING WITH H/W MUCH LESS THAN 1; (B) TALL BUILDING (>10 M) WITH H/W MUCH GREATER THAN 1; (c) LOW-RISE BUILDING WITH SLOPED ROOF AND ROOF OVERHANG (STRAUBE \& BURNETT,

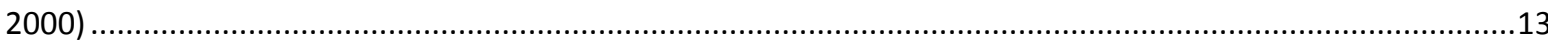

FIGURE 3: COMPARISON OF DIFFERENT WOOD SIDINGS FROM HAM-TOOLS AND WUFI DATABASE (WU, GE, \& HORVAT, 2012) .........20

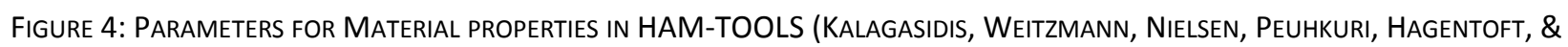

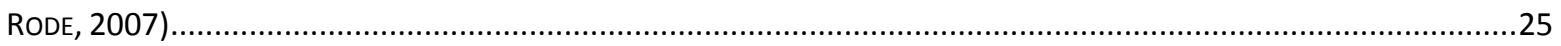

FIGURE 5: CONSTRUCTION BLOCK PROPERTIES MENU FOR MATERIAL INPUTS (SCREENSHOT FROM HAM-TOOLS) .............................26

FIGURE 6: CONFIGURATION MENU TO SET THE TIMESTEP OUTPUT (FROM HAM-TOOLS SOFTWARE) ...........................................27

FIGURE 7: BLOCK FOR MATERIAL WITHIN THE WALL CONSTRUCTION (SCREENSHOT FROM HAM-TOOLS) ......................................28

FIGURE 8: CONNECTION BETWEEN THREE LAYERS (SCREENSHOT FROM HAM-TOOLS) ........................................................28

FIGURE 9: THE THREE NODES PRESENTED IN ONE OF THE LAYERS (SCREENSHOT FROM HAM-TOOLS) .........................................29

FIGURE 10: WUFI UTILITY PROGRAM FOR CREATING CUSTOMIZED WEATHER FILE (FROM WUFI CREATECLIMATEFILE.XLS UTILITY)..........32

Figure 11: (ABOVE) CALCULATION OF RH FROM teMPERATURE AND SATURATION PRESSURE. (BelOW) CALCULATION OF PARTIAL OR

SATURATED PRESSURE FROM GIVEN TEMPERATURE (FROM HAM-TOOLS SOFTWARE) ................................................34

FIGURE 12: HEAT AND MOISTURE BALANCE IN THE EXTERNAL SURFACE (OBTAINED FROM HAM-TOOLS SOFTWARE) ..........................36

FIGURE 13: WEATHER ON SURFACE BLOCK UNDER THE CONSTRUCTION BLOCK (FROM HAM-TOOLS SOFTWARE) .............................36

FIGURE 14: AdDED WDR MOdULE TO HAM-TOOLS (WU, GE, \& HORVAT, 2012) ............................................................38

FIGURE 15: WUFI WALL CONSTRUCTION WITH OUTER LAYER DIVIDED IN ONE SECTION (FROM WUFI SOFTWARE) .............................39

FIGURE 16: WUFI WALL CONSTRUCTION WITH OUTER LAYER DIVIDED IN 3.5 SECTIONS (FROM WUFI SOFTWARE) ...........................40

FIGURE 17: LOCATION OF 04741 WEATHER STATION IN TORONTO, ON, CANADA (FROM HTTP://WWW.STATCAN.GC.CA/) ................41

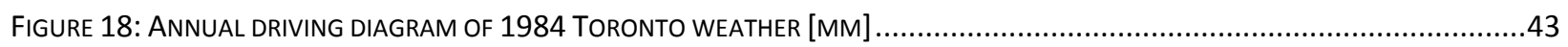

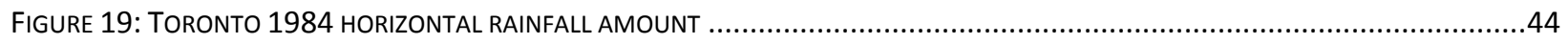

FIGURE 20: WALL CONSTRUCTION IN HAM-TOOLS (FROM HAM-TOOLS SOFTWARE) ........................................................46

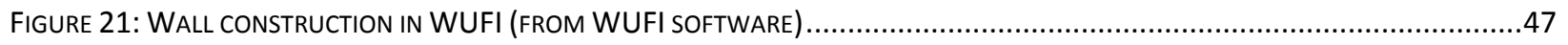

FIGURE 22: COMPARISON OF SORPTION ISOTHERM FOR AERATED CONCRETE BETWEEN JENZ MEASUREMENT AND WUFI'S DATABASE ....50

Figure 23: Retention CURVE Of AUtOCLAVED AERATED CONCRETE (JANZ \& AND JOHANNESSON, 2001) ..................................51 
FIGURE 24: COMPARISON OF HYDRAULIC CONDUCTIVITIES OF AERATED CONCRETE CALCULATED USING INFORMATION FROM LITERATURE AND WUFI.

FIGURE 25: (LEFT) COMPARISON OF MOISTURE CONTENT IN HAM-TOOLS SIMULATION. (RIGHT) THE RESULTING DIFFERENCE FOR THE COMPARISON

Figure 26: (ABOVE) COMPARISON OF MOISTURE CONTENT BETWEEN HAM-TOOLS AND WUFI FOR THE OUTER LAYER WITHOUT THE WIND DRIVEN RAIN MODULE. (BELOW) THE RESULTING DAILY AVERAGED DIFFERENCE FOR THE COMPARISON.

FIGURE 27: (ABOVE) COMPARISON OF MOISTURE CONTENT BETWEEN HAM-TOOLS AND WUFI FOR THE OUTER LAYER WITH THE WIND DRIVEN RAIN MODULE. (BELOW) THE RESULTING DAILY AVERAGED DIFFERENCE FOR THE COMPARISON ..................................55

FIGURE 28: (ABOVE) COMPARISON OF MOISTURE CONTENT IN OUTER LAYER BETWEEN HAM-TOOLS AND WUFI WITH THE WIND DRIVEN RAIN MODULE. (BELOW) THE RESULTING DAILY AVERAGED DIFFERENCE FOR THE COMPARISON.........................................56

FIGURE 29: (ABOVE) COMPARISON OF MOISTURE CONTENT IN PLYWOOD BETWEEN HAM-TOOLS AND WUFI WITH THE WIND DRIVEN RAIN MODULE. (BELOW) THE RESULTING DAILY AVERAGED DIFFERENCE FOR THE COMPARISON.........................................57

FIgURE 30: BUILDING ENVELOPE TEST FACILITY (BETF) SITE PLAN IN BCIT'S BURNABY CAMPUSES (SIMPSON \& AND GE, 2010) ..........58

FIGURE 31: ANNUAL WIND ROSE DIAGRAM OF BURNABY HOURLY WEATHER DATA [MM] .................................................59

FIGURE 32: COMPARISON OF PLYWOOD'S MOISTURE CONTENT WITH DIFFERENT INITIAL CONDITIONS IN OTHER LAYERS .......................62

FIGURE 33: COMPARISON OF PLYWOOD'S MOISTURE CONTENT IN WUFI WITH AND WITHOUT THE INCLUSION OF ATMOSPHERIC PRESSURE

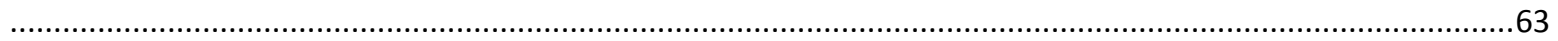

FIGURE 34: COMPARISON OF AVERAGE MC OF PLYWOOD IN BD7 WALL (SIMPSON \& AND GE, 2010) ......................................64

Figure 35: (ABOVE) COMPARISON OF MOISTURE CONTENT OF PlyWOOd BETWEen SiMULATEd (HAM-TOOLS) AND MEASURED DATA. (BELOW) THE RESULTING DAILY AVERAGED DIFFERENCE FOR THE COMPARISON ......................................................65

Figure 36: (ABOVE) COMPARISON OF MOISTURE CONTENT OF PlyWOOd BETWEen SiMULATEd (HAM-TOOLS) AND MEASUREd (BCIT) DATA WITH 38\% HIGHER RH OF THE INSULATION. (BELOW) THE RESULTING DIFFERENCE FOR THE COMPARISON .......................66

FIGURE 37: DRIVING RAIN SUM FOR THE SELECTED PERIOD FROM 1-MUNTE RESOLUTION WEATHER DATA [MM] .............................70

FIGURE 38: DRIVING RAIN SUM FOR THE SELECTED PERIOD FROM 1-MINUTE RESOLUTION WEATHER DATA [MM] ............................72

FIGURE 39: MOISTURE CONTENT COMPARISON ON THE OUTER LAYER BETWEEN DIFFERENT WEATHER DATASETS CREATED FROM 1 MINUTE

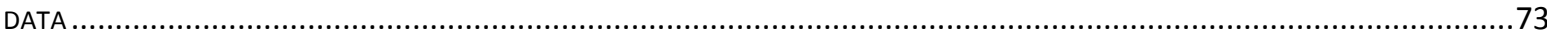

FIGURE 40: MOISTURE CONTENT COMPARISON ON THE PLYWOOD BETWEEN DIFFERENT WEATHER DATASETS CREATED FROM 1 MINUTE

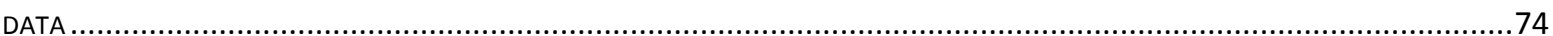

FIGURE 41: DRIVING RAIN SUM FOR THE SELECTED PERIOD FROM 10-MUNTE RESOLUTION WEATHER DATA [MM] ...........................76 FIGURE 42: MOISTURE CONTENT COMPARISON ON THE OUTER LAYER BETWEEN DIFFERENT WEATHER DATASETS CREATED FROM 10 MINUTE DATA .77 


\section{Nomenclature}

\begin{tabular}{|c|c|c|}
\hline Symbol & Description & Unit \\
\hline $\mathrm{C}_{\mathrm{r}}$ & Roughness coefficient & \\
\hline $\mathrm{C}_{\mathrm{t}}$ & Topography coefficient & {$\left[\mathrm{m}^{2} / \mathrm{s}\right]$} \\
\hline $\mathrm{D}$ & Direction of calculation & $\circ$ \\
\hline $\mathrm{D}_{\mathrm{w}}$ & Liquid transport coefficient & {$\left[\mathrm{m}^{2} / \mathrm{s}\right]$} \\
\hline $\mathrm{D}_{\varphi}$ & Freezing limit potential & \\
\hline $\mathrm{F}_{\mathrm{D}}$ & rain deposition factor & \\
\hline $\mathrm{F}_{\mathrm{E}}$ & Rain exposure factor & \\
\hline $\mathrm{F}_{\mathrm{L}}$ & empirical constant (0.2) & {$\left[\mathrm{kg} \cdot \mathrm{s} /\left(\mathrm{m}^{3} \cdot \mathrm{mm}\right)\right]$} \\
\hline$g_{w}$ & Liquid moisture flux (or density of moisture flow rate) & {$\left[\mathrm{kg} / \mathrm{m}^{2} \mathrm{~s}\right]$} \\
\hline $\mathrm{I}_{\mathrm{A}}$ & Driving rain sum & {$[\mathrm{mm} /$ year] } \\
\hline K & Hydraulic conductivity & {$[\mathrm{s}]$} \\
\hline $\mathrm{K}_{\mathrm{R}}$ & Terrain factor & \\
\hline $\mathrm{M}_{\mathrm{w}}$ & Molar weight of water (0.018) & {$[\mathrm{Kg} / \mathrm{mol}]$} \\
\hline $\mathrm{N}$ & Number of years & \\
\hline 0 & Obstruction factor & \\
\hline$P$ & Atmospheric pressure & {$[\mathrm{Pa}]$} \\
\hline $\mathrm{p}_{\mathrm{v} . \mathrm{sat}}$ & Partial pressure of water vapour in air at saturation & {$[\mathrm{Pa}]$} \\
\hline $\mathrm{P}_{\text {suc }}$ & Suction pressure & {$[\mathrm{Pa}]$} \\
\hline $\mathrm{R}$ & Ideal gas constant (8.314) & {$[\mathrm{j} /(\mathrm{mol} . \mathrm{k})]$} \\
\hline $\mathrm{R}_{\mathrm{h}}$ & Unobstructed horizontal rainfall intensity & {$[\mathrm{mm}]$} \\
\hline $\mathrm{R}_{\mathrm{wdr}}$ & Wind driven rain intensity & {$[\mathrm{mm} / \mathrm{h}]$} \\
\hline $\mathrm{T}$ & Thermodynamic temperature & {$[\mathrm{K}]$} \\
\hline $\mathrm{T}^{\prime}$ & Absolute temperature & {$[\mathrm{K}]$} \\
\hline U & Wind speed & {$[\mathrm{m} / \mathrm{s}]$} \\
\hline
\end{tabular}




\begin{tabular}{|lll|}
\hline$V_{t}$ & Raindrop terminal velocity & {$[\mathrm{m} / \mathrm{s}]$} \\
$w$ & Liquid moisture flux & {$\left[\mathrm{kg} / \mathrm{m}^{3}\right]$} \\
$\mathrm{Z}_{0}$ & Wall factor & \\
$\mathrm{z}$ & Aerodynamic roughness length & {$[\mathrm{m}]$} \\
$\mathrm{d} / \mathrm{dx}$ & Height & {$[\mathrm{m}]$} \\
$\alpha$ & & \\
$\theta$ & Differentiating in the $x$ direction & \\
$\rho_{\mathrm{w}}$ & Angle between wind direction and normal to facade & {$\left[\mathrm{kg} / \mathrm{m}^{3}\right]$} \\
$\varphi$ & Density of water (1,000) & \\
$\varphi_{\mathrm{e}}$ & Relative Humidity & \\
\hline
\end{tabular}




\section{Chapter 1: Introduction}

\subsection{Background}

Buildings are designed to keep the occupants healthy, safe and comfortable by creating a space isolated from the outdoor surroundings and an environment that can be controlled. Buildings are also expected to be durable and energy efficient. It has been estimated that most of problems that occur for building envelope are caused by moisture (Trechsel, 1994). Moisture related problems include increased energy use, decreased performance of heating, ventilation and air conditioning (HVAC) systems, decreased indoor air quality, and reduction in durability of the envelope (ASHRAE, 2001). The moisture transfer between building envelope and indoor air can create conditions for mould and bacteria to grow (Joseph, Arumala, \& Masce, 2006). Mould growth significantly affects air quality and comfort that can cause respiratory infections and increase the risk of asthma (Rode, Grau, \& Mitamura, 2001). Moreover, moisture accumulation in building envelope can result in cracking, crazing, spalling, delamination and disintegration of structure and building envelope (Bomberg, 1974). This decreases the durability and integrity of the building envelope, which can lead to increase in energy use of the building (ASHRAE, 2001). Therefore, the knowledge of moisture storage and transport in building materials is necessary to ensure proper performance of building envelopes.

Depending on the environmental conditions, the moisture in building materials can be present in solid, liquid or vaporous form. Depending on the relative humidity of the ambient, moisture in porous materials may be stored as single-layer or multi-layer adsorption molecules, discontinued capillary condensates, or continuous capillary liquid water. The mechanism that transports moisture through materials is governed through vapour diffusion, surface diffusion, capillary conduction, and convection due to gravitation and pressure differential (Künzel, 1995). Many construction materials are porous 
which allow water to be stored or transported through them. Heat, air and moisture all affect the water transport and evaporation through construction materials.

Wind driven rain is one of the most important boundary conditions and the main moisture source that affects the hygrothermal performance and durability of building envelopes (Kumaran \& Sanders, 2008). Wind driven rain can penetrate through the building facade, which potentially damages the building envelope and reduces its performance and service life. One of the notable examples is the leaky condo crisis in the lower mainland of British Columbia, where exterior moisture penetrated through the envelope and led to rot and mould in many condominiums. This affected many residents and repairs were estimated to average more than $\$ 50,000$ per individual unit owner with nearly $41 \%$ of wood frame units needing repairs in the 1990s totaling around a billion dollar (Lee, Ries, \& Somerville, 2012). Other notable building industry failure examples due to moisture are the Minnesota stucco crisis, moldy basements, moldy crawlspace, peeling paint, and rotting sheathing just to name a few (Lstiburek, J, 2006) .

Given the complexity of moisture storage, transport and influence of boundary conditions, it is important to assist the design of building envelope with analytical approach to be able to control moisture in buildings. This can be achieved by using proper tools that takes into account heat, air and moisture variations through the building envelope. Currently, there are several software tools that analyze the hygrothermal performance of buildings available, such as WUFI that is designed to calculate the simultaneous heat and moisture transport in one or two dimensional multi-layered building components.

HAM-Tools is another one-dimensional hygrothermal performance analysis tool that is developed using an open-source program, Simulink. It has the ability to analyze the moisture and temperature within an envelope in any climate, and any new modules can be added to the software. This flexibility allows the 
software to be used for research purposes. For example, WUFI only allows hourly weather data to be used in its simulation, while HAM-Tools with proper modifications can use higher resolution meteorological data. However, HAM-Tools simplifies the climatic loads from driving rain to an extent were it did not take into account the effects of wind-driven-rain (Kalagasidis A. , 2004). A study was carried out to broaden the capacity of HAM-Tools by introducing a module that accounts for the effects of wind driven rain on building envelopes ( $\mathrm{Wu}, \mathrm{Ge}, \&$ Horvat, 2012). The study then compared the hygrothermal results with WUFI using a climate with a relatively low rainfall amount (606 mm per year) to verify the module. It was noted that the chosen climate might not have sufficient rainfall amount to be used for verification purposes, and that the governing equations to translate the material properties between the two software were simplified.

This study is a continuation of the previous work that added wind driven rain (WDR) module to HAMTools software. The results from HAM-Tools simulation with the module needed to be compared to WUFI simulation for verification purposes. Chapter 3 verifies the module by taking into account the difference of the two software's calculations that governs the moisture transportation in materials. Chapter 4 then compares the result with field measurements to validate the model. Once the model is validated, it can be used to perform simulations using high resolution weather data. Since most available weather data are hourly averaged from high resolution data, it is important to analyze the impact of the averaging on the hygrothermal performance of walls. It is not possible to carry this study in other commercial hygrothermal analysis software (such as WUFI) since unlike HAM-Tools as they only allow hourly weather data for their outdoor climate input. Thus, chapter 5 further investigates the effects of different hourly averaging techniques of weather data on the hygrothermal performance of wall assemblies. 


\subsection{Literature Review}

This section reviews the fundamentals of moisture storage and transport mechanisms in building materials; and wind-driven rain as one of the most important boundary conditions in evaluating the hygrothermal performance of building envelopes. The effect of time resolution on wind driven rain intensity is also investigated. HAM-Tools program that can analyze the hygrothermal performance of buildings is then introduced. Finally, the incorporation and limitation of a wind driven rain module as a boundary condition is reviewed.

\subsubsection{Moisture Storage and Transport in porous materials}

In order to evaluate the influence of moisture in building envelopes, it is important to understand how moisture is stored and transported in building materials. When materials are exposed to increased moisture conditions, the moisture that is stored within the materials is categorized in three different regions: hygroscopic region, capillary water region, and supersaturated region (Künzel, 1995).

The hygroscopic region ranges from the dry state of the material all the way to a moisture content equal to near $95 \%$ relative humidity. When hygroscopic building materials are in contact with moist air, it would result in equilibrium moisture. Since the absorption and desorption in this region is not very distinct in most building materials such as building stones, generally the absorption isotherm is used to define the moisture storage of a building material. According to previous studies, for other materials that have a more distinct hysteresis such as expanded clay concrete, the moisture behaviour can be calculated sufficiently by averaging the absorption and desorption isotherms (Künzel, 1995).

The capillary water region is also characterized by states of equilibrium. It is defined by means of moisture storage functions over pore radius distribution known as suction stress. When a building material in this phase comes in contact with liquid water, it absorbs water to a point where it reaches free water saturation. When it comes in contact with another super-hygroscopic moist substance, 
moisture is exchanged until they both reach equilibrium. The material with smaller pores creates a greater capillary suction force and thus water is transported from that material to the one with larger capillaries. The hysteresis effect for mineral building materials is also minimal in the capillary water region. There are three techniques that are used to obtain the storage function: centrifugal tests, pressure plate test, and calometric examination of ice formation in the pre water for the case of materials with a high proportion of micropores (Künzel, 1995). For the purpose of this study, literature that used pressure plate test to obtain retention curves were used to obtain the required material properties, such as retention curves.

The supersaturated region occurs through diffusion under the temperature gradient (or through suction under pressure in laboratories) and has a relative humidity of $100 \%$ at all times with no more states of equilibrium. This region is reached when vapour diffusion causes condensation to occur in the material. This phase is more common in most insulation materials and is apparent when dew point conditions are met in these materials (Künzel, 1995). In principle during this state, the capillary suction stress is practically zero and so there can be no liquid transport through capillary conduction. Nevertheless, some moisture migration may be observed during this state in materials with coarse pores due to gravitation effects and vapour diffusion. However, moisture transport in the supersaturated region of capillary-active building materials is hard to model and since it occurs for a short period of time, it is mostly negligible (Künzel, 1995).

Figure 1 shows the schematic of the moisture storage function of a hygroscopic capillary-active building material, such as mortars, building stones, and wood products. Each region is shown and defined by the amount of water content of the material with respect to its relative humidity (Künzel, 1995). From this graph, it can be seen that the material's moisture content increases a lot faster in the capillary water region and supersaturated region than in the hygroscopic region. 


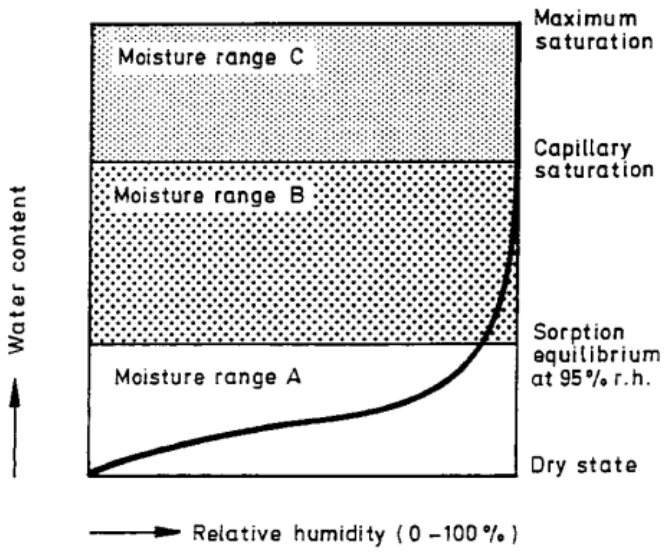

Figure 1: Moisture storage function of a typical hygroscopic capillary-active building material (Künzel, 1995)

Moisture can be transported in the form of water vapour, liquid water and adsorbate film in building materials. These processes are shown in Table 1.

Table 1: Moisture transport in building materials (Lstiburek, J, 2006)

\begin{tabular}{ccc}
\hline Phase & Process & Potential \\
\hline \hline Liquid & Liquid diffusion & Concentration \\
& Thermal diffusion & Temperature \\
& Capillary flow & Suction Pressure \\
& Gravitational flow & Height \\
& poiseuille flow & Liquid pressure \\
& Electrokinesis & Electrical voltage \\
\hline Vapour & Gas diffusion & Vapour pressure \\
& Thermal diffusion & Temperature \\
& Convective flow & Air pressure \\
\hline Adsorbate & Surface diffusion & Concentration \\
\hline Solid & Solid transport & Height \\
& & Air pressure
\end{tabular}

Water vapour diffusion occurs when moisture is transferred from partially dry solid from regions of high concentration to those of low concentration. The thermal diffusion is a water vapour diffusion that is 
driven by temperature gradients, which only accounts for $0.05 \%$ of the overall moisture transport in normal conditions. Moreover, convective flows resulting from air pressure around constructions are difficult to determine and usually neglected (Krus, 1995). Thus in many studies, only the water vapour diffusion resulting from partial water vapour pressure are investigated.

Surface diffusion is the phenomenon in which water vapour diffusion increases as relative humidity increases. This happens when building materials are in contact with moist air, which localizes them on the inner surface, creating a water film. This can be implicitly calculated using gradient of moisture content and overall moisture diffusivity coefficient (Kumaran, Mitalas, Kohonen, \& Ojanen, 1994). Other terms such as the laminar or streamline flow of an incompressible viscous fluid in a long narrow cylinder, known as poiseuille flow, and the surface diffusion as well as thermal diffusion are negligible and are mostly ignored.

Similarly, most of the processes that transport moisture through liquid water such as transportation due to gradient of electrical voltage or gravity are negligible in building physics and only capillary flow is of concern. The driving force of capillary flow is capillary suction that is directly related to surface tension and defined through the difference in the pressure for the non-wetting phase with the pressure for the wetting phase (Carmeliet \& and Roels, 2001).

When temperatures reach below freezing point, moisture transport can behave differently. At high moisture levels and below freezing point temperatures, ice is formed in the larger pores of building materials. Vapour diffusion process is through the smaller pores and changes only when the larger pores are filled about $60 \%$. Therefore the influence of ice formation on vapour diffusion can be disregarded in most cases. However, the effect of frost formation in materials is more pronounced for the liquid transport. Below freezing point, there is no capillary suction present anymore. However, water in the micropores freezes only at temperatures lower than zero degrees and thus, water can still be partially 
transported in the finer pores through capillary suction. It is possible to calculate this partial transport using a coefficient called the freezing limit potential (Künzel, 1995).

The water stored and transported through materials depends on the presence of water around that material. The most significant moisture source is rain, which is described in the next section.

\subsubsection{Wind Driven Rain}

HAM analysis requires sufficient boundary conditions that are calculated using input from standard meteorological data records. Most of these boundary conditions can be adequately defined. However, wind driven rain is the boundary condition that is considered to be the most important moisture source affecting the hygrothermal performance and durability of building facades. It is an important factor in the deposition of pollutants, erosion and surface soiling on buildings facades (Blocken \& Carmeliet, 2007). Moisture accumulation in porous materials due to WDR can lead to frost damage, water penetration, moisture induced salt migration, thermal cracking, and efflorescence just to name a few (Blocken \& Carmeliet, 2004). It is an essential boundary condition for numerical Heat, Air and Moisture (HAM) transfer models that are used for the purpose of examining hygrothermal performances on building envelopes. Thus, in order to analyze the hygrothermal performance and durability of building facades, the understanding and incorporation of WDR in HAM transfer models is essential.

There are many parameters that influence the WDR distribution, namely environment topology, position of building façade, wind direction and speed, rainfall intensity, and raindrop size distribution (Blocken \& Carmeliet, 2004). In the past, different approaches were taken to assess WDR amount on building facades. These include direct measurements, semi-empirical models, and numerical simulations (Blocken \& Carmeliet, 2004). Full scale WDR measurements were performed in the past to obtain coefficients for theoretical formulae to create these empirical models. Measurements have always been the primary tool in WDR research, but they can be time-consuming and expensive, and its application 
can be limited to the specific site that the measurements were taken. These limitations motivated researchers to establish semi-empirical relationships between WDR and the standard meteorological parameters (Moonen, Defraeye, Dorer, Blocken, \& Carmeliet, 2012).

Semi-empirical models are based on simple theoretical formula combined with coefficients obtained from measurements. Since WDR is a result of airflow carrying raindrops deposited on the building facade, the empirical formula generated takes into account the wind speed, wind direction, and rainfall intensity. If all raindrops are assumed to be the same size and that the wind flow is uniform, steady, and horizontal, the intensity of WDR can be expressed as follows (Blocken \& Carmeliet, 2010b).

$$
R_{w d r}=R_{h} \cdot \frac{U}{V_{t}} \quad \text { Equation } 1
$$

where $R_{w d r}$ is the wind driven rain intensity through imaginary vertical surface, $R_{h}$ is the unobstructed horizontal rainfall intensity that is measured using standard rain gauge with a horizontal orifice, $U$ is the wind speed, and $V_{t}$ is raindrop terminal velocity of fall. The speed at which the raindrops fall depends on the size of the drop itself, which defines $V_{t}$. As the drop size increases, the raindrop terminal velocity increases at a decreasing rate. Simple geometry reveals that, in Equation 1, the wind direction is assumed to be perpendicular to the vertical surface at all times and that no deflection happens that makes it a measure for a "free field" (Blocken \& Carmeliet, 2010a). However, the presence of a building strongly disturbs the wind-flow pattern around it, which leads to a very different WDR intensity when compared to WDR intensity in free-field conditions. In order to take this into account, Equation 1 is then rewritten as follows (Blocken \& Carmeliet, 2010b):

$$
\mathrm{R}_{\mathrm{wdr}}=\alpha \cdot U \cdot \mathrm{R}_{\mathrm{h}}{ }^{0.88} \cdot \cos \theta \quad \text { Equation } 2
$$

where $\alpha$ is the WDR coefficient and $\theta$ is the angle in horizontal plane between the wind direction and normal to the facade. The ISO Standard model (ISO model) and Straube and Burnett model (SB model) 
are two known semi-empirical models that are based on Equation 2. The former uses annual average index and spell index that is calculated based on airfield annual index (Blocken \& Carmeliet, 2010b). The resulting equation is summarized as follows.

$$
R_{\mathrm{wdr}}=2 / 9 \cdot \mathrm{C}_{\mathrm{R}} \cdot \mathrm{C}_{\mathrm{T}} \cdot \mathrm{O} \cdot \mathrm{W} \cdot \mathrm{U}_{10} \cdot \mathrm{R}_{\mathrm{h}} \cdot \cos \theta \quad \text { Equation } 3
$$

where $U_{10}$ is the unobstructed reference wind speed at $10 \mathrm{~m}$ height, $C_{R}$ is the roughness coefficient, $C_{T}$ the topography coefficient, $\mathrm{O}$ is the obstruction factor, and $\mathrm{W}$ is the wall factor. The obstruction factor $\mathrm{O}$ is applied when there is an obstruction near the building. The wall factor $W$ is the ratio of WDR hitting the building over the WDR passing through an equivalent unobstructed space. The wall factor accounts for the type of the wall (such as the height of the wall or if it has overhands) and the variation of WDR across its surface. The wall factor and the obstruction factor can be obtained using Table 2 and Table 3 respectively. 


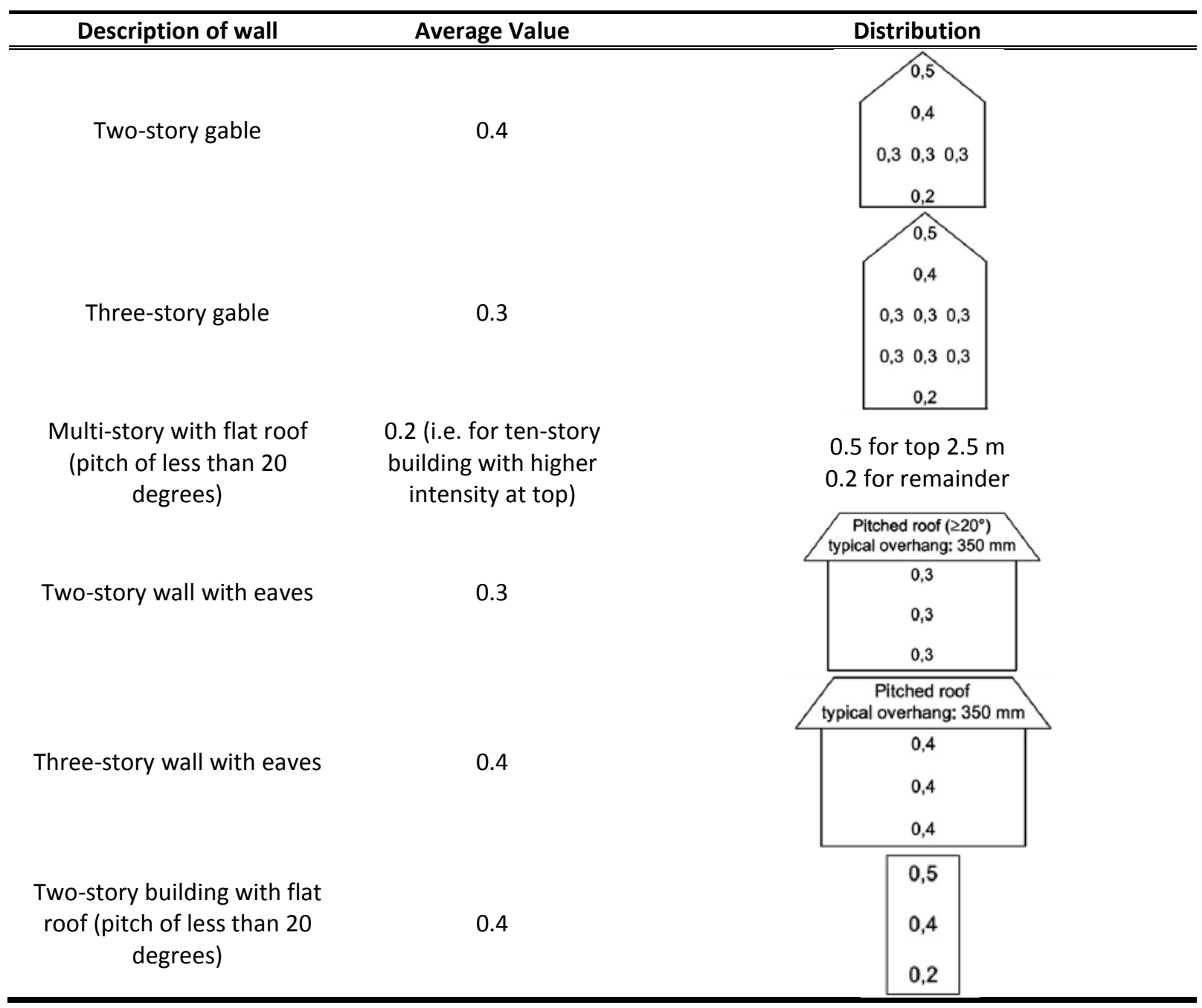

Table 3: Obstruction factor, O (ISO, 2009)

\begin{tabular}{cc}
\hline Distance of obstruction from façade $[\mathrm{m}]$ & Obstruction factor $\mathbf{0}$ \\
\hline \hline $4-8$ & 0.2 \\
$8-15$ & 0.3 \\
$15-25$ & 0.4 \\
$25-40$ & 0.5 \\
$40-60$ & 0.6 \\
$60-80$ & 0.7 \\
$80-100$ & 0.8 \\
$100-120$ & 0.9 \\
Over 120 & 1.0 \\
\hline
\end{tabular}


The topography coefficient $\mathrm{C}_{\mathrm{T}}$ takes into account the increase of mean wind speed over isolated hills and escarpments, ranging from 1.0 for upstream slopes of less than $5 \%$ inclinations, to 1.6 for buildings located at crests of steep hills. The roughness coefficient $C_{R}$ takes into account the change of mean wind speed at the site due to the upstream roughness of the terrain and the height above the ground. It is calculated using the equations below.

$$
\begin{array}{lll}
C_{R}(z)=K_{R} \cdot \ln \left(\frac{z}{z_{0}}\right) & \text { for } z \geq z_{\text {min }} & \text { Equation } 4 \\
C_{R}(z)=C_{R}\left(z_{\text {min }}\right) & \text { for } z<z_{\text {min }} & \text { Equation } 5
\end{array}
$$

where $z$ is the height above ground, $K_{R}$ the terrain factor, $z_{0}$ the aerodynamic roughness length and $z_{\min }$ is the minimum height. These values are presented as a function of the terrain category shown in Table 4.

Table 4: Roughness coefficient $C_{R}$ parameters (ISO, 2009)

\begin{tabular}{clccc}
\hline $\begin{array}{c}\text { Terrain } \\
\text { category }\end{array}$ & \multicolumn{1}{c}{ description } & $\mathrm{K}_{\mathrm{R}}$ & $\mathrm{Z}_{0}$ & $\mathrm{Z}_{\min }$ \\
\hline \hline I & $\begin{array}{l}\text { Rough open sea; lake shore with at least 5 km open water upwind and } \\
\text { smooth flat country without obstacles }\end{array}$ & 0.17 & 0.01 & 2 \\
II & $\begin{array}{l}\text { Farm land with boundary hedges, occasional small farm structures, houses } \\
\text { or trees }\end{array}$ & 0.19 & 0.05 & 4 \\
III & $\begin{array}{l}\text { Suburban or industrial areas and permanent forests } \\
\text { Urban areas in which at least 15\% of the surface is covered with buildings } \\
\text { IV } \quad 0.22\end{array}$ & 0.3 & 8 \\
\hline
\end{tabular}

The SB model also derives its formula from Equation 1. The model describing the WDR on building facade is given in Equation 6.

$$
\mathrm{R}_{\mathrm{wdr}}=\mathrm{DRF} \cdot \mathrm{RAF} \cdot \mathrm{U}(\mathrm{z}) \cdot \mathrm{R}_{\mathrm{h}} \cdot \cos \theta
$$

Equation 6

where DRF is the driving rain factor that is defined as the inverse of raindrop terminal velocity $V_{t}$, and RAF is the rain admittance factor that converts the free-field WDR intensity to the WDR intensity on the building facade. The values measured for RAF is presented in Figure 2. 


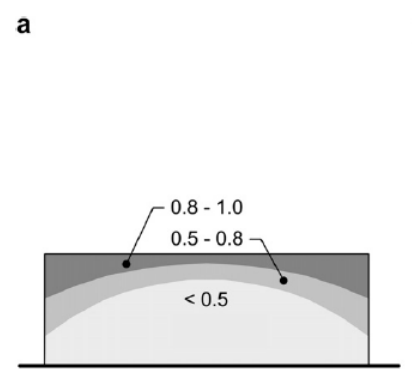

Low-rise Building $\mathrm{H} / \mathrm{W} \ll 1$

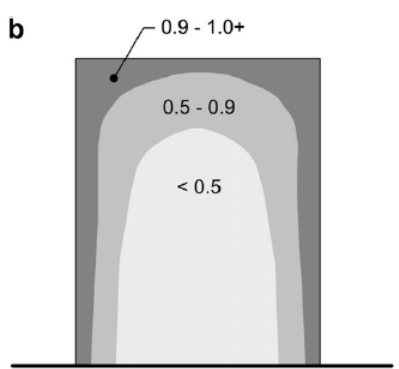

Tall Building $(>10 \mathrm{~m}) \mathrm{H} / \mathrm{W}>>1$

c

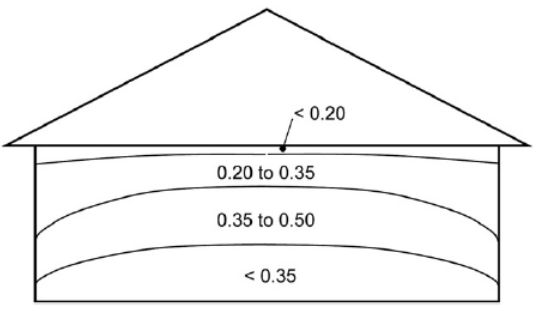

Figure 2: Rain Admittance Factors (RAF) for (a) low-rise building with H/W much less than 1; (b) tall building (>10 m) with H/W much greater than 1; (c) low-rise building with sloped roof and roof overhang (Straube \& Burnett, 2000)

Comparing these two models, it is found that the ISO model is more comprehensive than the SB model (Blocken \& Carmeliet, 2010a). This was concluded since the information of the coefficients have been obtained from on-site measurements at the facades of different buildings and thus the ISO model provides a more accurate representation of the influencing parameters. (Blocken \& Carmeliet, 2010a).

The third semi-empirical model is given by ASHRAE 160P (ASHRAE, 2009). This standard describes the rain load to be designed for walls exposed to rain. Equation 7 presents the model.

$$
r=F_{E} \cdot F_{D} \cdot F_{L} \cdot U \cdot \cos \theta \cdot r_{h}
$$

Equation 7

The exposure factor $F_{E}$ is obtained based on the height of the building and the terrain surrounding it. The rain deposition factor $F_{D}$ is based on the slope of the roof and that if the wall material is subject to rain runoff. $F_{L}$ is the empirical constant. This model is very similar to the SB model and since ASHRAE $160 \mathrm{P}$ is the latest North American standard, it is used in this study. 
The widespread use of semi-empirical model is due to its analytical formulas that can be easily implemented in HAM models, uses standard meteorological data that are generally available, and that no other suitable method that determines WDR has been available (Blocken, Roels, \& Carmeliet, 2007). However, while semi-empirical models are simple to use, their accuracy depends on the coefficients and correction factors.

More detailed but much more time consuming alternative is to use numerical modeling through Computational Fluid Dynamics (CFD). CFD models provide the WDR results on any particular building as a function of horizontal rainfall intensity, wind speed and wind direction and are mostly used to evaluate and validate the semi-empirical models and to improve their performance (Blocken \& Carmeliet, 2010a). CFD modeling can be employed to obtain the coefficients that required by the semi-empirical models, which allows the semi-empirical method being simple while integrating the complexity into its coefficients.

A three-step approach is normally used in CFD modeling of wind-driven rain: steady state wind-flow pattern, raindrop trajectories, and specific and integrated catch ratio and WDR coefficients. The first step calculates the steady-state wind-flow around a building using CFD and provides velocity-vector fields around the building. The second step calculates the raindrop trajectories by injecting raindrops of different sizes in the calculated velocity-vector field and calculating their equations of motion. The third and last step compares the horizontal raindrop density with WDR drop density to obtain the catch ratio for each diameter of the raindrop. Using the integrated catch ratio over raindrop spectrum and the reference wind speed, the WDR coefficient is acquired (Janssen, Blocken, \& Carmeliet, 2007). An example is the study of raindrop impact on porous materials combined with numerical investigation of impact speed, angle and specific catch ratios (Abuku, Jenssen, Poesen, \& Roels). The study measured the maximum spreading length and width of the drops as a function of drop diameter, impact speed and 
impact angle to be used for analyzing the distribution of impact speed and angle for raindrops hitting a facade. Finally, the WDR on building enclosure was compared to a 3-D simulation and was found that the simulation led to an underestimation of the average moisture content due to an overestimation of the evaporation rate when horizontal rainfall intensity was $0.1 \mathrm{~mm} / \mathrm{h}$. When the horizontal rainfall intensity was $0.5 \mathrm{~mm} / \mathrm{h}$, it led to an overestimation of the average moisture content due to an underestimation of the evaporation rate (Abuku, Jenssen, Poesen, \& Roels).

\subsubsection{Impact of time resolution of WDR data on hygrothermal performance of building envelopes}

Currently, due to the complexity of WDR, HAM models generally incorporate the semi-empirical methods to determine the WDR amount as the boundary conditions when analyzing the hygrothermal performance of buildings. The parameters determining the WDR amount, i.e. wind speed, wind direction, and horizontal rainfall intensity, are usually collected and averaged to an hourly data. The impact of time resolution of these input data for WDR has been investigated in the past (Blocken \& Carmeliet, 2007). The research found that significant underestimations can occur if the data is arithmetically averaged to obtain hourly data. Currently, most data available from weather stations around the world are arithmetically averaged hourly dataset, which results in this underestimation (Blocken \& Carmeliet, 2008). It was also found that weighted averaging technique is an improvement over arithmetically averaged method that can significantly reduce time resolution errors. The underestimation of arithmetical averaging was calculated to be $11 \%, 45 \%$ and $31 \%$ for Eindhoven in Netherlands, Bloomington in USA, and Grahamstown in South Africa respectively, while for weighted averaging, it was $0 \%, 4 \%$ and $3 \%$ respectively. It was suggested that a minimum of ten-minute averaged data is required to obtain results that are acceptable for quantifying WDR intensity. It should be noted that the wall model used to determine the results in the study was a simplified and theoretical example, all the boundary conditions except WDR were kept constant, and that an underestimation could have 
occurred due to the selection of its specific climate (Blocken \& Carmeliet, 2007). Thus, in order to determine the difference between the effect of high resolution and averaged data using different techniques, more research needs to be conducted.

Another study was conducted to create a HAM simulation using CFD modeling as boundary conditions to obtain detailed WDR on building façade. This combined CFD-HAM approach implements the catch-ratio charts resulting from CFD simulations into HAM models. The catch-ratios are then used within the HAM simulation to convert the standard meteorological data into WDR distribution records that define the boundary conditions of the HAM simulation. This study carried out a comparative analysis and concluded that the accuracy of the results from HAM simulations is determined by the time resolution and averaging technique of the meteorological input data (Blocken, Roels, \& Carmeliet, 2007). It should be pointed out that by using the ISO standard (ISO, 2009) guidelines, the weighted average approach will not be applicable in areas that have more than $25 \%$ annual rainfall due to heavy precipitation that lasts less than 1 hour. This is due to the ISO standard guideline stating that rain penetration around edges of doors, windows and cracks depends on shorter periods of heavy rain and strong winds (ISO, 2009), which is not the case for the climate that the study used.

\subsubsection{Hygrothermal simulation programs}

There are many software tools available that analyze the hygrothermal performance of buildings, such as WUFI (Fraunhofer IBP, 2010), HAM-Tools (Kalagasidis A. , 2004), and LATENITE-VTT that was developed to become hygIRC from Institute for Research Construction (IRC), to name a few. These various tools all have diverse purposes and each has its own advantages and limitations.

WUFI is a program that calculates the amount of heat and moisture transport at any point within a wall construction. The effects of wind driven rain is also included within the program. Users can also input their own meteorological data as well (Fraunhofer IBP, 2010). WUFI is the mostly used program by 
professionals and it has been validated through different benchmarks such as EN 1502 (Fraunhofer IBP, 2010). WUFI met the requirements of this benchmark by having its results not deviating from the reference solution by more than $2.5 \%$. However, it should be noted that WUFI only allows a time resolution of one hour for its climate data and that it limits the user to its own functions as it is not open source and no modules can be added to it.

\subsubsection{HAM-Tools}

HAM-Tools is a one-dimensional heat, air and moisture transfer simulation model developed at Chalmers University of Technology in Sweden. The main objective of the program is to obtain simulations of heat and mass transport in building components under operating conditions. It is based on Simulink and Matlab and is developed as a library of predefined calculation modules. There are five sub-systems for these modules: Constructions, Zones, Systems, Helpers and Gains (Kalagasidis A. , 2004). The software is an open source at research level, so the ability to add new modules and codes can be achieved. It can also handle high resolution meteorological data. Thus, HAM-Tools is a suitable program to be used for the purpose of this research. It is also a free program and can be downloaded from http://www.ibpt.org/libraries.html.

The software has been validated in three different ways: analytical, comparison with other codes, and empirical (Kalagasidis A. , 2004). The first step analytically validated the software through means of mathematical solutions to existing problems and analyzed the divergence of the solutions. This was performed to ensure that the basic balances of the calculations were met. The temperature and moisture profile of an example was compared with a reference analytical solution obtained through the benchmark from European Standard draft 'Hygrothermal performance of building components and building elements - Assessment of moisture transfer by numerical solutions' CEN/TC 89 WC 29.3. It was shown that the solution resides in the band of acceptance from the benchmark (Kalagasidis A. , 2004). 
The software was then compared with HAMSTAD (Heat, Air and Moisture Standard Development), which is a benchmark that focuses on standardization procedures and certification in HAM transport in buildings. The software was tested against the five HAMSTAD benchmarks and the results showed a satisfying agreement between the different solutions and achieved the requirements (Kalagasidis A. , 2004).

Finally, the simulations from the software were compared against field collected data to be validated. The software was compared against a whole building model that measured the temperature and relative humidity of a cold ventilated attic space in real operating conditions. The results concluded that the software has shown a high degree of reliability, both in a qualitative and in a quantitative manner (Kalagasidis A. , 2004).

The governing equations for one-dimensional HAM transfer and heat and mass balance in porous building materials that is used to develop HAM-Tools software include some assumptions. It is mentioned that these assumptions has led to the following boundary conditions and limitations (Kalagasidis A. , 2004).

- The boundary condition for the ambient temperature from the weather data cannot exceed the range of $-30^{\circ} \mathrm{C}$ to $+80^{\circ} \mathrm{C}$.

- Effects associated with phase change liquid from/to ice are neglected.

- Climatic load due to driving rain is simplified. There is no module that handles WDR and its intensity value is set to be zero at all times

- Hysteresis, the difference in the moisture content that a material can hold and the corresponding moisture potential during drying and wetting periods is not accounted for.

- Chemical reactions between materials are not considered.

- Gravity effects on materials and water are not considered.

- Drainage between material layers is not considered. 
- Ageing effects or changes in geometrical dimensions are neglected.

One of the limitations noted above is simplification of WDR, which is an important factor for hygrothermal analysis of building envelopes.

\subsubsection{Integration of Wind-Driven-Rain module in HAM-Tools}

Previous study (Wu, Ge, \& Horvat, 2012) analyzed the effects of microclimate and time resolution on the hygrothermal performance of building envelopes through HAM simulations. The study required to use a program that is able to analyze the hygrothermal performance of building envelope while being capable of providing a modular and open-source modeling platform so that any new module can be added in order to improve it. The software had to have the ability of accepting customized and high resolution meteorological data and materials to allow for comparative research on different climates with different constructions. Therefore, HAM-Tools was a suitable option and was chosen, while WUFI was used for verification purposes in that study. To further improve the HAM-Tools software, the previous study implemented a module in the program that takes into account the effect of wind driven rain. The designed module uses semi empirical ISO model from ASHRAE 160P (ASHRAE, 2009) to quantify wind driven rain. The module was developed using Simulink and was added to HAM-Tools ( Wu, Ge, \& Horvat, 2012). The developed module was then verified by comparing the results with WUFI, a widely accepted commercial hygrothermal simulation tool. It should be noted that WUFI has an option to use the ASHREA 160P model for its WDR analysis.

Given the limited material data for HAM-Tools, materials from WUFI's database were chosen to best reflect the ones in HAM-Tools data. The comparison was applied on two similar exterior materials: yellow pine wood siding from WUFI and wood siding from HAM-Tools database. However, although sorption isotherm curves of these two materials have the same trend, they do differ in the values of water content by a factor of 1.5 to 2 . This shifting of the sorption isotherm in HAM-Tools wood siding 
material can be observed in Figure 3 (Wu, Ge, \& Horvat, 2012). Therefore, the sorption isotherm of HAM-Tool's wood siding was linearly shifted down to create more similar values to yellow pine's water transport properties. Similarly, the same amount of linear shifting was applied to both hydraulic conductivity and vapour permeability of HAM-Tools' wood siding.

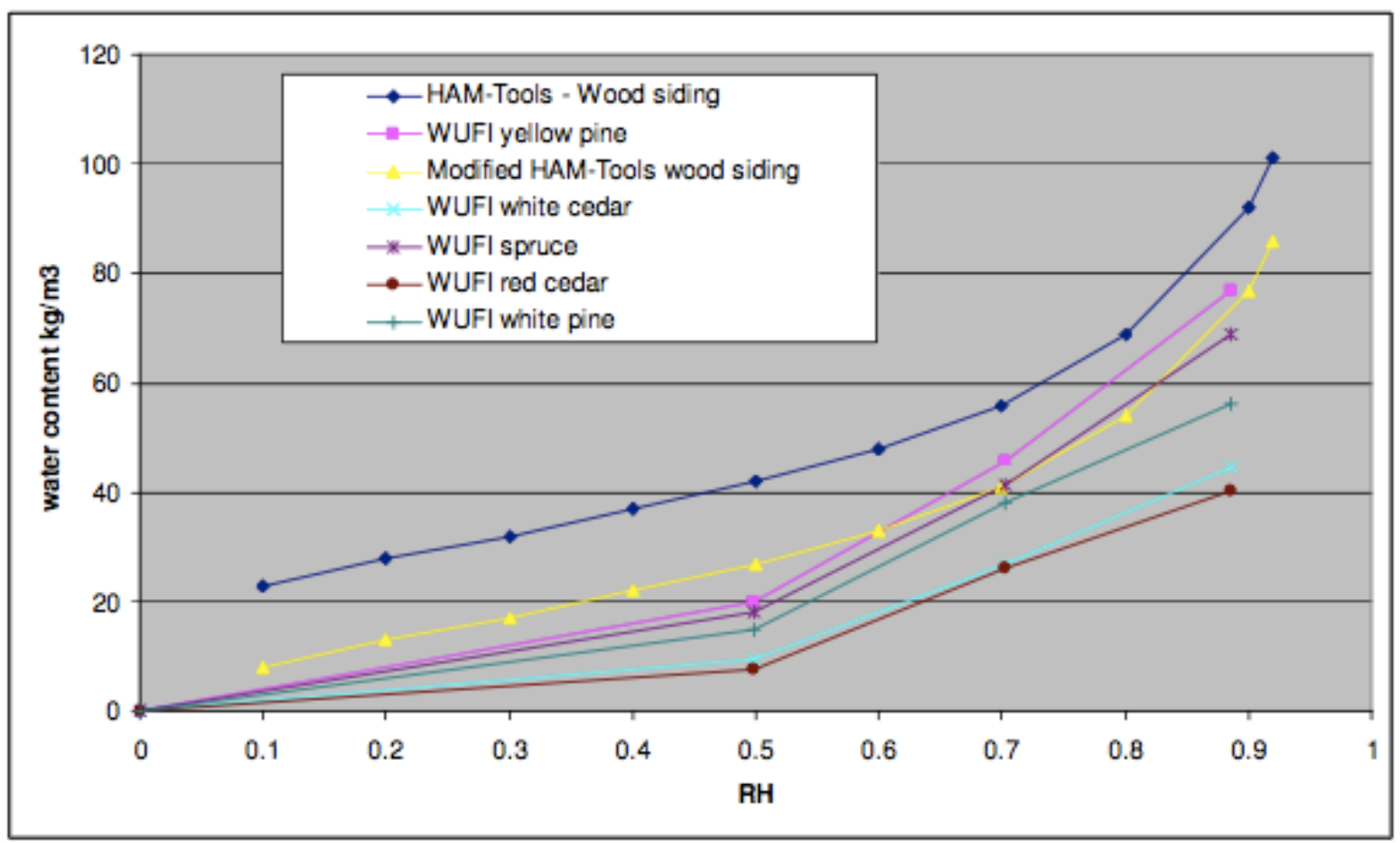

Figure 3: Comparison of different wood sidings from HAM-Tools and WUFI database (Wu, Ge, \& Horvat, 2012)

It should be noted that each software implements a different approach when calculating water transport through materials. Therefore the modification of linear shifting the hydraulic conductivity and vapour permeability causes uncertainty errors in the verification process. However, the focus of the study was not on this difference and assumed that the proposed line-shifting method would be sufficient for the purpose of its research. Therefore, more research is required in order to create consistency between the programs and to verify the module. 


\subsection{Summary - Research Problem}

Wind driven rain is the most important boundary condition for hygrothermal analysis. Previous studies showed that the accurate definition of WDR loads in terms of time resolution and averaging techniques has an impact on the hygrothermal simulation results. Efforts have been made to evaluate the WDR effect by improving the HAM-Tools' capacity to include a WDR module in the program. However, further verification and validation of the module is required. In addition, the effect of averaging techniques in converting high resolution such as of 1-minute weather data to hourly weather data sets needs to be examined.

\subsection{Research Questions and Objectives}

In order to address the research problem stated above, the following research questions are developed:

- Would HAM-Tools be able to predict the hygrothermal performance accurately when compared to real data from field measurements?

- Does hourly-averaged weather data from a higher resolution one affect the accuracy of hygrothermal performance results?

- What averaging method provides more realistic results when compared to its high resolution data?

Given these research questions, the objectives of this study are:

- To demonstrate the accuracy of the developed WDR module through verification by comparing results with WUFI, a similar and validated software

o Ensuring that the governing moisture transport mechanisms and material properties are consistent between the two software 
- To demonstrate the accuracy of the developed WDR module through validation by comparing results with real data from field measurements

- To evaluate the impact of different methods of averaging high resolution wind and rain data to an hourly data on the hygrothermal performance of wall assemblies using the validated module.

\subsection{Research Methodology}

First, to further improve and verify the wind-driven rain module in HAM-Tools, an alternative approach was implemented to convert the material property related to liquid water transport from one program to the other. A conversion method was developed that translates the liquid diffusivity used in WUFI to hydraulic conductivity of HAM-Tools. Then a material with sufficient information was selected and implemented in both programs to further verify the conversion method. HAM-Tools' results were compared to WUFI's simulation using Toronto weather data in order to verify the WDR module. Since the wind driven rain module heavily depends on wind speed, wind direction and rain (Kumaran \& Sanders, 2008), the need to use a different climate with more rainfall is also considered. Therefore, the second weather data used was collected from onsite weather station located in British Columbia Institute of Technology (BCIT) in Burnaby, Canada. This weather data has a higher amount of yearly rainfall (1161 mm) when compared to Toronto's weather data (683 mm) (Environment Canada, 2012). To validate the module, the simulation was then compared to field measurements taken under the same climate. Finally, comparison between high resolution climate data and hourly data using different averaging techniques was conducted in HAM-Tools. This would enable the study to understand the impact of averaging weather data on hygrothermal performance of walls and to analyze the best method of averaging the data that results in the least loss of accuracy in hygrothermal performance simulation. The steps to carry out this research are summarized as follows: 
1. Find proper relationship between the two software's material properties to be able to use WUFI's database for HAM-Tools.

2. Construct the same wall assemblies and weather data for both programs

3. Conduct simulation using the programs and compare results to verify the module

4. Conduct simulation using HAM-Tools and compare results with field measurements to validate the module

5. Construct 1-hour weather data from a 1-minute weather data

- Use weighted average for wind speed and horizontal rainfall intensity

- Use vector average technique for wind speed and direction

6. Conduct simulation using the different hourly averaged weather data and compare the results with the high resolution data to obtain the best averaging technique between them

Chapter 2 presents the steps to construct simulations in HAM-Tools. Chapter 3 presents the verification of the WDR module using WUFI, while chapter 4 validated the module with real data. Chapter 5 then uses HAM-Tools to investigate the differences of averaging high resolution weather data. 


\section{Chapter 2: Construction of Simulation in HAM-Tools}

This chapter explains the construction of simulation in HAM-Tools and the development of WDR module into the software. It should be noted that a basic knowledge of Matlab and Simulink program is recommended to be able to recreate the process.

HAM-Tools allows for a customized wall assembly to be created by using the "construction" block in the HAM-Tools library. There are 14 materials presented in the software and their properties are predefined in a 'MAT_DATABASE.m' file provided with the software. Some of the other parameters are set directly in the software, such as duration of simulation, heat and vapour transfer coefficients, thicknesses of the materials, etc. Finally, the 'InputData.m' file defines the initial conditions, location and the weather data to be used for the simulation.

\subsection{HAM-Tools Material Data}

As mentioned before, HAM-Tools contains only 14 materials with their properties in its database. This is a very limited database but it is possible to add more materials to it. Given that WUFI has extensive material database, new materials can be selected from WUFI and placed in HAM-Tools' library. However, some of these properties need to be converted to HAM-Tool's format. These conversions are described in details in section 3.3. The variable name and units for each parameter is shown in Figure 4. For simplicity, the resistive materials (such as rain screens, vapour retarders, and air barriers) are not part of the material library and are specified separately in the main construction block of HAM-Tools. They only require information for their heat, liquid, and vapour resistance. The placement for inputting the resistive layer's properties is shown in Figure 5. 


\begin{tabular}{|c|c|c|c|}
\hline Fieldname & Parameter & Unit & Drample \\
\hline name & material name & - & Concrete \\
\hline dry density & dry density of the material & $\mathrm{kg} / \mathrm{m}^{3}$ & 2400 \\
\hline porosity & porosity & - & 0.204 \\
\hline lambda dry & thermal conductivity of the dry material & $\mathrm{W} / \mathrm{m} \cdot \mathrm{K}$ & 1.5 \\
\hline lambda_T & $\begin{array}{l}\text { thermal conductivity factor dependent on } \\
\text { temperature }\end{array}$ & $\mathrm{W} / \mathrm{m} \cdot \mathrm{K}^{2}$ & 0 \\
\hline lambda_U & $\begin{array}{l}\text { thermal conductivity factor dependent on } \\
\text { moisture content by weight }\end{array}$ & $\mathrm{W} / \mathrm{m} \cdot \mathrm{K}$ & 36 \\
\hline lambda_W & $\begin{array}{l}\text { thermal conductivity factor dependent on } \\
\text { moisture content by volume }\end{array}$ & $\mathrm{W} \cdot \mathrm{m}^{2} / \mathrm{kg} \cdot \mathrm{K}$ & 0.015 \\
\hline heat capacity & specific heat capacity of the dry material & $\mathrm{J} / \mathrm{kg} \cdot \mathrm{K}$ & 800 \\
\hline $\mathrm{U}$ critical & critical moisture content by weight & $\mathrm{kg} / \mathrm{kg}$ & 0.04 \\
\hline W critical & critical moisture content by volume & $\mathrm{kg} / \mathrm{m}^{3}$ & 96 \\
\hline U capillary & capillary moisture content by weight & $\mathrm{kg} / \mathrm{kg}$ & 0.062 \\
\hline W capillary & capillary moisture content by volume & $\mathrm{kg} / \mathrm{m}^{3}$ & 148.8 \\
\hline $\mathrm{U}$ vacuum & vacuum moisture content by weight & $\mathrm{kg} / \mathrm{kg}$ & 0.085 \\
\hline delta $\mathrm{RH}$ & RH entries for vapor permeability & - & {$\left[\begin{array}{llll}0 & 0.6 & 0.98\end{array}\right]$} \\
\hline delta $\mathrm{p} \mathrm{RH}$ & vapor permeability $\mathrm{f}(\mathrm{RH})$ & $\mathrm{kg} /(\mathrm{s} \cdot \mathrm{Pa} \cdot \mathrm{m})$ & {$[2.5 \mathrm{e}-12 \quad 2.5 \mathrm{e}-12 \quad 1.0 \mathrm{e}-11]$} \\
\hline delta_U & $\begin{array}{l}\text { moisture content by weight } \\
\text { entries for vapor permeability }\end{array}$ & $\mathrm{kg} / \mathrm{kg}$ & {$\left[\begin{array}{lll}0.048 & 0.085\end{array}\right]$} \\
\hline delta $\mathrm{p} \mathrm{U}$ & vapor permeability f(U) & $\mathrm{kg} /(\mathrm{s} \cdot \mathrm{Pa} \cdot \mathrm{m})$ & {$[1.0 \mathrm{e}-111.0 \mathrm{e}-16]$} \\
\hline delta_W & $\begin{array}{l}\text { moisture content by volume } \\
\text { entries for vapor permeability }\end{array}$ & $\mathrm{kg} / \mathrm{m}^{3}$ & [115.2 204] \\
\hline delta $\mathrm{p} \mathrm{W}$ & vapor permeability f(W) & $\mathrm{kg} /(\mathrm{s} \cdot \mathrm{Pa} \cdot \mathrm{m})$ & {$[1.0 \mathrm{e}-111.0 \mathrm{e}-16]$} \\
\hline absorption $\mathrm{RH}$ & $\mathrm{RH}$ entries for absorption isotherm & - & \\
\hline absorption_U & $\begin{array}{l}\text { moisture content by weight } \\
\text { entries for absorption isotherm }\end{array}$ & $\mathrm{kg} / \mathrm{kg}$ & \\
\hline desorption $\mathrm{RH}$ & RH entries for desorption isotherm & - & \\
\hline desorption_U & $\begin{array}{l}\text { moisture content by weight } \\
\text { entries for desorption isotherm }\end{array}$ & $\mathrm{kg} / \mathrm{kg}$ & \\
\hline sorption_RH & $\begin{array}{l}\text { RH entries for sorption isotherm } \\
\text { (mean value) }\end{array}$ & - & 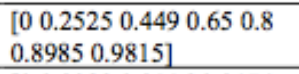 \\
\hline sorption_U & $\begin{array}{l}\text { moisture content by weight entries for } \\
\text { sorption isotherm (mean value) }\end{array}$ & $\mathrm{kg} / \mathrm{kg}$ & 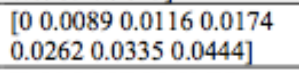 \\
\hline sorption_W & $\begin{array}{l}\text { moisture content by volume entries for } \\
\text { sorption isotherm (mean value) }\end{array}$ & $\mathrm{kg} / \mathrm{m}^{3}$ & $\begin{array}{l}{\left[\begin{array}{llll}0 & 21.36 & 27.84 & 41.76 \\
62.88 & 80.4 & 106.56\end{array}\right]} \\
\end{array}$ \\
\hline slope sorption $\mathrm{RH}$ & $\mathrm{RH}$ entries for slope of the sorption isotherm & - & \\
\hline slope sorption ksi & slope of the sorption isotherm & $\mathrm{kg} / \mathrm{m}^{3}$ & \\
\hline wet_suction_U & $\begin{array}{l}\text { moisture content by weight entries for } \\
\text { suction (wetting) }\end{array}$ & $\mathrm{kg} / \mathrm{kg}$ & \\
\hline wet suction $\ln \mathrm{P}$ & logarithmic suction pressure (wetting) & $\mathrm{Pa}$ & \\
\hline dry_suction_U & $\begin{array}{l}\text { moisture content by weight entries for } \\
\text { suction (drying) }\end{array}$ & $\mathrm{kg} / \mathrm{kg}$ & \\
\hline dry suction $\ln \mathrm{P}$ & logarithmic suction pressure (drying) & $\mathrm{Pa}$ & \\
\hline suction_U & $\begin{array}{l}\text { moisture content by weight entries for } \\
\text { suction }\end{array}$ & $\mathrm{kg} / \mathrm{kg}$ & 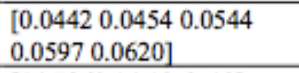 \\
\hline suction $\ln \mathrm{P}$ & logarithmic suction pressure & $\mathrm{Pa}$ & {$[14.786014106-10]$} \\
\hline suction_W & $\begin{array}{l}\text { moisture content by volume entries for } \\
\text { suction }\end{array}$ & $\mathrm{kg} / \mathrm{m}^{3}$ & $\begin{array}{l}{\left[\begin{array}{lll}106.08 & 108.96 & 130.56 \\
143.28 & 148.81\end{array}\right.}\end{array}$ \\
\hline \begin{tabular}{|l} 
Fleldname \\
\end{tabular} & Parameter & Unit & Dxample \\
\hline suction_Psuc & suction pressure & $\mathrm{Pa}$ & $\begin{array}{l}{[2639236120260422026} \\
4030]\end{array}$ \\
\hline WAC & water absorption coefficient & $\mathrm{kg} / \mathrm{m}^{2} \mathrm{~h}^{0.5}$ & 0.018 \\
\hline hyd_cond_U & $\begin{array}{l}\text { moisture content by weight entries for } \\
\text { hydraulic conductivity }\end{array}$ & $\mathrm{kg} / \mathrm{kg}$ & {$\left[\begin{array}{lllll}0.0400 & 0.0620 & 0.0850\end{array}\right]$} \\
\hline hyd_cond_W & $\begin{array}{l}\text { moisture content by volume entries for } \\
\text { hydraulic conductivity }\end{array}$ & $\mathrm{kg} / \mathrm{m}^{3}$ & {$\left[\begin{array}{llll}96 & 148.8 & 204\end{array}\right]$} \\
\hline hyd_cond_K & hydraulic conductivity & $\mathrm{kg} /(\mathrm{s} \cdot \mathrm{Pa} \cdot \mathrm{m})$ & $\begin{array}{l}{[1.1000 \mathrm{e}-0146.2500 \mathrm{e}-} \\
0136.2500 \mathrm{e}-013]\end{array}$ \\
\hline air permeability & air permeability & $\mathrm{m}^{2}$ & 0 \\
\hline absorptivity & radiative absorptivity & - & 0.8 \\
\hline emissivity & radiative emissivity & - & 0.8 \\
\hline transmittance & solar transmittance & - & 0 \\
\hline
\end{tabular}

Figure 4: Parameters for Material properties in HAM-TOOLS (Kalagasidis, Weitzmann, Nielsen, Peuhkuri, Hagentoft, \& Rode, 2007) 


\subsection{HAM-Tools input Parameters}

The software uses the Matlab file 'InputData. $m$ ' to initialize the necessary parameters required to run the simulation. This includes latitude, longitude, local standard time, albedo, weather data file, angle of incidents and their transmittance for direct solar radiation, initial $\mathrm{RH}$ and temperature, and long-wave radiation shading. Other values such as glazing properties can be specified in this file, but are not necessary for this study. If any new variables are required, such as rain exposure factor, rain deposition factor, and initial moisture content of each layer, it can be created and specified in this file as well. The materials are selected using a pop-up menu from the construction block. The values for the resistive layers are also set in the same menu. Figure 5 presents a sample of this menu.

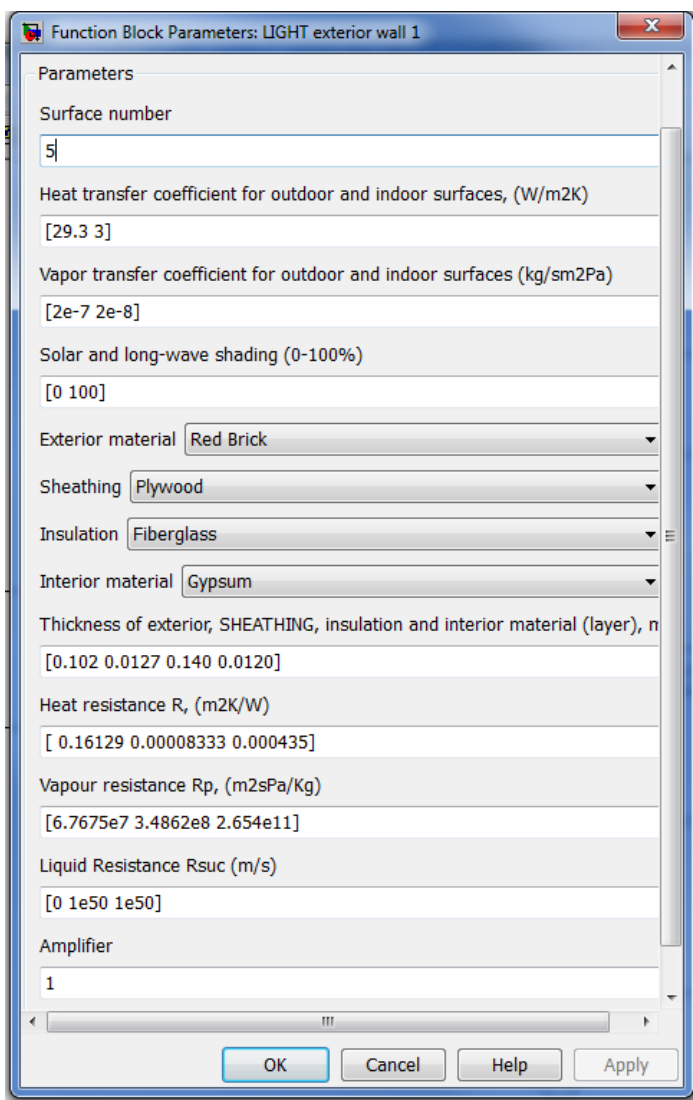

Figure 5: Construction block properties menu for material inputs (Screenshot from HAM-Tools) 
HAM-Tool's output time can be defined in the 'data import/export' section of 'configuration' under 'Simulation' menu. Figure 6 highlights the placement of this setting. It is written as a Matlab array format, that includes start time, time-step, and stop time respectively separated by colon. The duration of the simulation can also be adjusted in the 'solver' section of this 'configuration' menu.

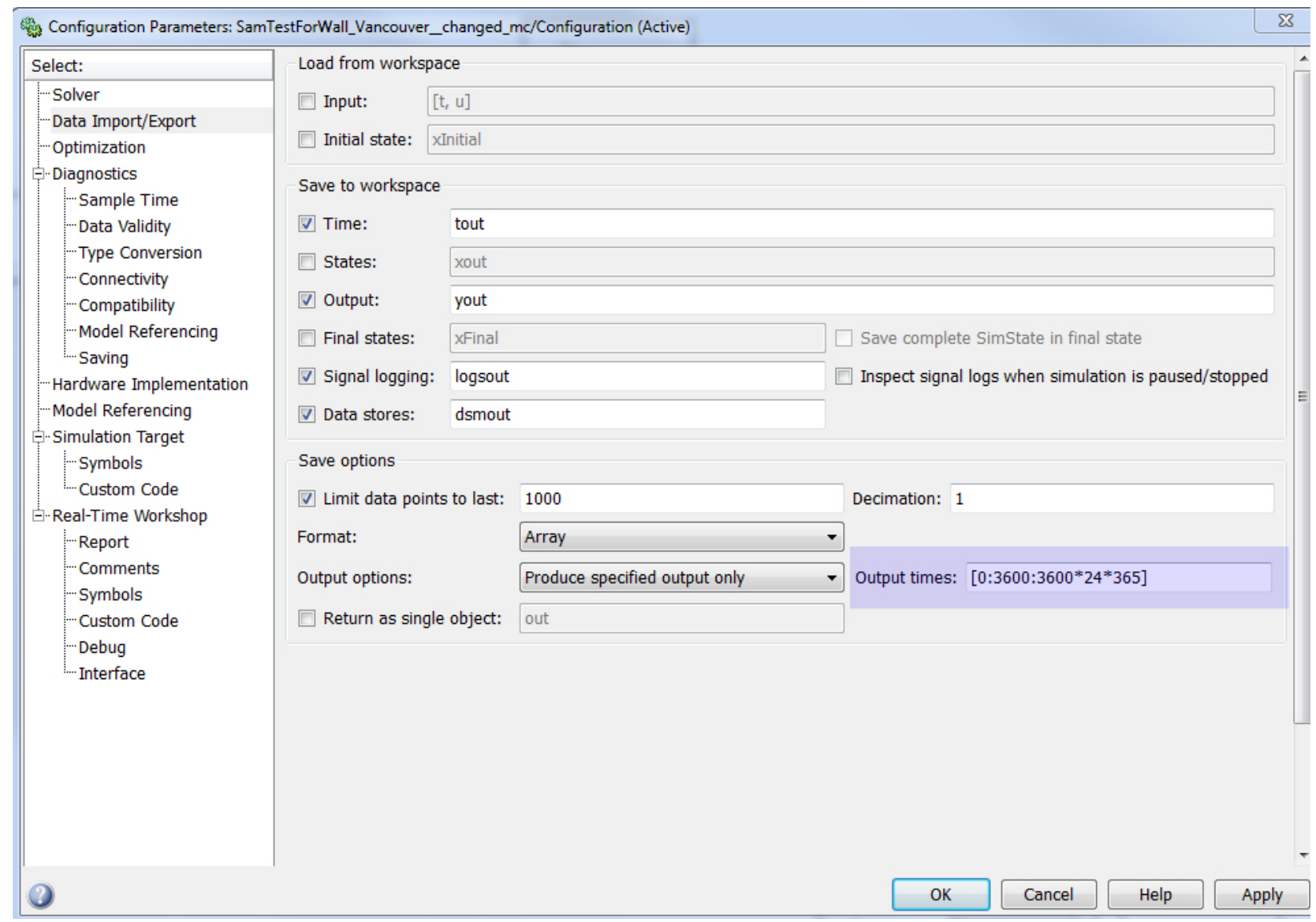

Figure 6: Configuration menu to set the timestep output (from HAM-Tools software)

\subsection{HAM-Tools Wall Construction and Nodes}

In order to construct a wall assembly in HAM-Tools, the pre-defined construction block is used. This block contains external material that includes the external surface node, internal material with the interior surface node, and the middle materials which lie in between external and internal surfaces.

Within the block, it is possible to add, remove and rearrange layers to create the required assembly. It 
should be noted that the layer blocks have to be properly connected to one another. Each node block contains placement for both input and output that the left and right side of the block is dedicated to respectively.

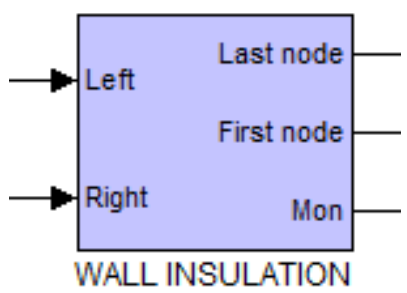

Figure 7: Block for material within the wall construction (Screenshot from HAM-Tools)

The "left" variable of each block is connected to the output of the layer towards the exterior (namely "Last node" or "to right node" for resistive layers) and the "right" variable is connected to the output of the layer towards the interior (the "First node" or "to left node" for resistive layers). This arrangement can be seen in Figure 8

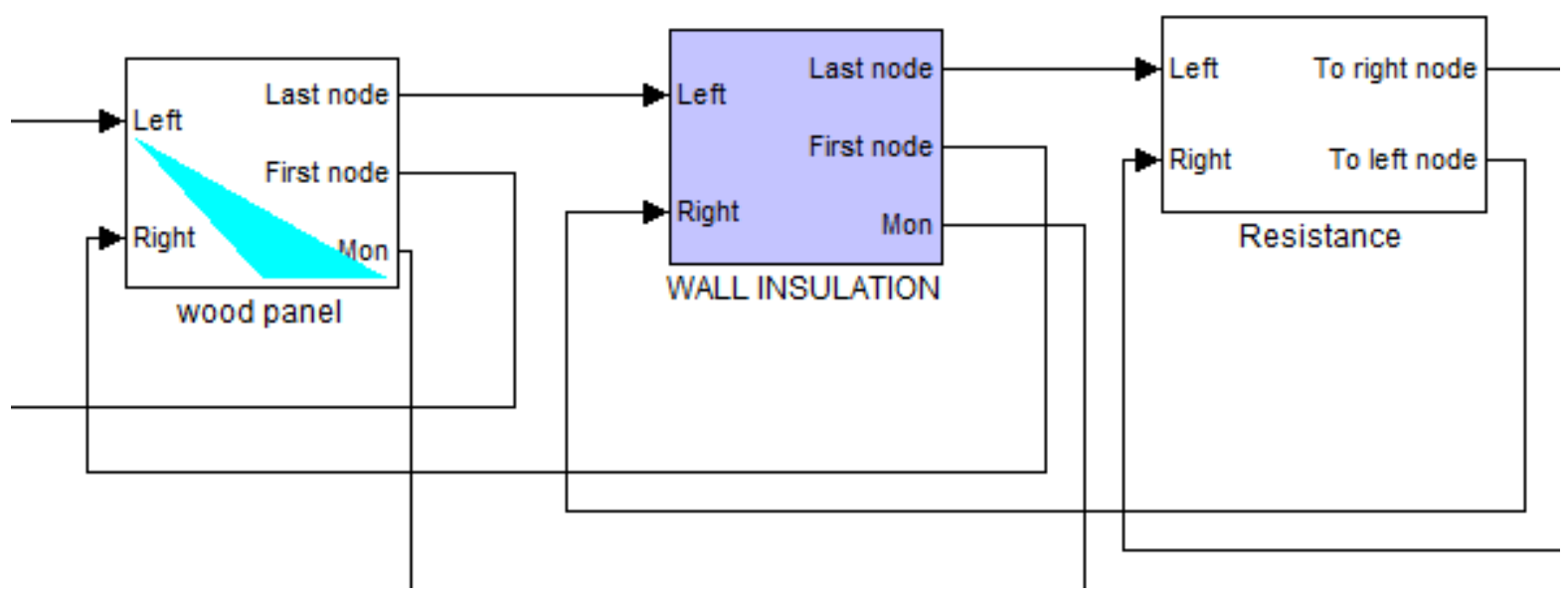

Figure 8: Connection between three layers (Screenshot from HAM-Tools) 
The nodes for each layer are specified under its own block. For example, the exterior layer uses half a node for the outermost section and three other nodes for the rest of the material. Each material can have as many nodes as needed, but needs to have at least one node for the software to run. The nodes can output moisture content, temperature and relative humidity at that specific location through "mon" variable in the construction. Each node consists of the "mon" output, which are all combined and presented in a single array in the construction block. Figure 9 represents a layer that contains three nodes. It should be noted that the resistive layers do not present any output to be analyzed. If a result for a resistive layer is needed (i.e. temperature, moisture content, relative humidity), then that layer's properties should be placed in the material database. This would allow for the program to treat it as a predefined material and not a resistive layer, allowing for results to be shown.

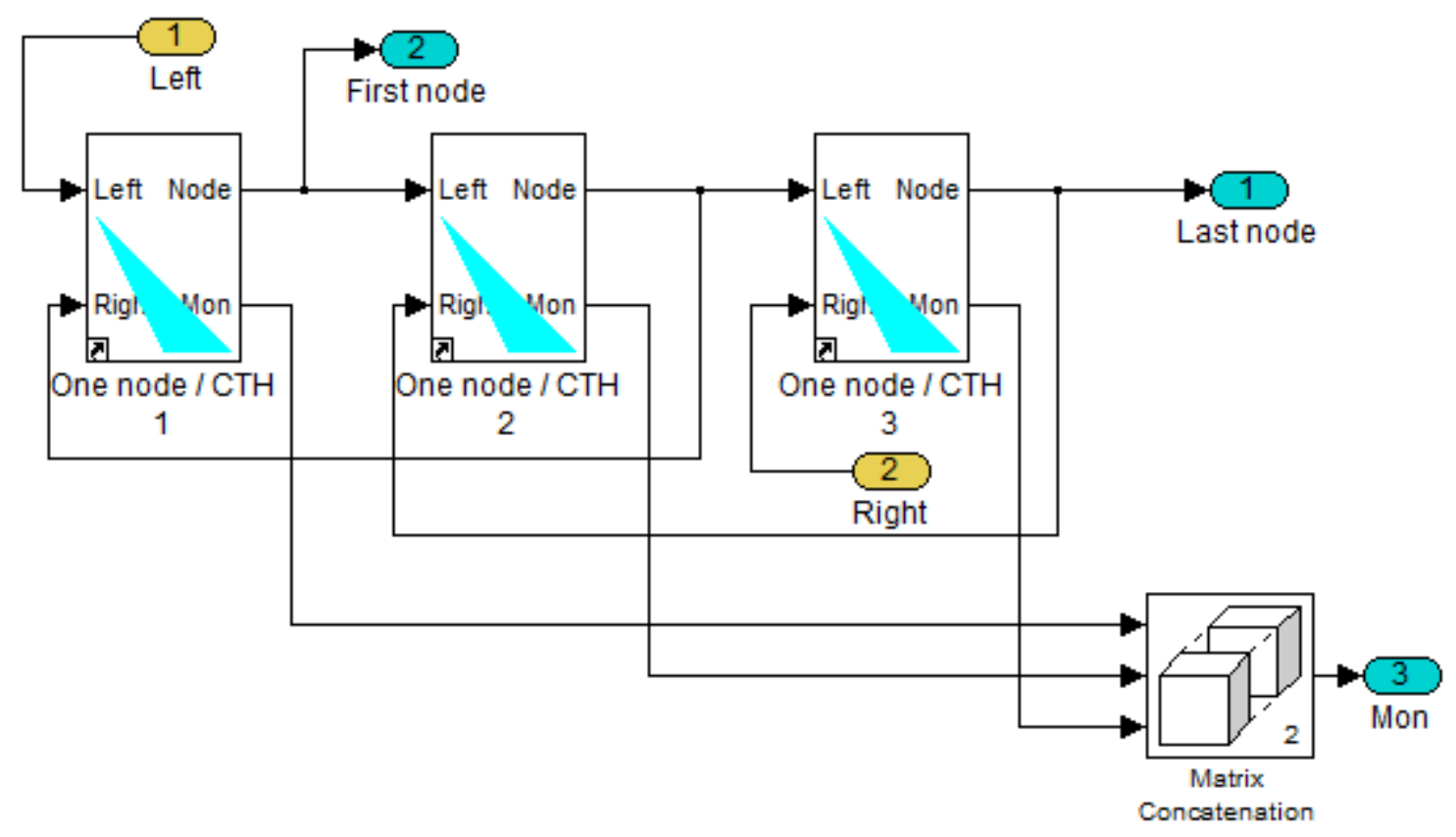

Figure 9: The three nodes presented in one of the layers (Screenshot from HAM-Tools) 


\subsection{Boundary Conditions}

The boundary conditions consist of outdoor weather data including wind driven rain factors and indoor climate data. Since WUFI is being used for verification purposes and that the input parameters between HAM-Tools and WUFI have to be consistent, WUFI's boundary conditions are also covered in this section.

\subsubsection{Exterior weather}

Environment Canada records meteorological data across Canada and creates data files that can be obtained (Environment Canada, 2012). It has two different data sets that are readily available to be used:

- CWEEDS, Canadian Weather Energy and Engineering Data Sets that contains hourly data of the weather elements (such as wind speed, luminance, radiation, temperature, dew point, etc.) starting from 1953;

- CWEC, Canadian Weather for Energy Calculation, that represents a 12 month highest occurrence data created from the long term statistics of thirty years of CWEEDS data. This data set is prepared by National Research Council of Canada and it is used to create a typical weather of a Canadian city and is available for 75 cities across Canada.

The two weather data selected for this research are Toronto obtained from Environment Canada, and Burnaby, British Colombia, obtained from an on-site location weather station.

\subsubsection{Software Input Requirements for weather data}

When comparing results from two different softwares, it is important to keep a consistency between the parameters, especially the weather data. Thus, it is necessary to create a weather data file and modify the format to be readable in both WUFI and HAM-Tools. As each software has its own layout and units 
requirements, they have to be properly arranged and formatted in order for them to be used for simulations. The format of HAM-Tools' file consists of twelve inputs plus the added rainfall intensity shown in Table 5.

Table 5: HAM-Tools weather data format (Kalagasidis, Weitzmann, Nielsen, Peuhkuri, Hagentoft, \& Rode, 2007)

\begin{tabular}{cc}
\hline Description & Unit \\
\hline \hline Time & $\mathrm{S}$ \\
Air temperature & $10^{\circ} \mathrm{C}$ \\
Dew point temperature & $10^{\circ} \mathrm{C}$ \\
Global Radiation on horizontal surface & $\mathrm{W} / \mathrm{m}^{2}$ \\
Diffuse radiation on horizontal surface & $\mathrm{W} / \mathrm{m}^{2}$ \\
Normal direct radiation & $\mathrm{W} / \mathrm{m}^{2}$ \\
Incident long wave radiation & $\mathrm{W} / \mathrm{m}^{2}$ \\
Illuminance, global & $\mathrm{Lux}$ \\
Illuminance, diffused & $\mathrm{Lux}$ \\
Illuminance, direct & $\mathrm{Lux}$ \\
Wind direction & $\circ$ \\
Wind Speed & $10 \mathrm{~m} / \mathrm{s}$ \\
Rain, horizontal & $10 \mathrm{~mm} / \mathrm{hr}$ \\
\hline
\end{tabular}

It should be noted that the original HAM-Tools had a constant zero value for horizontal rain amount. Therefore, the last parameter (horizontal rainfall intensity) was added to the program in the previous study in order to account for WDR as it did not exist in the original weather format $(\mathrm{Wu}, \mathrm{Ge}$, \& Horvat, 2012).

In addition to the weather data sets that are already built in the software package, WUFI also allows for customized weather data as well. WUFI provides a utility program in excel format called "CreateClimateFile.xIs" that has temperature, relative humidity, global horizontal radiation, diffuse radiation, wind direction, wind speed and rain as its input and outputs a ".wac" extension format that is readable with its software. Figure 10 presents the utility program. 


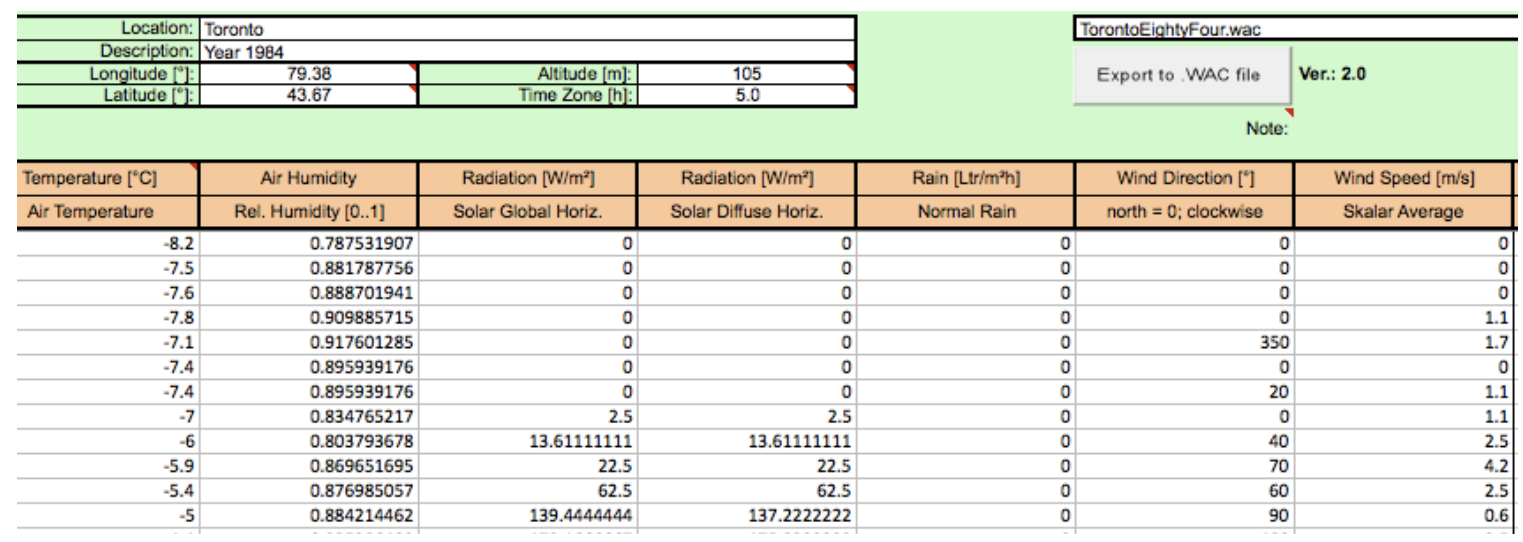

Figure 10: WUFI utility program for creating customized weather file (from WUFI createClimateFile.xls utility)

The input for longitude, latitude, altitude and time zone are written in the top section, while the parameters are selected in each column and weather data values are written in these columns. Finally, once the "Export to .WAC file" is clicked, the proper weather data file is generated and placed in the same folder where the excel utility program is located. This file can then be used in WUFI's software for simulation purposes.

\subsubsection{Formatting the weather data}

Additional point of attention is that the units for each element in a data set vary between data and software. Table 6 summarizes the data presented and their units that each software requires.

To construct the weather data to be the correct format for either HAM-Tools or WUFI, a software is needed to organize and manage the data accordingly. This is achieved using both Microsoft Excel and Microsoft Access and the conversions given in Table 6. 
Table 6: Weather data unit requirements

\begin{tabular}{ccccc}
\hline Description & WUFI & HAM-Tools & $\begin{array}{c}\text { Environment } \\
\text { Canada }\end{array}$ & $\begin{array}{c}\text { Burnaby, BC } \\
\text { data }\end{array}$ \\
\hline Temperature & ${ }^{\circ} \mathrm{C}$ & $10^{\circ} \mathrm{C}$ & $10^{\circ} \mathrm{C}$ & ${ }^{\circ} \mathrm{C}$ \\
RH & 0 to 1 & $\mathrm{~N} / \mathrm{A}$ & $\mathrm{N} / \mathrm{A}$ & $\%$ \\
$\begin{array}{c}\text { Dew point } \\
\text { Solar Radiations on } \\
\text { horizontal surface }\end{array}$ & $\mathrm{N} / \mathrm{A}$ & $10^{\circ} \mathrm{C}$ & $10^{\circ} \mathrm{C}$ & $\mathrm{N} / \mathrm{A}$ \\
$\begin{array}{c}\text { Illuminance } \\
\text { Wind speed }\end{array}$ & $\mathrm{W} / \mathrm{m}^{2}$ & $\mathrm{~W} / \mathrm{m}^{2}$ & $3.6 \mathrm{~W} / \mathrm{m}^{2}$ & $\mathrm{~W} / \mathrm{m}^{2}$ \\
Wind direction & lux & lux & $1 / 100 \mathrm{lux}$ & $\mathrm{lux}$ \\
Rain amount & $\mathrm{m} / \mathrm{s}$ & $10 \mathrm{~m} / \mathrm{s}$ & $10 \mathrm{~m} / \mathrm{s}$ & $\mathrm{m} / \mathrm{s}$ \\
\hline
\end{tabular}

If the relative humidity is needed but not provided in the weather data, it can be obtained by dividing the calculated saturation pressure from dew point temperature with the calculated saturation pressure from the ambient temperature. This process is described in Equation 8 and shown in Figure 11.

$$
\varphi=\frac{P_{v . s a t}\left(@ T_{\text {dew }}\right)}{P_{\text {v.sat }}\left(@ T_{\text {ambient }}\right)} \times 100 \% \quad \text { Equation 8 }
$$

where $P_{v \text {.sat }}$ is the partial pressure of water vapour in air at saturation.

However, if the relative humidity is given and dew point temperature is required, it can be calculated using the same process but in an opposite manner, as shown in Equation 9.

$$
P_{v . s a t}\left(@ T_{\text {ambient }}\right)=\frac{P_{v . s a t}\left(@ T_{\text {dew }}\right)}{\varphi} \times 100 \% \quad \text { Equation } 9
$$

The saturation pressure with respect to a given temperature can be calculated using the formulas below (Hens H. , 1996): 


$$
\begin{array}{ll}
p_{v, \text { sat }}=\exp \left(23.5771-\frac{4042.9}{T+273.15-37.58}\right), \quad 0 \leq T \leq 80^{\circ} \mathrm{C} & \text { Equation } 10 \\
p_{v \text { sat }}=611 \cdot \exp \left(82.9 \cdot 10^{-3} \cdot T-288.1 \cdot 10^{-6} \cdot T^{2}+4.403 \cdot 10^{-6} \cdot T^{3}\right) & \\
\text { for }-30 \leq T \leq 0^{\circ} \mathrm{C} & \text { Equation } 11
\end{array}
$$

If the temperature is above zero degrees Celsius, the saturation pressures are obtained using Equation 10 and if the temperature is below freezing point, Equation 11 is used. HAM-Tools uses this method to find relative humidity based on the ambient and dew point temperatures. Figure 11 illustrates the process in HAM-Tools that calculates relative humidity and partial pressure at saturation for both below and above zero degrees temperatures.
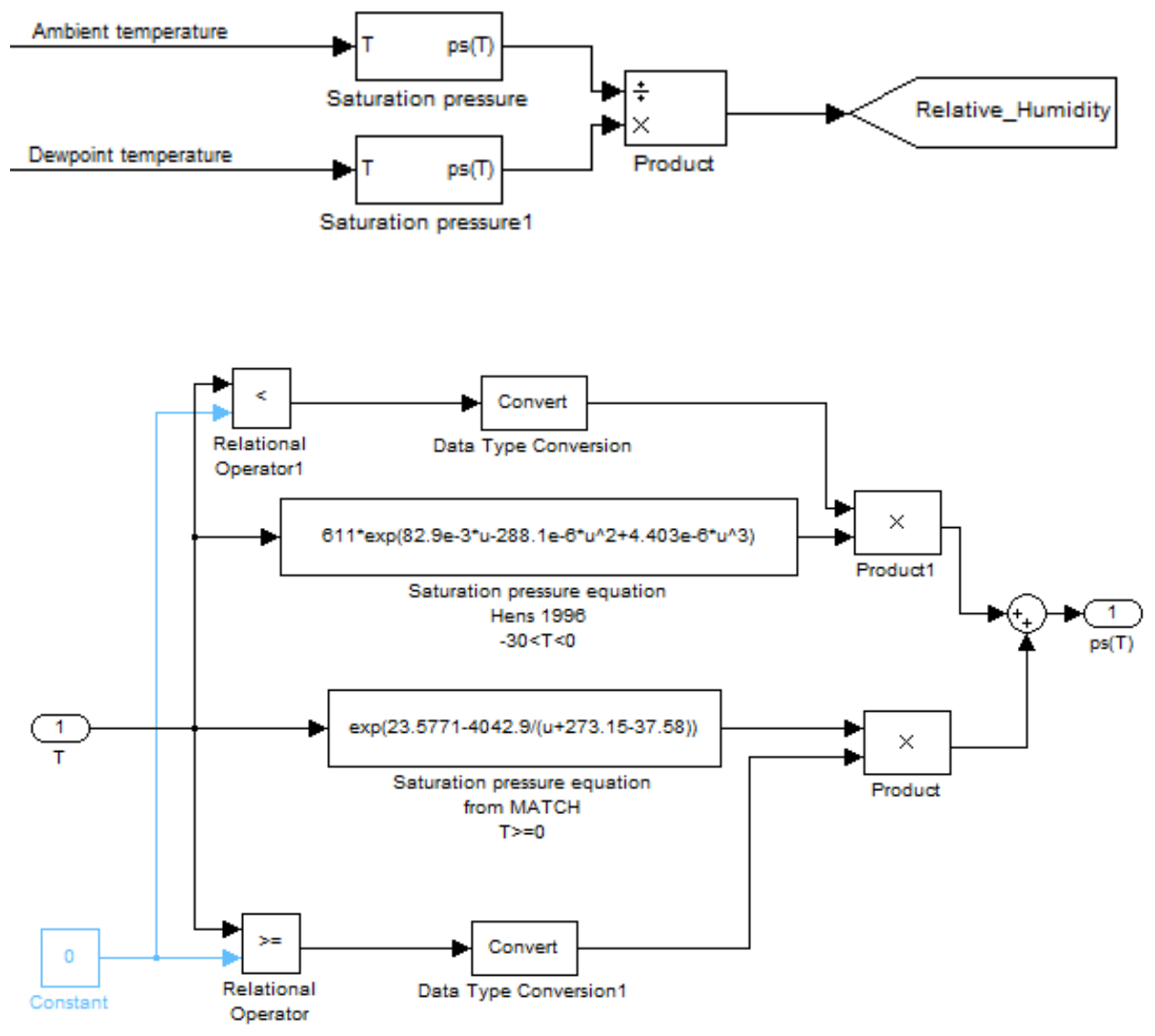

Figure 11: (Above) Calculation of RH from temperature and saturation pressure. (Below) Calculation of partial or saturated pressure from given temperature (from HAM-Tools Software) 
As an example, if the input for ambient temperature is 1 degrees and the dew point temperature is given at -0.5 degrees, the relative humidity is then calculated to be $89.24 \%$.

\subsubsection{Interior climate}

The interior climate is set according to EN 15026 standard (WTA, 2004) from International Association for Science and Technology of Building Maintenance and Monument Preservation Guideline 6-2-01/E. This is chosen since both HAM-Tools and WUFI have the option to select this standard for the indoor condition. The moisture load is set to a normal load (30\% to $60 \%$ relative humidity) and initial conditions of the building envelope are set at $20^{\circ} \mathrm{C}$ to represent typical values.

\subsubsection{Development of Wind Driven Rain in HAM-Tools Software}

As described in previous chapter, a WDR module was developed in accordance to ASHRAE Standard 160P (ASHRAE 2009) to be used in HAM-Tools (Wu, Ge, \& Horvat, 2012). It was necessary to understand the structure of HAM-Tool's moisture transport to be able to implement the WDR module. The heat and moisture balances are located under the external node block, and is presented in Figure 12. The amount of rain is obtained from the 'weather' port, which is connected to 'weather on surface' block shown in Figure 13. 


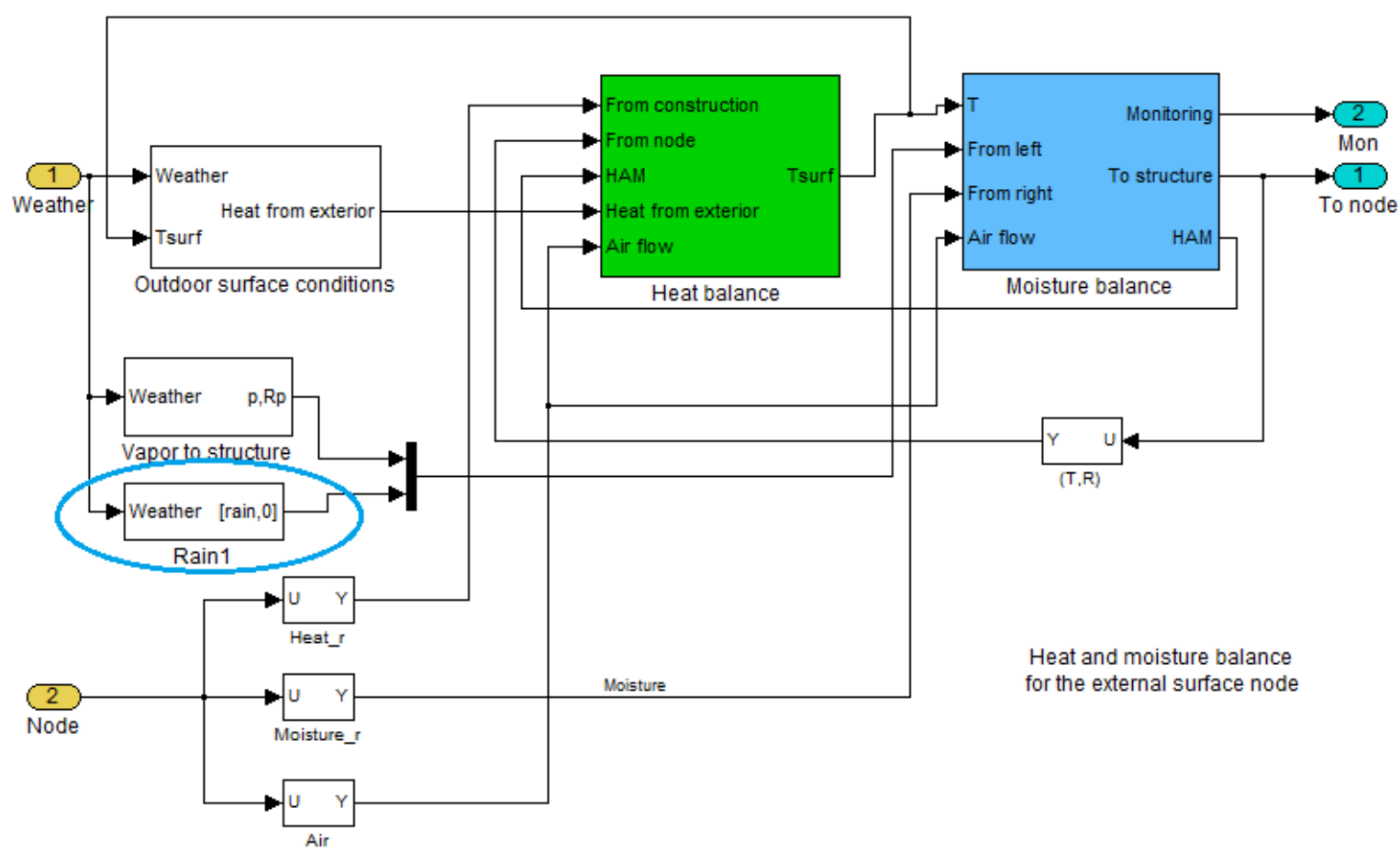

Figure 12: Heat and moisture balance in the external surface (obtained from HAM-Tools software)

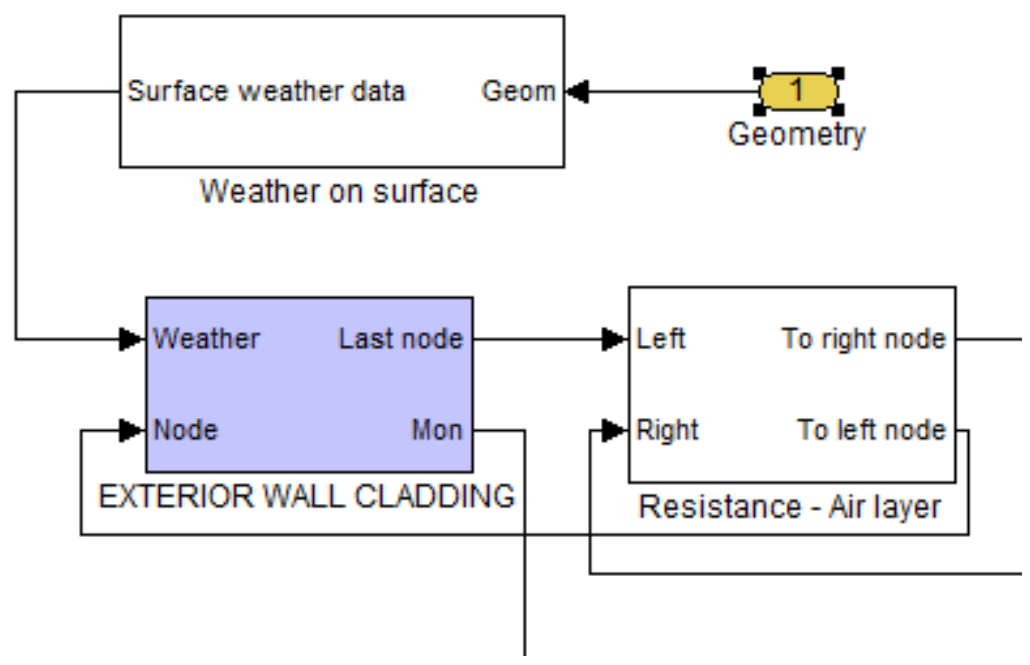

Figure 13: Weather on surface block under the construction block (from HAM-Tools software) 
Looking under the 'weather on surface' block, it was realized that the value for rain was set to zero at all times. Therefore, the module was written as a block and placed in the weather on surface block, replacing the constant zero. As mentioned before, the weather block was changed to add a new parameter of horizontal rainfall to be read from the weather file.

To create the WDR module, Equation 7 from section 1.2.2 was used to calculate the WDR intensity. The completed model is shown in Figure 14. Since HAM-Tools has defined south to be zero degrees and increase by moving counter clockwise, section ' $A$ ' changes this to define north to be zero degrees and count clockwise. This ensures that the weather data that is input in HAM-Tools is consistent with the normal meteorological data that provides the data. Section ' $B$ ' verifies if the surface chosen in the geometry is the roof, while section ' $\mathrm{C}$ ' ensures that the wall orientation faces the direction of the wind blowing by setting the WDR intensity to zero if wind is not hitting the surface of the wall. Finally, section ' $D$ ' is the multiplication of all these and the parameters defined in Equation 7. Since the unit for HAMTool's calculations are in seconds, it is important to convert the result of the WDR module to be consistent with the software. For example, if the weather data is presented in hourly data, then a factor of $1 / 3600$ is introduced. If a 1 minute weather data is used, then a factor of $1 / 60$ is used. 


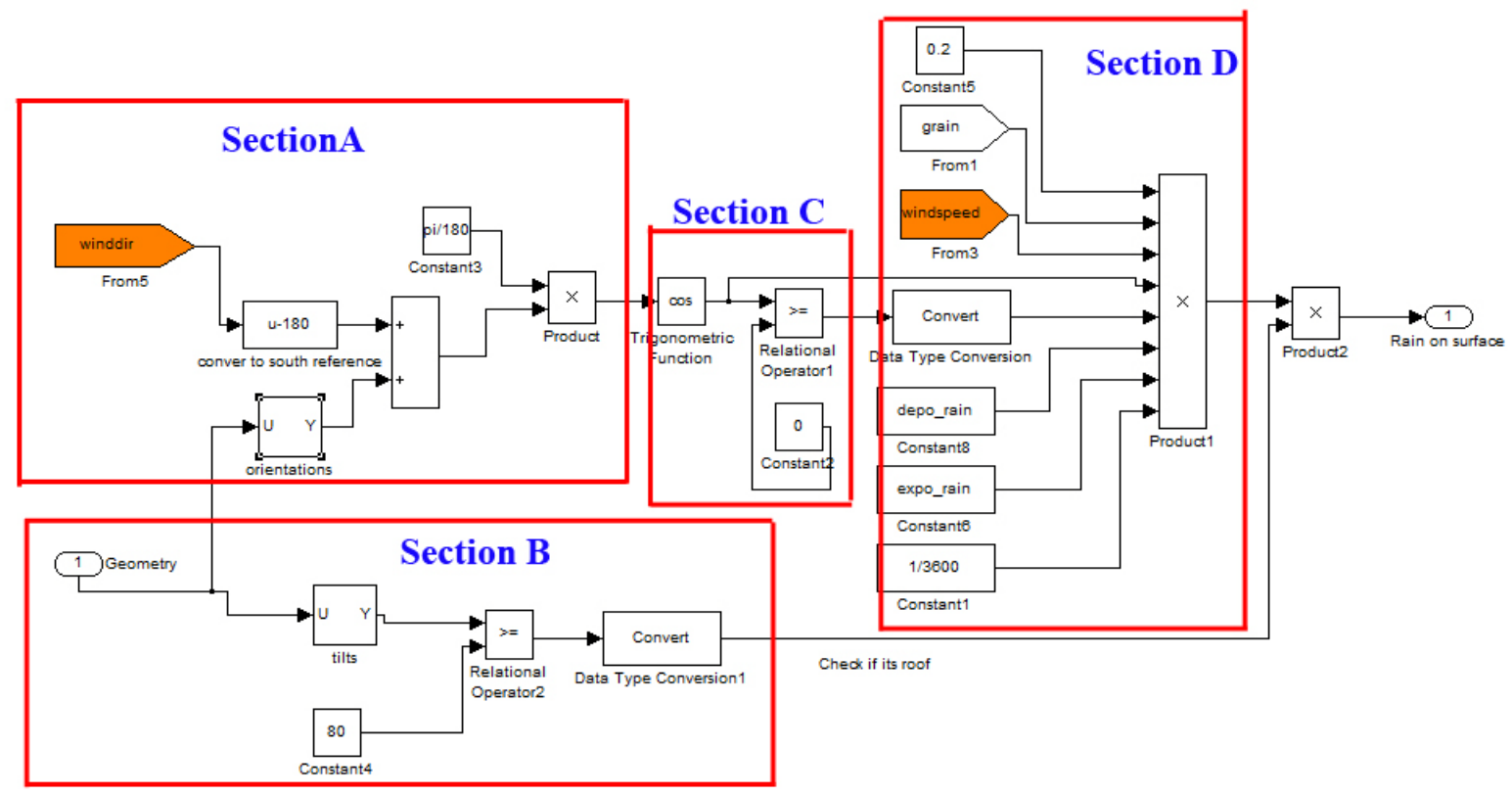

Figure 14: Added WDR module to HAM-Tools (Wu, Ge, \& Horvat, 2012)

\subsection{Wind Driven Rain in WUFI Software}

Similar to HAM-Tools, WUFI requires outdoor weather data and indoor climate conditions, surface transfer coefficients, driving rain load and initial moisture content of each wall component to be input for simulation. In order to calculate the wind driven rain, WUFI allows the user to choose between the two semi-empirical models, SB model and ASHRAE Standard 160P model. The WDR model can also be disabled by changing the "adhering Fraction of Rain" to zero in the "surface transfer coefficient" section of the program.

\subsection{WUFI's Limitation and how it is addressed}

When the research for this study was performed, it was important to be able to analyze the results from both WUFI and HAM-Tools in each specific node. This was later changed to analyze the whole layer 
(averaging all the nodes in that layer), but was an important learning and problem solving step. By trying to obtain moisture content results for each node, one of WUFI's limitations was realized.

WUFI allows for the placement of nodes to be set in each section of a layer. They are known as monitor positions. However, while these monitor positions can output the temperature and relative humidity at that location of the layer, the output of moisture content is limited to the average of the whole layer. This can be an issue when a specific location within a material is needed to be studied and compared with HAM-Tools. In order to overcome this limitation, it can be possible to divide the specific layer into smaller sections. To verify this technique, a software experiment in WUFI was performed. The outer layer (aerated concrete) was replaced with four new layers consisting of the same material. The thickness of these layers were adjusted to have a total thickness of the initial outer layer $(105 \mathrm{~mm})$ and are divided into three and a half equal sections. These sections resemble the nodes set in HAM-Tools outer layer. Figure 15 and Figure 16 show the two different setup.

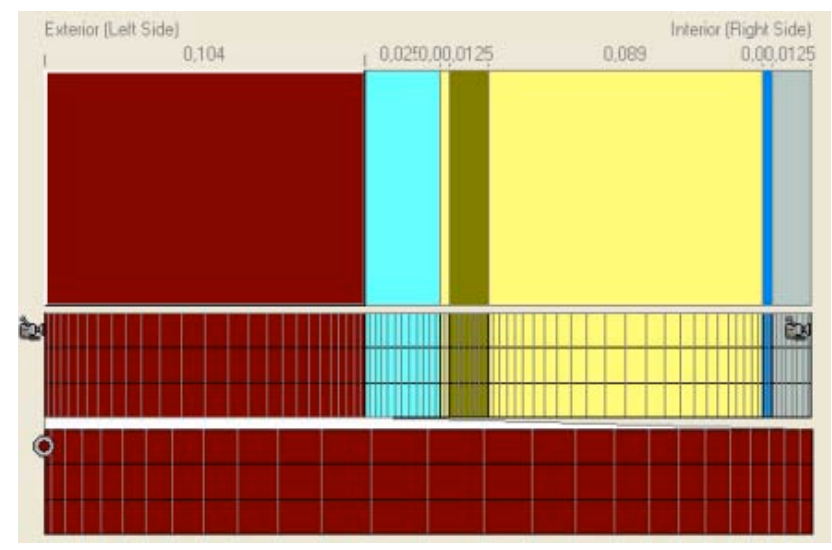

Figure 15: WUFI wall construction with outer layer divided in one section (from WUFI Software) 


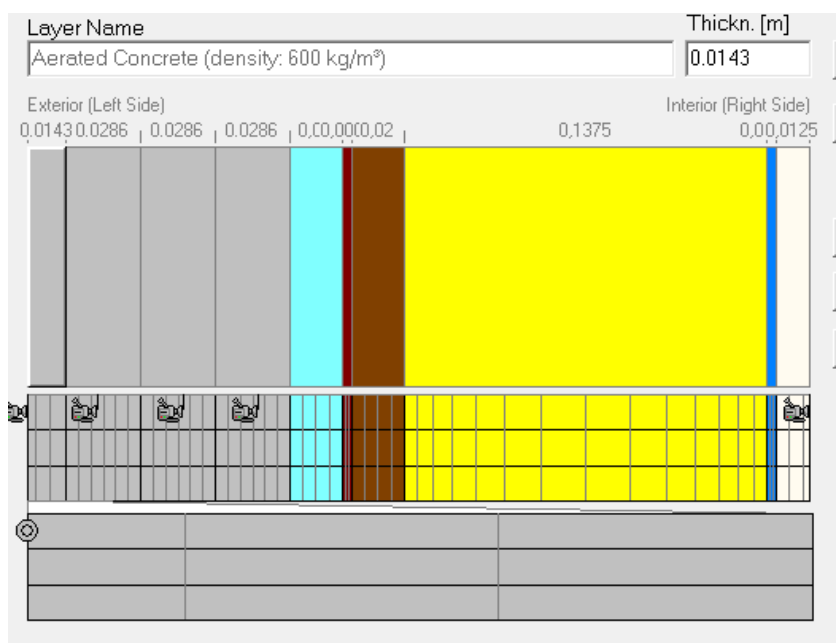

Figure 16: WUFI wall construction with outer layer divided in 3.5 sections (from WUFI Software)

Finally, a comparison was done between the initial construction (one outer layer of $105 \mathrm{~mm}$ ) and the modified construction (three and a half sections totalling $105 \mathrm{~mm}$ ). The monitor positions were placed exactly at the same positions for each construction and the relative humidity and temperature at these nodes were compared. The result shows that there is no difference between these constructions and this method can be applied to find moisture content values at a specific location within a material. 


\section{Chapter 3: Verification of the module}

The implemented WDR module in HAM-Tools is verified against WUFI software. This requires the use of the same weather data and wall construction in both programs. The verification is conducted in order to ensure that the differences between the two programs, such as material properties and water transport mechanism, are addressed. First, the water transport conversion was verified, and then a comparison between the programs was conducted with both the WDR turned off and on.

\subsection{Toronto weather data}

The first data that is used is from CWEEDS data for station number 04741 in downtown Toronto. It is located in Trinity College at University of Toronto and resembles a populated and dense environment.

Figure 17 shows the map of greater Toronto with its average density and the location of this station.

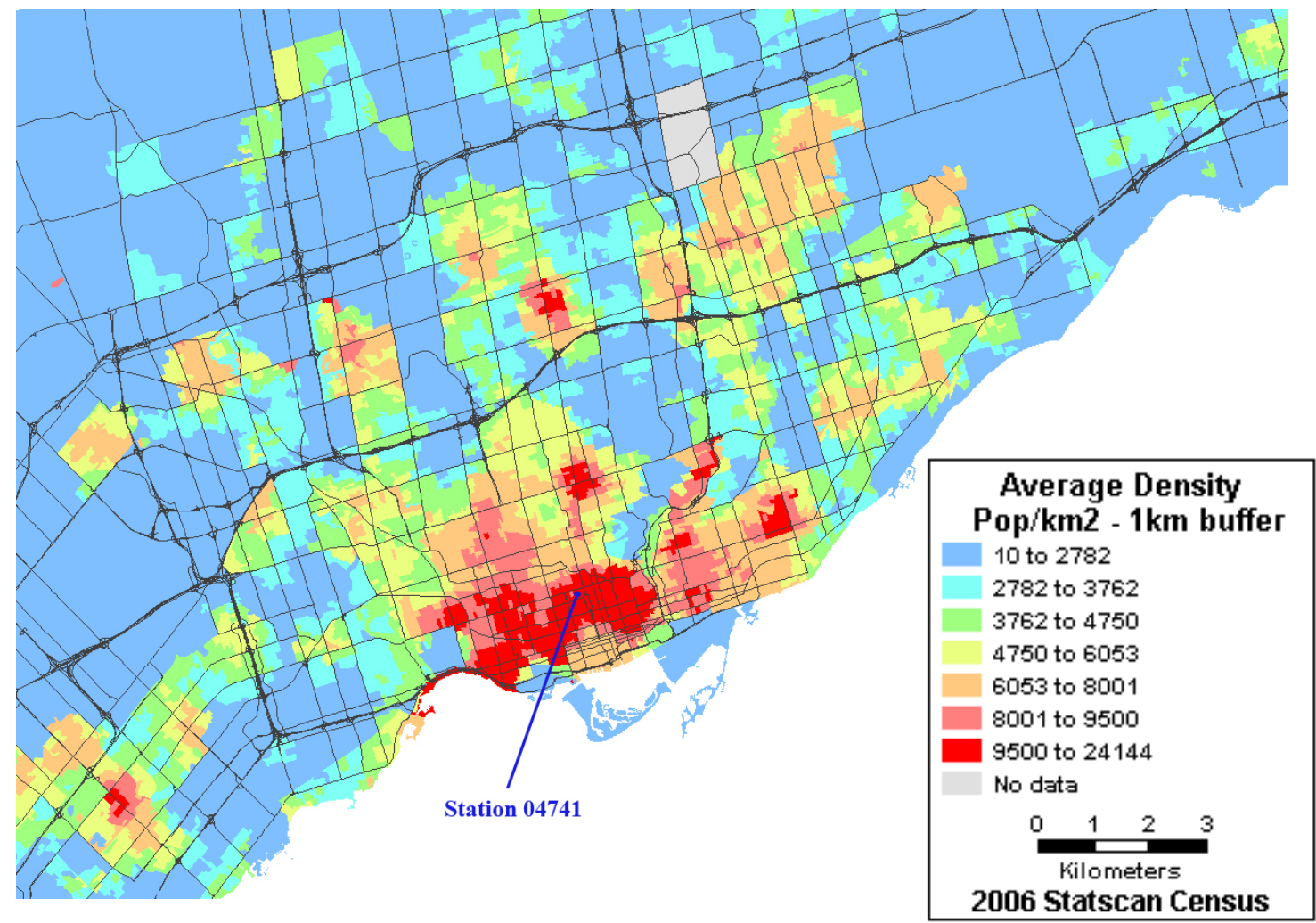

Figure 17: Location of 04741 weather station in Toronto, ON, Canada (from http://www.statcan.gc.ca/) 
For a better accuracy, it is important to choose a year that has minimum or no missing data. A Matlab code shown in Appendix G was written to read through the data and output the year and the amount of missing measurements for that year. The year 1984 includes all the information for each hour of that year without missing any lines of data. Hence, 1984 is chosen for simulation purposes. It should be noted that the CWEEDS does not contain hourly rain values, which is necessary information for this research. Thus, this data was previously obtained from Environment Canada (Wu, Ge, \& Horvat, 2012). Therefore, the main reason for using the weather data at this location for this study is the availability of the hourly rain data. Both the CWEEDS and rain amount files need to be organized using database software, such as Microsoft Access or Excel, to be converted in a useful format.

The wind driven rain can be viewed using a wind rose graph that represents the driving rain sum. In order to create this graph, Equation 12 is used (ISO, 2009).

$$
I_{A}=\frac{2}{9} \frac{U R_{h}^{8 / 9} \cos (D-\theta)}{N} \quad \text { Equation } 12
$$

where ' $U$ ' is the wind speed, ' $R_{h}$ ' is the rain amount, $\theta$ is wind direction, ' $N$ ' is number of years, $I_{A}$ is the driving rain sum and ' $D$ ' is the direction of the calculation relative to the wall. A Matlab program is written that calculates 24 different direction of $D$ to obtain the driving rain sum at that direction. The results are then graphed using Excel software. The result shows the sum of rainfall amount with respect to its direction. The program and a sample of the excel file is provided in Appendix E.

The wind rose diagram for the obtained weather data is represented in Figure 18. 


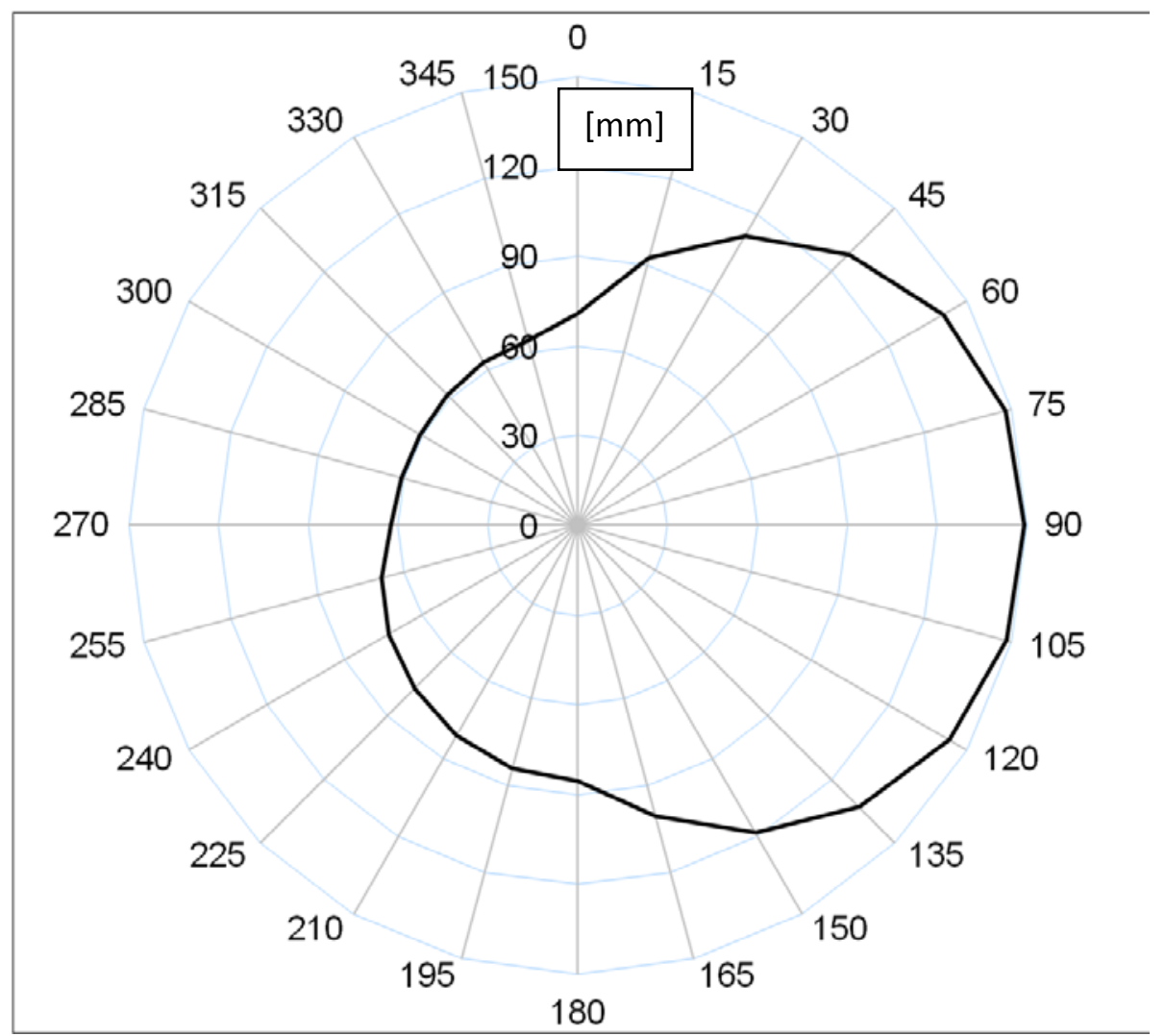

Figure 18: Annual driving diagram of 1984 Toronto weather [mm]

This explains that the prevailing wind driven rain has the highest impact on the East side of a given surface. Therefore the simulations using this weather data are conducted on the walls facing the East side. The horizontal rainfall amount is shown in Figure 19. This graph is used later for analysis. The total annual rain amount for that year is calculated to be $393 \mathrm{~mm}$. 


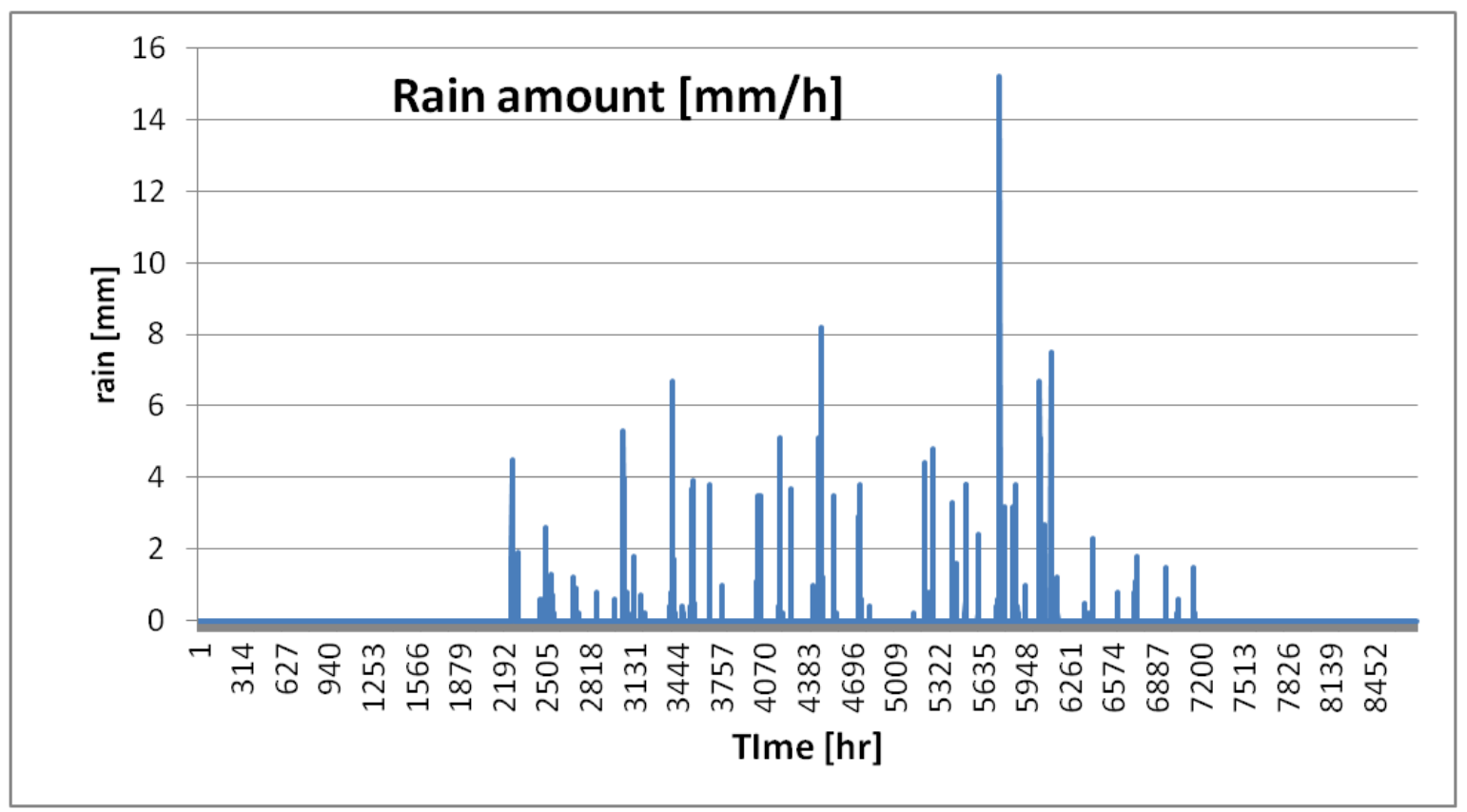

Figure 19: Toronto 1984 horizontal rainfall amount

\subsection{Toronto wall construction}

To compare simulation results from HAM-tools to WUFI, the material properties of wall assemblies need to be consistent. Since HAM-Tools has a very limited material database, materials from WUFI's database are used to construct the simulations. Most of the material properties can either be directly input from one program to the other, or can be converted.

The first wall assembly constructed in both programs is chosen to be a typical North American wood frame residential building envelope. The outer layer is selected to be a material with enough sorption isotherm details provided in WUFI's database to be able to convert its liquid diffusivity to hydraulic conductivity. The detail of the wall assembly is shown in Table 7. This assembly is tested against Toronto weather data. 
Table 7: Simulated wall construction

\begin{tabular}{cc}
\hline Material (outdoor to indoor) & Thickness [mm] \\
\hline Wood siding & 20 \\
Air space & 25 \\
60 minute building paper & 0.1 \\
OSB Sheathing & 12.5 \\
Fiberglass insulation & 89 \\
Polyethylene vapour retarder & 0.15 \\
Gypsum board & 12.5 \\
\hline
\end{tabular}

Using the construction block and HAM-Tools library, the blocks 'weather on surface', 'external material', 'internal material', 'material', and 'resistance' were used to create the wall assembly. Figure 20 illustrates this construction. 


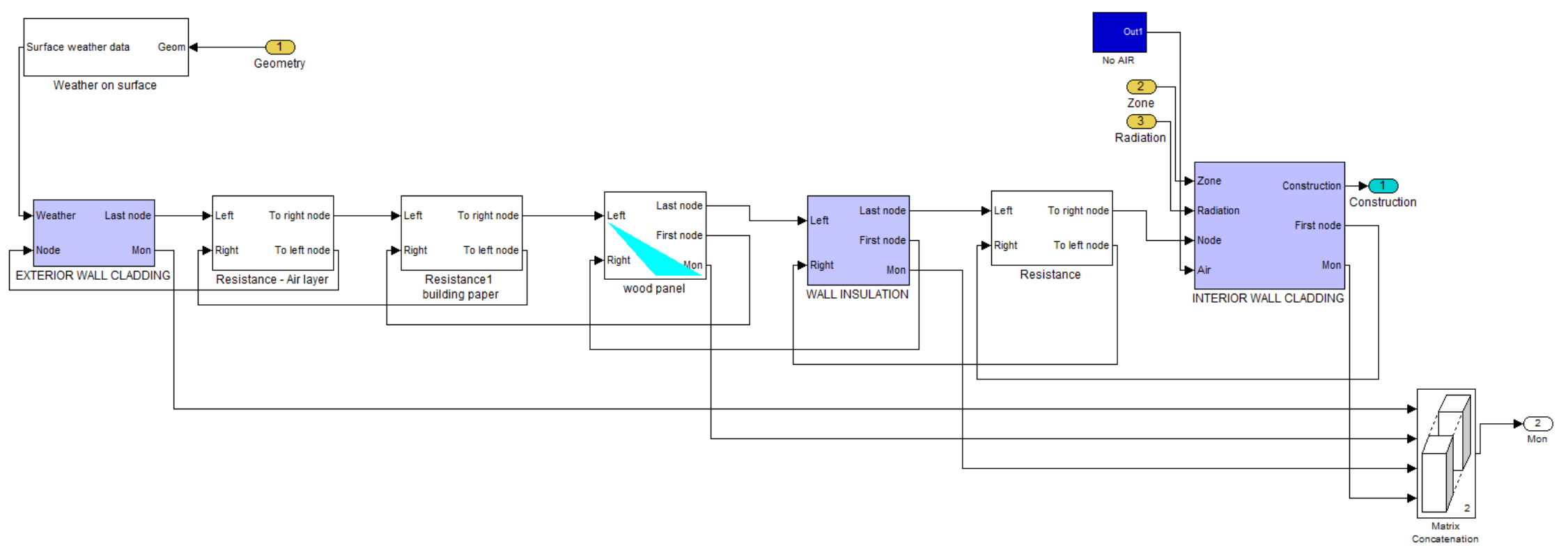

Figure 20: Wall construction in HAM-Tools (from HAM-Tools software) 
The wall construction applied to WUFI is presented in Figure 21.

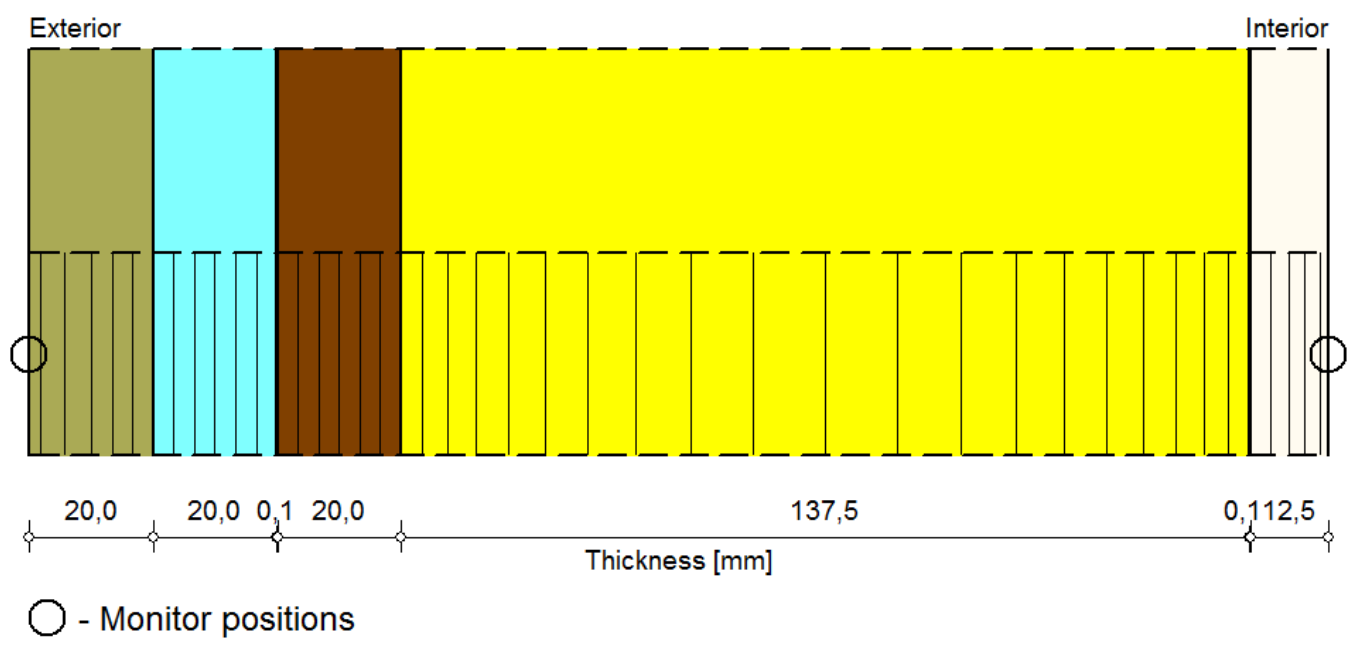

Materials :

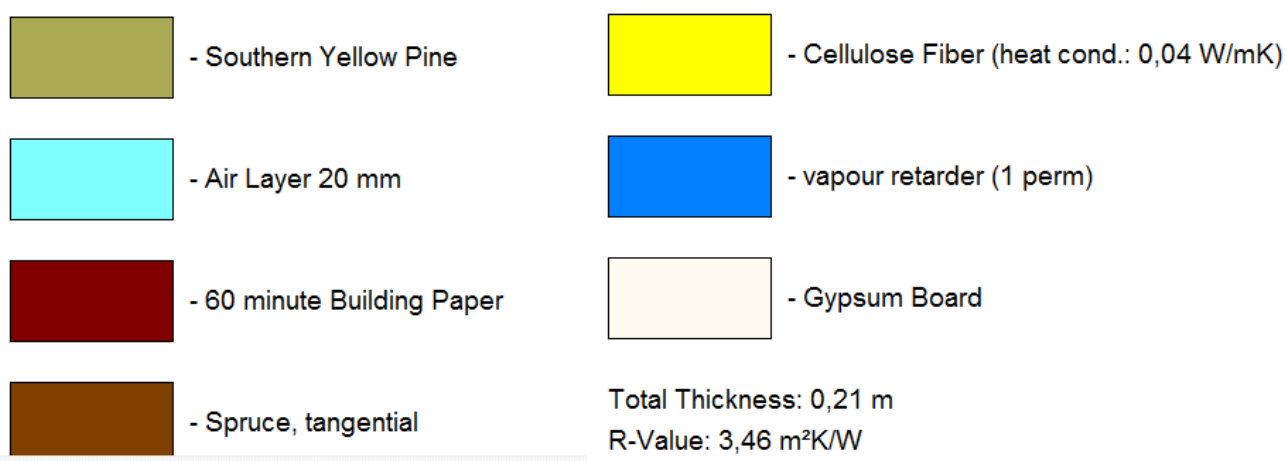

Figure 21: Wall construction in WUFI (from WUFI software)

\subsection{Water Transport properties Conversion}

The main differences between WUFI and HAM-Tools are the driving force and material properties to account for liquid transport. WUFI uses the gradient of water content and liquid diffusivity while HAMTools uses suction pressure difference across the material thickness and hydraulic conductivity. To convert liquid diffusivity for materials from WUFI's database to hydraulic conductivity required by HAM- 
Tools, the material's retention curve is needed. The retention curves found from literature can be used to verify the conversion.

To be able to find the relationship between hydraulic conductivity and liquid diffusivity, the formulas for both methods are analyzed. The liquid diffusivity in WUFI is governed by Equation 13 (Fraunhofer IBP, 2010).

$$
g_{1}=-D_{w} \frac{\partial w}{\partial x}
$$

Equation 13

where $g_{w}$ is the liquid moisture flux, $D_{w}$ is liquid transport coefficient, $w$ is moisture content in $\mathrm{kg} / \mathrm{m}^{3}$, and $\frac{\partial}{\partial x}$ is the differentiation term in the $\mathrm{x}$ direction. WUFI uses tabulated data to provide the transport coefficient as a function of water content in the material. It applies to two kinds of moisture transports: the suction, which is when free water is presented at the material surface (such as rain), and redistribution, which is the transport of moisture without the presence of free water. The transport redistribution coefficient is approximated $1 / 10^{\text {th }}$ of the suction coefficient.

In HAM-Tools, the liquid transport uses the water retention curve and is based on the suction pressure difference across the material thickness. It is governed by Darcy's law shown in Equation 14.

$$
g_{w}=-K \cdot \frac{\partial P_{s u c}}{\partial x}
$$

Equation 14

where $\mathrm{K}$ is the Hydraulic conductivity and $\mathrm{P}_{\text {suc }}$ is the suction pressure. The relationship between these two means of water transports can then be obtained and is shown in Equation 15. 


$$
K=-\frac{D_{y}}{\frac{\partial P_{s u c}}{\partial w}}
$$

Equation 15

The relationship between suction pressure and moisture content is known as the suction isotherm or the retention curve, thus the term $\frac{\partial P_{\text {capillary }}}{\partial w}$ is the derivative of this relationship. Finding the relationship between relative humidity and suction (at high $\mathrm{RH}$ ) allows for calculating the retention curve. Equation 16 describes this relationship (ASTM-Standard, 2009).

$$
\ln (\varphi)=\frac{P_{\text {suc }} M_{w}}{R T \rho_{w}}
$$

Equation 16

where $M_{w}$ is the molar weight of water and $R$ is the ideal gas constant.

It is possible to find the suction pressure at a specific relative humidity from the formula above. The calculated relative humidity is then used to find the moisture content of a material at the specific suction pressure by using sorption isotherm curve. Subsequently, the relationship between moisture content and suction pressure provides the retention curve that is then used in Equation 15 to obtain the relationship between hydraulic conductivity and liquid diffusivity of a material.

If the sorption isotherm of a material in WUFI's database has enough details (moisture content values at high relative humidity), then the retention curve can be generated.

\subsubsection{Retention curve comparison between measured data and WUFI database}

In order to validate the water transport conversion, it is necessary to compare the results with measured data. The use of relative humidity to determine the moisture storage potential would result in 
low resolution in the super-hygroscopic range. Therefore it is better to use suction and obtain the retention curve for moisture storage potential. The retention curve can be measured directly through lab experiments known as pressure plate extraction. It uses overpressure to force water out of a saturated specimen. Since pores are saturated with water, they allow only water and not air to pass through it (Janz \& and Johannesson, 2001). Previous studies have measured the retention curve of some commonly used construction materials such a few materials such as calcium silicate, ceramic brick (Carmeliet \& and Roels, 2000), Bamburger sandstone, Sander sandstone (Hansen, Houvenghel, Janz, Krus, \& . Stromdahl, 1999), autoclaved aerated concrete, cement mortar, cement lime mortar, lime silicate brick, Kanic Antik brick, Kanik Gul brick (Janz \& and Johannesson, 2001) to name some.

For validation purposes, it is important to select a material that has similar properties with one of the materials from WUFI's database. These properties include density, porosity and sorption isotherm. The best suitable material is found to be between Autoclaved Aerated Concrete from a literature (Janz \& and Johannesson, 2001) and Aerated concrete from WUFI database (Fraunhofer IBP, 2010). The properties are shown in Figure 22.

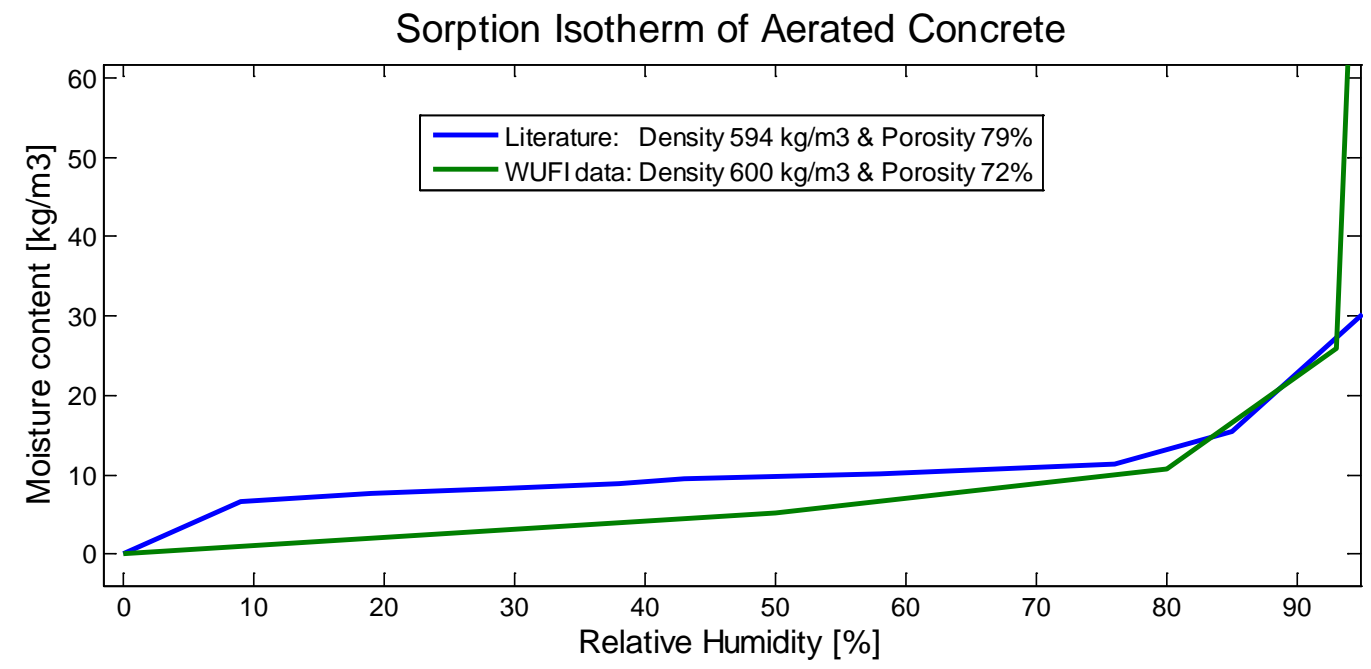

Figure 22: Comparison of sorption isotherm for aerated concrete between Janz measurement and WUFI's database 


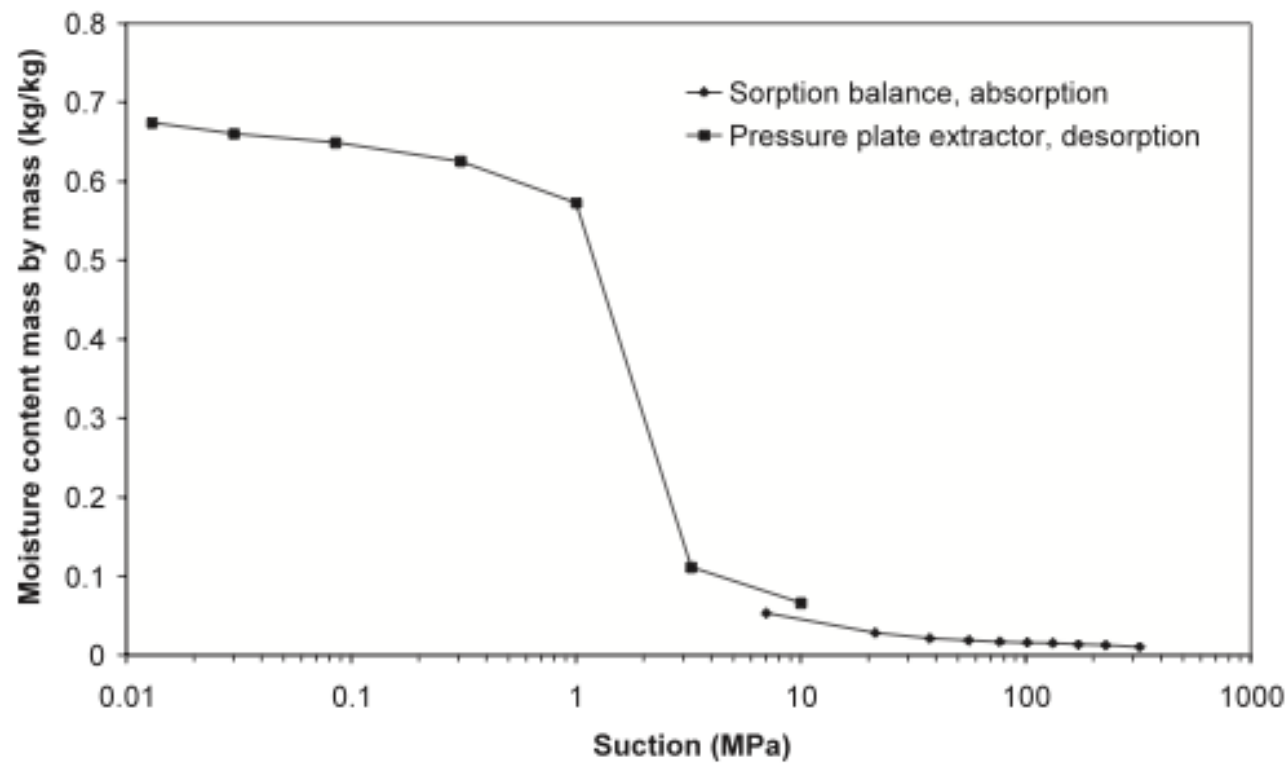

Retention curve for autoclaved aerated concrete.

Figure 23: Retention Curve of autoclaved aerated concrete (Janz \& and Johannesson, 2001)

Figure 23 shows the retention curve of Autoclaved aerated concrete. Using this retention curve, the hydraulic conductivity of Autoclaved Aerated Concrete is obtained. The other hydraulic conductivity is calculated using WUFI's database and the Matlab code given in Appendix C. The comparison is shown in Figure 24.

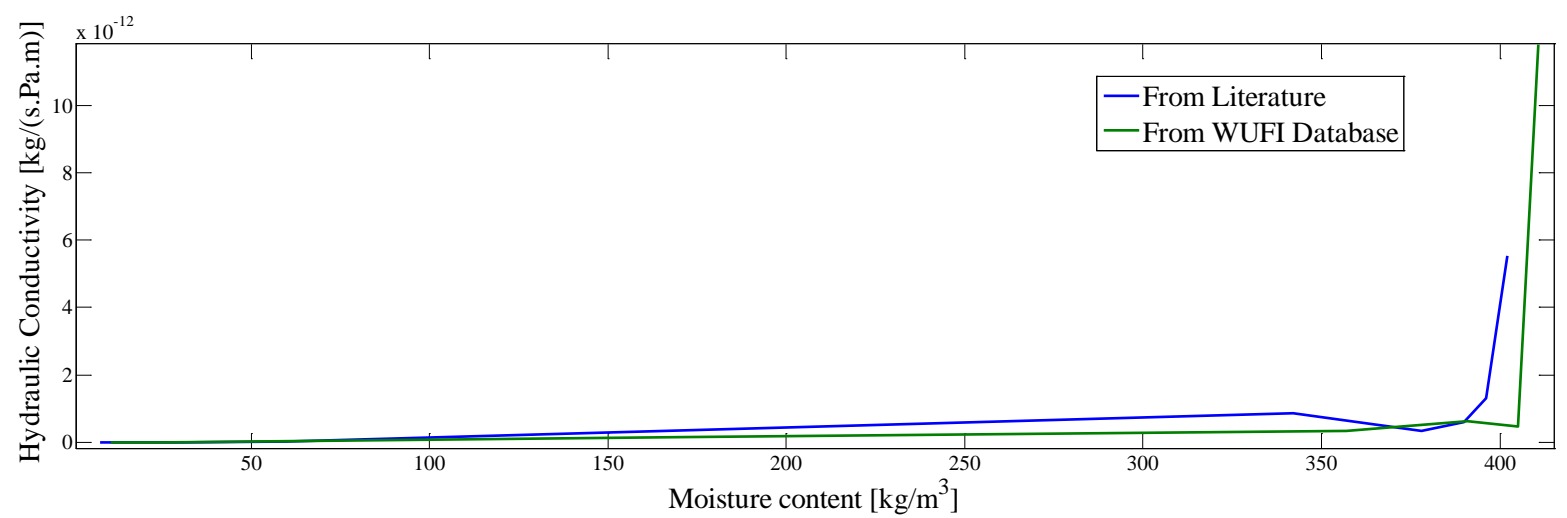

Figure 24: Comparison of hydraulic conductivities of aerated concrete calculated using information from literature and WUFI 
These two different hydraulic conductivities are then put in HAM-Tools software. Using Toronto 1984 weather data and wall construction specified in section 3.1, the moisture content of aerated concrete with these different hydraulic conductivities are compared. Figure 25 presents the results of this comparison for moisture content of Aerated Concrete and the relative difference between the results are shown as well. This relative difference is calculated using Equation 18.
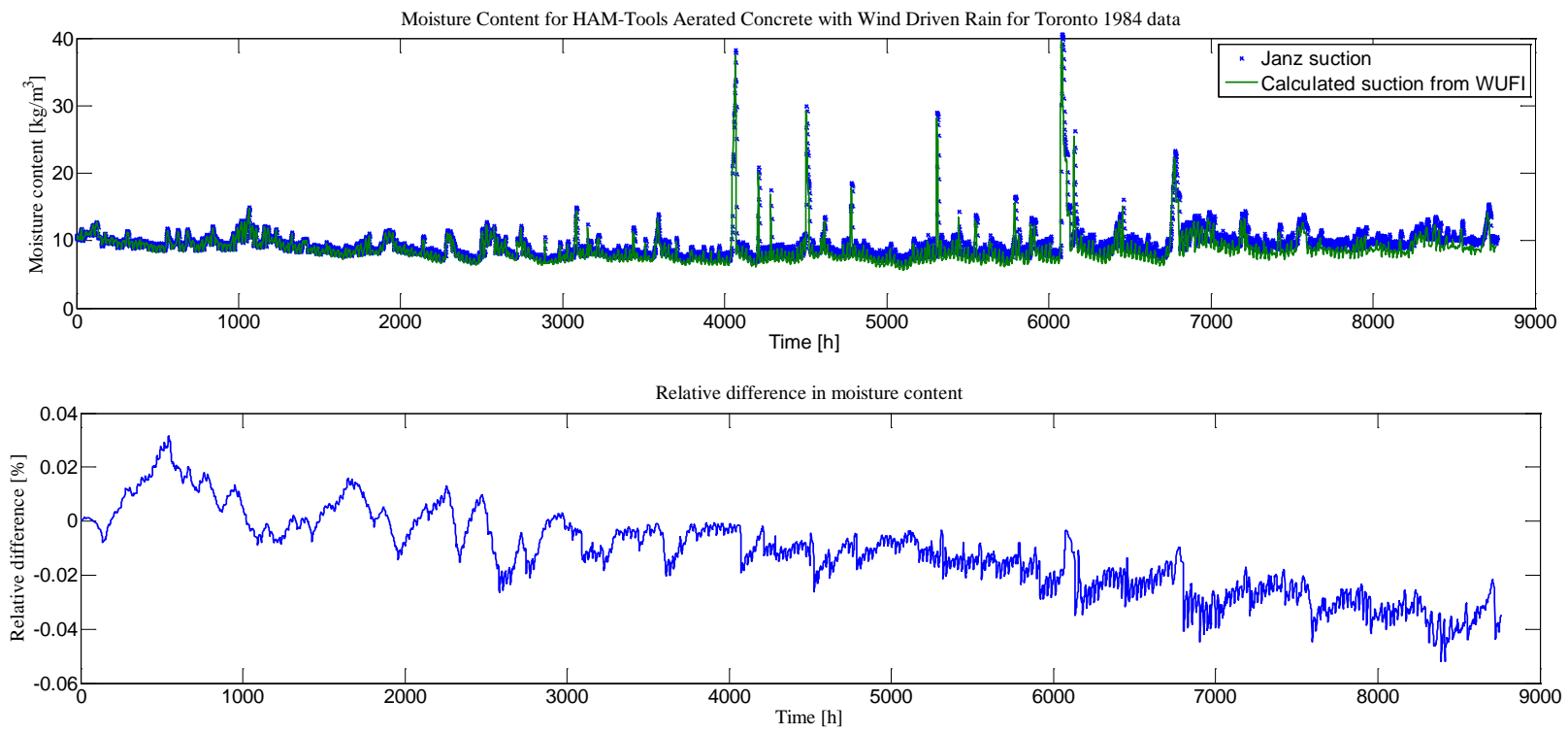

Figure 25: (LEFT) Comparison of moisture content in HAM-Tools simulation. (Right) The resulting difference for the comparison

$$
\text { Relative difference }=100 \cdot \frac{\left(w_{\text {HAMtools }}-w_{\text {wufi }}\right)}{w_{\text {wufi }}} \quad \text { Equation } 17
$$

Were " $w$ " is the resulting moisture content. The difference for moisture content is less than $0.08 \%$. Given these results, it can be concluded that the proposed conversion method from liquid diffusivity to hydraulic conductivity is valid. The necessary conversions for material properties between HAM-Tools and WUFI are all summarized in Table 8. 
Table 8: Material property conversions for HAM-Tools and WUFI

\begin{tabular}{|c|c|c|}
\hline WUFI input & $\begin{array}{c}\text { Conversion from WUFI } \\
\text { to HAM-Tools } \\
\end{array}$ & Ham-Tools input \\
\hline Thermal conductivity & Same & $\begin{array}{c}\text { Lambda_dry: Thermal conductivity of } \\
\text { dry material }\end{array}$ \\
\hline $\begin{array}{l}\text { Water vapour diffusion } \\
\text { resistance factor, } \mu_{(@ R H)}\end{array}$ & $\begin{array}{c}\text { Delta_p_RH }=\delta_{0} / \mu_{(@ R H)} \\
\text { Where } \delta_{0}=2 * 10^{-7} * T^{0.81} / \mathrm{P}\end{array}$ & Delta_p_RH: Vapor permeability \\
\hline $\begin{array}{c}\text { Temperature dependent } \\
\text { thermal conductivity } \\
\text { supplement }\end{array}$ & Same & $\begin{array}{l}\text { Lambda_T: Thermal conductivity } \\
\text { factor dependent on temperature }\end{array}$ \\
\hline $\begin{array}{l}\text { Water absorption } \\
\text { coefficient }\end{array}$ & Same & WAC \\
\hline Free water saturation & Same & $\begin{array}{l}\text { W_capillary: Capillary moisture } \\
\text { content by volume }\end{array}$ \\
\hline $\begin{array}{l}\text { Moisture storage } \\
\text { function(@RH) }\end{array}$ & $\begin{array}{c}\text { Slope_sorption_ksi }=\nabla(\text { moisture storage } \\
\text { function }(@ R H))\end{array}$ & $\begin{array}{l}\text { Slope_sorption_ksi: Slope of the } \\
\text { sorption isotherm at specific RH }\end{array}$ \\
\hline $\begin{array}{l}\text { Liquid diffusion resistance } \\
\text { factor }\end{array}$ & $\begin{array}{l}K=-\frac{\rho_{\text {diry }} \cdot D_{y}}{\frac{\partial P_{\text {capillary }}}{\partial w}}, \text { where } \\
P_{\text {suc }}=\frac{\ln (R H) * R * T * \rho_{w}}{M_{w}}\end{array}$ & $\begin{array}{l}\text { Hyd_Cond_K = Hydraulic } \\
\text { Conductivity }\end{array}$ \\
\hline Thermal conductivity & $\begin{array}{l}\text { Heat resistance }=(1 / \text { thermal } \\
\text { conductivity })^{*} \text { thickness }\end{array}$ & Heat resistance \\
\hline$\mu$ & Vapour resistance $=1 /\left(\delta_{0} / \mu\right) *$ thickness & Vapour resistance \\
\hline
\end{tabular}




\subsection{Verification Results}

First, the weather data from Toronto with the wall assembly described in 3.1 was used. In order to achieve a base comparison, the wind driven rain module was turned off. The adhering fraction of rain in WUFI was also set to zero. The results are shown in Figure 26. It should be noted that HAM-Tools results is an average of all the nodes in the material. The amount of nodes is selected to be the same as the amount WUFI uses.
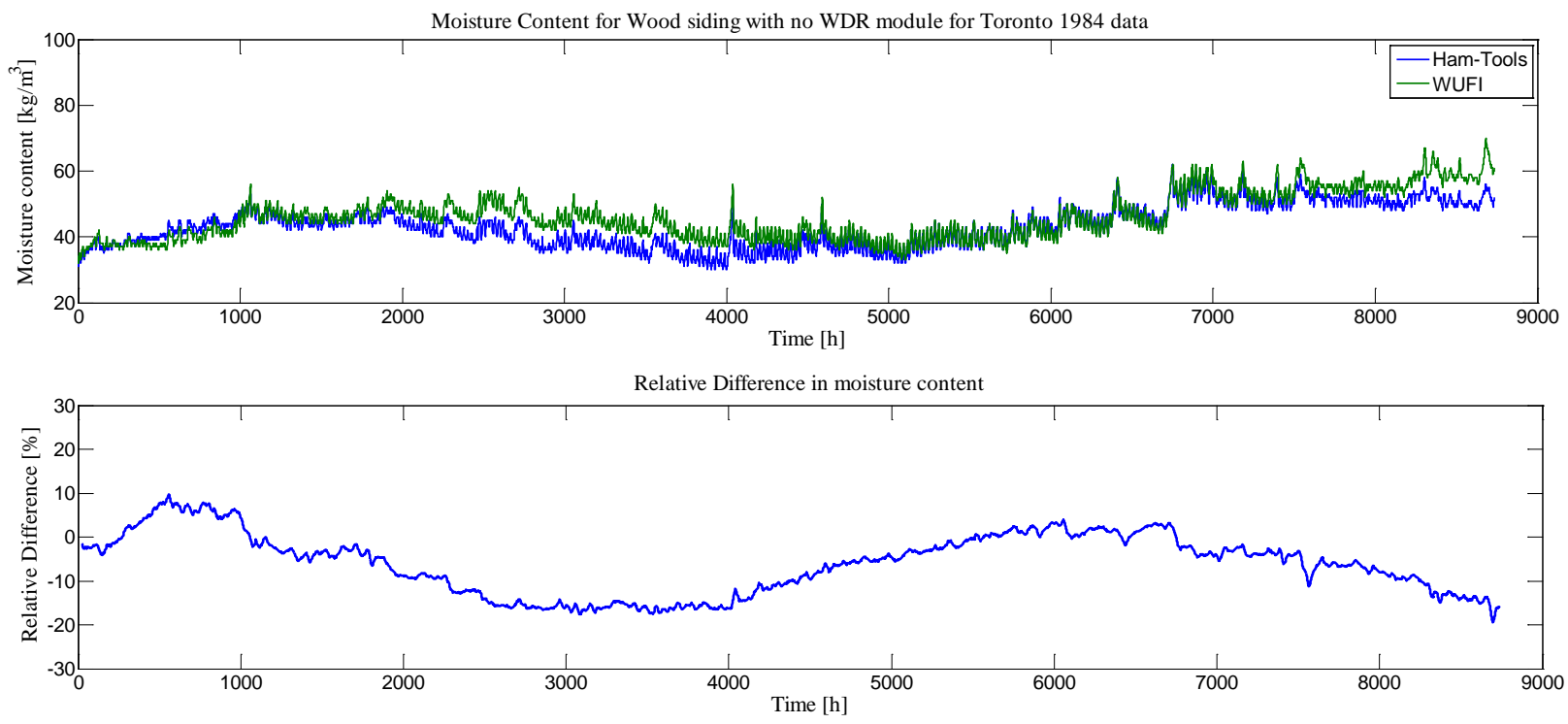

Figure 26: (Above) Comparison of moisture content between HAM-Tools and WUFI for the outer layer without the wind driven rain module. (Below) The resulting daily averaged difference for the comparison

The relative difference in moisture content (\%) is shown to be $20 \%$ between the two programs. Looking at Figure 19 that shows the rainfall amount over the period of 1984, it can be seen that the first and last couple of months have a minimal amount of rainfall, and thus the mechanism for moisture transfer during these dry periods is through vapour diffusion. It can be seen that results from HAM-Tools simulation is a bit more responsive to moisture due to vapour diffusion during the dry period. However, once rain is present in the data, the results become significantly closer. This difference between the two 
programs during the dry period should be considered when analyzing the results with the WDR module activated.

The same simulation is then performed with the with the WDR module turned on for both programs. The result is shown in Figure 27.
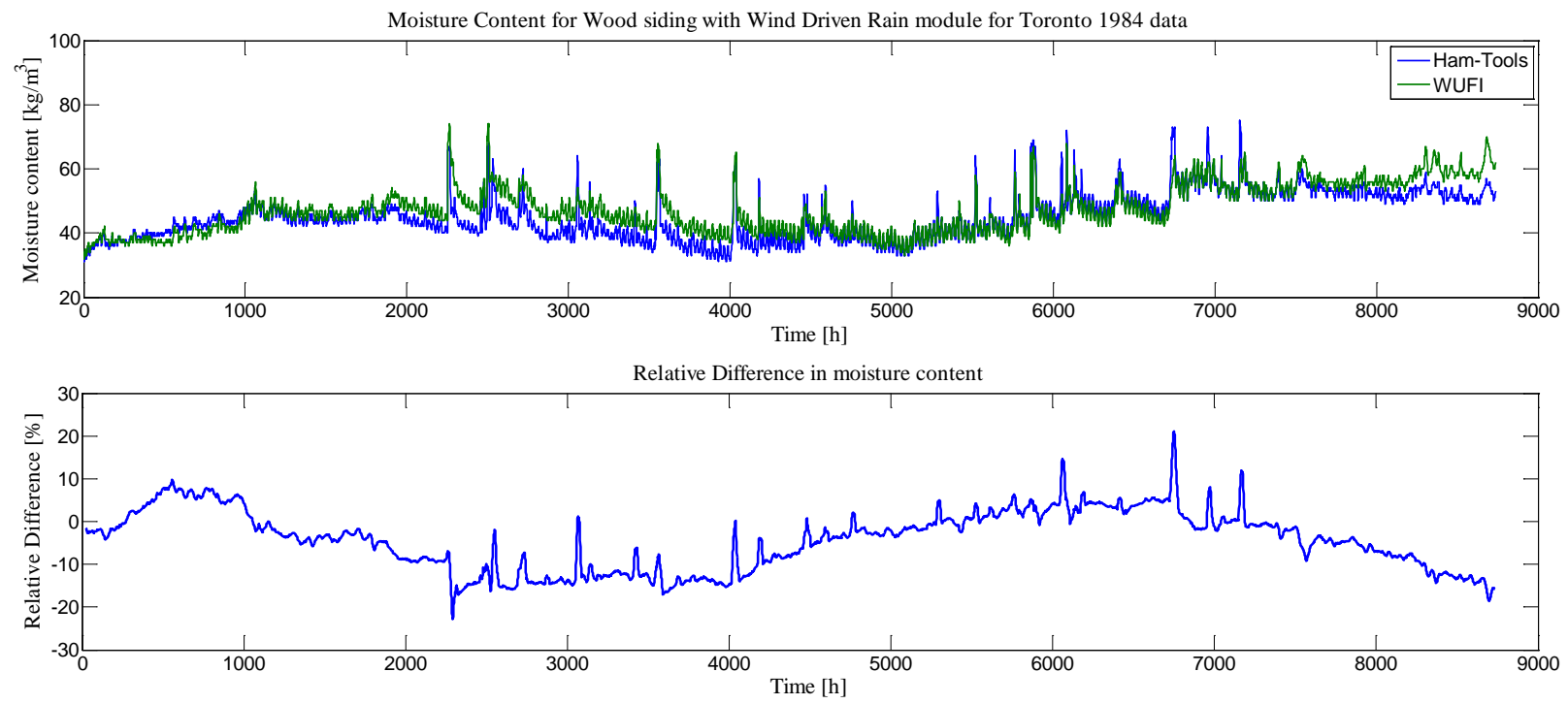

Figure 27: (Above) Comparison of moisture content between HAM-Tools and WUFI for the outer layer with the wind driven rain module. (Below) The resulting daily averaged difference for the comparison

When the wind driven rain is on, the same difference is observed between the results from WDR being on and off during the dry period. However, when rain is present and the difference due to vapour diffusion is reduced, the difference is seen to be less than $10 \%$ since HAM-Tools results tends to stay drier than WUFI. The reason for this effect is due to the difference in liquid diffusivity for suction and distribution used in WUFI program. When rain is present, the suction transport coefficient in WUFI is used in the calculation. This is the same value that is used to calculate the hydraulic conductivity for HAM-Tools. However, WUFI uses the redistribution transport coefficient when the rain stops and there is no presence of free water. As mentioned before, the redistribution coefficient is generally one tenth 
of the suction coefficient. Therefore, HAM-Tools results tend to dry out faster during the rainy seasons.

This effect is more pronounced in outer layer materials that are generally more than 0.1 meters thick.

The same simulation is also performed with Burnaby weather data and wall construction described in Table 9. The moisture content of the outer layer and plywood, the fourth layer from exterior, is shown in Figure 28 and Figure 29 respectively.
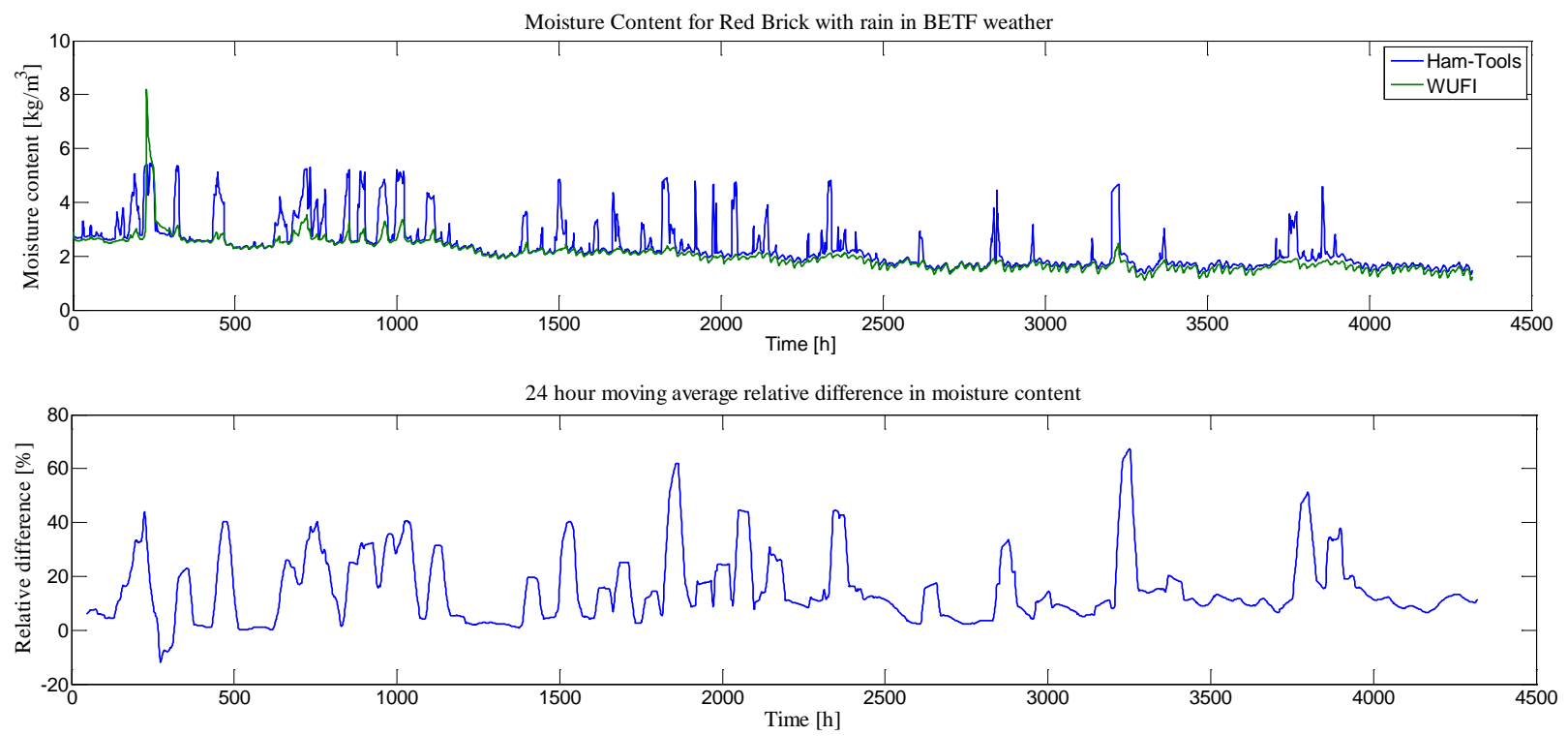

Figure 28: (Above) Comparison of moisture content in outer layer between HAM-Tools and WUFI with the wind driven rain module. (Below) The resulting daily averaged difference for the comparison 

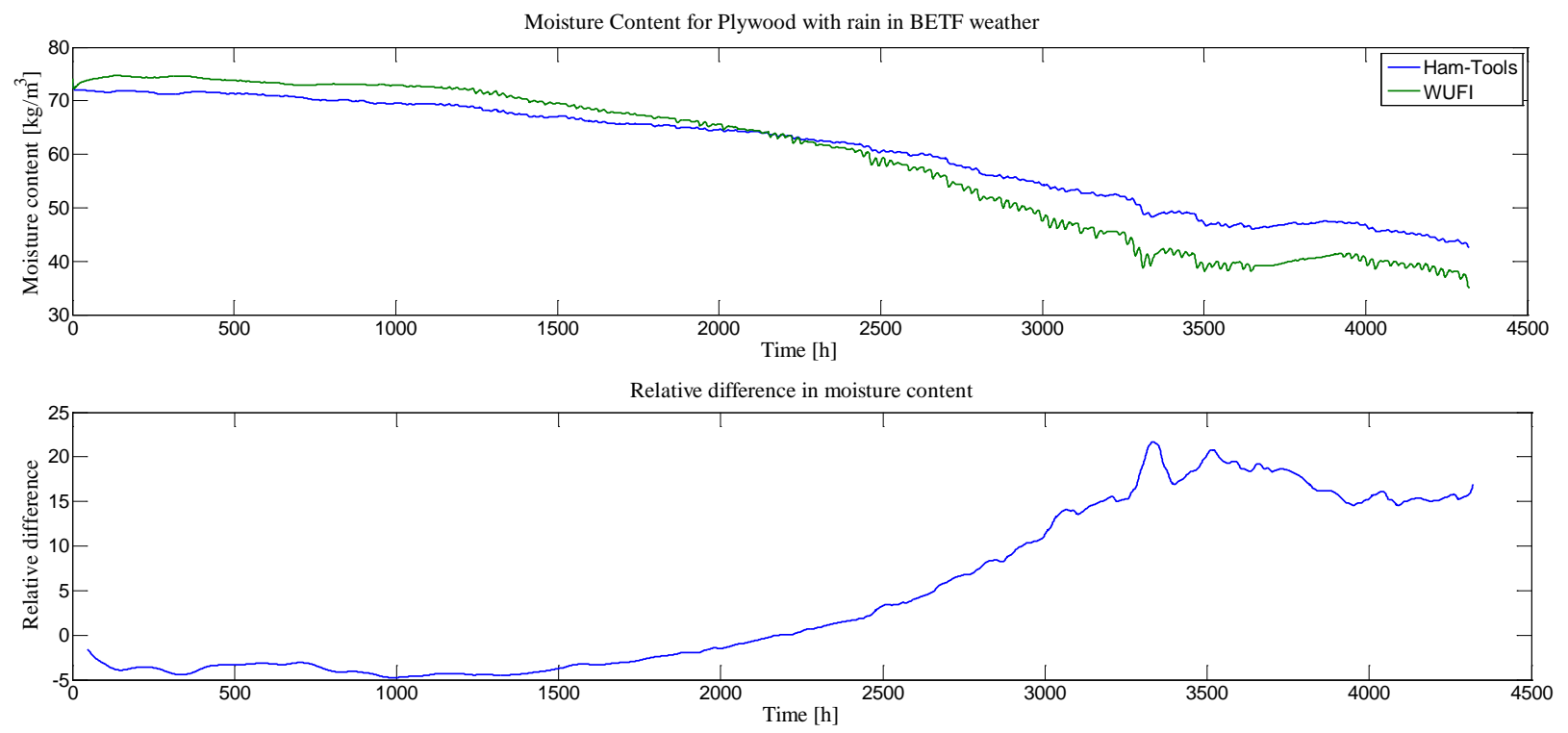

Figure 29: (Above) Comparison of moisture content in plywood between HAM-Tools and WUFI with the wind driven rain module. (Below) The resulting daily averaged difference for the comparison

For the outer layer, the relative difference is low except when there is presence of rainfall, averaging around $20 \%$. Similarly, the relative difference in the plywood between the two simulations is mostly around $5 \%$ to $20 \%$. Initially, WUFI's result has a very sharp drop in moisture content of the plywood that can be caused by its numerical balancing equations. This drop results in $5 \%$ relative difference between the two software. Furthermore, the moisture content from WUFI's simulation tends to dry out more. Similar to previous comparison of wood siding, this difference can be explained from the variation in vapour diffusion mechanism between the two programs. 


\section{Chapter 4: Validation of the WDR module}

This chapter presents the validation of the WDR module to further ensure that the module and the conversion of moisture transport mechanisms produce accurate results. This is done through comparison of the simulated results against data from field obtained measurements.

\subsection{Burnaby Weather data}

The second weather data set is obtained from BCIT's Building Envelope Test Facility (BETF) in Burnaby, BC. This location has a higher amount of rainfall as well as fewer days of temperatures below freezing point when compared to Toronto's weather (Environment Canada, 2012). This is an ideal climate for verification and validation purposes for the wind driven rain module. BETF is located at a relatively exposed area on BCIT campus. The orientation of this test facility is presented in Figure 30 . This facility allows for a broad range of wall assemblies and junctions to be tested. It includes two mechanical systems that enable the interior spaces to have two conditioned horizontal zones.

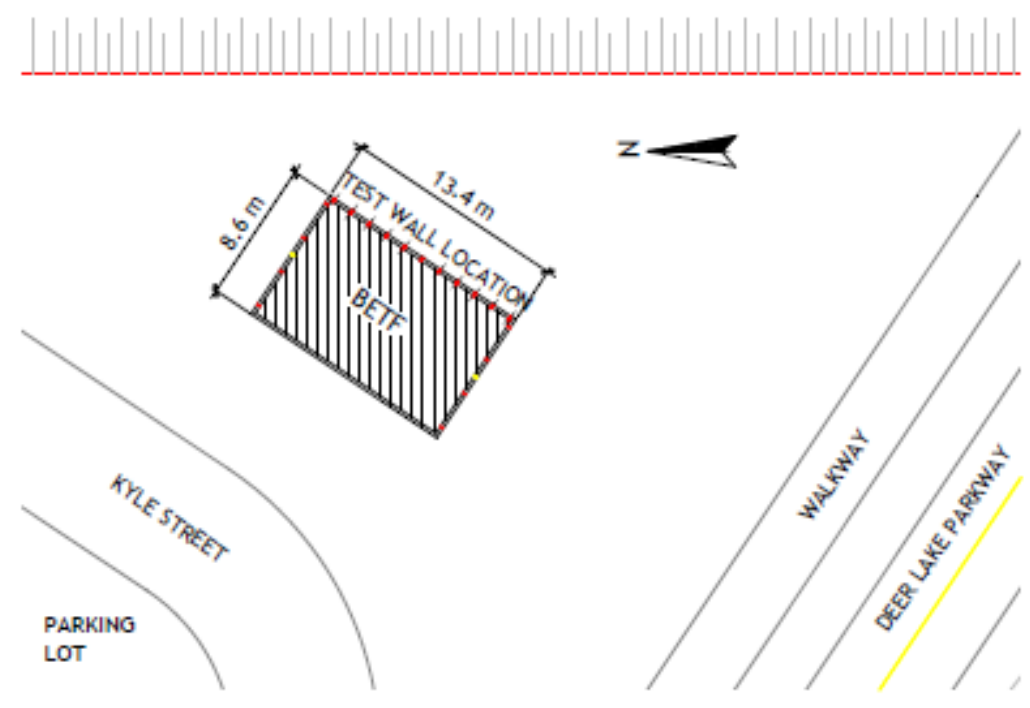

Figure 30: Building Envelope Test Facility (BETF) site plan in BCIT's Burnaby campuses (Simpson \& and Ge, 2010) 
The weather station is located at the center of the facility's rooftop and monitors the on-site environmental conditions. These data include horizontal rainfall, wind speed, wind direction, and global solar radiation to name a few (Simpson \& and Ge, 2010). The obtained weather data for this study is presented in a Microsoft Excel file called "test_hut.xls". The information for wind speed, corrected wind direction, external temperature, external $\mathrm{RH}$, global solar radiation and horizontal rainfall can be obtained. This file has one minute data resolution. The missing information (illuminances and longwave radiation) are obtained from Environment Canada CWEC file. The normal direct radiation is found from subtracting the global radiation on horizontal surface by diffused radiation on horizontal surface.

The driving rain index diagram for this weather data is shown in Figure 31. It can be observed that the prevailing wind driven rain in Burnaby has the highest impact on the south-east facing surfaces and thus the simulations are conducted on that direction. The total rainfall amount is $467 \mathrm{~mm}$.

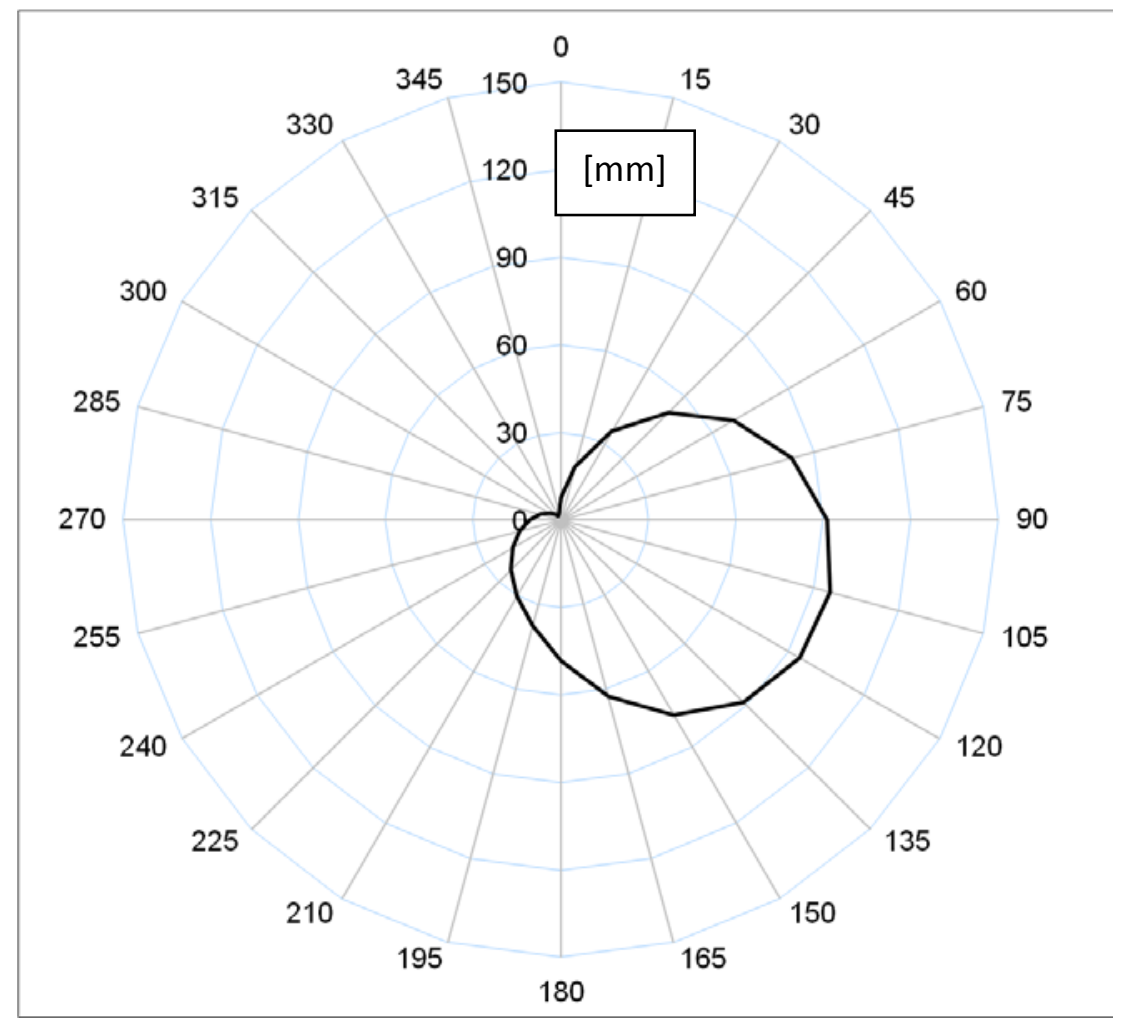

Figure 31: Annual wind rose diagram of Burnaby hourly weather data [mm] 
It should be noted that this wind-rose diagram is not based on an annual sum and only reflects a five months period.

One of the requirements of HAM-Tools for its weather data is that it should not have any missing lines and that the time resolution should be consistent throughout the data. Thus, the BCIT weather data was checked and any missing values were added from its previous lines. A linear interpolation was not necessary since the missing data were either only for few minutes or couple of hours at most. These corrections were done manually using Microsoft Excel.

\subsection{Burnaby wall construction}

The second wall represents the wall assembly tested in the test facility in Burnaby. The details of the wall can be found in Table 9.

Table 9: Field experiment wall assembly

\begin{tabular}{cc}
\hline Material (outdoor to indoor) & Thickness [mm] \\
\hline \hline Red Matt Clay Brick & 90 \\
Air space & 25 \\
Spun Bonded Polyolefine Membrane & 0.2 \\
Plywood & 12.7 \\
Low Density Fiberglass Batt Insulation & 140 \\
Polyethylene Membrane & 1 \\
Gypsum board & 12.5 \\
\hline
\end{tabular}

This wall construction is facing the south east direction towards the prevailing wind driven rain. Therefore any simulation done on this wall construction is set to face the south east direction. The wall construction in Table 9 is used with Burnaby weather for both verification and validation purposes. 


\subsection{Initial moisture content and atmospheric pressure}

A field measurement experiment was conducted on the test facility in Burnaby using the wall assembly described in Table 9 and the Burnaby weather data in 2008 (Simpson \& and Ge, 2010). The field measured initial moisture content of each layer is shown in Table 10.

Table 10: Initial relative humidity of wall components in Burnaby test hut

\begin{tabular}{cc}
\hline Wall Component & Relative Humidity (\%) \\
\hline \hline Brick Veneer & 91.5 \\
Plywood & 87 \\
Insulation & 50 \\
Gypsum Board & 50 \\
\hline
\end{tabular}

It should be noted that there were no sensors present in the insulation and gypsum board to obtain initial relative humidity for those layers, and so they were assumed to have the same value as the interior conditions (Simpson \& and Ge, 2010).

One of HAM-Tools input data is initial relative humidity. This value controls the initial moisture content of all the layers in HAM-Tools. However, the moisture content for each layer cannot be controlled independently. Given that the test wall has different moisture content for each layer, the simulation would be inconsistent with field measurements. In reality, different layers would not always have the same relative humidity. In order to demonstrate this effect, a simple comparison is performed on the plywood using WUFI. For the first setup, the initial moisture content of all the layers is set at $87 \% \mathrm{RH}$. In the second setup, the initial moisture content of plywood is kept at $87 \%$ while all the other layers are changed to be at $40 \% \mathrm{RH}$. The results are shown in Figure 32. 


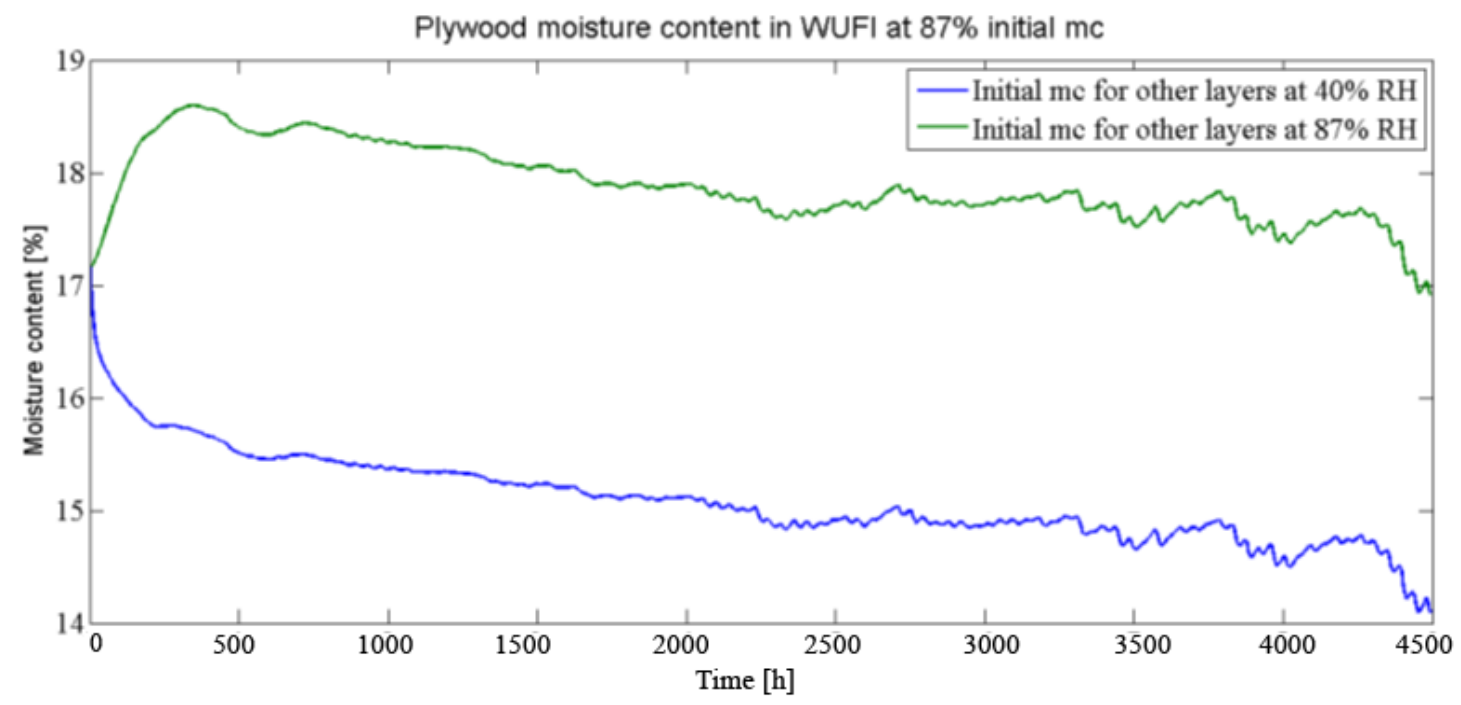

Figure 32: Comparison of plywood's moisture content with different initial conditions in other layers

This result show that having different initial moisture content in the surrounding layers directly affect the moisture content in the studied layer. This affects the result at the very beginning of the simulation by increasing or decreasing the moisture content of the surrounding layer. As a result, new initial relative humidity inputs were added to HAM-Tools and the variable for every single node within the construction block was changed accordingly.

It was realized that WUFI requires the atmospheric pressure to be added for this simulation to obtain more accurate results with respect to field measurements. The difference between including and not having atmospheric pressure in its weather data is shown in Figure 33 . 


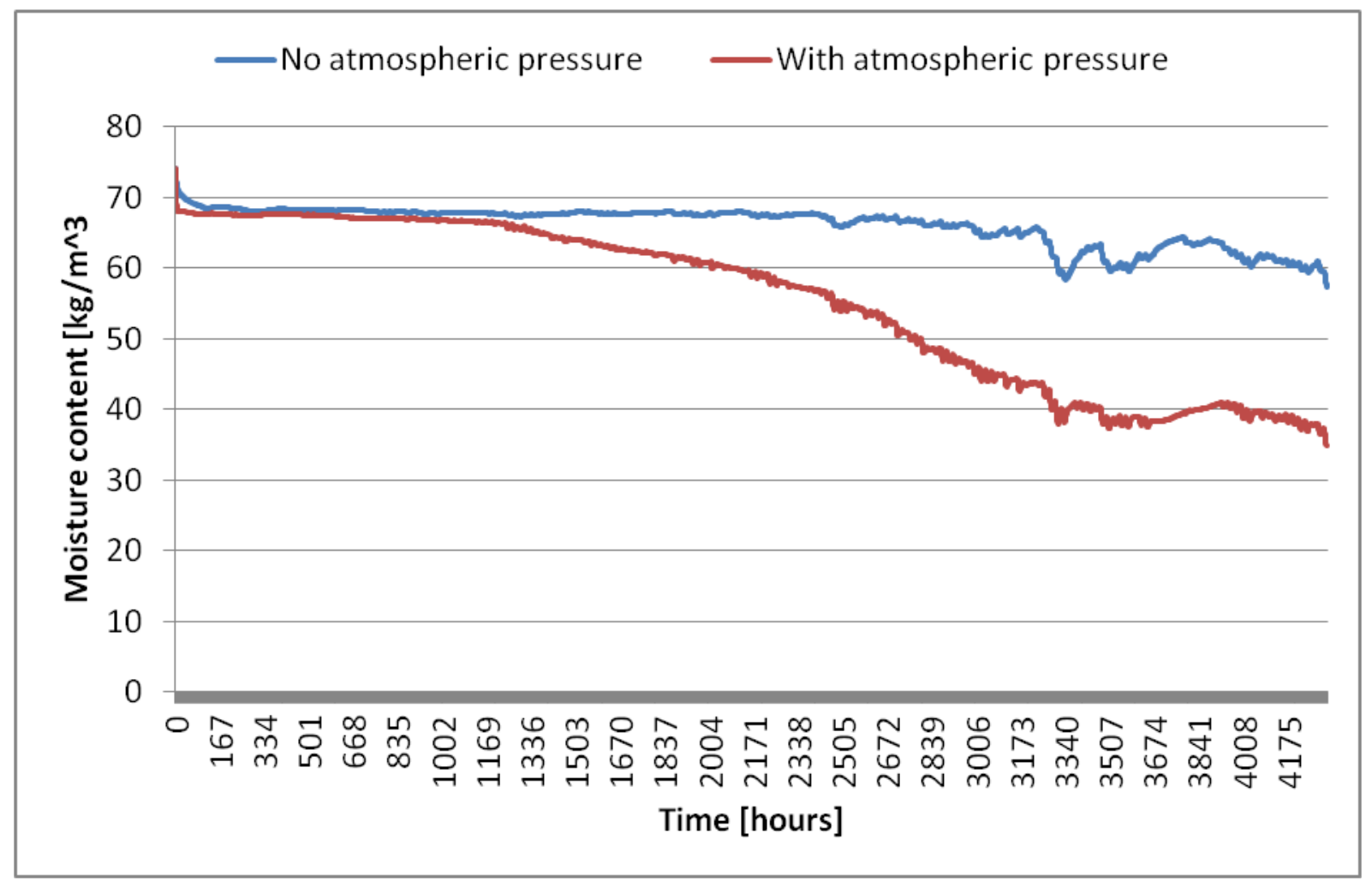

Figure 33: Comparison of plywood's moisture content in WUFI with and without the inclusion of atmospheric pressure

On the other hand, HAM-Tools provides a constant atmospheric pressure to be added in the weather block. In order to make HAM-Tools be consistent with WUFI, a new column was added to HAM-Tools weather data to contain hourly atmospheric pressures. The weather block is also changed to be able to read the hourly atmospheric data and replace the constant atmospheric pressure value. This is done by increasing the array size of the weather block to be able to output air pressure. 


\subsection{Sensor placements and results from field measurements}

Figure 34 shows the field measured results in the plywood layer of the BD7 wall assembly. There are four gravimetric sensors used (numbered 2, 3, 4, and 6) and the average of these sensors are presented in Figure 34. This data is used for comparison with results from simulations.

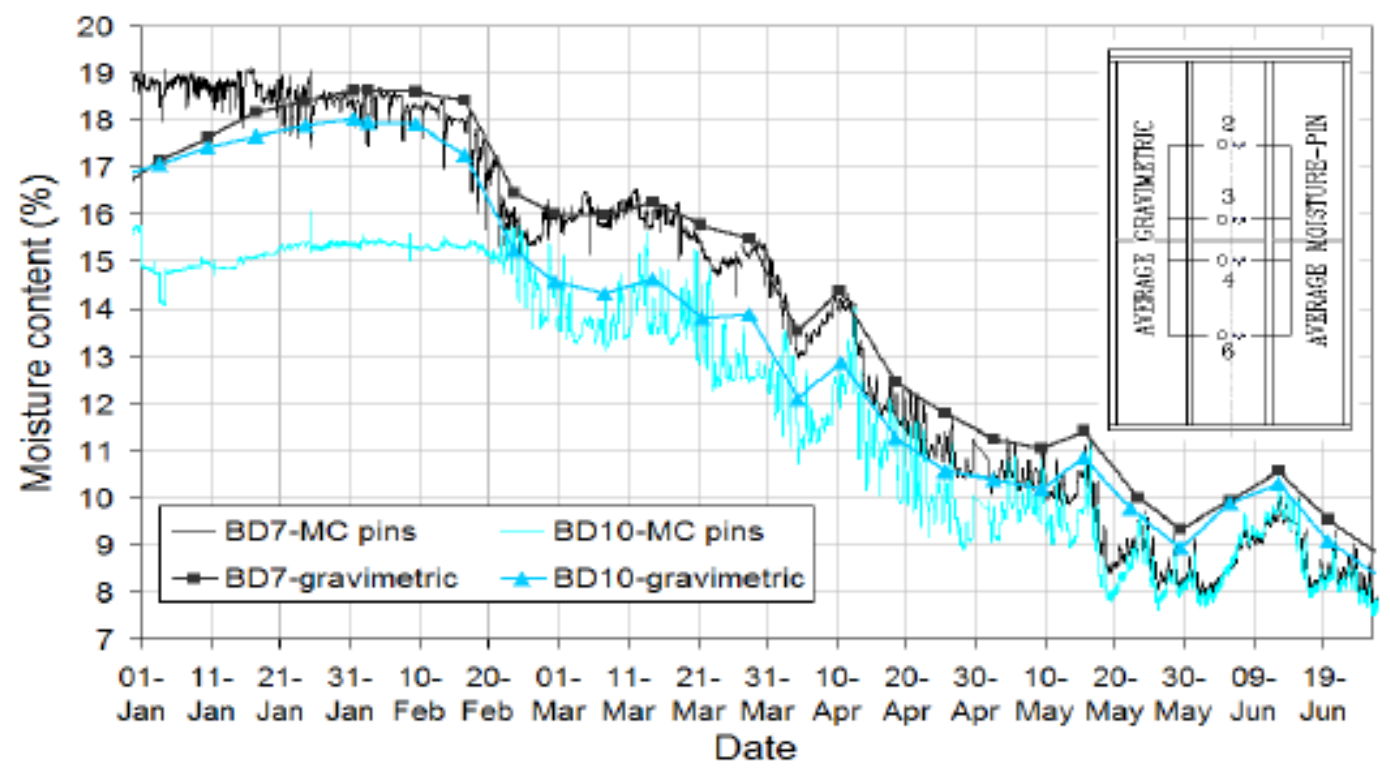

Figure 34: Comparison of average MC of plywood in BD7 wall (Simpson \& and Ge, 2010)

\subsection{Validation Results}

With correct initial moisture content input, HAM-Tools was then tested and compared with field measurements. Figure 35 shows the simulated and measured results. 

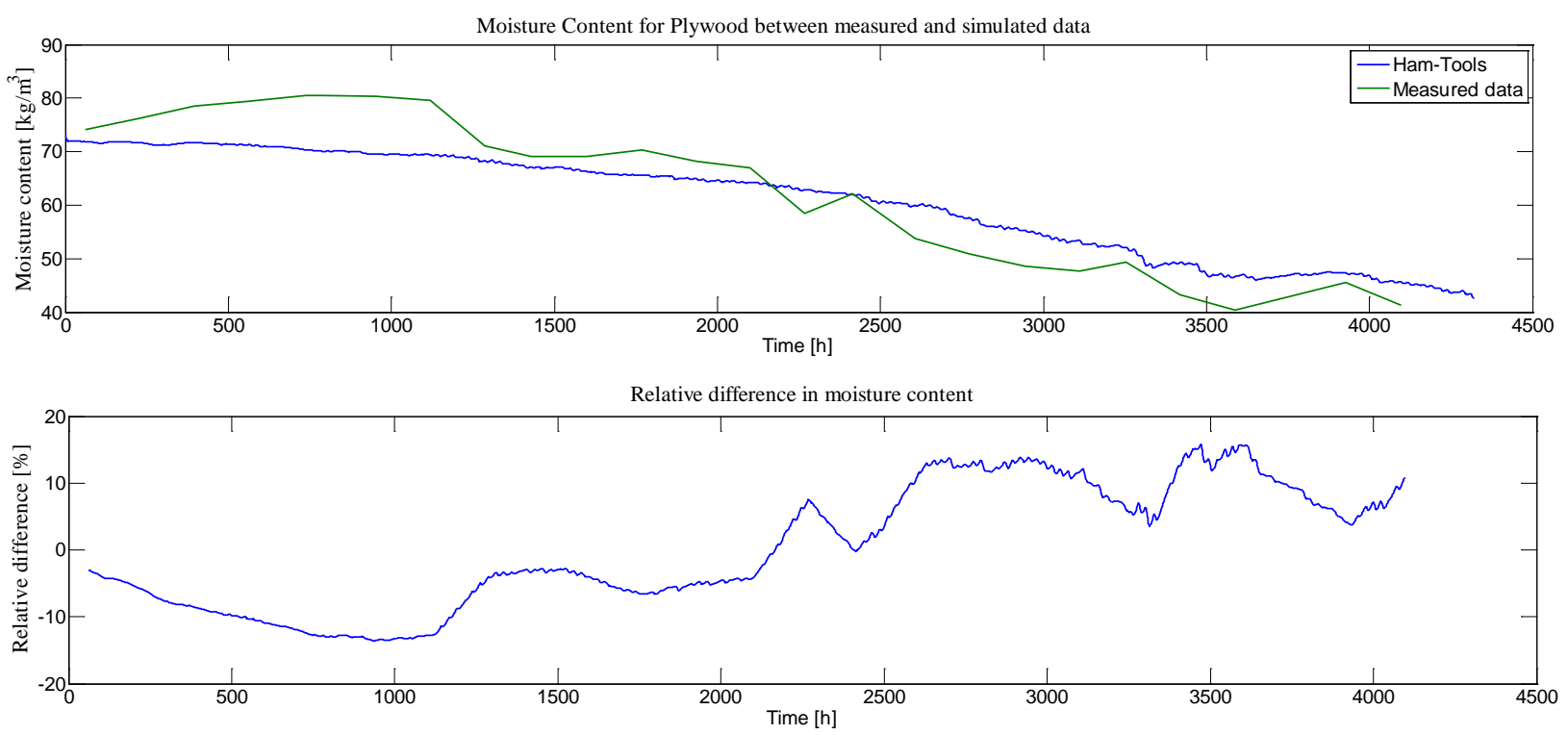

Figure 35: (Above) Comparison of moisture content of Plywood between Simulated (HAM-Tools) and measured data. (Below) The resulting daily averaged difference for the comparison

The simulated result shows the same trend as the measured data with an average relative difference of $8 \%$ and a maximum difference of $13 \%$. The differences may be attributed to the initial moisture content of the materials, discrepancy in material properties, and measurement errors, and air movement in the cavity.

The first difference that should be pointed out is the effect of HAM-Tools drying potential that acts faster than the field measurement's data. This effect is due to HAM-Tools's transport properties being equal during wetting and drying periods. This condition of HAM-Tools is also visible with WUFI's results as mentioned in 0 .

Other differences are due to the initial moisture content of the materials. There were no sensors present to measure the moisture content in the layers other than the plywood since it was not needed for the study (Simpson \& and Ge, 2010). WUFI was used to approximate the initial moisture contents of those layers for the study. As seen in Figure 35, the moisture content of plywood in field measurements 
is increasing from 0 to 1,000 hour, while HAM-Tools results dries out from the start. This increase shows that the brick or the insulation layer had higher initial moisture content comparing to HAM-Tools' simulation inputs. Furthermore, the liquid and vapour diffusivity of each were not directly measure. Instead, WUFI's material database was used to provide these values. Also, even though the test hut's cavity was not vented, in reality the vent would have air movement present in it. This would help the plywood dry slightly more than the results shown in HAM-Tools. Figure 36 provides the results for the same simulation but with $38 \%$ increase in initial relative humidity of the insulation as well as an increase of vapour diffusivity of the outer layer by a factor of 20 to account for the air movement in the cavity.
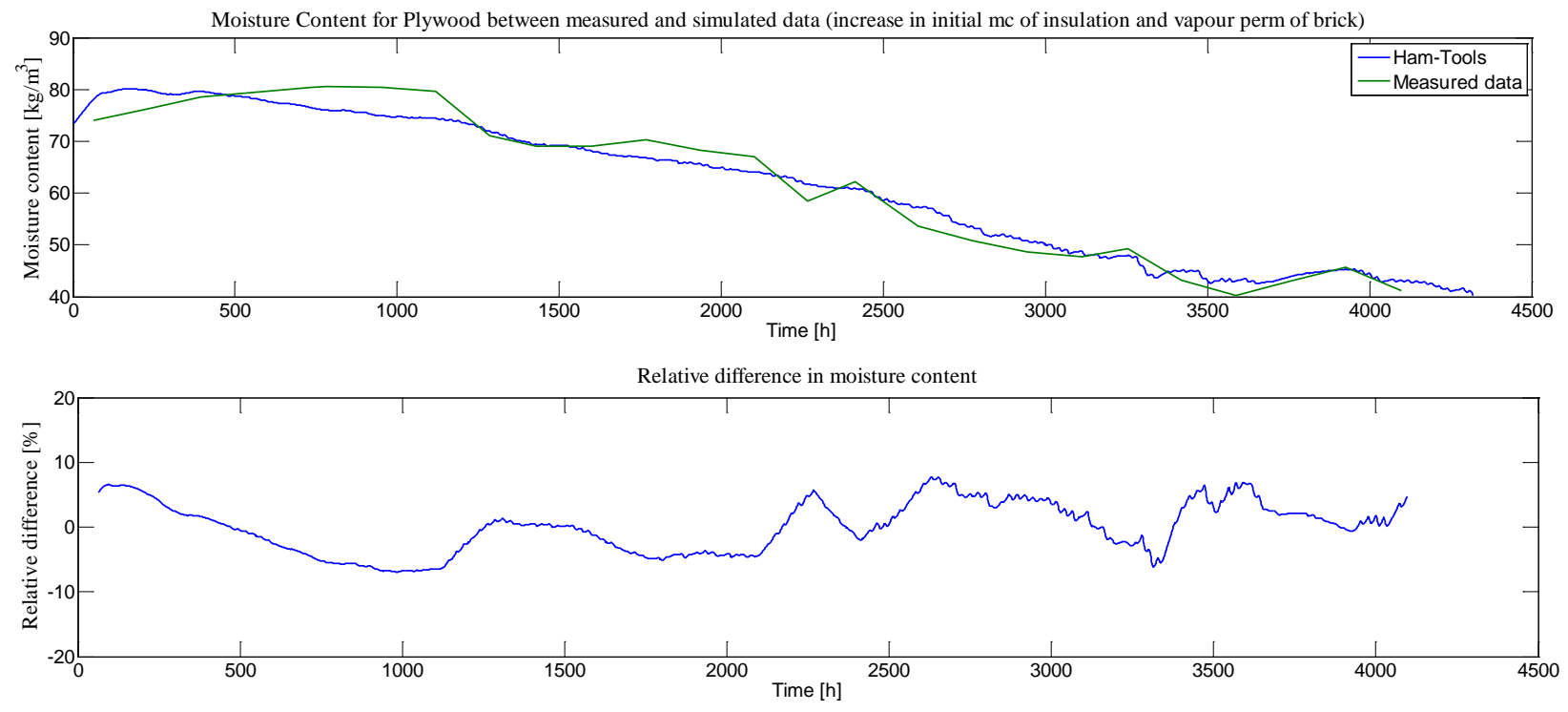

Figure 36: (Above) Comparison of moisture content of Plywood between Simulated (HAM-Tools) and measured (BCIT) data with $38 \%$ higher $\mathrm{RH}$ of the insulation. (Below) The resulting difference for the comparison

This modification results in an average relative difference of less than $5 \%$ with a maximum difference of 7\%. Thus with a more accurate measurements, the program can obtain better results in comparison with real data. 


\section{Chapter 5: Impact of averaging technique on hygrothermal response}

Meteorological datasets that are used in most hygrothermal analysis use hourly data that is provided from weather stations. For better accessibility and storage, these data are arithmetically averaged from high resolution raw data, so the raw data is not usually available for public access. It was suggested that this arithmetical averaging techniques of high resolution weather data would impact the accuracy of hygrothermal analysis and lead to errors in WDR analysis (Blocken \& Carmeliet, 2008). A weighted averaging technique was concluded to be more accurate than the widely used arithmetic averaging technique. However, the analysis was performed for a specific climate only and was suggested that the weighted technique might not be suitable for other climates. Therefore this chapter investigates the differences in averaging techniques of high resolution weather data collected in Burnaby, British Columbia. Considering that different averaging techniques for wind driven rain's parameters, namely wind speed, wind direction, and rain can all have a different impact on the accuracy of the hygrothermal performance results, a mixture of different averaging techniques were used, namely arithmetic, weighted and vector averaging.

\subsection{Averaging techniques of time resolution}

As mentioned in section 1.2.3, different techniques can be used to average one minute data to hourly data. The averaging technique can greatly influence the WDR amount, which ultimately can affect the accuracy of the hygrothermal analysis of simulations. However, to realize the amount of accuracy in hourly averaged data, HAM-Tools with the WDR module can be used, since the software is capable of simulating results using high resolution weather data. Therefore, different averaging techniques were used for simulations and results were compared to investigate the differences in their accuracies. For the purpose of this study, the temperature, dew point, radiances and illuminances were all arithmetically averaged, while the WDR parameters were averaged using different techniques. 
One averaging technique is to consider the wind speed and wind direction as vectors. The factors relating to wind driven rain, namely wind direction and wind speed, are averaged using trigonometric technique. This is done by breaking down the wind direction into its east-west and north-south components. They are then multiplied with their corresponding wind speed and then the average is taken, as shown below.

$$
\begin{array}{ll}
\mathrm{U}_{\mathrm{e}}=-\frac{1}{N} \sum \mathrm{U}_{\mathrm{i}} \sin \left(\theta_{\mathrm{i}}\right) & \text { Equation } 18 \\
\mathrm{U}_{\mathrm{n}}=-\frac{1}{N} \sum \mathrm{U}_{\mathrm{i}} \cos \left(\theta_{\mathrm{i}}\right) & \text { Equation } 19
\end{array}
$$

where $U_{e}$ and $U_{n}$ are the wind speed components found using wind angle $\theta_{i}$ and wind speed ' $U_{i}$ '.

The averaged wind speed and directions are then found from using hypotenuse equation, as shown below.

$$
\begin{array}{ll}
\mathrm{U}_{\mathrm{RV}}=\left(\mathrm{U}_{\mathrm{e}}^{2}+\mathrm{U}_{\mathrm{n}}{ }^{2}\right)^{1 / 2} & \text { Equation } 20 \\
\theta_{\mathrm{RV}}=\operatorname{atan} 2\left(\mathrm{U}_{\mathrm{e}} / \mathrm{U}_{\mathrm{n}}\right) & \text { Equation } 21
\end{array}
$$

Where $U_{R V}$ is the averaged wind speed and $\theta_{R V}$ is the averaged wind angle.

Another technique is to use the horizontal rainfall amount as weighting factor for both wind speed and horizontal rainfall intensity (Blocken \& Carmeliet, 2008). The formulas are as follows:

$$
\begin{aligned}
& U_{j}=\frac{\sum U_{i} \cdot S}{\sum S} \\
& \text { Equation } 22 \\
& R_{j}=\frac{\sum R_{i} S}{\sum S}
\end{aligned}
$$

where $U$ is wind speed, $S$ is horizontal rainfall amount, $R$ is horizontal rainfall intensity and $U_{j}$ and $R_{j}$ are the corresponding weighted average of wind speed and rainfall intensity respectively. Moreover, 
another technique that obtains the hourly horizontal rainfall intensity is to accumulate the values from a higher resolution to an hourly dataset.

Different combinations of these techniques are used in this study. The summary is given in Table 11.

Table 11: Summary of hourly averaging techniques for each calculated weather dataset

\begin{tabular}{cccc}
\hline Weather data & Direction & $\begin{array}{c}\text { Wind } \\
\text { speed }\end{array}$ & Horizontal rain \\
\hline \hline Dataset 1 & Vector & Vector & Accumulative \\
Dataset 2 & Vector & Weighted & Weighted \\
Dataset 3 & Vector & Weighted & Accumulative \\
Dataset 4 & Arithmetical & Weighted & Weighted \\
\hline
\end{tabular}

The weather data used for this chapter is obtained from BCIT's weather station. It is the same data used in section 4.1 but the raw data with an interval of 1 minute. The averaging calculation is performed through the Matlab code given in Appendix F.

\subsection{One minute to hourly conversion of weather data}

The datasets in Table 11 is used to convert the 1-minute weather data to an hourly data. The driving rain sum for that period for all the datasets as well as the 1-minute reference dataset is presented in Figure 37. 


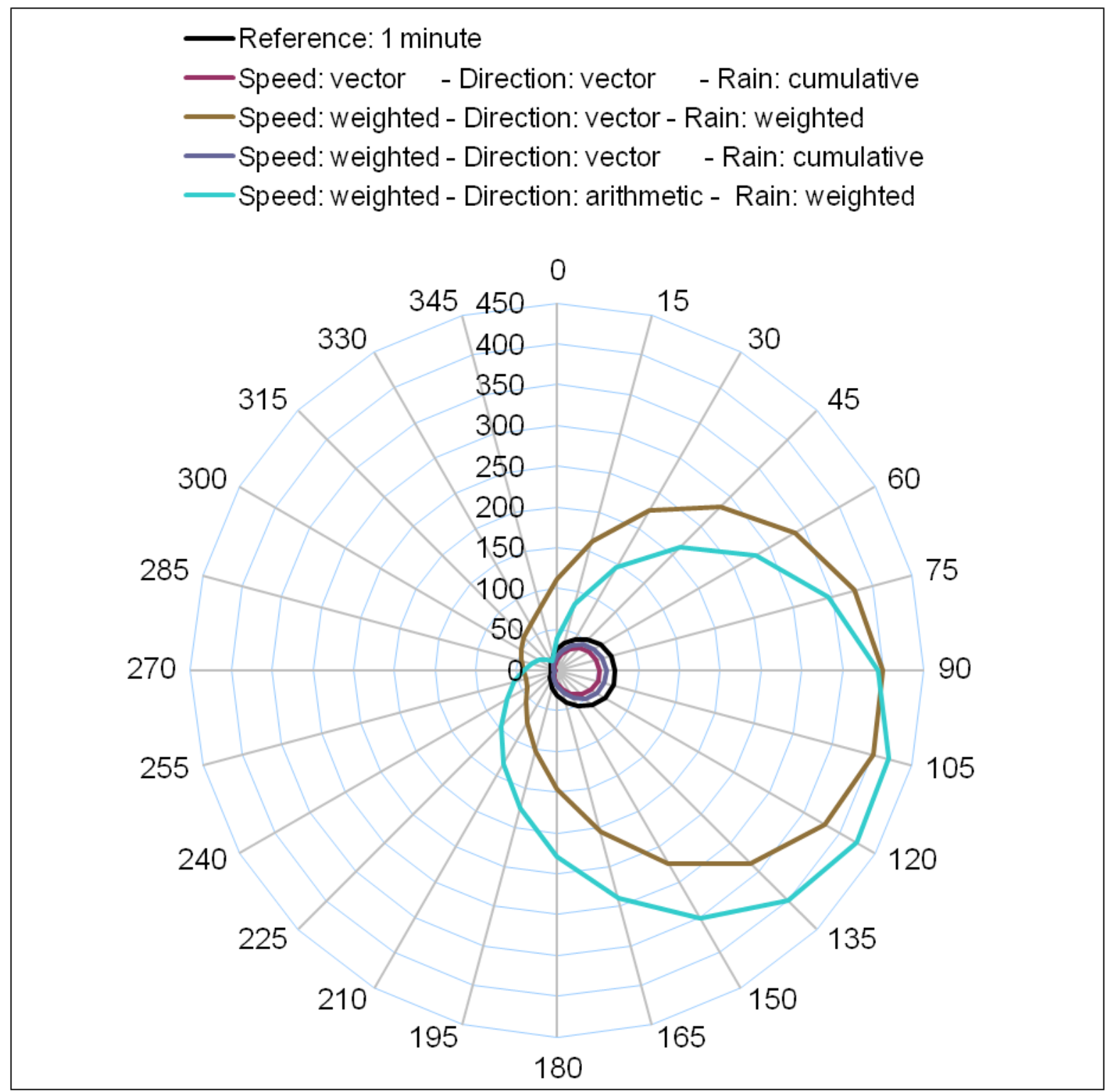

Figure 37: Driving rain sum for the selected period from 1-munte resolution weather data [mm]

Looking at the driving rain sums of each data, it is clear that when the rainfall is averaged using the weighted technique, a large overestimation occurs. To be able to understand this effect, the high resolution weather data needs to be observed. The weather data reveals that there are many instances that a little bit of rain occur $(0.1 \mathrm{~mm})$. This occurrences happens regularly and isn't necessarily in a continuous manner. Using Equation 23, the weighted averaged horizontal rainfall can be calculated and 
is seen that this type of climate results in this overestimation. For example, looking at one hour of this high resolution dataset, it is found that only three minutes in that one hour contains rain, each having only $0.1 \mathrm{~mm}$ of rain. The weighted average is thus calculated by dividing the sum rain intensity of those three minutes $\left(3^{*}(0.1 \mathrm{~mm} \times 60 \mathrm{~min} /\right.$ hour $\left.)\right)$ over the cumulative sum of the rainfall $(0.1 \mathrm{~mm} \times 3)$. This results in $60 \mathrm{~mm} /$ hour of rain for that hour, which is a very large overestimation from the original data. This overestimation can be seen in Figure 37 with the data that contains weighted averaging for rain.

Another point that should be noted is that when the direction is arithmetically averaged, the driving rain sum shows the intensity to be slightly in a different direction than the reference data. This occurs since wind direction is dependent on wind speed and cannot be independently averaged. For example, if the wind is blowing from the east with wind speed of $0.2 \mathrm{~m} / \mathrm{s}$ for half of the hour and $10 \mathrm{~m} / \mathrm{s}$ from the north for the other half of the hour, the averaged wind direction should be near the east side and not at 45 degrees as the arithmetical averaging suggests. This change of direction is visible in Figure 37 as well.

The closest result similar to the reference is obtained when the rainfall amount is accumulated and wind direction is averaged using vector technique. The wind speed can be averaged using either vector or weighted technique, with the latter having a slightly closer result to the reference rainfall intensity sum. For clarity, the sums of driving rain for these data are shown in Figure 38. 


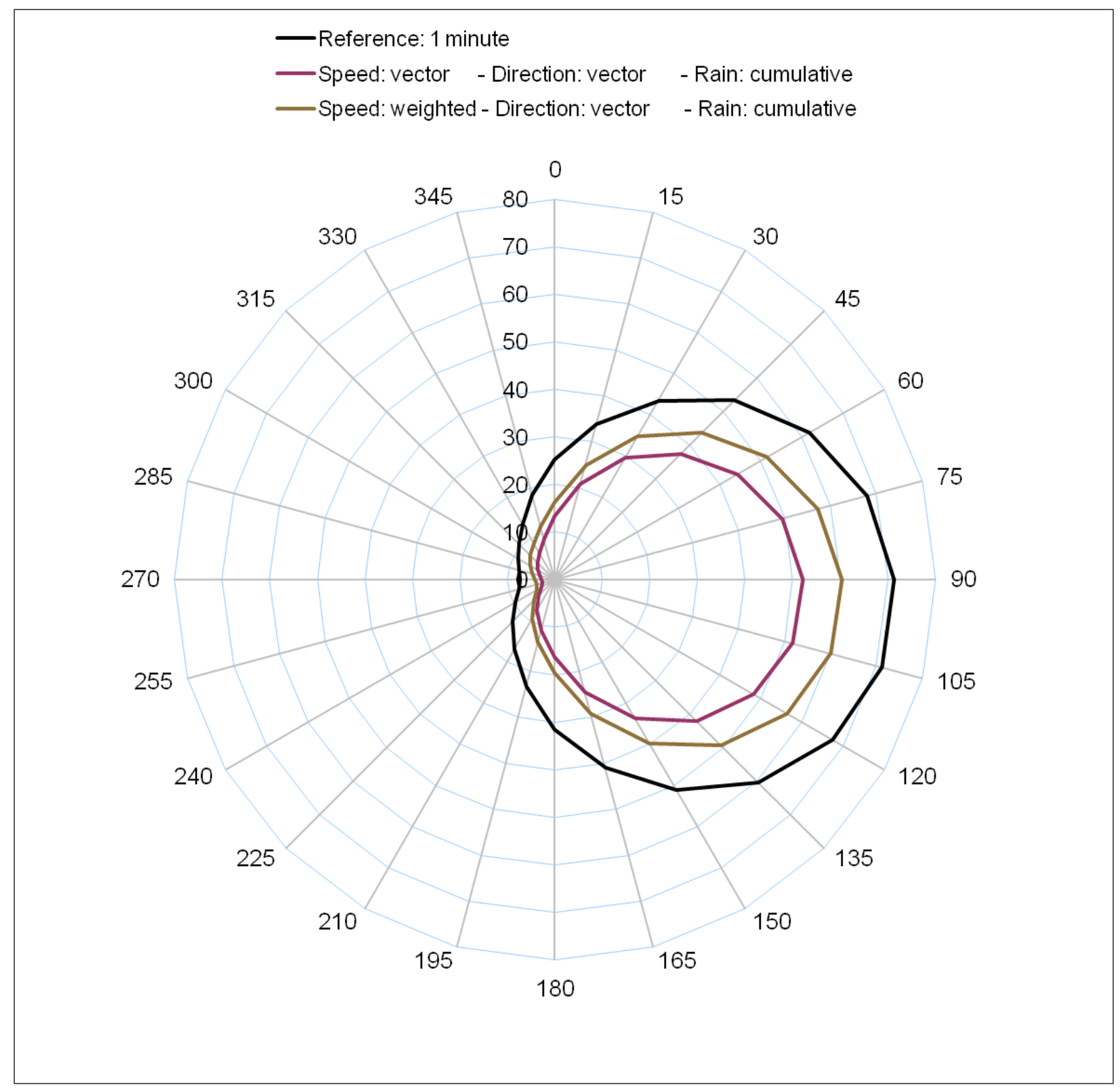

Figure 38: Driving rain sum for the selected period from 1-minute resolution weather data [mm]

HAM-Tools is then used to perform simulations that use these two weather datasets. The wall assembly used is the same construction as in section 4.2. The results for these simulations on the outer layer are presented in Figure 39 and for plywood are shown in Figure 40. 


\section{1 minute to 1 hour: Direction: vector Speed: vector Rain: accumulative}
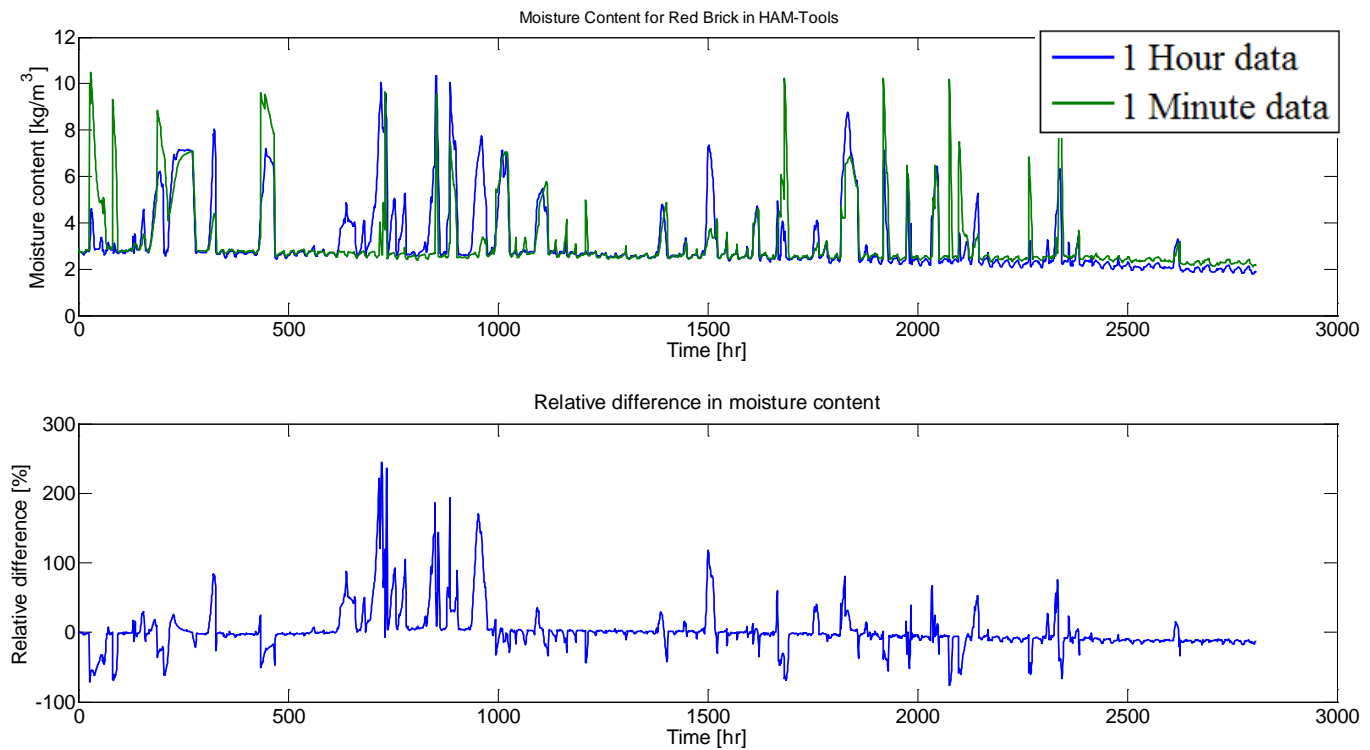

\section{1 minute to 1 hour: Direction: vector Speed: weighted Rain: accumulative}
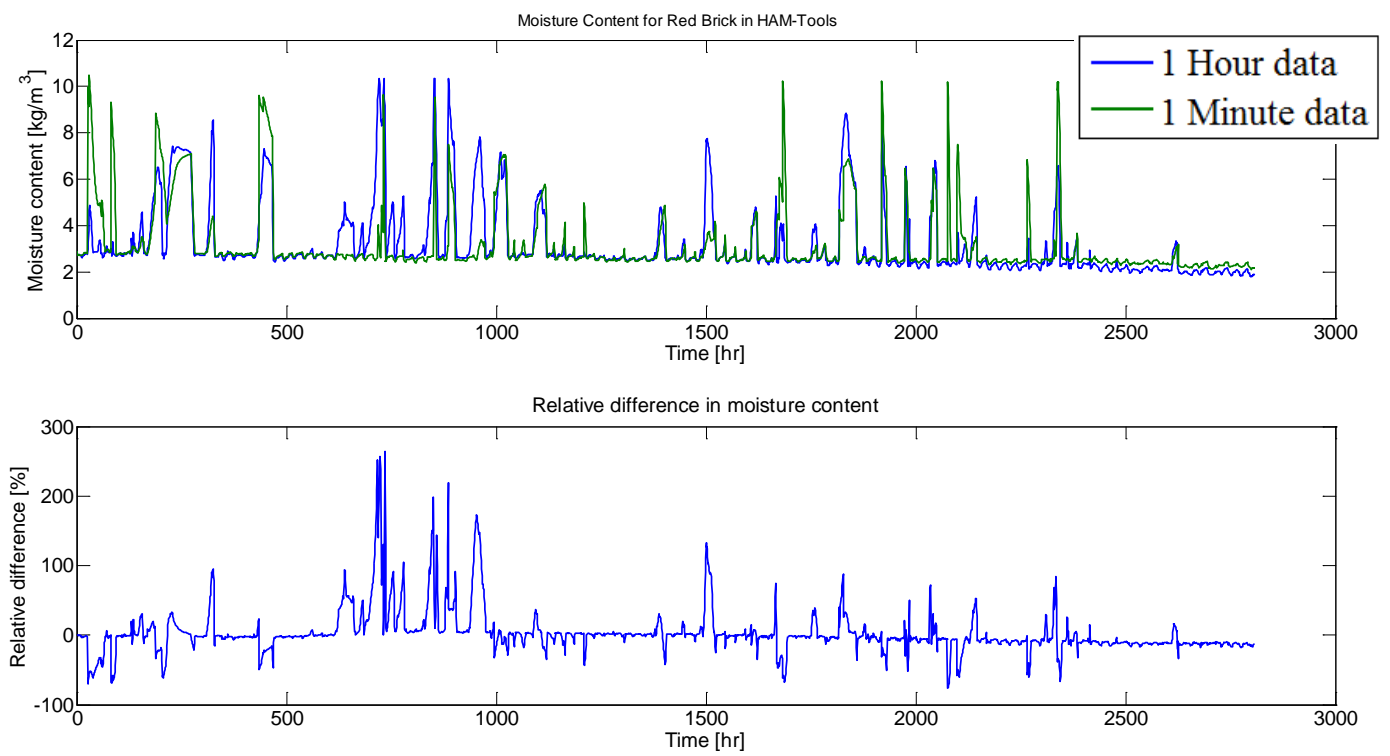

Figure 39: Moisture content comparison on the outer layer between different weather datasets created from 1 minute data 


\section{1 minute to 1 hour: Direction: vector Speed: vector Rain: accumulative}
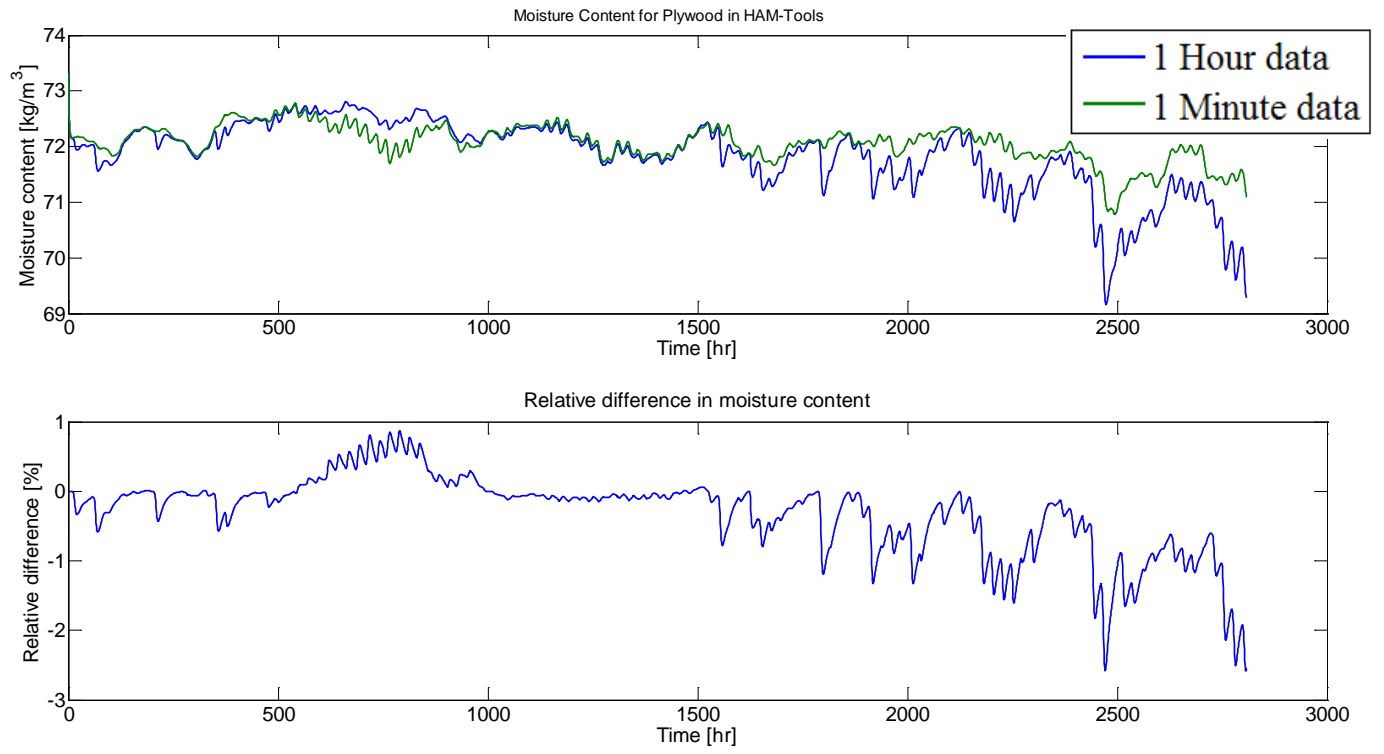

\section{1 minute to 1 hour: Direction: vector Speed: weighted Rain: accumulative}
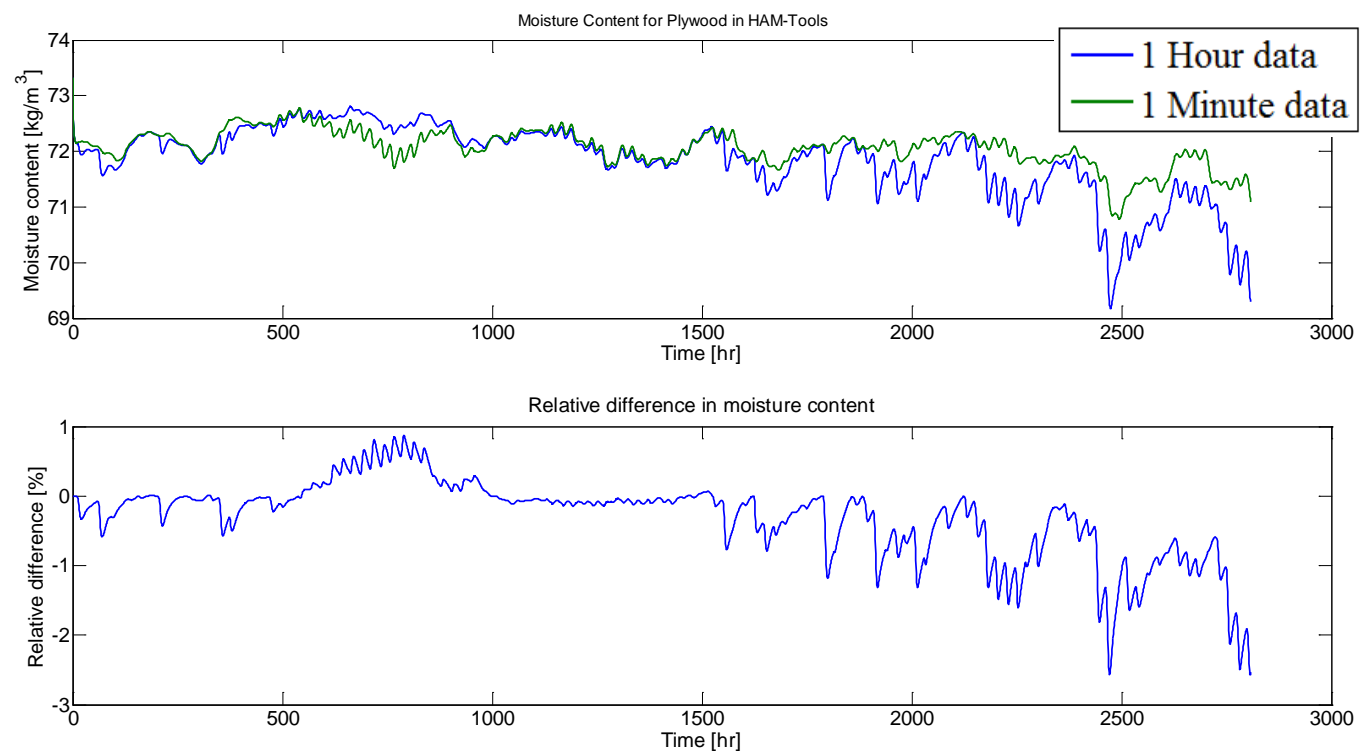

Figure 40: Moisture content comparison on the plywood between different weather datasets created from 1 minute data

Using the results from 1-minute data as the reference, it can be seen that vector averaging of wind speed has the same overall outcome when compared to the weighted averaging of wind speed results. 
It can be seen that an overestimation occurs at the peaks in the results for the outer layer, while the results for plywood have a very low relative difference ( $0 \%$ to $2 \%$ ). For full details of the results at both the outer layer and the plywood layer, refer to Appendix E.

\subsection{Ten minute to hourly conversion of weather data}

To better understand the performance of weighted average technique on WDR parameters, the same process described in the previous section is used but with a 10 minute weather data as the reference. This analysis is performed since some weather stations collect data with lower resolution than 1-minute. The reference data was obtained using the vector averaging technique for wind speed and direction, and horizontal rainfall was accumulated over 10 minutes. This new weather data was then used as the reference to obtain the hourly data. The guideline datasets in Table 11 was used to convert the 10minute weather data to an hourly data.

The driving rain sum for that period for all the datasets as well as the 10-minute reference dataset is presented in Figure 41. The results show that the weighted averaged technique improves drastically when used with a 10-minute data. However, slight overestimation still occurs. The vector averaging technique is the closest match that is very similar to the reference. Moreover, the arithmetic averaging technique shifts the angle of overall driving rain rosette, as previously observed. 
- Reference: 1 minute

-Speed: vector - Direction: vector - Rain: cumulative

— Speed: weighted - Direction: vector - Rain: weighted

—-Speed: weighted - Direction: vector - Rain: cumulative

- Speed: weighted - Direction: arithmetic - Rain: weighted

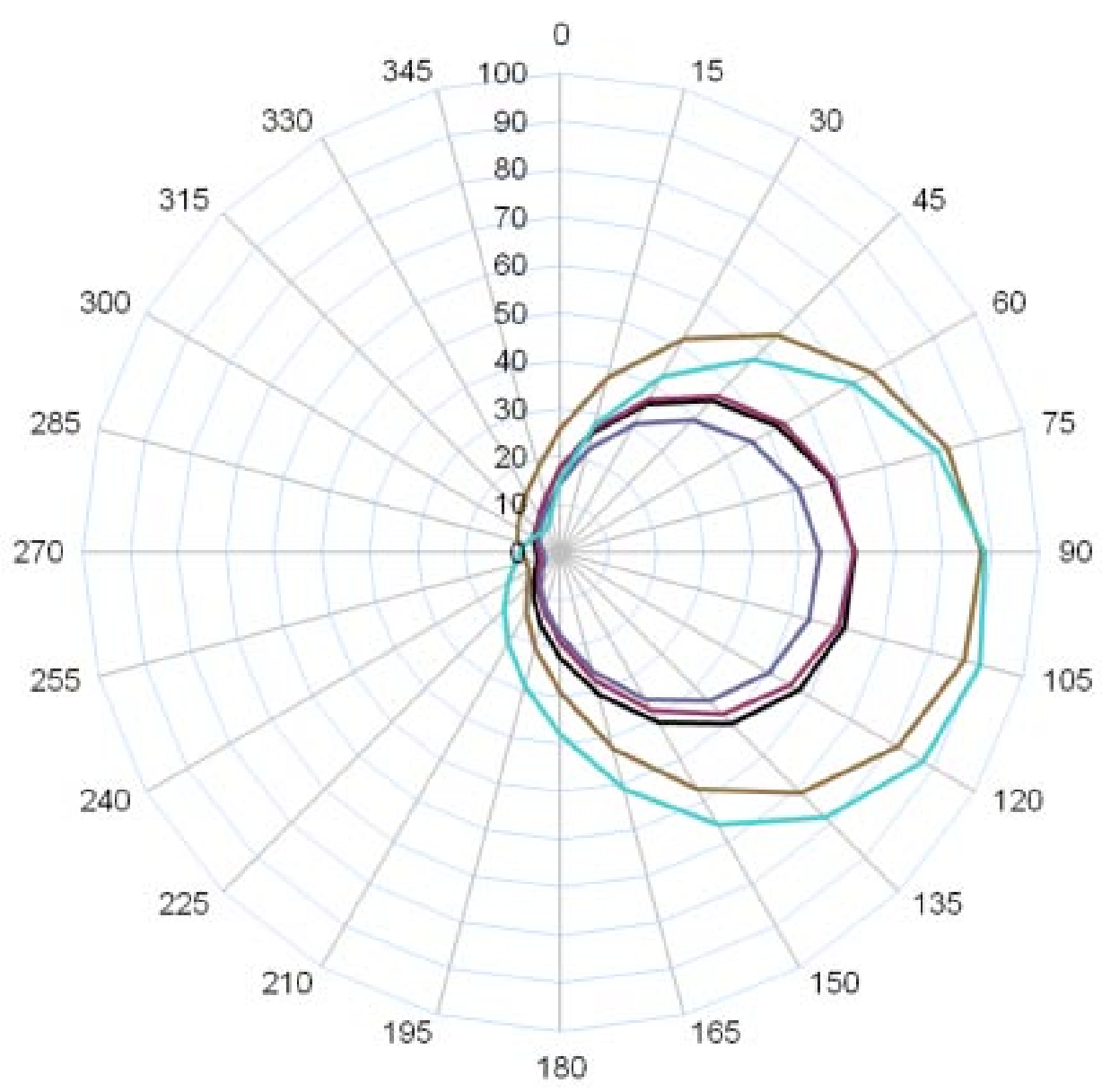

Figure 41: Driving rain sum for the selected period from 10-munte resolution weather data [mm]

HAM-Tools is then used to perform simulations with the reference 10-minute and the weighted averaged dataset using vector averaging for direction. The wall assembly used is the same construction as in section 4.2. The simulations were performed in HAM-Tools and the results for both outer layer and plywood for the weighted averaging technique using vector averaging for direction are presented in Figure 42. It can be seen that the some overestimations occur at the peaks when compared to the reference. 


\section{0 minute to 1 hour (brick): Direction: vector Speed: weighted Rain: weighted}
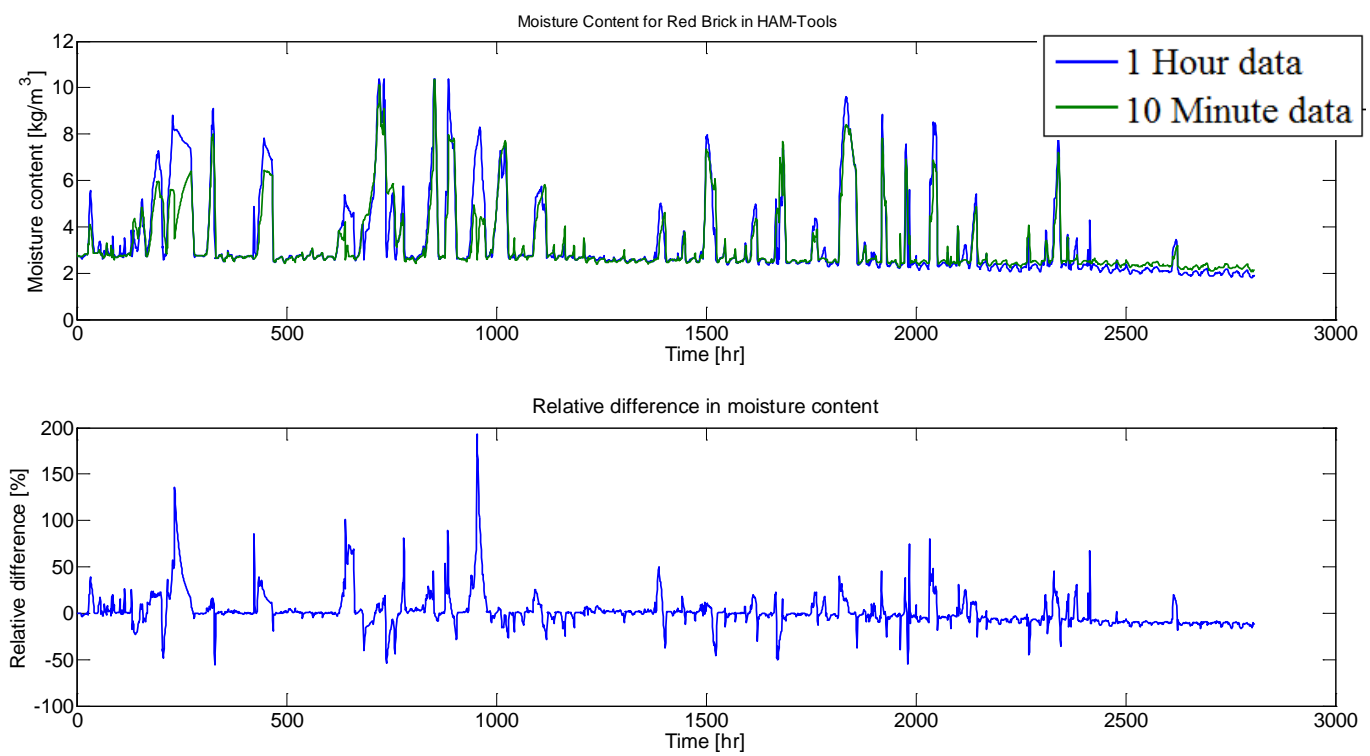

\section{0 minute to 1 hour (plywood): Direction: vector Speed: weighted Rain: weighted}
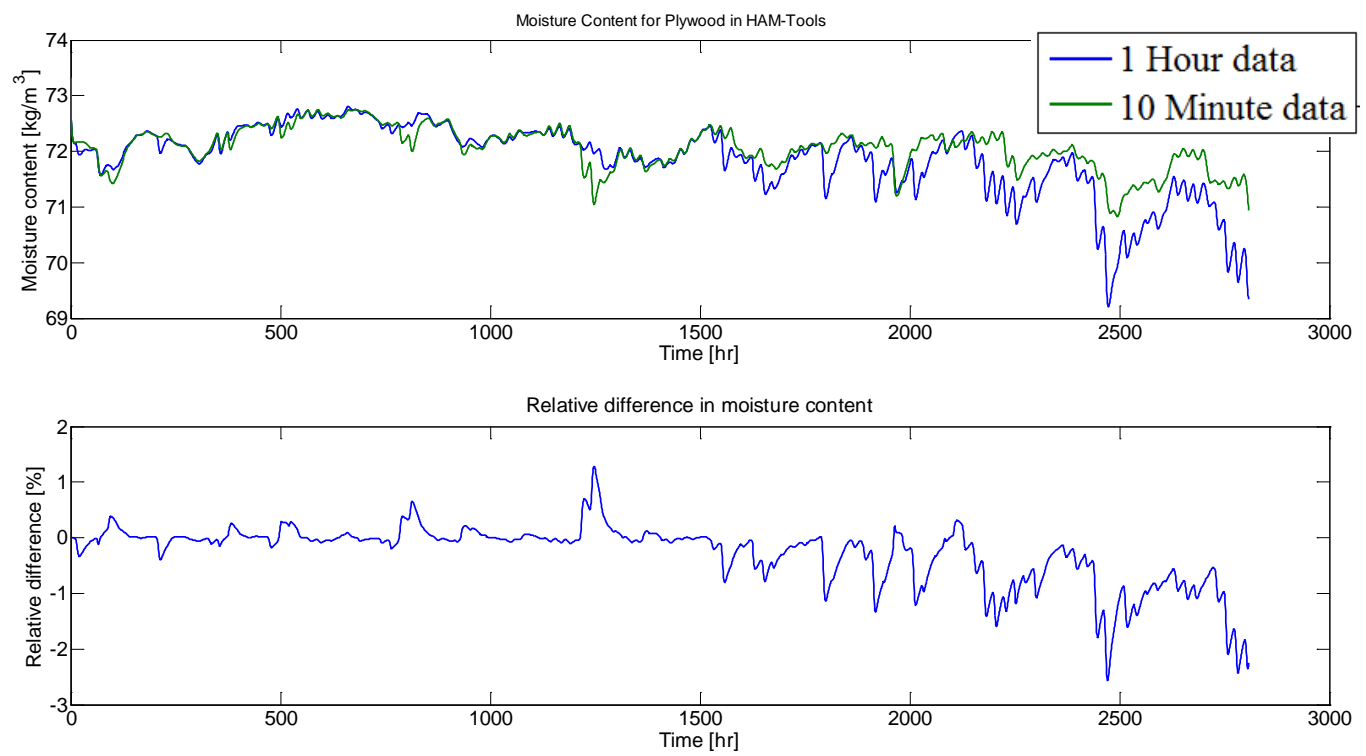

Figure 42: Moisture content comparison on the outer layer between different weather datasets created from 10 minute data

Similar to the 1-minute data, the hourly weather data from 10-minute data had the best outcome when accumulative rain combined with vector or weighted averaging technique for wind speed was used. The relative difference for the plywood is less than $2 \%$. Therefore, if the measured weather data has a resolution of 10 minutes or higher, it can be converted to hourly data using the suggested techniques. 
Appendix E provides the full details of the results at both the outer layer and the plywood layer using all the different averaging techniques.

In conclusion, the 1-minute to 1 hour converted data had acceptable results for the hygrothermal performance of the inner layer ( $2 \%$ relative difference). However, a more significant relative difference was observed in the outer layer. Therefore the use of hourly averaging of high resolution 1-minute data should be used with cautious in climates that have high amount of yearly rainfall, especially if the outer layer has low resistance to moisture. Moreover, the use of arithmetic averaging for wind direction shifted the resulting rainfall intensity angles and is not recommended to be used.

It can also be concluded that the 10-minute to hourly converted data has a better accuracy of the hygrothermal performance of a wall. Thus, if the resolution of the measured meteorological data is 10 minutes or more, the data can be stored as an hourly data. The closest result to the reference for both 1-minute and 10-minute averaging techniques were observed when the vector/weighted averaging technique for wind speed combined with accumulative rainfall and vector averaging for direction was used. 


\section{Chapter 6: Conclusion}

Previous study to create a wind driven rain module for HAM-Tools required proper verification with other simulation programs and validation with measured data. WUFI, a widely accepted commercial program is used for the verification. Because of the very limited material database in HAM-Tools, materials from WUFI's database were selected. Importance was placed on proper conversion of these material properties from WUFI to the HAM-Tools. The most significant one was the water transport properties, in which HAM-Tools uses hydraulic conductivity while WUFI uses liquid diffusivity. It was also important to adjust the HAM-Tools program to be able to include an input for initial moisture content for each material.

First, the conversion formula between hydraulic conductivity and liquid diffusivity was found and presented in Equation 15. A wall assembly was chosen using proper materials from WUFI's database and used to verify the module by comparing the results with WUFI. The same process was applied for a different weather data and a different wall construction. The results showed $10 \%$ relative difference in the exterior layer when the WDR module was turned off and $10 \%$ relative difference at the spikes when WDR module was used. This difference is because HAM-Tools uses the same water transport coefficient (hydraulic conductivity) for both wetting and drying periods while WUFI has a smaller value for drying periods, as well as the vapour diffusion handling between each of the two programs. The module was also compared for the field test wall assembly with Burnaby weather data. The result showed an average of $20 \%$ relative difference in the outer layer and $5 \%$ to $20 \%$ in plywood.

Then, the module was compared with field measurements from a test hut. The comparison showed an average relative difference of $5 \%$ with a maximum of less than $13 \%$ in the plywood layer. This difference was suggested to be due to the discrepancy in material properties, initial moisture content, air movement in the cavity layer, and measurement errors. In general, the simulation results from HAM- 
Tools agree well with simulation results from WUFI and field measurements. Thus, it can be concluded that the newly designed HAM-Tools wind driven rain module is performing properly.

Finally, HAM-Tools with the added WDR module was used to study the effects of hourly averaging highresolution meteorological data in a climate with high rainfall amount. Since most available weather data are hourly averaged from high resolution data, it is important to analyze the impact of this averaging on the hygrothermal performance of walls. It is not possible to carry this study in other commercial hygrothermal analysis software (such as WUFI) since unlike HAM-Tools as they only allow hourly weather data for their outdoor climate input. This study showed that arithmetic averaging of the wind direction results in a shift of the direction of overall driving rain sum and agreed with previous research, which stated that arithmetic averaging could cause errors in the data (Blocken \& Carmeliet, 2007). Therefore weighted and vector averaging techniques for wind speed were considered. For wind direction, vector averaging was recommended and used. It was found that weighted averaging of wind speed and rainfall amount for time resolution higher than 10 minute would cause a large overestimation of the data. It was suggested that a vector/weighted based averaging for wind speed with the accumulation of rainfall results in better estimation of the hourly conversion. However, if the measured weather data has a resolution of higher than 10 minutes, then a significant underestimation can occur in the hygrothermal analysis of the outer layer when using hourly data. Thus it is recommended to use the higher resolution data rather than hourly averaged data to analyze the hygrothermal performance of building facades. 


\section{Contributions}

The main contributions of this research include:

1. Process of correct implementation of WUFI's material database in HAM-Tools was found and presented in Table 8.

2. Recommendations are provided to properly set up and adjust HAM-Tools in order for the program to run successfully. These include setting up appropriate boundary conditions, material properties, wall constructions, initial conditions of each layer, weather data and addition of atmospheric pressure (or any other required data) to the weather data. This information will be useful for other professionals that require to use HAM-Tools for their own research

3. HAM-Tools with the wind-driven rain module was validated by comparing the simulation results with on-site field measurements

4. Insight to different averaging techniques for high resolution weather data is presented. This was achieved by comparing the driving rain rosette of all the datasets together and by comparing the impact of these averaging techniques on hygrothermal performance of a wall assembly in a climate with high amount of rainfall.

5. Recommendations on suitable weather data resolution and the best averaging technique are provided. 10 minute or higher resolution weather data is recommended when used for hygrothermal performance of building facade analysis. It is also recommended to use vector averaging technique combined with accumulating rainfall to hourly average the wind-driven rain parameters from higher resolution weather data. 


\section{Future works}

HAM-Tools with the wind driven rain module can now be used to include the effects of wind driven rain for different analysis. The main recommendation for improving the module is to enable HAM-Tools to distinguish between the different moisture transport during wetting and drying periods, which would improve the accuracy of HAM-Tools output. Another is to create modules that enable the program to add a water, air and heat source to any layer of a construction. This would ultimately enable HAM-Tools to study the hygrothermal performance of a construction with many different scenarios. There have been studies using HAM-Tools that manipulated the material property database to create a new material resembling a vented cavity, but the study has not been validated against real data.

Finally, the analysis for hourly averaging techniques for high resolution weather data was conducted on one type of climate and wall assembly. Other climates and assemblies are recommended to be used to further investigate the effect of hourly averaging the weather data. Moreover, there are other semiempirical models defined to provide wind driven rain intensity. In order to find the strength and weaknesses of these models, they can be compared using HAM-Tools at different climates and scenarios. 


\section{References}

Abuku, M., Jenssen, H., Poesen, J., \& Roels, S. (n.d.). Impact, absorption and evaporation of raindrops on building facades. Building and Environment, 44, 113-124.

ASHRAE. (2001). Thermal and moisture contron in insulated assemblies - fundamentals. In ASHRAE Fundamentals Handbook. Chapter 23.

ASTM-Standard. (2009). http://www.astm.org/Standards/C1699.htm. Designation C1699.

Blocken, B., \& Carmeliet, J. (2004, November). A review of wind-driven rain research in building science. Journal of Wind Engineering and Industrial Aerodynamics, 92(13), 1079-1130.

Blocken, B., \& Carmeliet, J. (2007). On the errors associated with the use of hourly data in winddriven rain calculations on building facades. Atmospheric Environment, 41(11), 2335-2343.

Blocken, B., \& Carmeliet, J. (2008). Guidelines for the required time resolution of meteorological input data for wind-driven rain calculations on buildings. Journal of Wind Engineering and Industrial Aerodynamics, 96, 621-639.

Blocken, B., \& Carmeliet, J. (2010a). Overview of three state-of-the-art wind-driven rain assessment models and comparison based on model theory. 45, pp. 691-703. Elsevier.

Blocken, B., \& Carmeliet, J. (2010b). Overview of three state-of-the-art wind-driven rain assessment models. Building and Environment, 45, 691-703.

Blocken, B., Roels, S., \& Carmeliet, J. (2007). A combined CFD-HAM approach for wind-driven rain on building facades. Journal of Wind Engineering and Industrial Aerodynamics, 95, 585-607.

Bomberg, M. T. (1974). Moisture flow through porous building materials. Report 52, Lund Institute of Technology, Division of Building Technology, Sweden.

Carmeliet, J., \& and Roels, S. (2001). Determination of the Isothermal Moisture Transport Properties of Porous Building Materials. THERMAL ENV. \& BLDG. SCI., 24, 183-210.

Environment Canada. (2012). National Climate Data and Information Archive. Retrieved 9 2012, from http://www.climate.weatheroffice.gc.ca/prods_servs/index_e.html

Fraunhofer IBP. (2010). Retrieved 05 20, 2012, from WUFI: http://www.wufi-pro.com/

Hansen, M., Houvenghel, G., Janz, M., Krus, M., \& . Stromdahl, K. (1999). Interlaboratory Comparison of the Measurement of Retention Curves. Technical University of Denmark, Department of Structural Engineering and Materials, Denmark.

Hens, H. (1996). IAE Annex 24, Final report, Volume 1, Modelling. K.U. Leuven, Belgium: Laboratorium Bouwfysica, Departement Burgerlijke Bouwkunde. 
Hens, H. (2010). Wind-Driven Rain: From Theory to Reality. BUILDING XI. ASHRAE.

ISO. (2009). Hygrothermal performance of buildings - calculation and presentation of climatic data Part 3: calculation of a driving rain index for vertical surfaces from hourly wind and rain data. ISO 2009;15927-3: International Organization for Standardization.

Janssen, H., Blocken, B., \& Carmeliet, J. (2007). Conservative modelling of the moisture and heat transfer in building components under atmospheric excitation. International Journal of HEAT and MASS TRANSFER, 50, 1128-1140.

Janz, M., \& and Johannesson, B. (2001, Apr). Measurement of the Moisture Storage Capacity Using Sorption Balance and Pressure Extractors. Journal of Building Physics, 24: 316-334.

Joseph, O., Arumala, \& Masce, P. (2006). International Journal of Construction Education and Research, 2:75-89.

Kalagasidis, A. (2004). HAM-Tools: An Integrated Simulation Tool for Heat, Air and Moisture Transfer Analyses in Building Physics. CHALMERS UNIVERSITY OF TECHNOLOGY, Department of Building Technology, Building Physics Division, Gothenburg, Sweden.

Kalagasidis, A. S., Weitzmann, P., Nielsen, T. R., Peuhkuri, R., Hagentoft, C. E., \& Rode, C. (2007). The international building physics toolbox in simulink. Energy and Buildings, 39(6), 665-674.

Karagiozis, A. (2001). Advanced Hygrothermal Modeling of Building Materials using Moisture Expert 1.0. Washington.

Krus, M. (1995). Moisture transport and storage coefficients of porous mineral building materials. Ph.D. Thesis, University of Stuttgard, Germany.

Kumaran, K., \& Sanders, C. (2008). Annex 41, Whole Building Heat, Air, Moisture Response - Boundary Conditions and Whole Building HAM Analysis. International Energy Agency.

Kumaran, M., Mitalas, G., Kohonen, R., \& Ojanen, T. (1994). Fundemental of transport and storage of moisture in building materials and components. Moisture control in buildings, Chapter 1, 3-17.

Künzel, H. M. (1995). Simultaneous Heat and Moisture Transport in Building Components - One- and two-dimentional calculation using simple parameters. Fraunhofer IRB.

Lee, S., Ries, J., \& Somerville, T. (2012). Repairs under imperfect information. Journal of Urban Economics, 73, 43-56.

Lstiburek, J. (2006). Increase the Durability of Building Construction. Retrieved 2013, from Building Science Digest 144: BuildingScience.com

Moonen, P., Defraeye, T., Dorer, V., Blocken, B., \& Carmeliet, J. (2012). Urban Physics: Effect of the micro-climate on comfort, health and energy demand. SciVerse ScienceDirect. 
Rode, C., Grau, K., \& Mitamura, T. (2001). Hygrothermal Conditions in the Envelope and Indoor Air of Buildings. Proceedings (CD) of Performance of Exterior Envelopes of Whole Buildings VIII: Integration of Building Envelopes (pp. 55-60). Clearwater Beach, Florida: ASHRAE.

Rode, C., Ruut, P., \& Woloszyn, M. (2008, August 26-31). Simulation tests in whole building heat and moisture transfer. Proceeding of the third International Building Physics/Engineering Conference, (pp. 527-534). Montreal, Canada.

Ruut, P., \& Rode, C. (2005). Common Exercise 1 - Case OA and OB Revised. IEA, ANNEX 41, Task 1, Modeling Common Exercise.

Simpson, Y., \& and Ge, H. (2010). Field evaluation of ventilation wetting and drying of rainscreen walls in coastal British Columbia. Concordia University, Department of Building, Civil and Environmental Engineering, Montreal, Quebec.

Straube, J., \& Burnett, E. (2000). Simplified prediction of driving rain on buildings. Proc. of the International Building Physics Conference, (pp. 375-382). Eindhoven, The Netherlands.

Tariku, F., Kumaran, K., \& Fazio, P. (2010). Integrated analysis of whole building heat, air and moisture transfer. Int. J. Heat Mass Transfer.

Trechsel, H. R. (1994). Moisture Control in Buildings. Philadelphia: American Society for Testing and Materials.

WTA. (2004). WTA-Guideline 6-2-01/E 2004, Simulation of heat and moisture transfer. Stuttgart: Fraunhofer IRB-Verlag: Wissenschaftlich-Technische Arbeitsgemeinschaft für Bauwerkserhaltung und Denkmalpflege (International Association for Science and Technology of Building Maintenance and the Preservation of Monuments).

Wu, R., Ge, H., \& Horvat, M. (2012). Wind-driven rain module for HAM-Tools (International Building Physics Toolbox) according to ASHRAE 160P-design and verification. Proceedings of 5th International Building Physics conference. Kyoto, Japan. 


\section{Appendix A}

\section{WUFI $@$ Pro 5.1}

\section{Component Assembly}

\section{Case: wood}

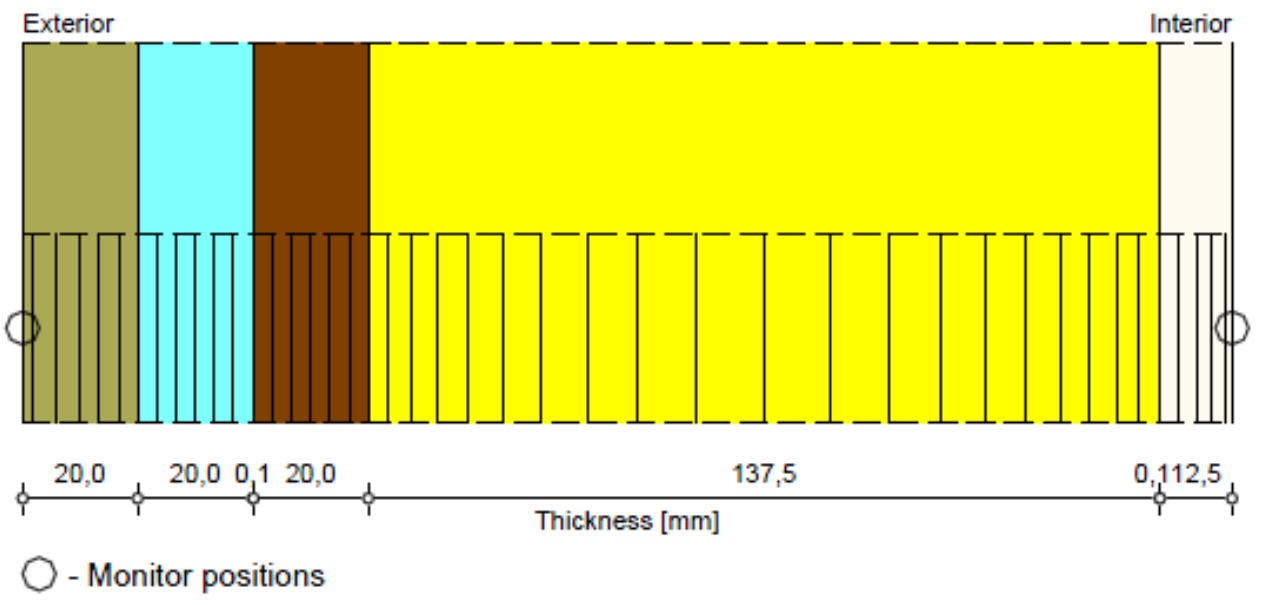

Materials :

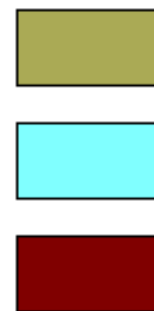

- Southern Yellow Pine

- Air Layer 20 mm

-60 minute Building Paper

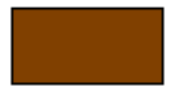

- Spruce, tangential

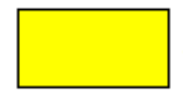

- Cellulose Fiber (heat cond.: 0,04 W/mK)

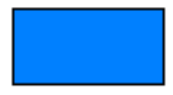

- vapour retarder (1 perm)

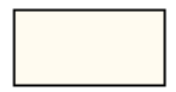

- Gypsum Board

Total Thickness: $0,21 \mathrm{~m}$

R-Value: $3,46 \mathrm{~m}^{2} \mathrm{~K} / \mathrm{W}$

U-Value: $0,275 \mathrm{~W} / \mathrm{m}^{2} \mathrm{~K}$ 
WUFI@ Pro 5.1

Material : Southern Yellow Pine

Checking Input Data

\begin{tabular}{|l|c|c|}
\hline \multicolumn{1}{|c|}{ Property } & Unit & Value \\
\hline Bulk density & {$\left[\mathrm{kg} / \mathrm{m}^{2}\right]$} & 500,0 \\
\hline Porosity & {$\left[\mathrm{m}^{2} / \mathrm{m}^{2}\right]$} & 0,858 \\
\hline Specific Heat Capacity, Dry & {$[\mathrm{J} / \mathrm{kg} \mathrm{K}]$} & 1880,0 \\
\hline Thermal Conductivity, Dry, $10^{\circ} \mathrm{C}$ & {$[\mathrm{W} / \mathrm{mK}]$} & 0,119 \\
\hline Water Vapour Diffusion Resistance Factor & {$[-]$} & 1734,1 \\
\hline \hline Reference Water Content & {$\left[\mathrm{kg} / \mathrm{m}^{2}\right]$} & 62,2 \\
\hline Free Water Saturation & {$\left[\mathrm{kg} / \mathrm{m}^{2}\right]$} & 300,0 \\
\hline Water Absorption Coefficient & {$\left[\mathrm{kg} / \mathrm{m}^{2} \mathrm{~s}^{\wedge} 0.5\right]$} & 0,0014 \\
\hline Temp-dep. Thermal Cond. Supplement & {$\left[\mathrm{W} / \mathrm{mK}^{2}\right]$} & 0,0002 \\
\hline
\end{tabular}
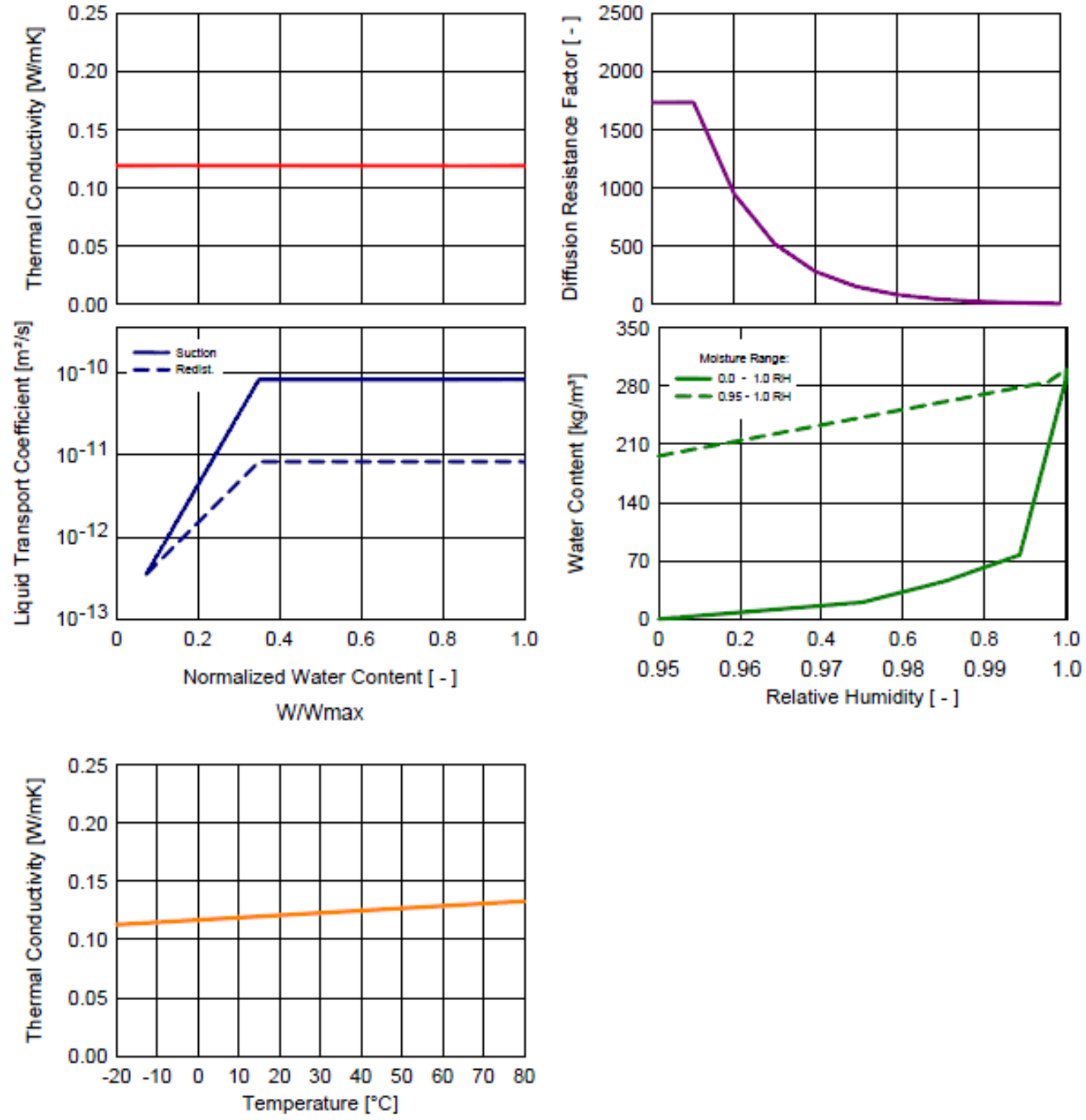
WUFI@ Pro 5.1

Material : Air Layer $20 \mathrm{~mm}$

Checking Input Data

\begin{tabular}{|l|c|c|}
\hline \multicolumn{1}{|c|}{ Property } & Unit & Value \\
\hline Bulk density & {$\left[\mathrm{kg}^{\mathrm{m}} \mathrm{m}^{2}\right]$} & 1,3 \\
\hline Porosity & {$\left[\mathrm{m}^{2} / \mathrm{m}^{2}\right]$} & 0,999 \\
\hline Specific Heat Capacity, Dry & {$[\mathrm{J} / \mathrm{kgK}]$} & 1000,0 \\
\hline Thermal Conductivity, Dry, 10 ${ }^{\circ} \mathrm{C}$ & {$[\mathrm{W} / \mathrm{mK}]$} & 0,13 \\
\hline Water Vapour Diffusion Resistance Factor & {$[-]$} & 0,56 \\
\hline
\end{tabular}
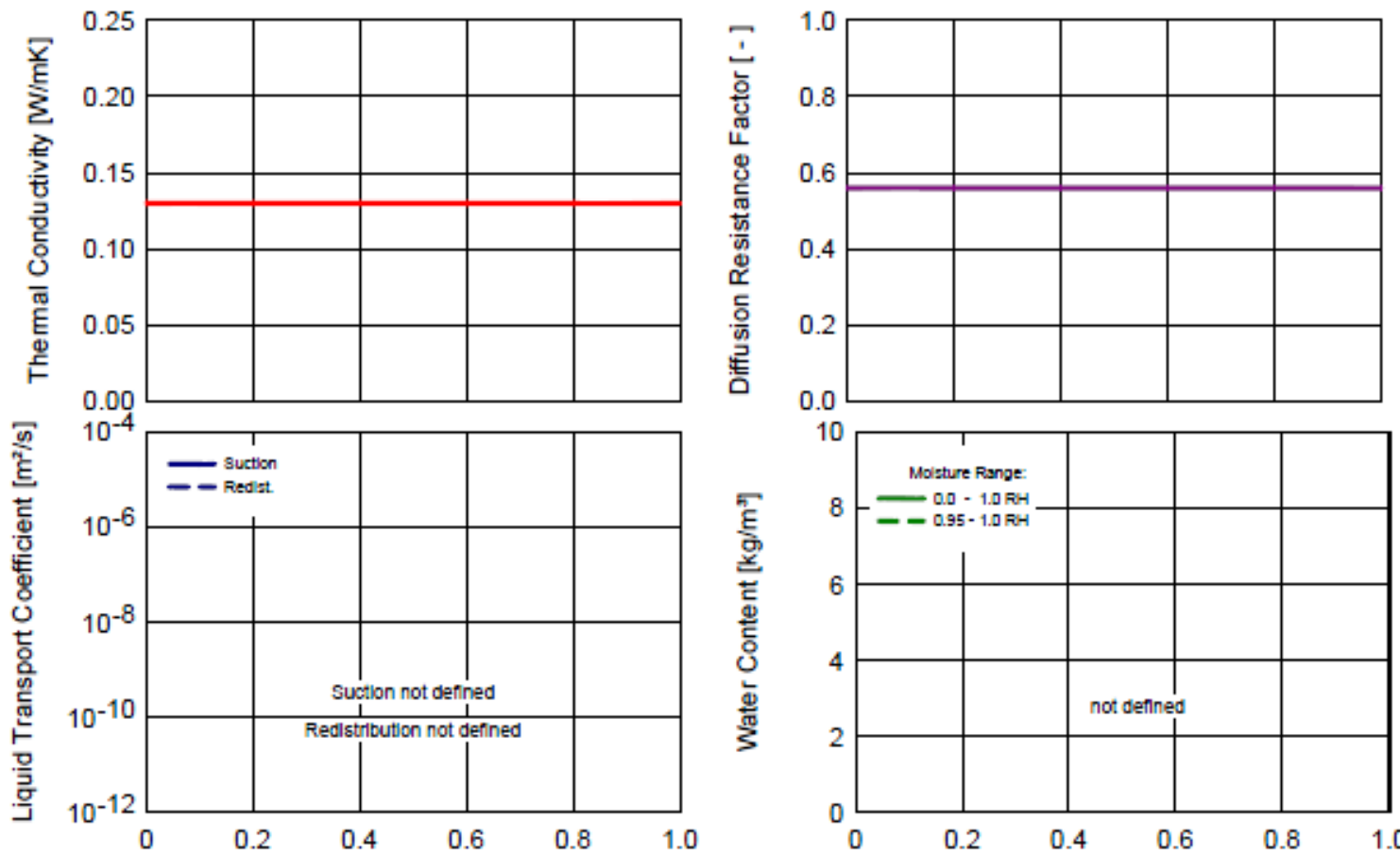

Normalized Water Content [ - ]

W/Wmax
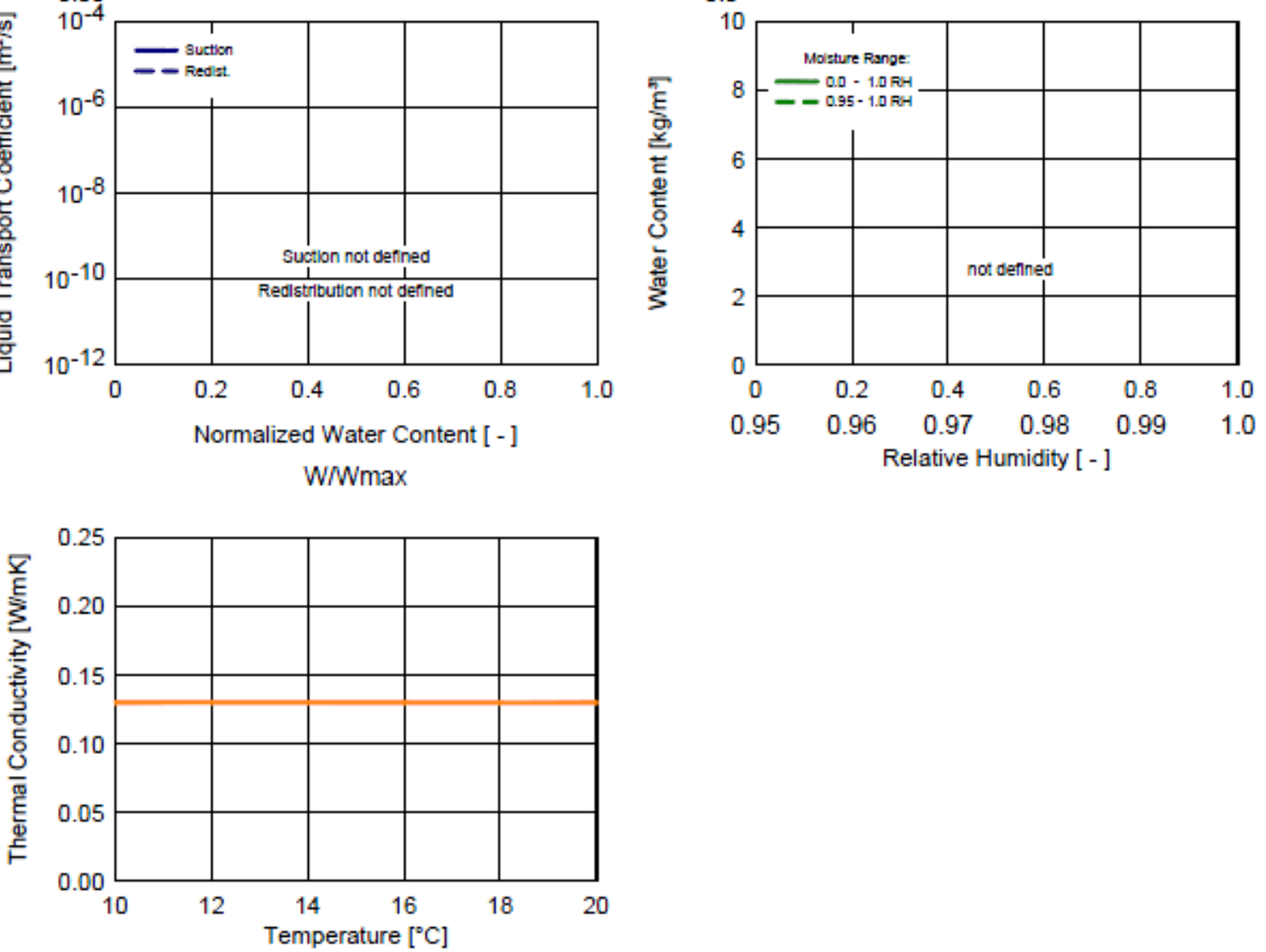
WUFI@ Pro 5.1

Material : 60 minute Building Paper

Checking Input Data

\begin{tabular}{|l|c|c|}
\hline \multicolumn{1}{|c|}{ Property } & Unit & Value \\
\hline Bulk density & {$\left[\mathrm{kg} / \mathrm{m}^{2}\right]$} & 280,0 \\
\hline Porosity & {$\left[\mathrm{m}^{2} / \mathrm{m}^{2}\right]$} & 0,001 \\
\hline Specific Heat Capacity, Dry & {$[\mathrm{J} / \mathrm{kgK}]$} & 1500,0 \\
\hline Thermal Conductivity, Dry, $10^{\circ} \mathrm{C}$ & {$[\mathrm{W} / \mathrm{mK}]$} & 12,0 \\
\hline Water Vapour Diffusion Resistance Factor & {$[-]$} & 144,0 \\
\hline Temp-dep. Thermal Cond. Supplement & {$\left[\mathrm{W}_{\mathrm{m}} \mathrm{K}^{2}\right]$} & 0,0002 \\
\hline
\end{tabular}
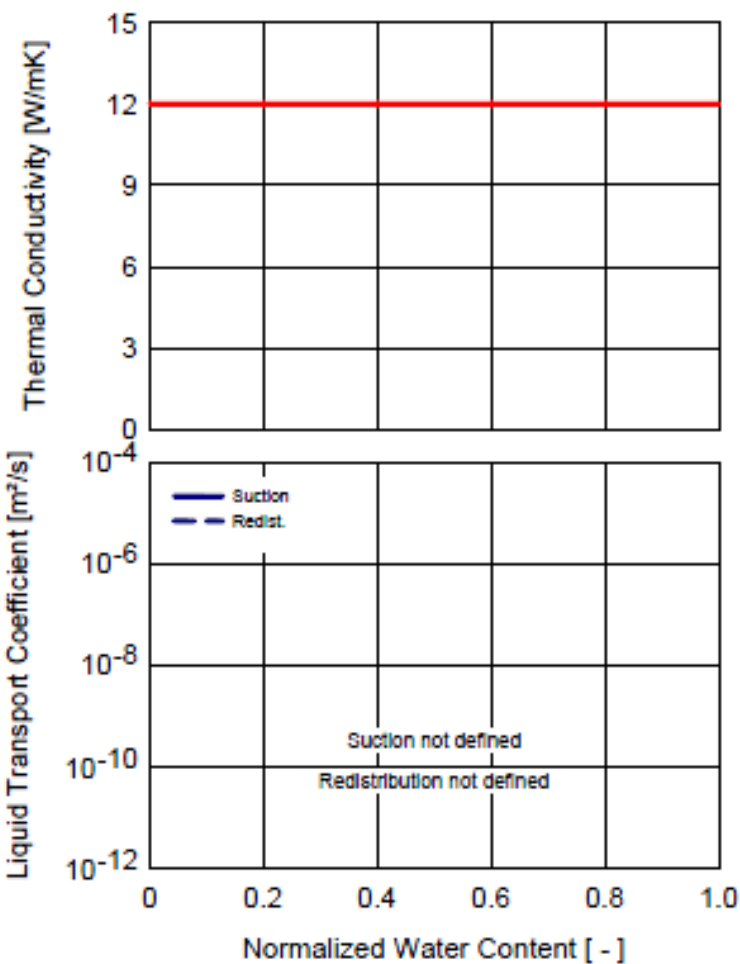

WINmax
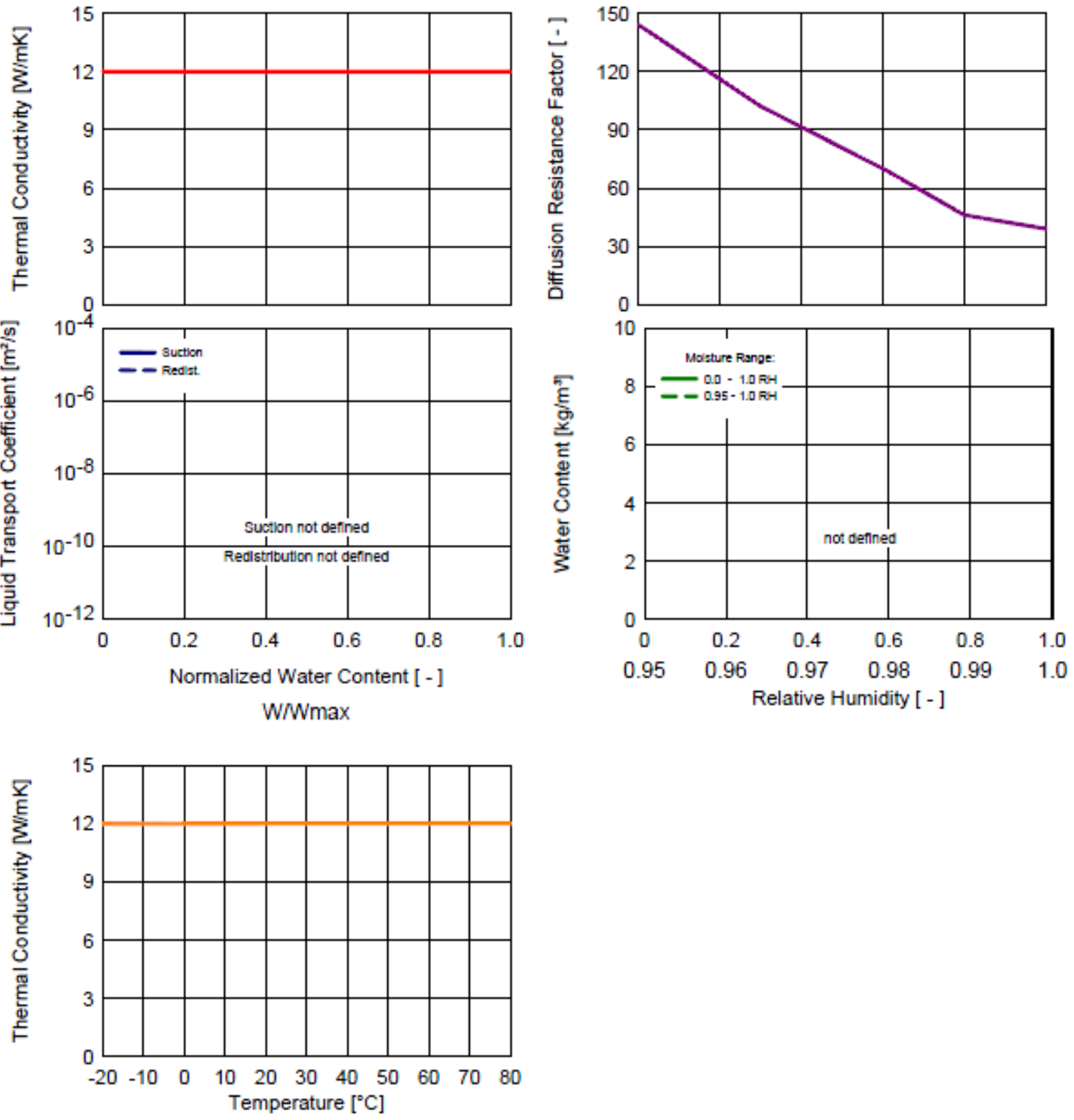


\section{WUFI@ Pro 5.1}

\section{Material : Spruce, tangential}

Checking Input Data

\begin{tabular}{|l|c|c|}
\hline \multicolumn{1}{|c|}{ Property } & Unit & Value \\
\hline Bulk density & {$\left[\mathrm{kg}^{2} \mathrm{~m}^{2}\right]$} & 430,0 \\
\hline Porosity & {$\left[\mathrm{m}^{2} / \mathrm{m}^{2}\right]$} & 0,73 \\
\hline Specific Heat Capacity, Dry & {$[\mathrm{J} / \mathrm{kg} /]$} & 1600,0 \\
\hline Thermal Conductivity, Dry, $10^{\circ} \mathrm{C}$ & {$[\mathrm{W} / \mathrm{mK}]$} & 0,14 \\
\hline Water Vapour Diffusion Resistance Factor & {$[-]$} & 83,3 \\
\hline Temp-dep. Thermal Cond. Supplement & {$\left[\mathrm{W} / \mathrm{mK}^{2}\right]$} & 0,0002 \\
\hline
\end{tabular}
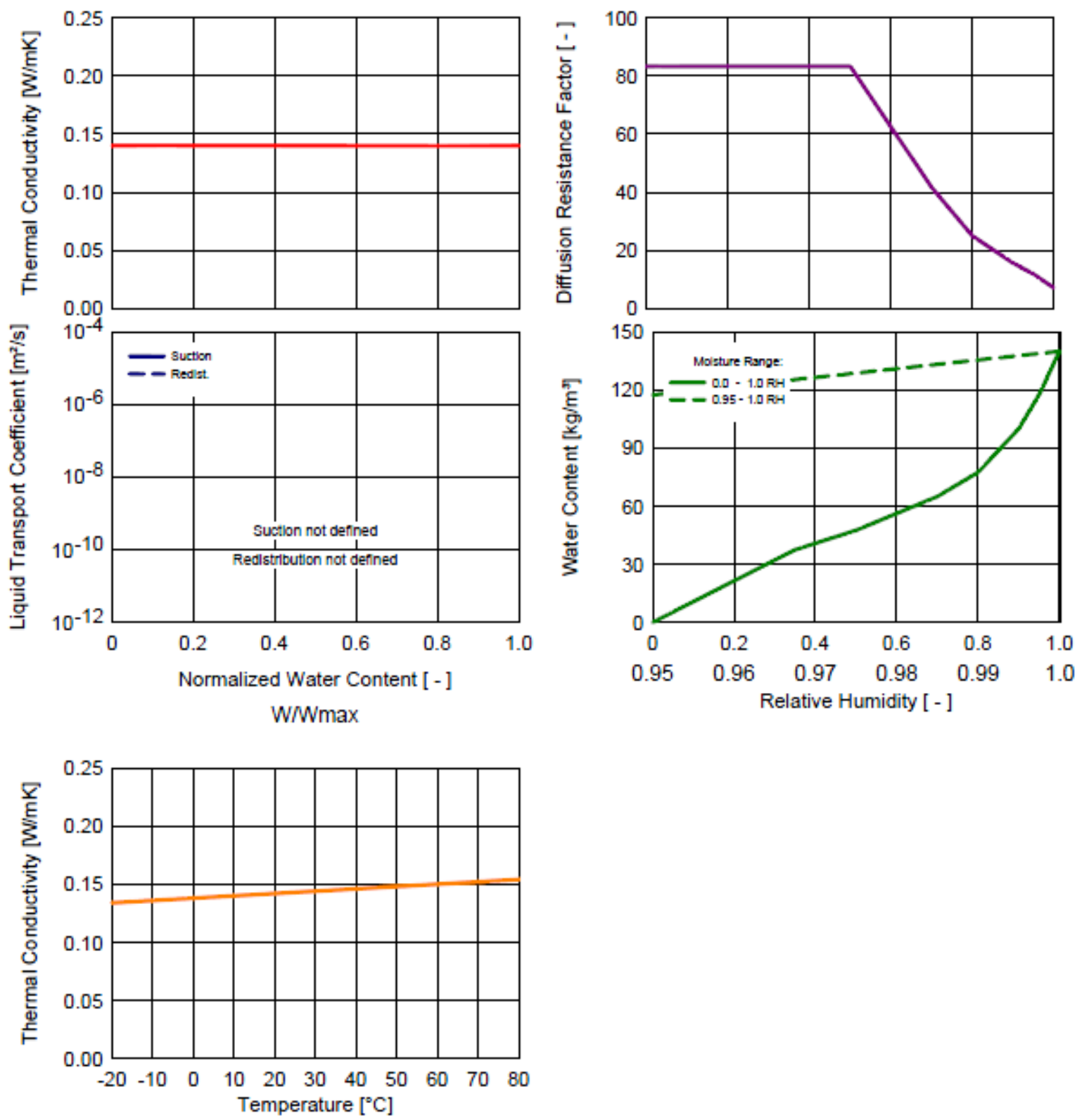
WUFI@ Pro 5.1

Material : Cellulose Fiber (heat cond.: 0,04 W/mK)

Checking Input Data

\begin{tabular}{|l|c|c|}
\hline \multicolumn{1}{|c|}{ Property } & Unit & Value \\
\hline Bulk density & {$\left[\mathrm{kg} / \mathrm{m}^{2}\right]$} & 70,0 \\
\hline Porosity & {$\left[\mathrm{m}^{2} / \mathrm{m}^{2}\right]$} & 0,85 \\
\hline Specific Heat Capacity, Dry & {$[\mathrm{J} / \mathrm{kg} /]$} & 2500,0 \\
\hline Thermal Conductivity, Dry, $10^{\circ} \mathrm{C}$ & {$[\mathrm{W} / \mathrm{mK}]$} & 0,04 \\
\hline Water Vapour Diffusion Resistance Factor & {$[-]$} & 1,5 \\
\hline \hline Moisture-dep. Thermal Cond. Supplement & {$[\% / \mathrm{M} .-\%]$} & 1,0 \\
\hline Temp-dep. Thermal Cond. Supplement & {$\left[\mathrm{W} / \mathrm{mK}^{2}\right]$} & 0,0002 \\
\hline
\end{tabular}
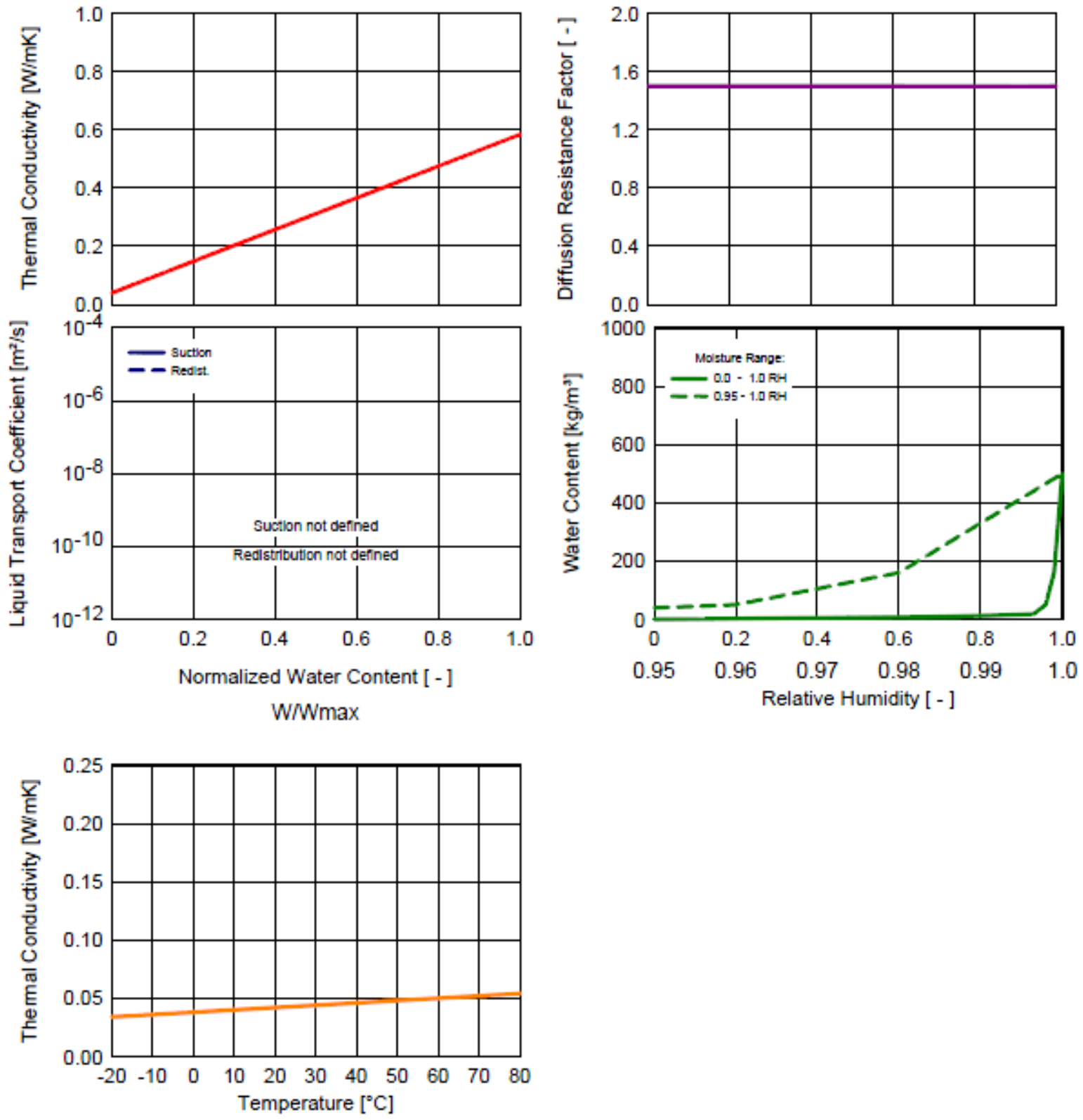
WUFI@ Pro 5.1

Material : vapour retarder (1 perm)

Checking Input Data

\begin{tabular}{|l|c|c|}
\hline \multicolumn{1}{|c|}{ Property } & Unit & Value \\
\hline Bulk density & {$\left[\mathrm{kg}^{2} \mathrm{~m}^{2}\right]$} & 130,0 \\
\hline Porosity & {$\left[\mathrm{m}^{2} / \mathrm{m}^{2}\right]$} & 0,001 \\
\hline Specific Heat Capacity, Dry & {$[\mathrm{J} / \mathrm{kgK}]$} & 2300,0 \\
\hline Thermal Conductivity, Dry,10 ${ }^{\circ} \mathrm{C}$ & {$\left[\mathrm{W} / \mathrm{mK}^{2}\right]$} & 2,3 \\
\hline Water Vapour Diffusion Resistance Factor & {$[-]$} & 3300,0 \\
\hline Temp-dep. Thermal Cond. Supplement & {$\left[\mathrm{W} / \mathrm{mK}^{2}\right]$} & 0,0002 \\
\hline
\end{tabular}
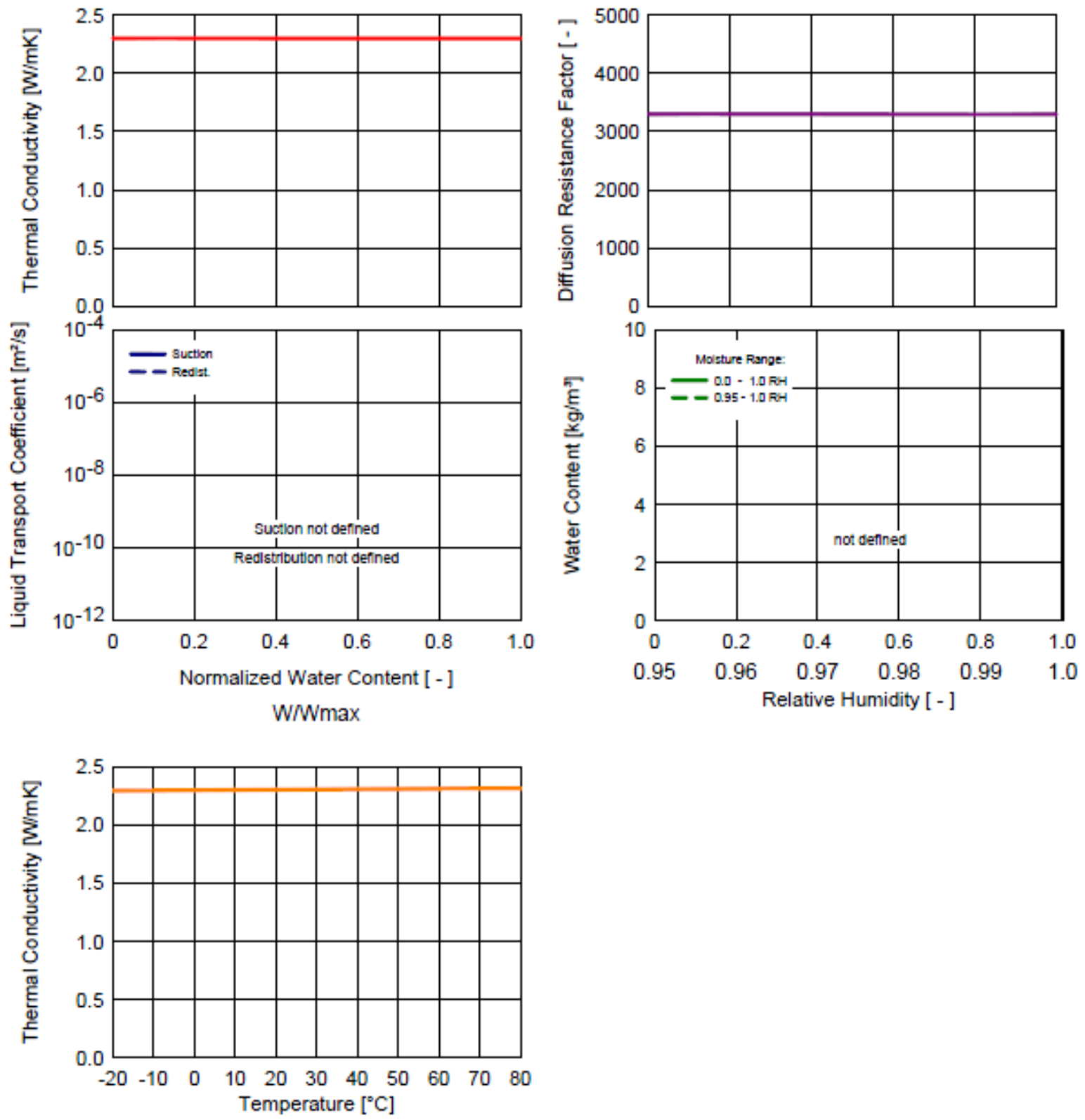
WUFI@ Pro 5.1

Material : Gypsum Board

Checking Input Data

\begin{tabular}{|l|c|c|}
\hline \multicolumn{1}{|c|}{ Property } & Unit & Value \\
\hline Bulk density & {$\left[\mathrm{kg}^{2} \mathrm{~m}^{2}\right]$} & 850,0 \\
\hline Porosity & {$\left[\mathrm{m}^{2} / \mathrm{m}^{2}\right]$} & 0,06 \\
\hline Specific Heat Capacity, Dry & {$[\mathrm{J} / \mathrm{kgK}]$} & 850,0 \\
\hline Thermal Conductivity, Dry, $10^{\circ} \mathrm{C}$ & {$[\mathrm{W} / \mathrm{mK}]$} & 0,2 \\
\hline Water Vapour Diffusion Resistance Factor & {$[-]$} & 8,3 \\
\hline \hline Moisture-dep. Thermal Cond. Supplement & {$[\% / \mathrm{M} .-\%]$} & 8,0 \\
\hline Temp-dep. Thermal Cond. Supplement & {$\left[\mathrm{W} / \mathrm{mK}^{2}\right]$} & 0,0002 \\
\hline
\end{tabular}
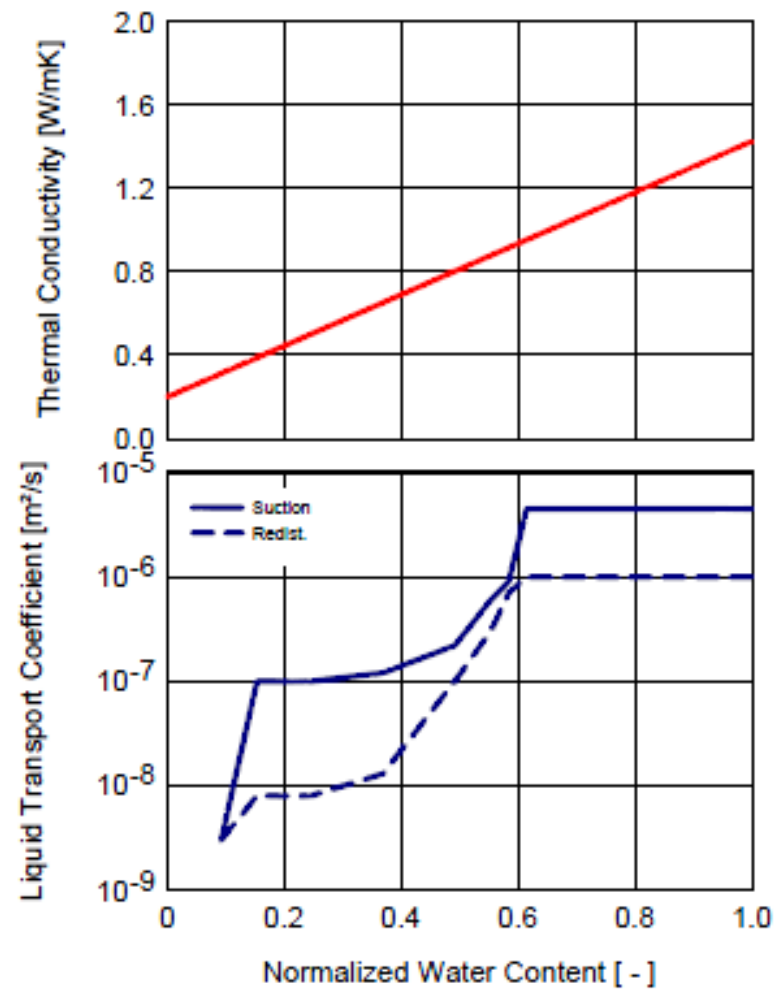

W/Wmax
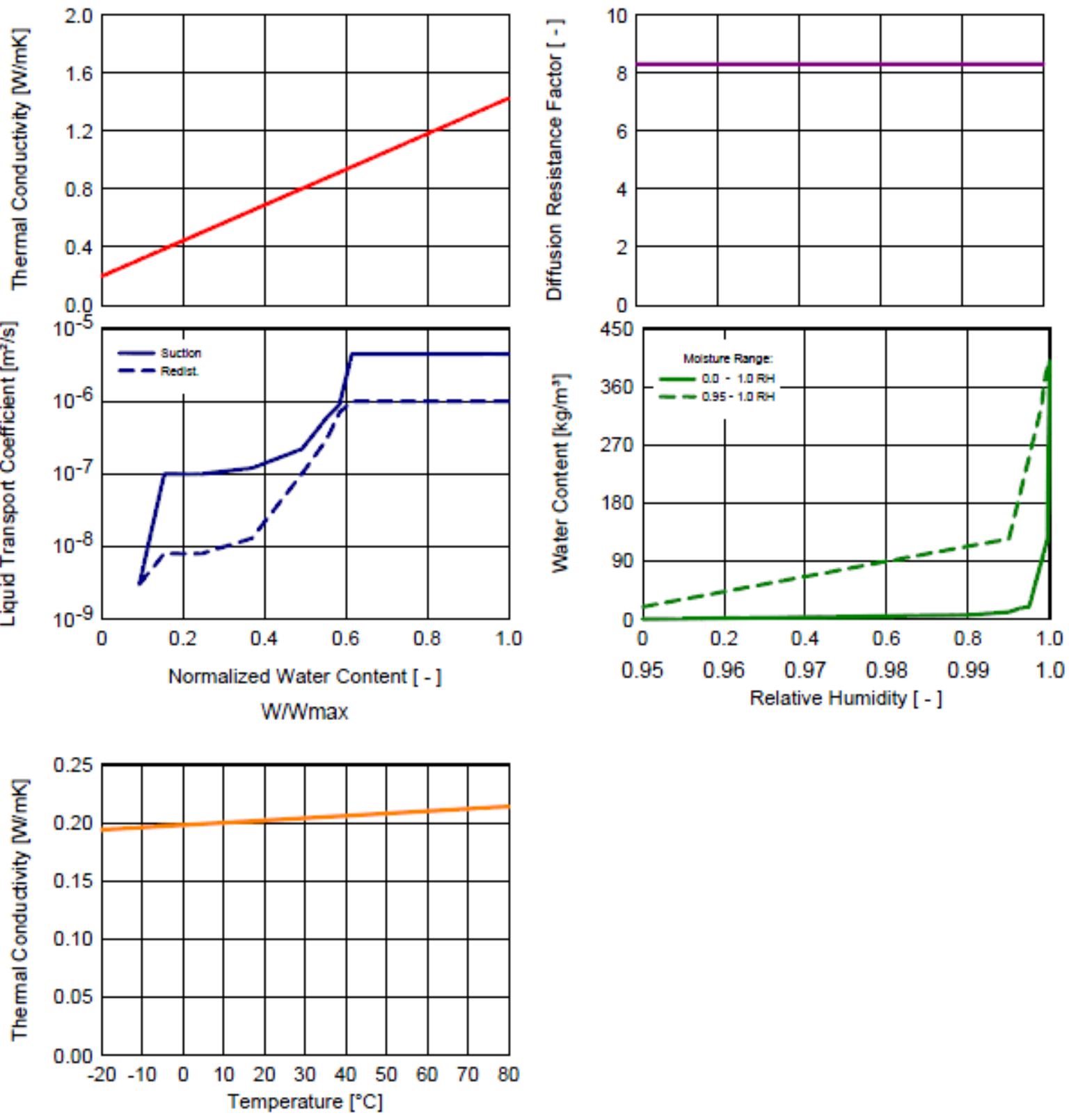
WUFI@ Pro 5.1

\section{Boundary Conditions}

\section{Exterior (Left Side)}

Location: TorontoEightyFour2.wac

Orientation / Inclination: East / $90^{\circ}$

Interior (Right Side)

Indoor Climate: EN 15026

Normal Moisture Load

\section{Surface Transfer Coefficients}

\section{Exterior (Left Side)}

\begin{tabular}{|l|c|c|l|}
\hline \multicolumn{1}{|c|}{ Name } & Unit & Value & \multicolumn{1}{|c|}{ Description } \\
\hline Heat Resistance & {$\left[\mathrm{m}^{2} \mathrm{~K} / \mathrm{W}\right]$} & 0.0588 & External Wall \\
\hline Sd-Value & {$[\mathrm{m}]$} & - & No coating \\
\hline Short-Wave Radiation Absorptivity & {$[-]$} & 0.6 & \\
\hline Long-Wave Radiation Emissivity & {$[-]$} & 0.9 & \multirow{2}{*}{ According to inclination and constry } \\
\cline { 1 - 3 } Adhering Fraction of Rain & {$[-]$} & 0,7 & \multicolumn{2}{|r}{} \\
\cline { 1 - 3 }
\end{tabular}

Interior (Right Side)

\begin{tabular}{|l|c|c|l|}
\hline \multicolumn{1}{|c|}{ Name } & Unit & Value & \multicolumn{1}{c|}{ Description } \\
\hline Heat Resistance & {$\left[\mathrm{m}^{2} \mathrm{~K} / \mathrm{W}\right]$} & 0.125 & External Wall \\
\hline Sd-Value & {$[\mathrm{m}]$} & - & No coating \\
\hline
\end{tabular}




\section{WUFI $\left({ }^{\circledR}\right.$ Pro 5.1}

\section{Component Assembly}

Case: Simpson RAW with atmospheric pressure

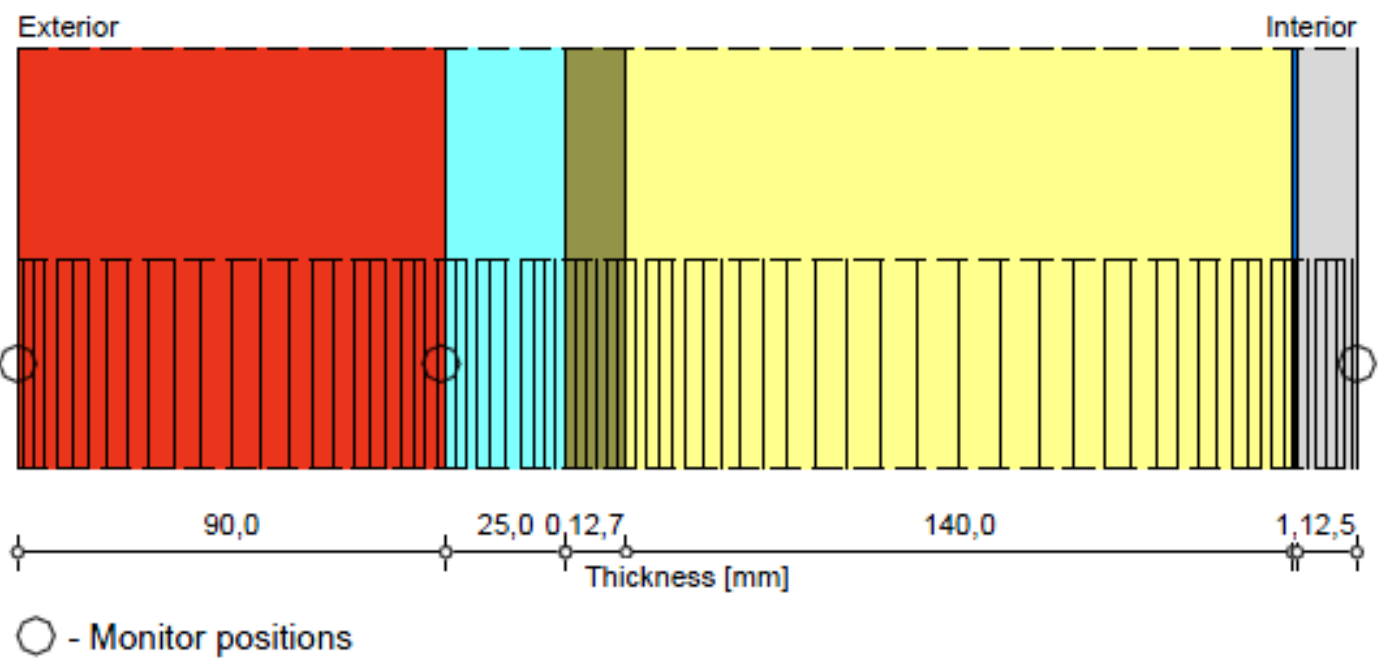

Materials :

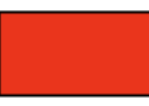

- *Red Matt Clay Brick

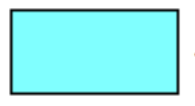

- *Air Layer $25 \mathrm{~mm}$

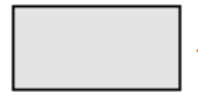

- *Spun Bonded Polyolefine Membrane (SBP)

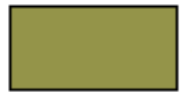

- *Plywood

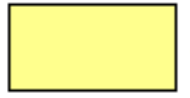

- "Low Density Glass Fibre Batt Insulation

- *PE-Membrane (Poly; 0.07 perm)

- *Interior Gypsum Board

Total Thickness: $0,28 \mathrm{~m}$

R-Value: $3,83 \mathrm{~m}^{2} \mathrm{~K} / \mathrm{W}$

II-Value: $0249 \mathrm{~W} / \mathrm{m}^{2} \mathrm{~K}$ 
WUFI $@$ Pro 5.1

\section{Material : " Red Matt Clay Brick}

Checking Input Data

\begin{tabular}{|l|c|c|}
\hline \multicolumn{1}{|c|}{ Property } & Unit & Value \\
\hline Bulk density & {$\left[\mathrm{kg}^{2}\right]$} & 1935,0 \\
\hline Porosity & {$\left[\mathrm{m}^{2} / \mathrm{m}^{2}\right]$} & 0,217 \\
\hline Specific Heat Capacity, Dry & {$[\mathrm{J} / \mathrm{kgK}]$} & 800,0 \\
\hline Thermal Conductivity, Dry, 10 ${ }^{\circ} \mathrm{C}$ & {$[\mathrm{W} / \mathrm{mK}]$} & 0,495 \\
\hline Water Vapour Diffusion Resistance Factor & {$[-]$} & 137,8 \\
\hline
\end{tabular}
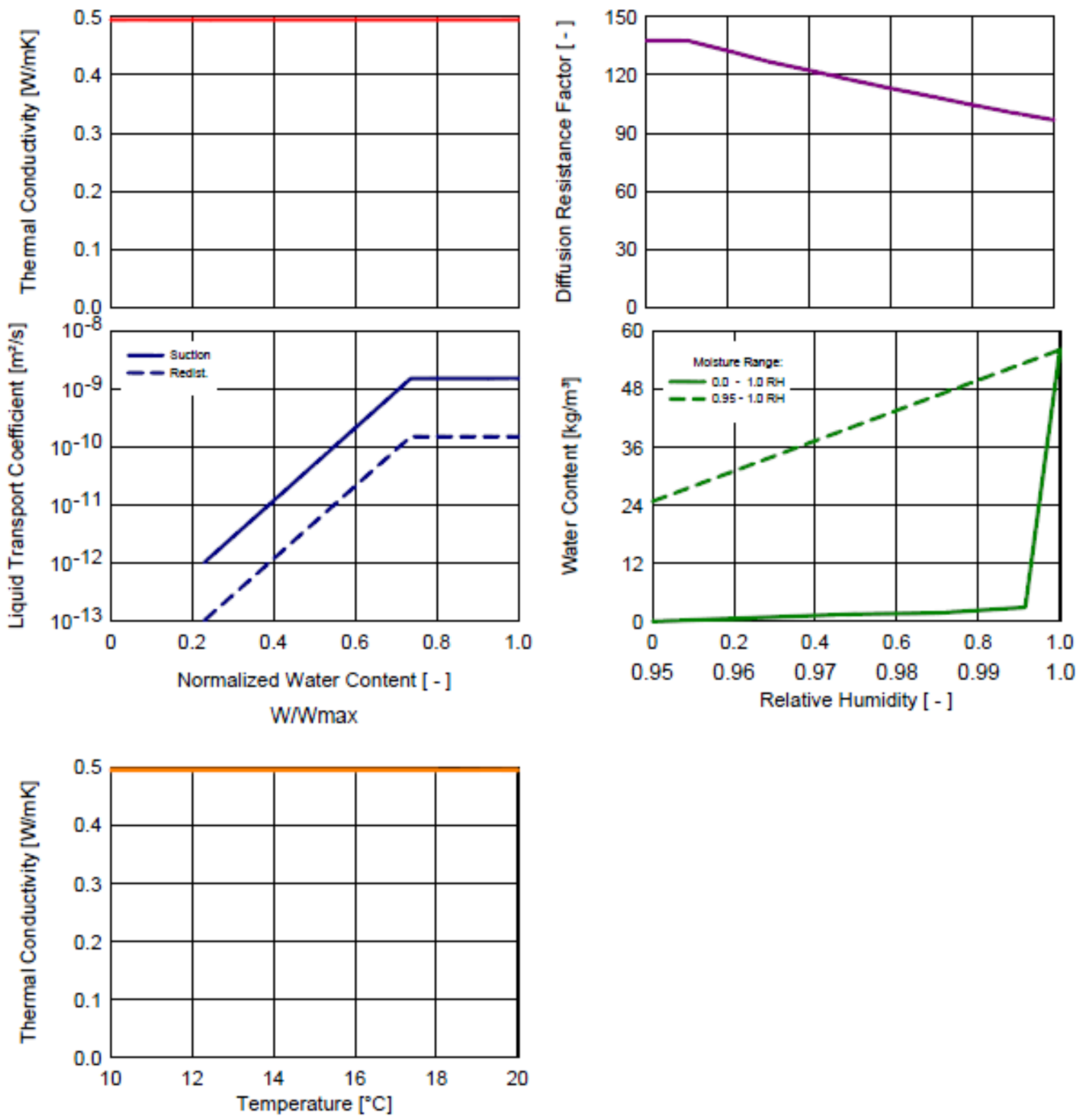
WUFI $@$ Pro 5.1

Material : *Air Layer $25 \mathrm{~mm}$

Checking Input Data

\begin{tabular}{|c|c|c|}
\hline Property & Unit & Value \\
\hline Bulk density & {$\left[\mathrm{kg} / \mathrm{m}^{2}\right]$} & 1,3 \\
\hline Porosity & {$\left[\mathrm{m}^{2} / \mathrm{m}^{2}\right]$} & 0,999 \\
\hline Specific Heat Capacity, Dry & {$[\mathrm{J} / \mathrm{kgK}]$} & 1000,0 \\
\hline Thermal Conductivity, Dry, $10^{\circ} \mathrm{C}$ & {$[\mathrm{W} / \mathrm{mK}]$} & 0,155 \\
\hline Water Vapour Diffusion Resistance Factor & {$[-]$} & 0,51 \\
\hline
\end{tabular}
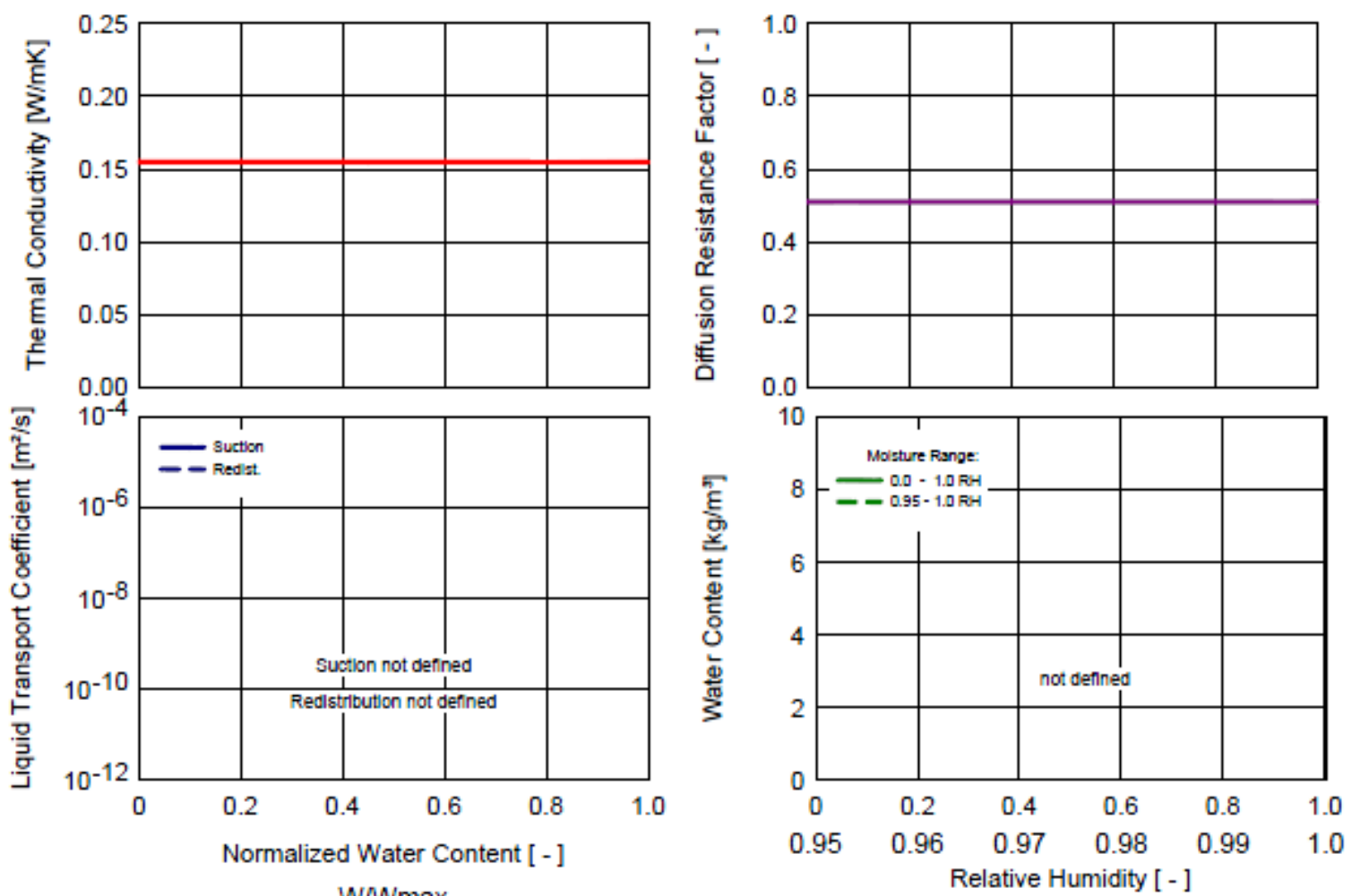

W/Wmax

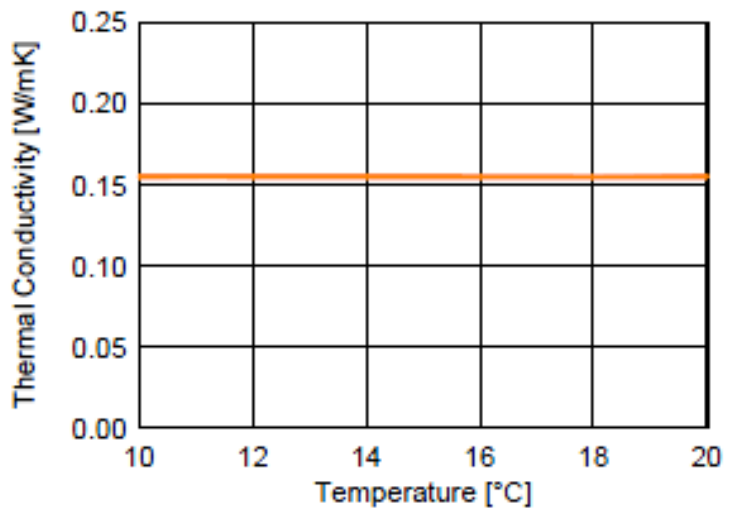


WUFI@ Pro 5.1

\section{Material : "Spun Bonded Polyolefine Membrane (SBP)}

Checking Input Data

\begin{tabular}{|l|c|c|}
\hline \multicolumn{1}{|c|}{ Property } & Unit & Value \\
\hline Bulk density & {$\left[\mathrm{kg}^{2} \mathrm{~m}^{2}\right]$} & 448,0 \\
\hline Porosity & {$\left[\mathrm{m}^{2} / \mathrm{m}^{2}\right]$} & 0,001 \\
\hline Specific Heat Capacity, Dry & {$[\mathrm{J} / \mathrm{kgK}]$} & 1500,0 \\
\hline Thermal Conductivity, Dry, $10^{\circ} \mathrm{C}$ & {$[\mathrm{W} / \mathrm{mK}]$} & 2,4 \\
\hline Water Vapour Diffusion Resistance Factor & {$[-]$} & 328,4 \\
\hline
\end{tabular}
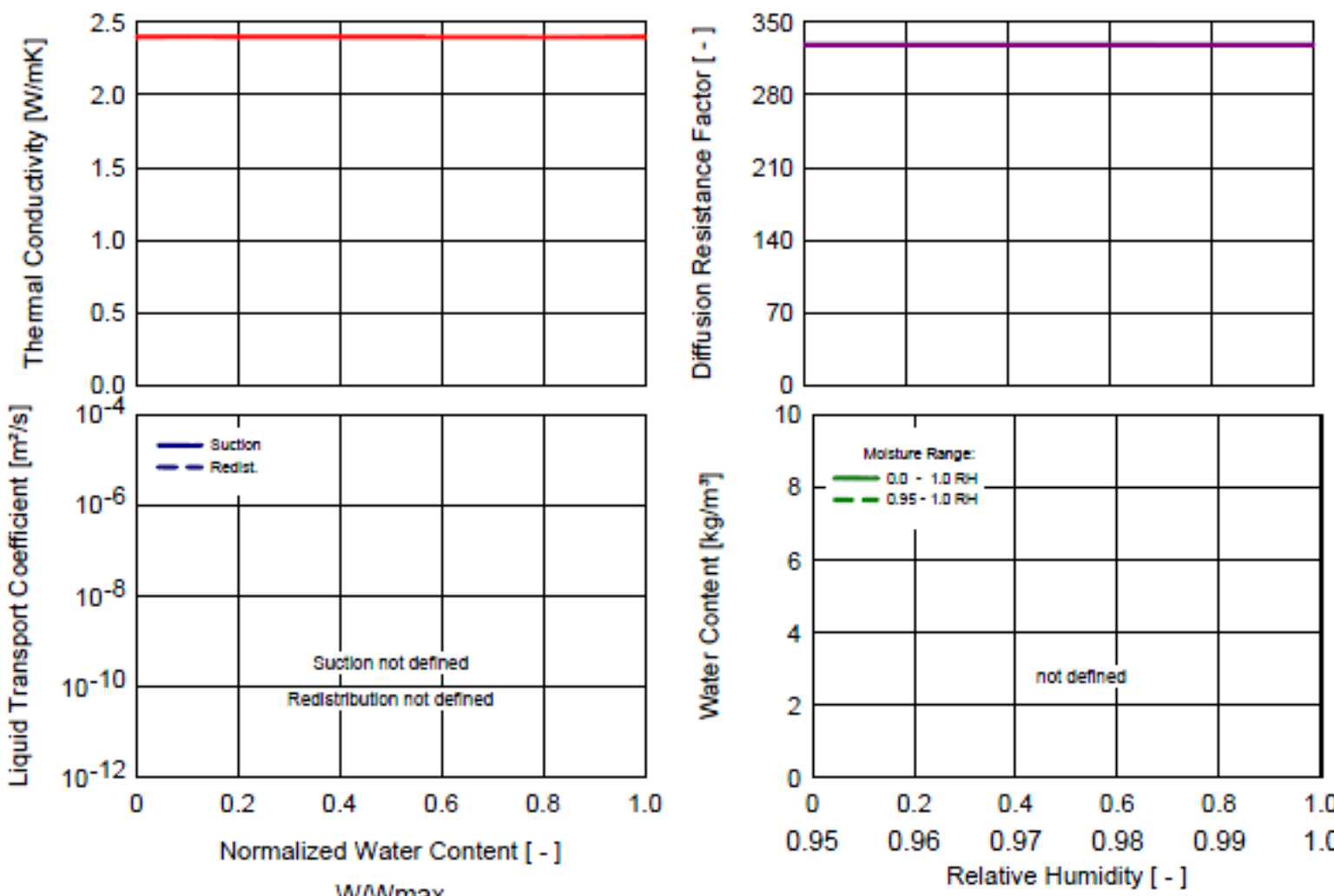

W/Wmax
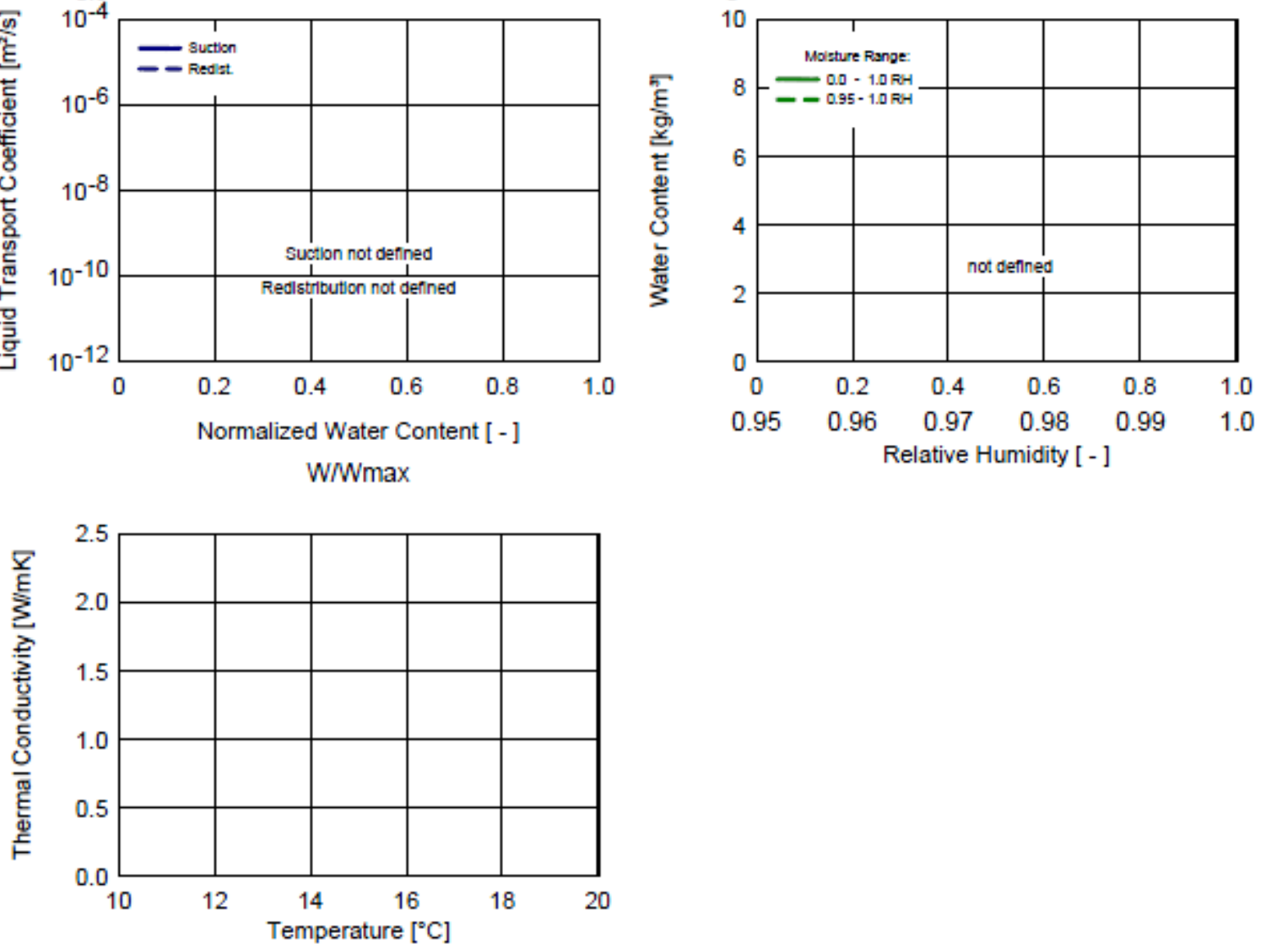
WUFI@ Pro 5.1

Material: "Plywood

Checking Input Data

\begin{tabular}{|l|c|c|}
\hline \multicolumn{1}{|c|}{ Property } & Unit & Value \\
\hline Bulk density & {$\left[\mathrm{kg} / \mathrm{m}^{2}\right]$} & 432 \\
\hline Porosity & {$\left[\mathrm{m}^{2} / \mathrm{m}^{2}\right]$} & 0,69 \\
\hline Specific Heat Capacity, Dry & {$[\mathrm{J} / \mathrm{kgK}]$} & 1880,0 \\
\hline Thermal Conductivity, Dry, 10 $\mathrm{C}$ & {$[\mathrm{W} / \mathrm{mK}]$} & 0,084 \\
\hline Water Vapour Diffusion Resistance Factor & {$[-]$} & 1078,2 \\
\hline \hline Reference Water Content & {$\left[\mathrm{kg} / \mathrm{m}^{2}\right]$} & 64,4 \\
\hline Free Water Saturation & {$\left[\mathrm{kg} / \mathrm{m}^{2}\right]$} & 550,0 \\
\hline Water Absorption Coefficient & {$\left[\mathrm{kg}^{2} \mathrm{~m}^{2} \mathrm{~s}^{\wedge} 0.5\right]$} & 0,0042 \\
\hline
\end{tabular}
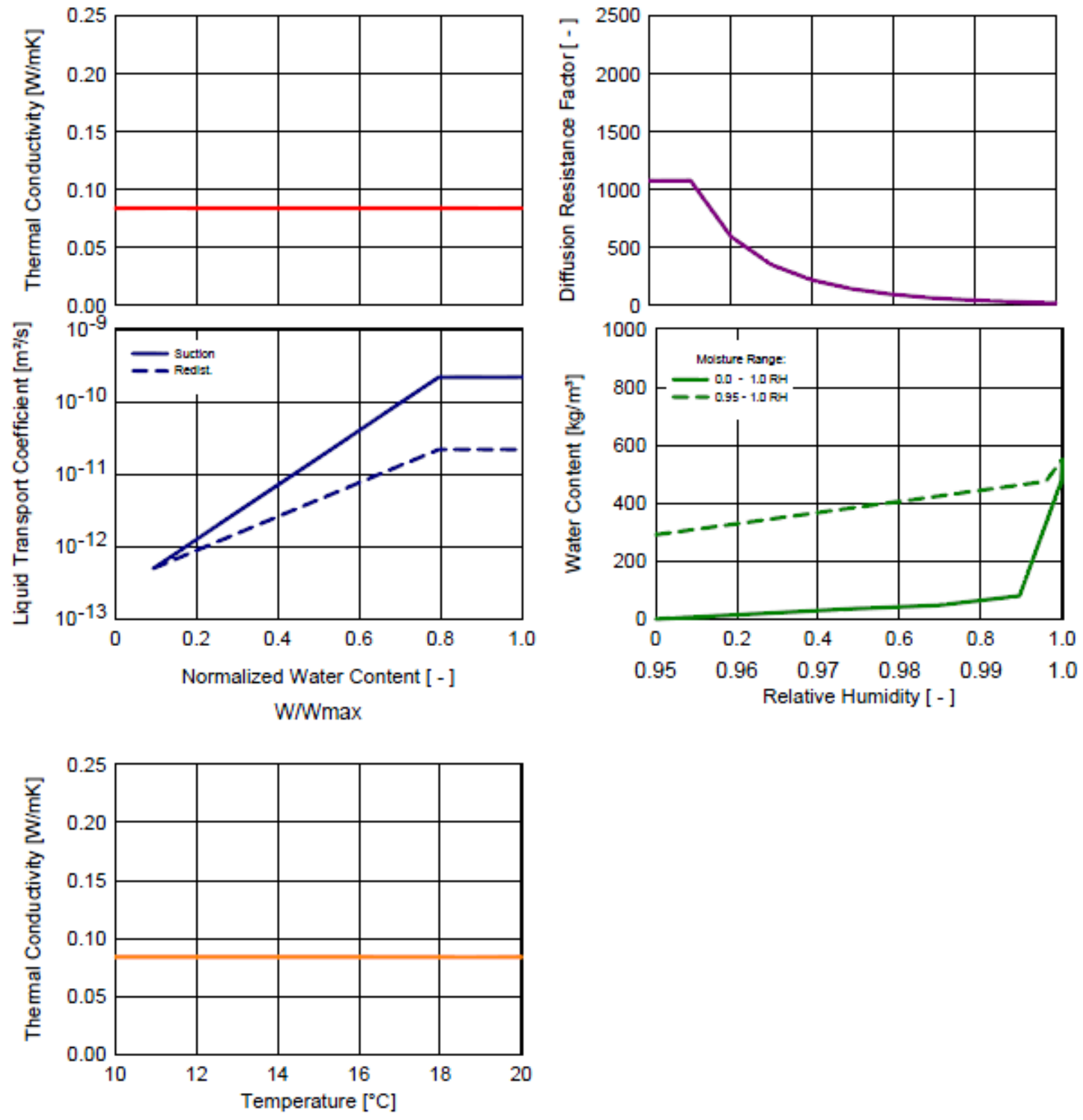
WUFI $\circledast$ Pro 5.1

Material : " Low Density Glass Fibre Batt Insulation

Checking Input Data

\begin{tabular}{|l|c|c|}
\hline \multicolumn{1}{|c|}{ Property } & Unit & Value \\
\hline Bulk density & {$\left[\mathrm{kg} / \mathrm{m}^{2}\right]$} & 88,0 \\
\hline Porosity & {$\left[\mathrm{m}^{2} / \mathrm{m}^{2}\right]$} & 0,999 \\
\hline Specific Heat Capacity, Dry & {$[\mathrm{J} / \mathrm{kgK}]$} & 840,0 \\
\hline Thermal Conductivity, Dry, $10^{\circ} \mathrm{C}$ & {$[\mathrm{W} / \mathrm{mK}]$} & 0,043 \\
\hline Water Vapour Diffusion Resistance Factor & {$[-]$} & 1,21 \\
\hline
\end{tabular}
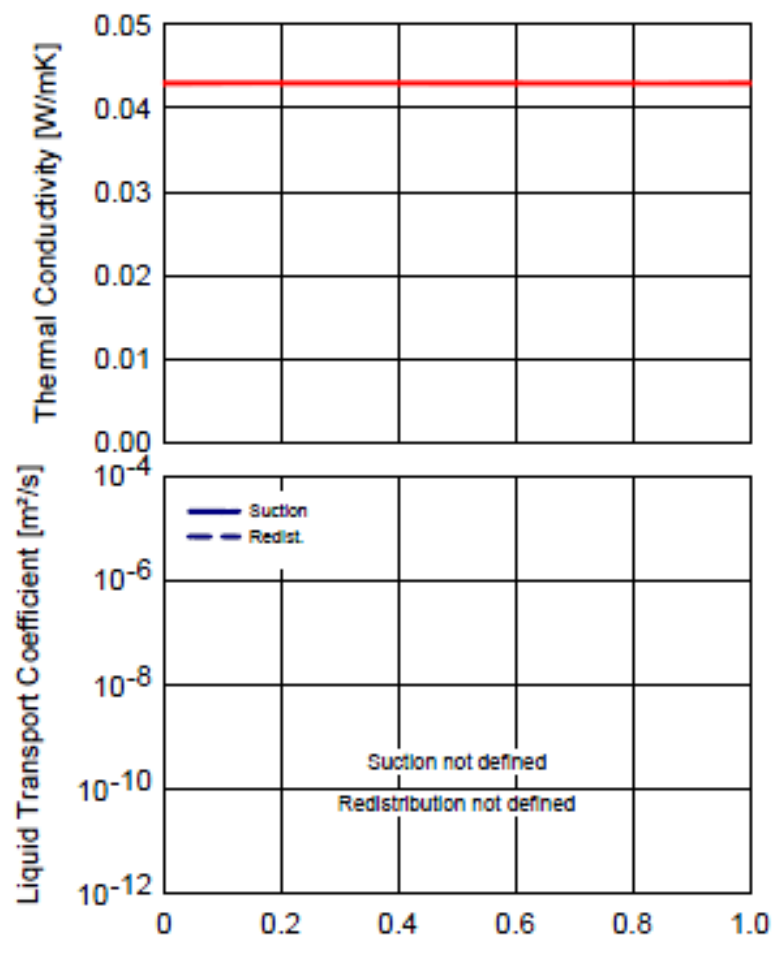

Normalized Water Content [ - ]

WINmax
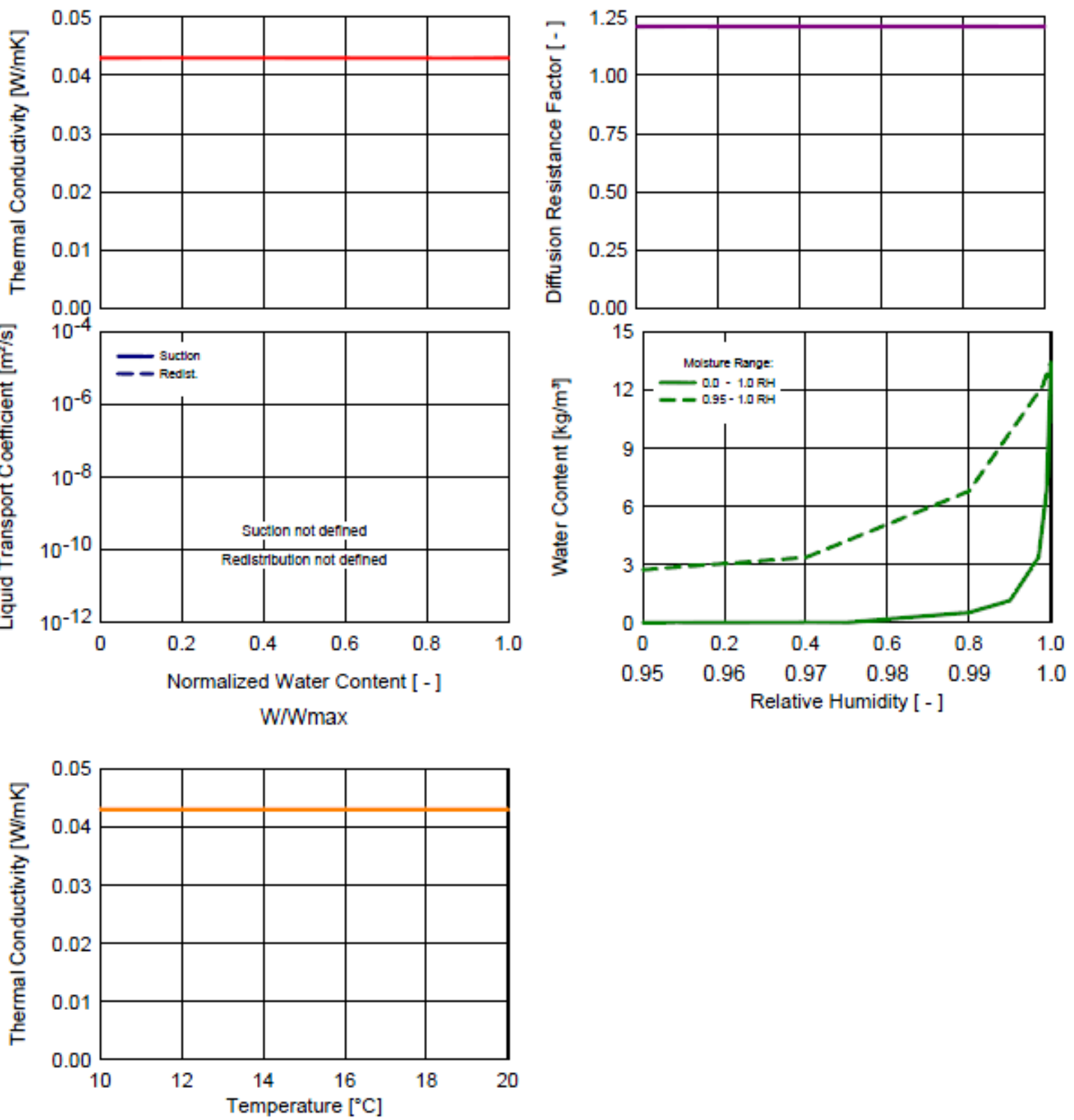
WUFI@ Pro 5.1

Material : *PE-Membrane (Poly; 0.07 perm)

Checking Input Data

\begin{tabular}{|l|c|c|}
\hline \multicolumn{1}{|c|}{ Property } & Unit & Value \\
\hline Bulk density & {$\left[\mathrm{kg} / \mathrm{m}^{2}\right]$} & 130,0 \\
\hline Porosity & {$\left[\mathrm{m}^{2} / \mathrm{m}^{2}\right]$} & 0,001 \\
\hline Specific Heat Capacity, Dry & {$[\mathrm{J} / \mathrm{kgK}]$} & 2300,0 \\
\hline Thermal Conductivity, Dry, $10^{\circ} \mathrm{C}$ & {$[\mathrm{W} / \mathrm{mK}]$} & 2,3 \\
\hline Water Vapour Diffusion Resistance Factor & {$[-]$} & 50000,0 \\
\hline
\end{tabular}
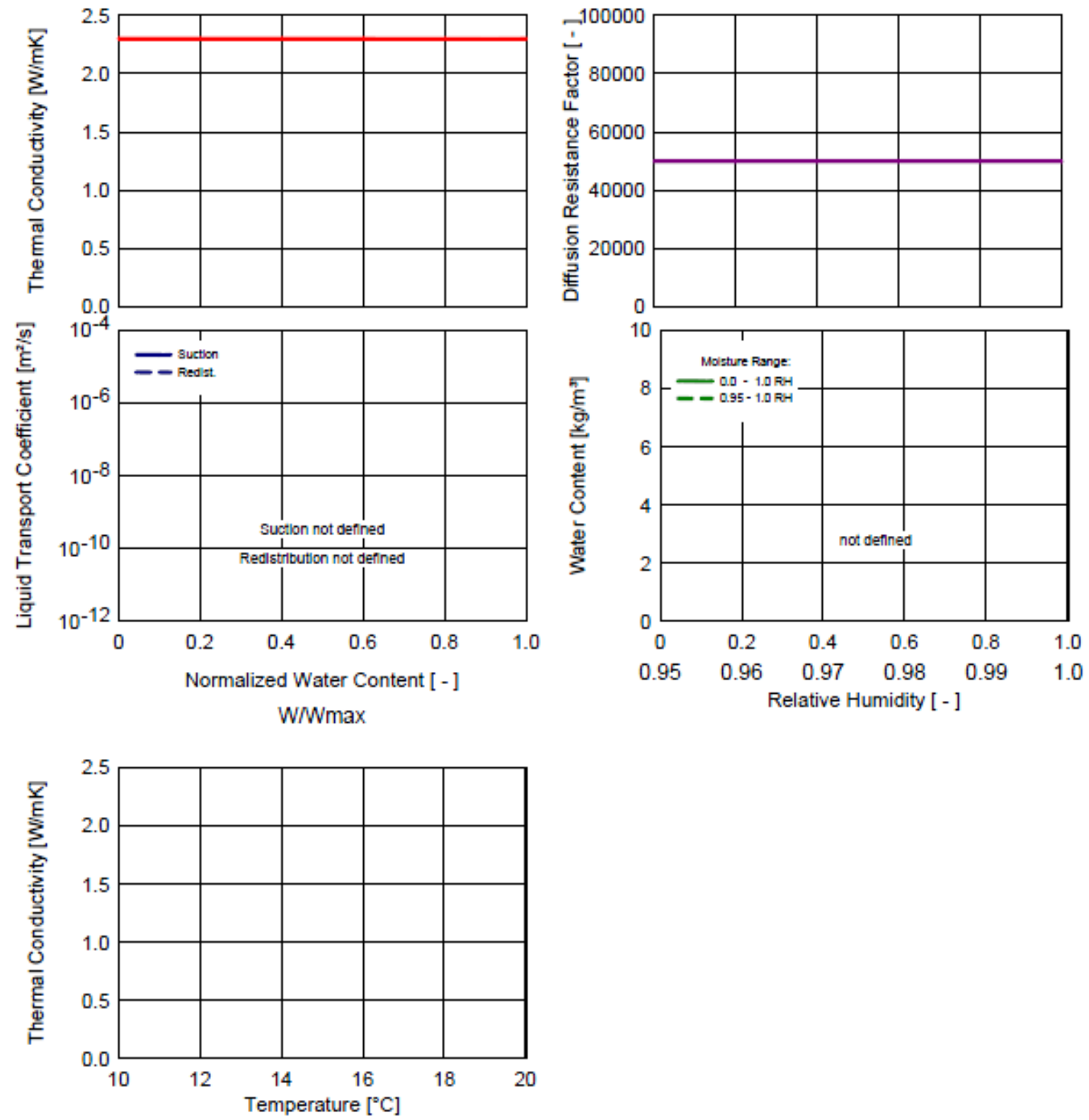
WUFI@ Pro 5.1

\section{Material : *Interior Gypsum Board}

Checking Input Data

\begin{tabular}{|l|c|c|}
\hline \multicolumn{1}{|c|}{ Property } & Unit & Value \\
\hline Bulk density & {$\left[\mathrm{kg} / \mathrm{m}^{2}\right]$} & 625,0 \\
\hline Porosity & {$\left[\mathrm{m}^{2} / \mathrm{m}^{2}\right]$} & 0,706 \\
\hline Specific Heat Capacity, Dry & {$[\mathrm{J} / \mathrm{kgK}]$} & 870,0 \\
\hline Thermal Conductivity, Dry,10 ${ }^{\circ} \mathrm{C}$ & {$[\mathrm{W} / \mathrm{mK}]$} & 0,16 \\
\hline Water Vapour Diffusion Resistance Factor & {$[-]$} & 7,03 \\
\hline
\end{tabular}
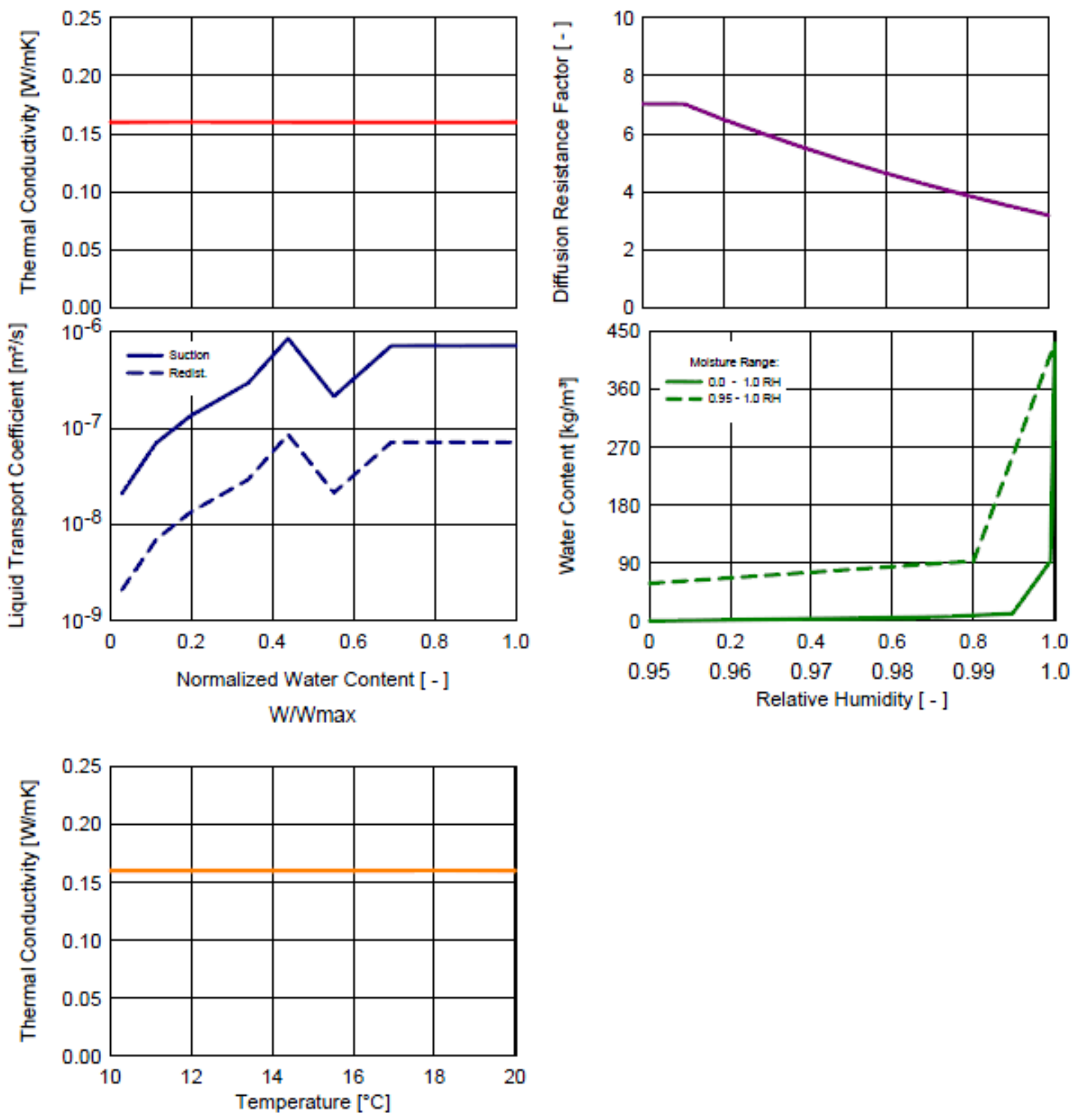
WUFI@ Pro 5.1

\title{
Boundary Conditions
}

\author{
Exterior (Left Side) \\ Location: simpson_raw.wac \\ Orientation / Inclination: South-East / $90^{\circ}$ \\ Interior (Right Side) \\ Indoor Climate: WTA Guideline 6-2-01/E \\ Indoor Condition, Medium Moisture Load
}

\section{Surface Transfer Coefficients}

Exterior (Left Side)

\begin{tabular}{|l|c|c|l|}
\hline \multicolumn{1}{|c|}{ Name } & Unit & Value & \multicolumn{1}{|c|}{ Description } \\
\hline Heat Resistance & {$\left[\mathrm{m}^{2} \mathrm{~K} / \mathrm{W}\right]$} & 0.0588 & External Wall \\
\hline Sd-Value & {$[\mathrm{m}]$} & - & No coating \\
\hline Short-Wave Radiation Absorptivity & {$[-]$} & 0.68 & Brick, red \\
\hline Long-Wave Radiation Emissivity & {$[-]$} & 0.9 & Brick, red \\
\cline { 1 - 3 } Adhering Fraction of Rain & {$[-]$} & 0,7 & According to inclination and constry \\
\hline
\end{tabular}

Interior (Right Side)

\begin{tabular}{|l|c|c|l|}
\hline \multicolumn{1}{|c|}{ Name } & Unit & Value & \multicolumn{1}{c|}{ Description } \\
\hline Heat Resistance & {$\left[\mathrm{m}^{2} \mathrm{~K} / \mathrm{W}\right]$} & 0.125 & External Wall \\
\hline Sd-Value & {$[\mathrm{m}]$} & - & No coating \\
\hline
\end{tabular}




\section{Appendix B}

Retention curves obtained from literature.
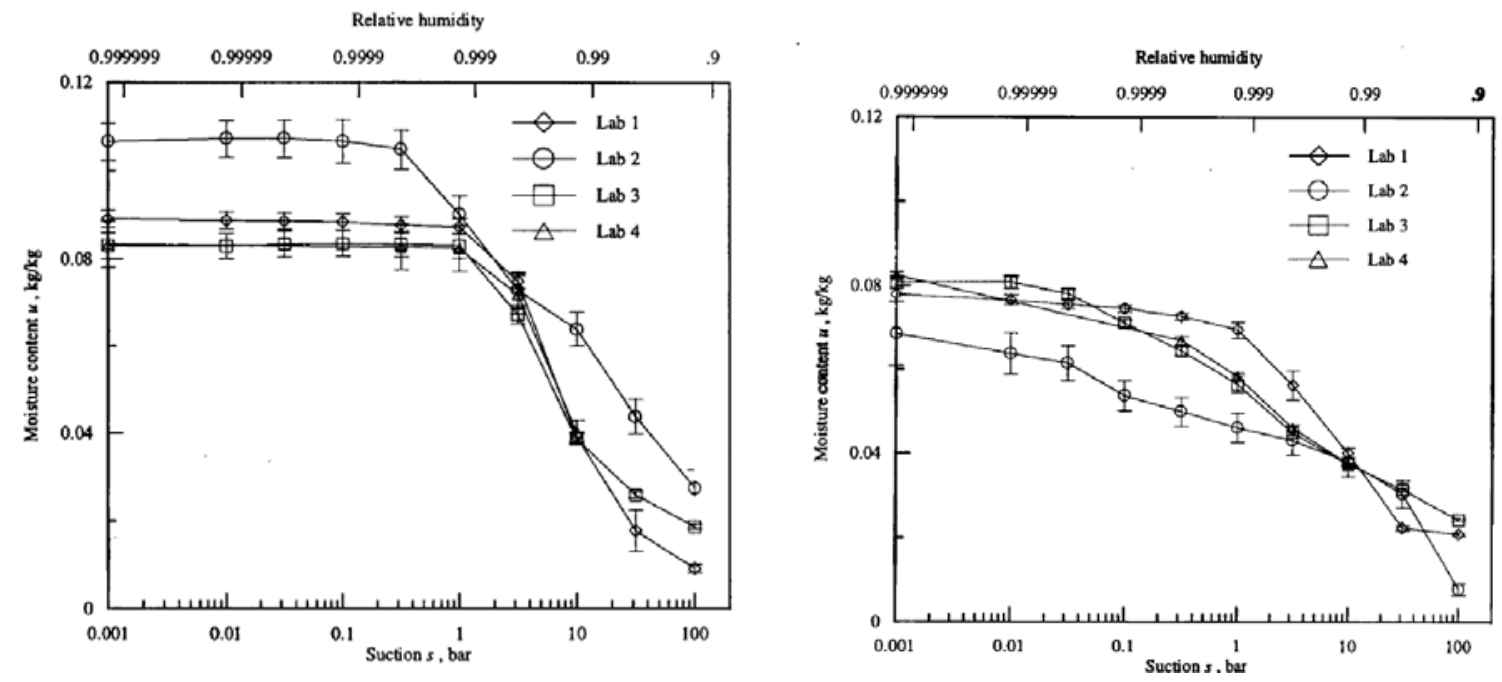

Bamburger sandstone (left) and Sander sandstone (right) shown above (Hansen et al, 1999).
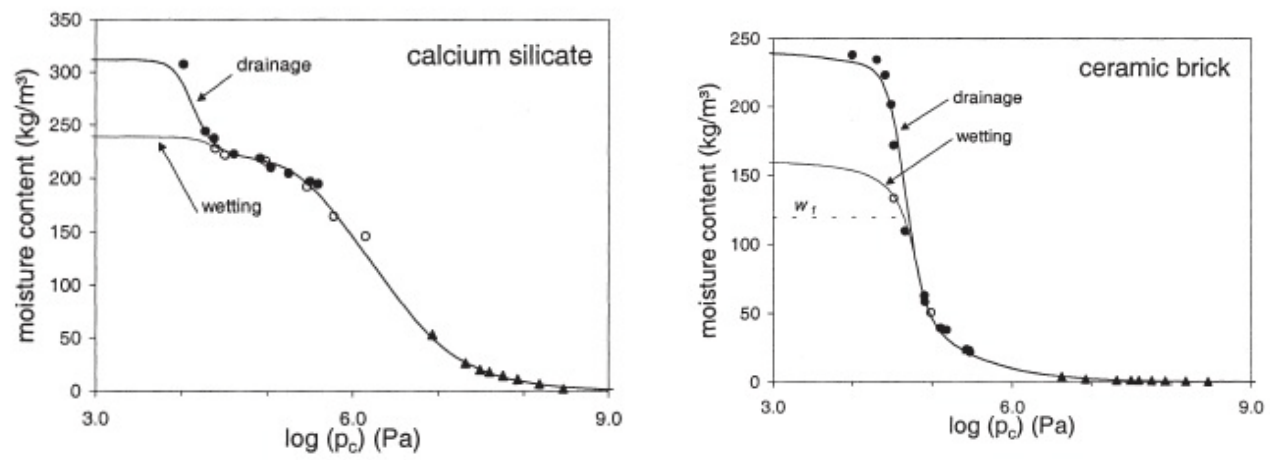

Calcium silicate (left) and Ceramic brick (right) shown above (Carmeliet \& Roels, 2000).

The rest of the graphs below show other materials obtained from one report (Janz \& Johannesson, 2001). 


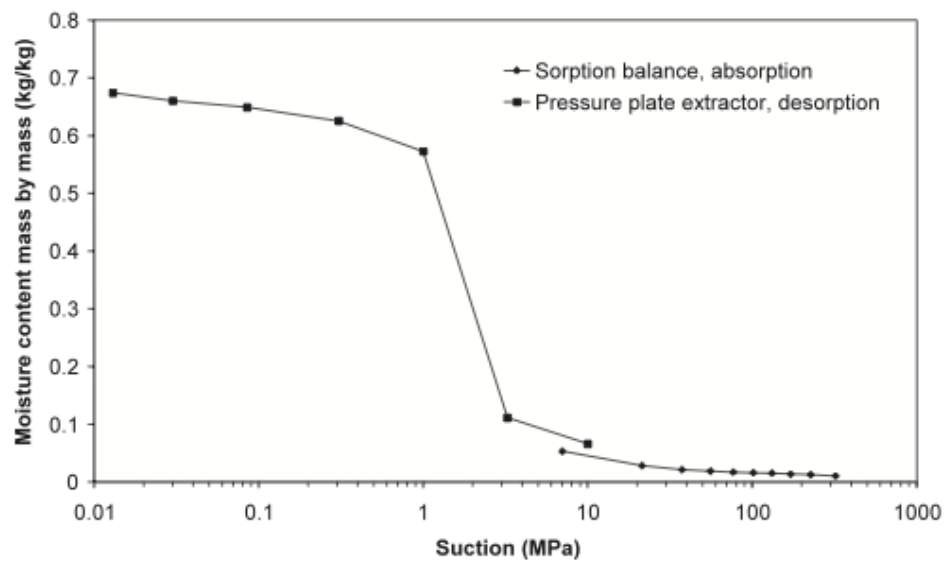

Retention curve for autoclaved aerated concrete.

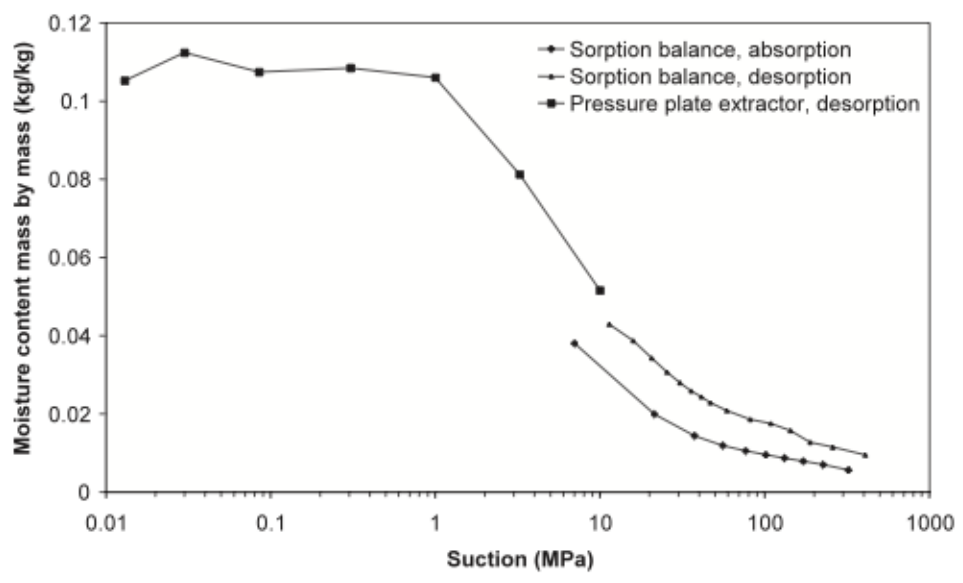

Retention curve for cement mortar.

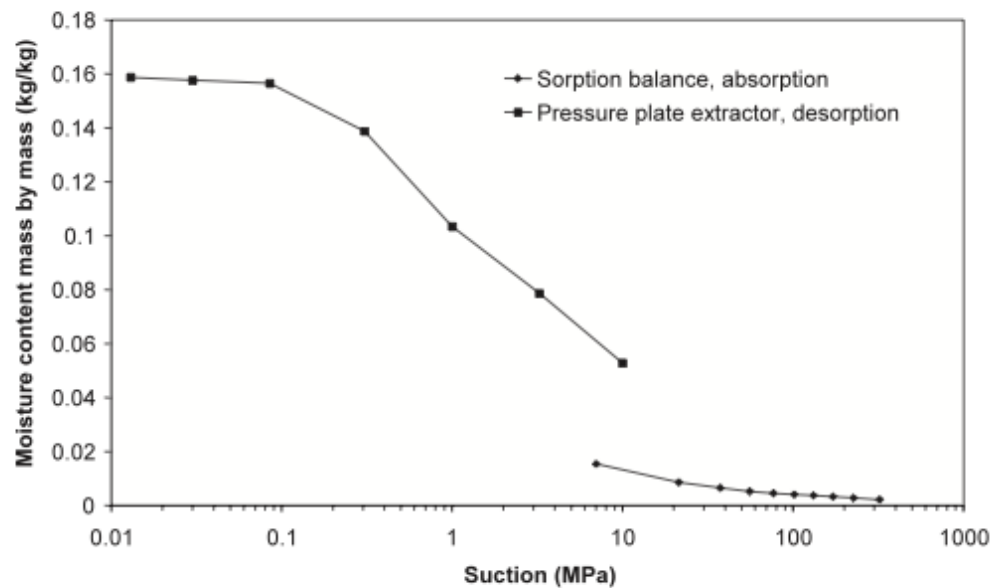

Retention curve for cement-lime mortar CL 50/50/650. 


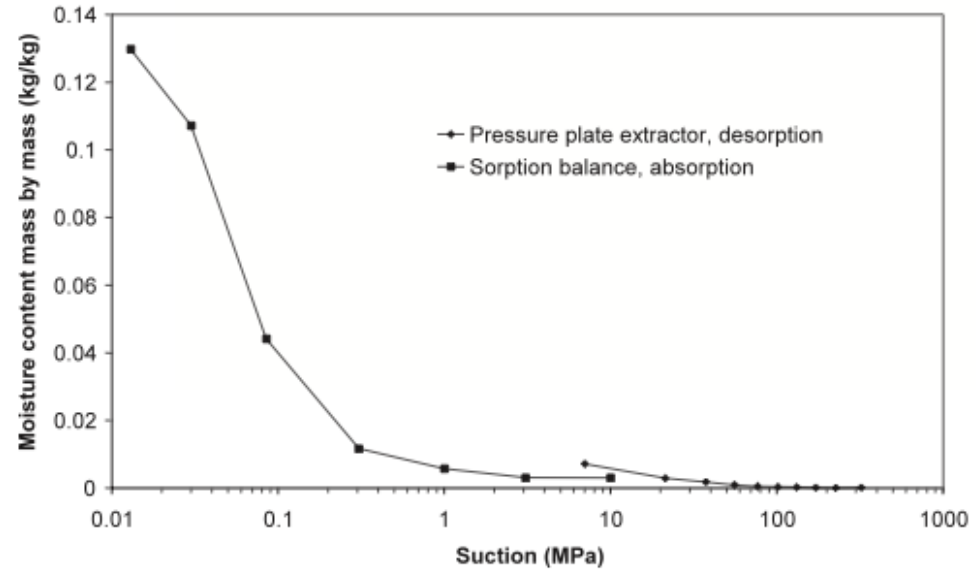

Retention curves for Brick 1, "Kantik Antik."

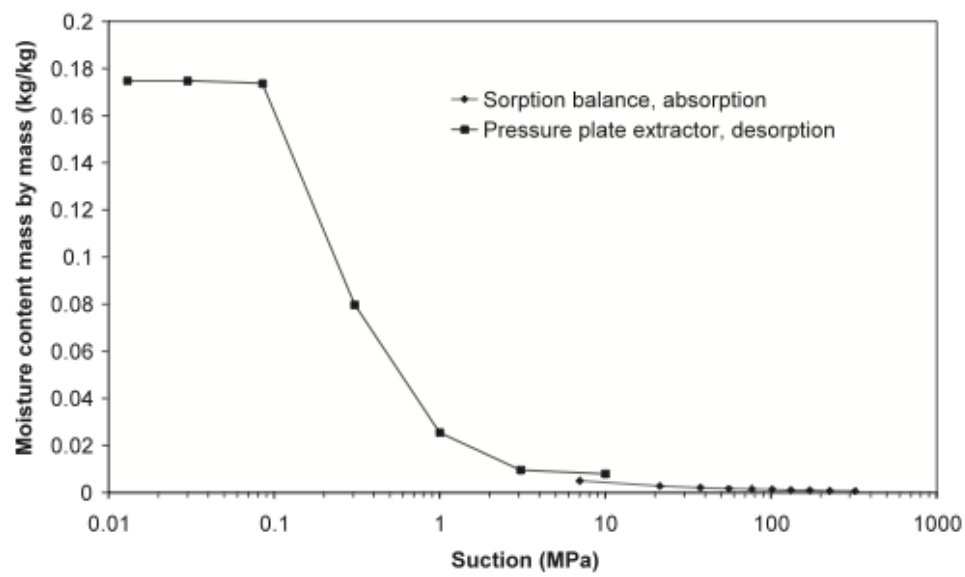

Retention curve for Brick 2, "Kantik Gul."

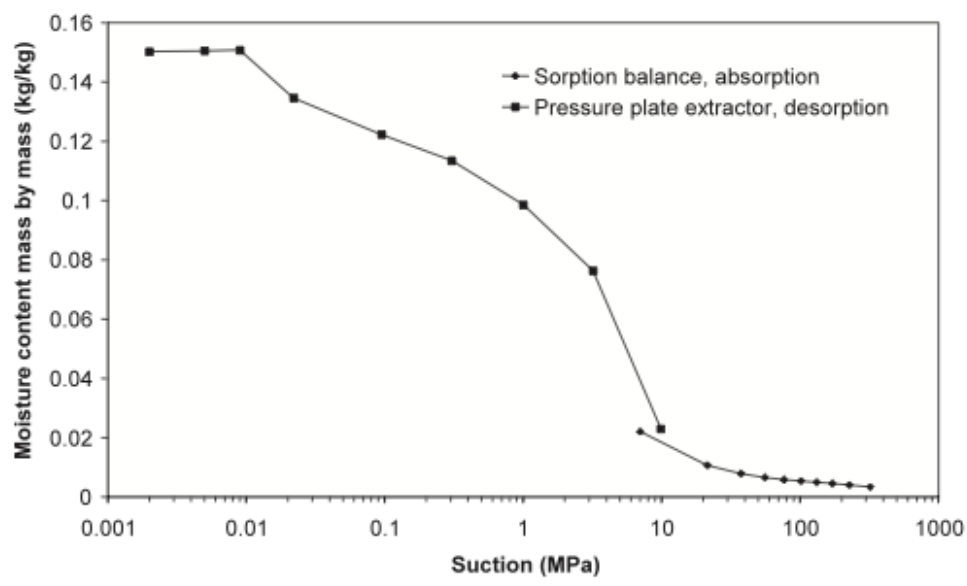

Retention curve for the lime silica brick. 


\section{Appendix C}

$\%$ The font in green (after the \%) are comments.

\%This program is to calculate hydraulic conductivity given sorption

\%isotherm, density and liquid diffusivity

format long

material = 'southern yellow pine';

if strcmp(material, 'southern yellow pine')

den $=500$;

$\mathrm{RH}=\left[\begin{array}{llllll}0 & 49.9 & 70.3 & 88.6 & 99.78 & 100\end{array}\right] ;$

$\mathrm{mc}=\left[\begin{array}{llllll}0 & 20 & 45.5 & 77 & 285 & 300\end{array}\right] ; \% \mathrm{~kg} / \mathrm{m} 3$

old_dws $=\left[\begin{array}{lll}0 & 3.5 \mathrm{E}-13 & 8.3 \mathrm{E}-11\end{array}\right] ;$

old_dws_mc $=\left[\begin{array}{lll}\Theta & 62 & 300\end{array}\right]$;

dws $=$ interp1(old_dws_mc, old_dws, mc); \%to give values at moisture content of mc array

end

if strcmp (material, 'concrete')

den $=600$;

$\mathrm{RH}=\left[\begin{array}{lllllllll}0 & 50 & 80 & 93 & 96.4 & 99 & 99.5 & 99.9 & 100\end{array}\right] ;$

$\mathrm{mc}=\left[\begin{array}{lllllllll}0 & 5.3 & 10.7 & 26 & 171 & 357 & 391 & 405 & 470\end{array}\right] ; \% \mathrm{~kg} / \mathrm{m} 3$

old_dws $=\left[\begin{array}{llllll}0 & 2 \mathrm{e}-10 & 3.7 \mathrm{e}-9 & 6.5 \mathrm{e}-9 & 2.5 \mathrm{e}-8 & 2.7 \mathrm{e}-7\end{array}\right] ;$

old_dws_mc $=\left[\begin{array}{llllll}0 & 3.5 & 47 & 375 & 423 & 470\end{array}\right]$;

dws $=$ interp1(old_dws_mc, old_dws, mc); \%to give values at moisture content of mc array

end

if strcmp(material, 'red brick')

den $=1935$;

$\mathrm{RH}=\left[\begin{array}{llllll}0 & 50 & 69.5 & 91.5 & 99.999 & 100\end{array}\right] ;$

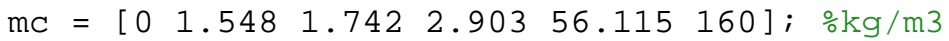

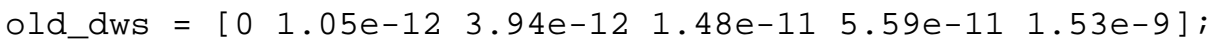

old_dws_mc $=\left[\begin{array}{llllll}0 & 50 & 70 & 90 & 110 & 160\end{array}\right]$;

dws $=$ interp1(old_dws_mc, old_dws, mc); \%to give values at moisture content of mc array

end

if strcmp(material, 'red brick 2')

den $=1935$;

$\mathrm{RH}=\left[\begin{array}{llllllllll}0 & 50 & 69.5 & 91.5 & 93 & 95 & 99 & 99.5 & 99.9 & 100\end{array}\right] ;$

$\mathrm{mc}=\left[\begin{array}{llllllllll}\Theta & 1.548 & 1.742 & 2.903 & 4 & 8 & 36 & 40 & 47 & 56.115\end{array}\right] ; \% \mathrm{~kg} / \mathrm{m} 3$

old_dws $=\left[\begin{array}{llllll}0 & 1.05 e-12 & 3.94 \mathrm{e}-12 & 1.48 \mathrm{e}-11 & 5.59 \mathrm{e}-11 & 1.53 \mathrm{e}-9\end{array}\right] ;$

old_dws_mc $=\left[\begin{array}{llllll}0 & 50 & 70 & 90 & 110 & 160\end{array}\right]$;

dws $=$ interp1(old_dws_mc, old_dws, mc); \%to give values at moisture content of mc array

end 


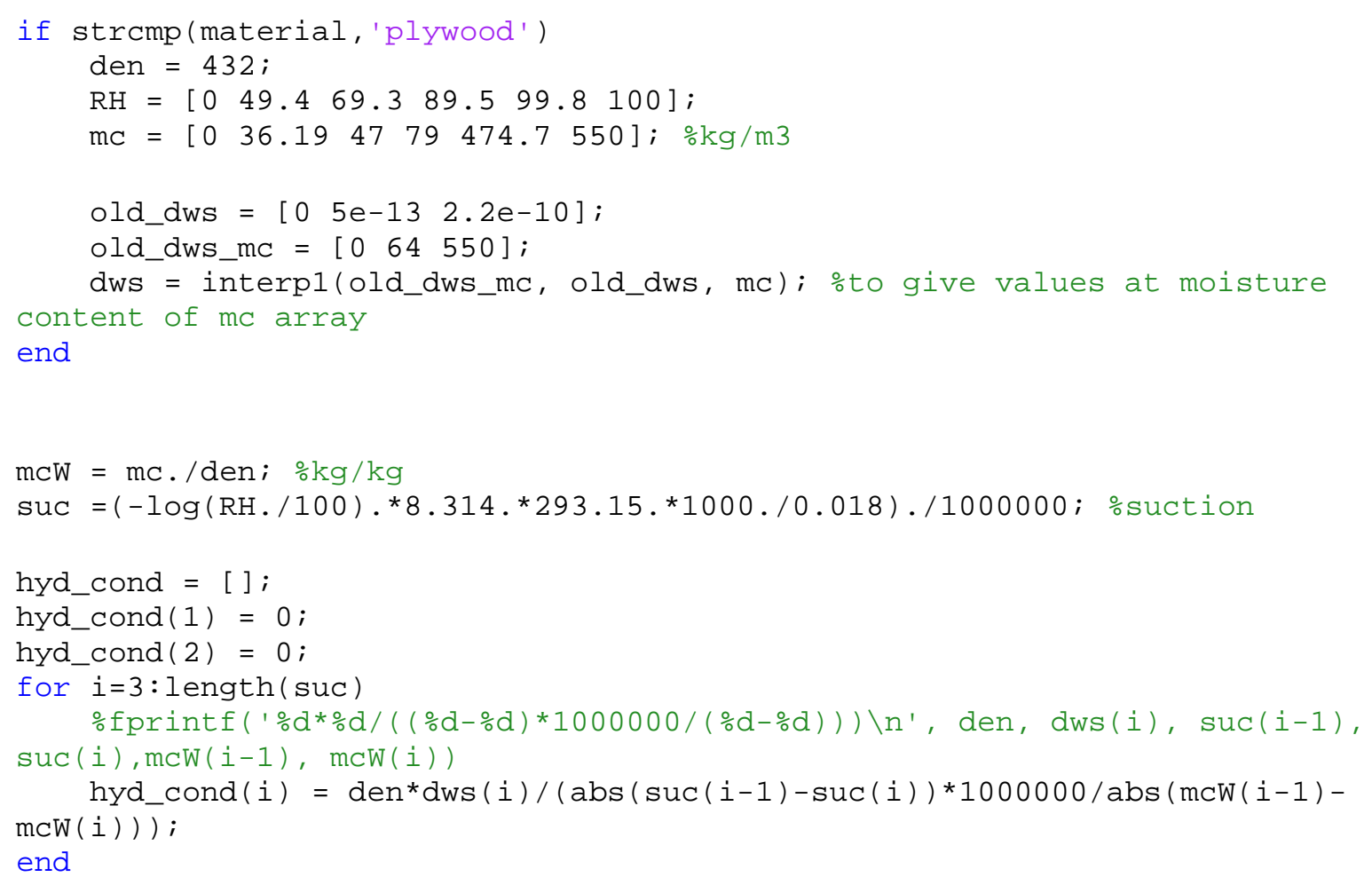


Calculated hydraulic conductivity values for aerated concrete, using literature retention curve (Janz \& and Johannesson, 2001)

\begin{tabular}{|c|c|c|c|c|}
\hline \multicolumn{2}{|c|}{ Janz et al } & \multicolumn{2}{|c|}{ WUFI } & \multirow{2}{*}{$\begin{array}{l}\text { Calculation } \\
\text { Hydrolic } \\
\text { conductivity } \\
\text { [kg/(s.Pa.m) }\end{array}$} \\
\hline $\begin{array}{l}\text { Suction } \\
\text { (Mpa) }\end{array}$ & $\begin{array}{l}\text { Moisture } \\
\mathrm{kg} / \mathrm{kg}\end{array}$ & $\begin{array}{l}\text { Moisture } \\
\mathrm{kg} / \mathrm{m} 3\end{array}$ & $\begin{array}{l}\mathrm{D}(\mathrm{WS}) \\
\mathrm{m} 2 / \mathrm{s}\end{array}$ & \\
\hline 500 & 0 & 0 & 0 & \\
\hline 330 & 0.011 & 6.6 & $4.50 \mathrm{E}-10$ & \\
\hline 230 & 0.013 & 7.8 & $5.50 \mathrm{E}-10$ & $6.60 \mathrm{E}-18$ \\
\hline 180 & 0.014 & 8.4 & $5.90 \mathrm{E}-10$ & 7.08E-18 \\
\hline 140 & 0.015 & 9 & $6.30 \mathrm{E}-10$ & $9.45 \mathrm{E}-18$ \\
\hline 100 & 0.016 & 9.6 & $6.80 \mathrm{E}-10$ & $1.02 \mathrm{E}-17$ \\
\hline 78 & 0.017 & 10.2 & $7.20 \mathrm{E}-10$ & $1.96 \mathrm{E}-17$ \\
\hline 55 & 0.018 & 10.8 & $7.75 \mathrm{E}-10$ & $2.02 E-17$ \\
\hline 37 & 0.019 & 11.4 & $8.20 \mathrm{E}-10$ & 2.73E-17 \\
\hline 22 & 0.026 & 15.6 & $1.16 \mathrm{E}-09$ & 3.25E-16 \\
\hline 7 & 0.051 & 30.6 & $2.35 \mathrm{E}-09$ & $2.35 \mathrm{E}-15$ \\
\hline 3 & 0.1 & 60 & $3.81 \mathrm{E}-09$ & $2.80 \mathrm{E}-14$ \\
\hline 1 & 0.57 & 342 & $6.20 \mathrm{E}-09$ & $8.74 \mathrm{E}-13$ \\
\hline 0.3 & 0.63 & 378 & $6.50 \mathrm{E}-09$ & 3.34E-13 \\
\hline 0.09 & 0.65 & 390 & $1.07 \mathrm{E}-08$ & $6.09 \mathrm{E}-13$ \\
\hline 0.03 & 0.66 & 396 & $1.32 \mathrm{E}-08$ & $1.32 \mathrm{E}-12$ \\
\hline \multirow[t]{3}{*}{0.013} & 0.67 & 402 & $1.57 \mathrm{E}-08$ & $5.54 \mathrm{E}-12$ \\
\hline & & 423 & $2.50 \mathrm{E}-08$ & \\
\hline & & 470 & $2.70 \mathrm{E}-07$ & \\
\hline
\end{tabular}

and calculating retention curve from WUFI data.

\begin{tabular}{|c|c|c|c|c|c|}
\hline \multicolumn{5}{|c|}{ WUFI DATABASE } & \multirow{2}{*}{\begin{tabular}{|l} 
Calculation \\
Hydrolic \\
conductivity \\
[kg/(s.Pa.m)
\end{tabular}} \\
\hline $\mathrm{RH}[\%]$ & $\begin{array}{l}\mathrm{mc} \\
{[\mathrm{kg} / \mathrm{m} 3]}\end{array}$ & $\begin{array}{l}\text { Moisture } \\
{[\mathrm{kg} / \mathrm{kg}]}\end{array}$ & $\begin{array}{l}\text { calculated } \\
\text { Suction }\end{array}$ & $\begin{array}{l}\mathrm{D}(\mathrm{WS}) \\
\mathrm{m} 2 / \mathrm{s}\end{array}$ & \\
\hline 0 & 0 & 0 & & 0 & \\
\hline 50 & 5.3 & 0.008833 & 93.8540 & $3.45 \mathrm{E}-10$ & \\
\hline 80 & 10.7 & 0.017833 & 30.2142 & $7.79 \mathrm{E}-10$ & $6.61 \mathrm{E}-17$ \\
\hline 93 & 26 & 0.043333 & 9.8263 & $2.01 \mathrm{E}-09$ & $1.51 \mathrm{E}-15$ \\
\hline 96.4 & 171 & 0.285 & 4.9644 & 4.76E-09 & $1.42 \mathrm{E}-13$ \\
\hline 99 & 357 & 0.595 & 1.3608 & $6.35 \mathrm{E}-09$ & 3.28E-13 \\
\hline 99.5 & 391 & 0.651667 & 0.6787 & $1.27 E-08$ & $6.31 \mathrm{E}-13$ \\
\hline 99.9 & 405 & 0.675 & 0.1355 & $1.81 E-08$ & $4.65 \mathrm{E}-13$ \\
\hline 100 & 470 & 0.783333 & 0.0000 & $2.70 \mathrm{E}-07$ & $1.30 E-10$ \\
\hline
\end{tabular}




\section{Appendix D}

\% Calculates the WDR for each angle in variable 'angle'

$\%$ plot wdr result in excel "wind driven rain plot.xls"

$\%$ The values and plot for 1-minute data for Burnaby weather is shown below

load VAN1min.txt

data = VAN1min;

rain $=\operatorname{data}(:, 13) \cdot / 10 ; \quad \%$ divide by 10 to get $\mathrm{mm}$

speed $=\operatorname{data}(:, 12) \cdot / 10 ; \%$ \%ivide by 10 to get $\mathrm{m} / \mathrm{s}$

dir $=\operatorname{data}(:, 11){ }^{*} \mathrm{pi} / 180 ; \%$ change to rad for calculation

$j=0$;

for angle $=0: 15: 345$

$j=j+1$;

wdrsect $=$ speed $\cdot{ }^{*}$ rain. $\wedge(8 / 9) \cdot{ }^{*} \cos \left(\right.$ dir - angle ${ }^{*}$ pi/180 $) ;$

$\operatorname{wdrSect}(w d r \operatorname{sect}<0)=0$; \% if value is less than zero, make it zero $w d r(j)=\operatorname{sum}(w d r S e c t) ; \%$ sums array into one value for that angle

end

$w d r=(2 / 9){ }^{*} w d r ;$ 
For data: 1-minute data

\begin{tabular}{|c|c|}
\hline Direction & WDR \\
\hline 0 & 25.17037 \\
\hline 15 & $\begin{array}{l}53.76415 \\
\end{array}$ \\
\hline 30 & 43.46925 \\
\hline 45 & \begin{tabular}{|l|l}
5 & 53.29608
\end{tabular} \\
\hline 60 & 61.84279 \\
\hline 75 & 67.95594 \\
\hline 90 & 71.28901 \\
\hline 105 & 71.2585 \\
\hline 120 & 67.50031 \\
\hline 135 & 60.46595 \\
\hline 150 & 51.0474 \\
\hline 165 & 41.02103 \\
\hline 180 & 31.50537 \\
\hline 195 & 23.3143 \\
\hline 210 & 16.9467 \\
\hline 225 & 12.5083 \\
\hline 240 & 9.569385 \\
\hline 255 & 7.759266 \\
\hline 270 & 7.271372 \\
\hline 285 & 7.782593 \\
\hline 300 & 8.891904 \\
\hline 315 & 10.71912 \\
\hline 330 & 13.55231 \\
\hline 345 & 18.33291 \\
\hline & \\
\hline & \\
\hline & $r^{8} / 9 \cos (D-\theta$ \\
\hline
\end{tabular}

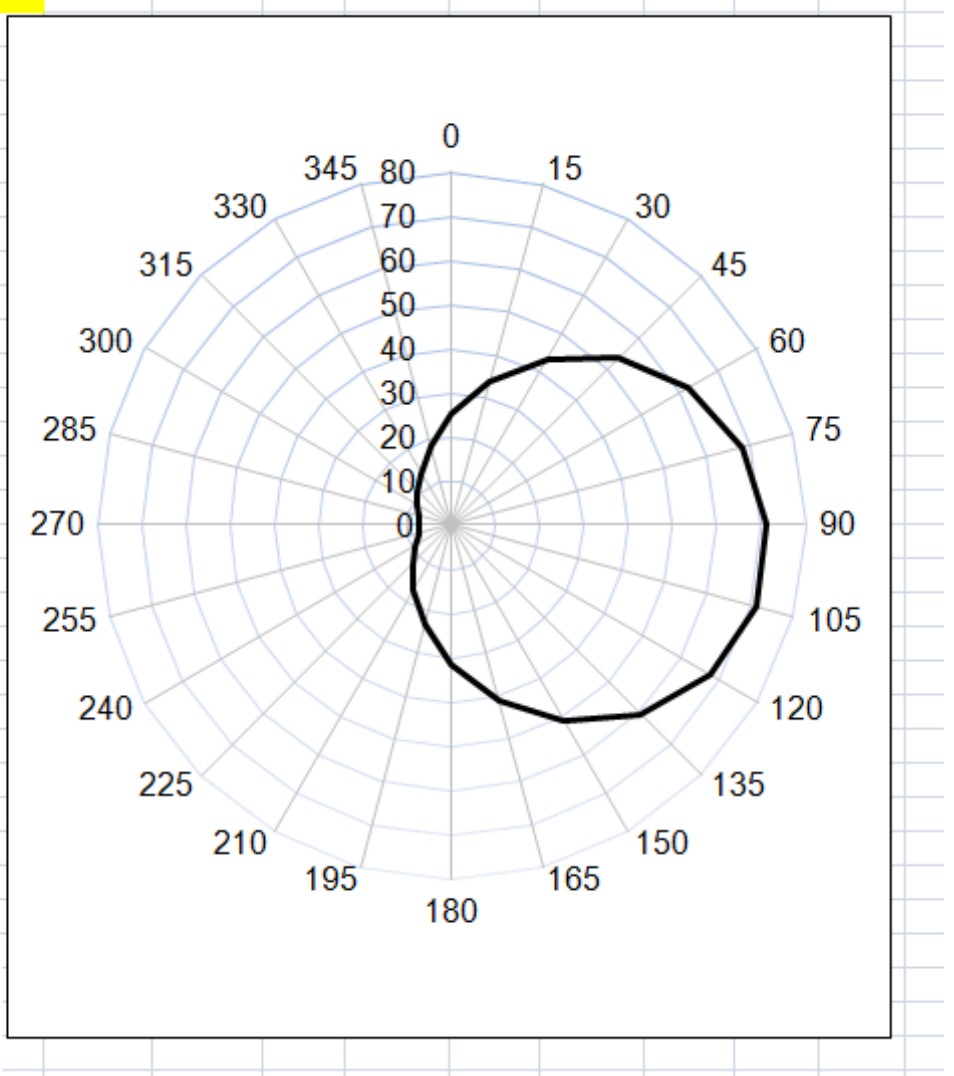




\section{Appendix E}

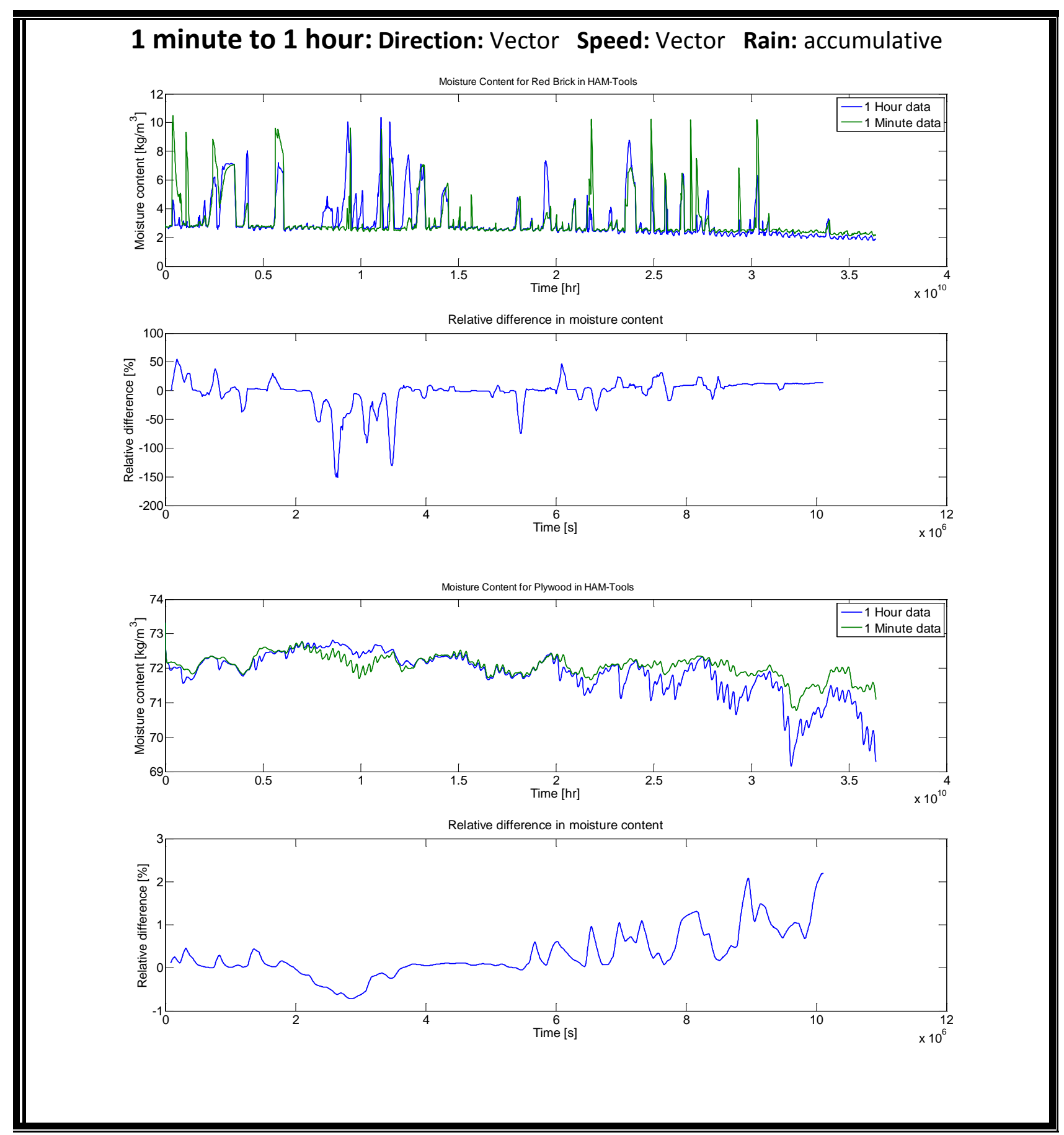




\section{1 minute to 1 hour: Direction: Vector Speed: Weighted Rain: Weighted}
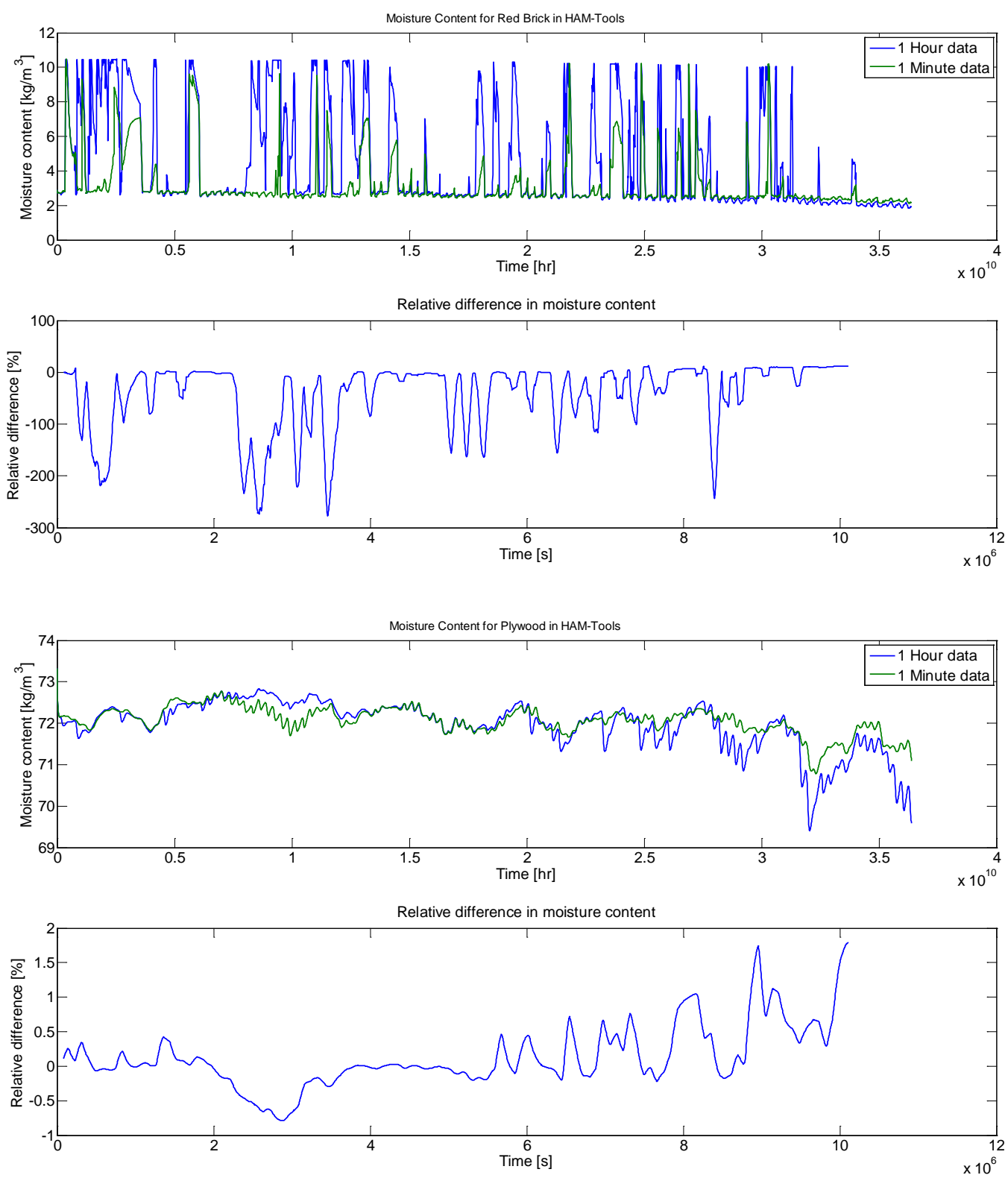


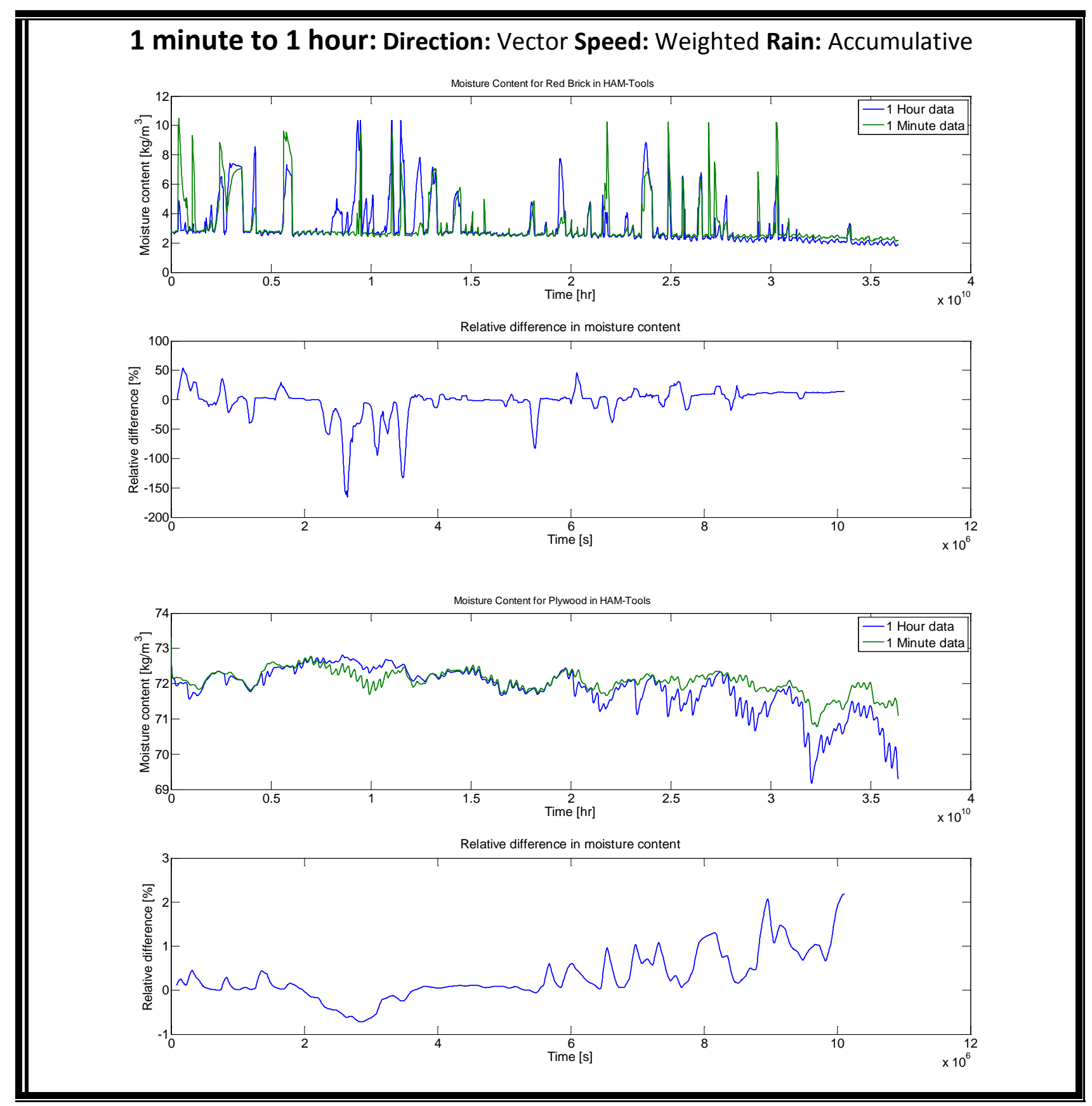


1 minute to 1 hour: Direction: Arithmetic Speed: Weighted Rain: Weighted
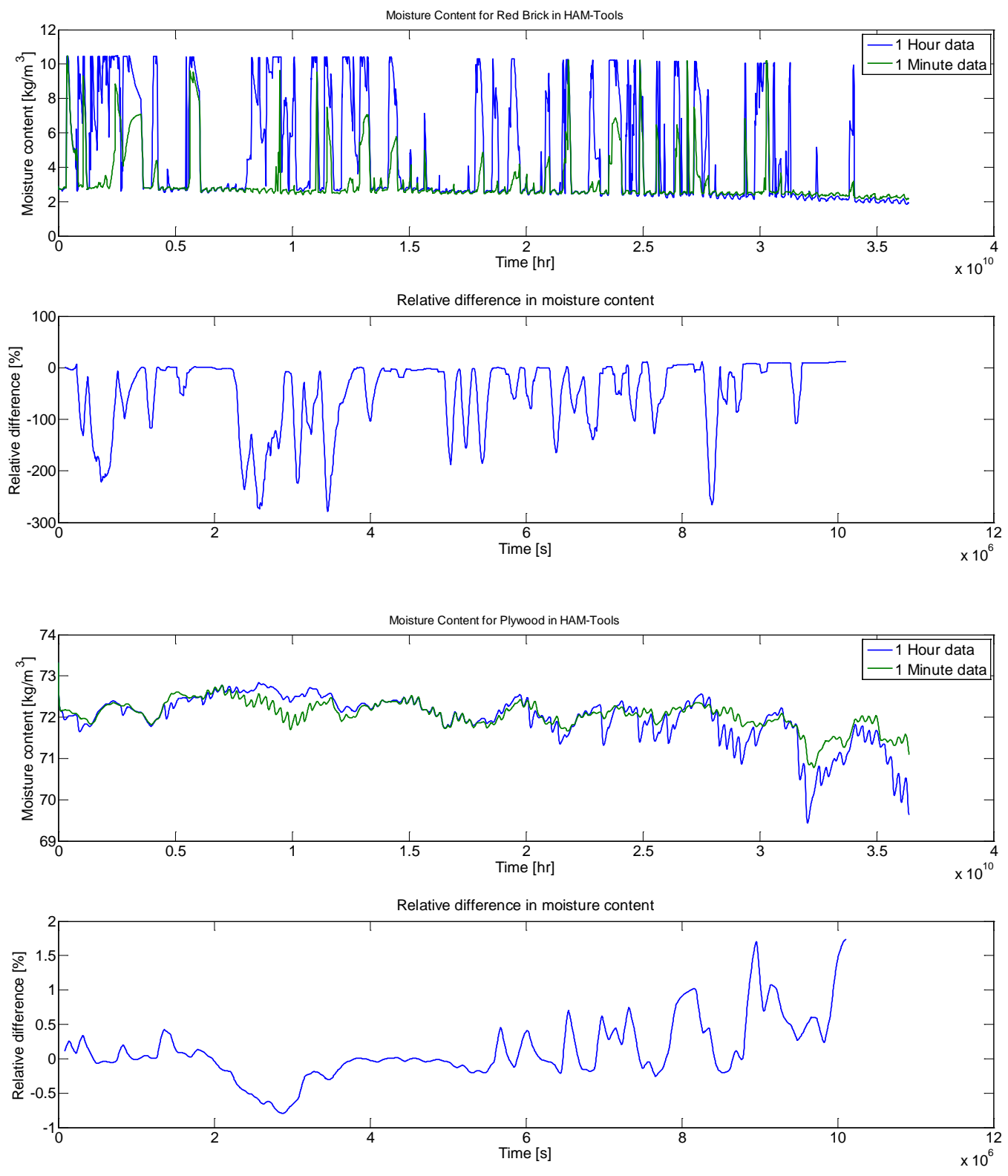


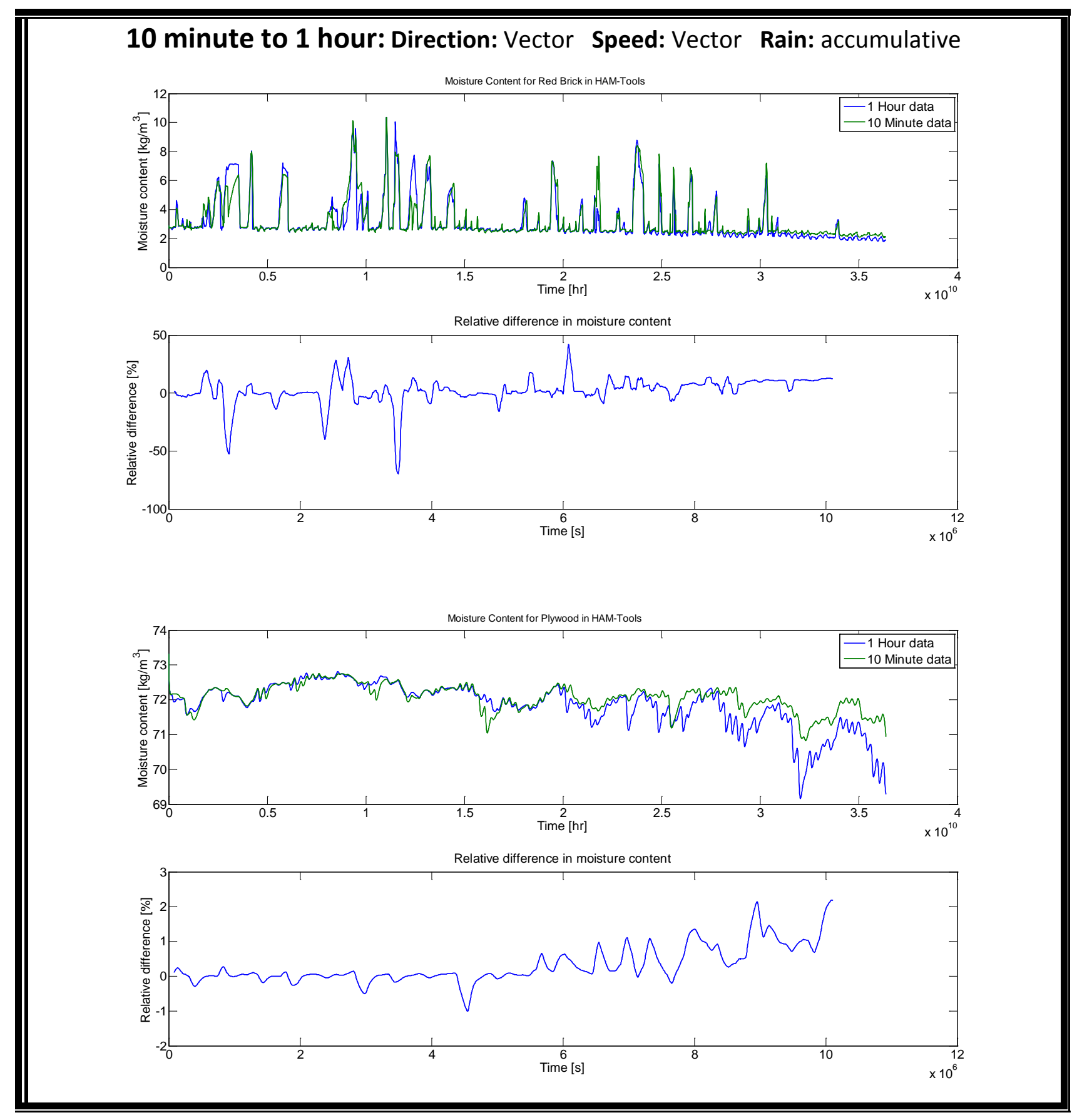




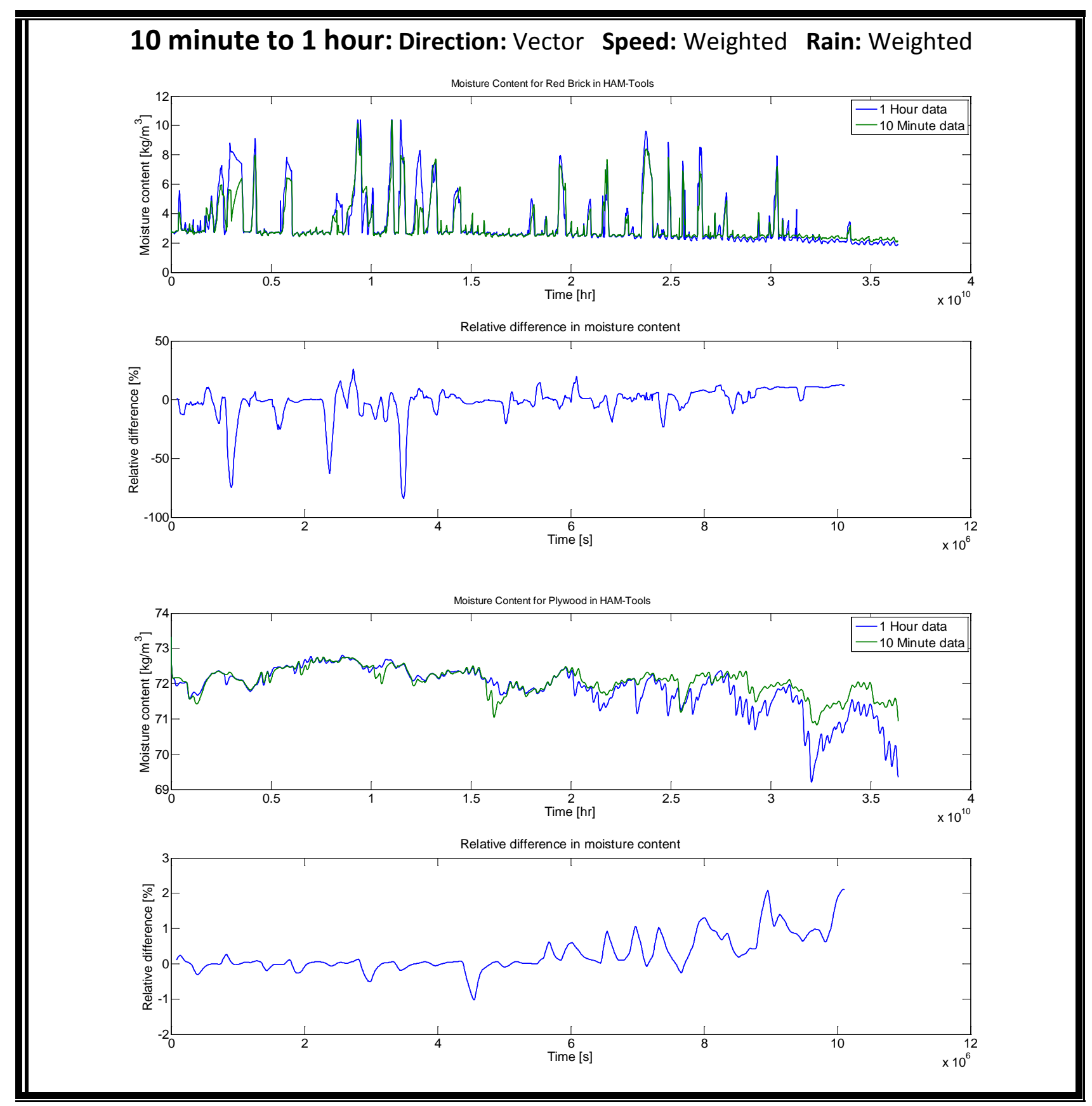


10 minute to 1 hour: Direction: Vector Speed: Weighted Rain: Accumulative
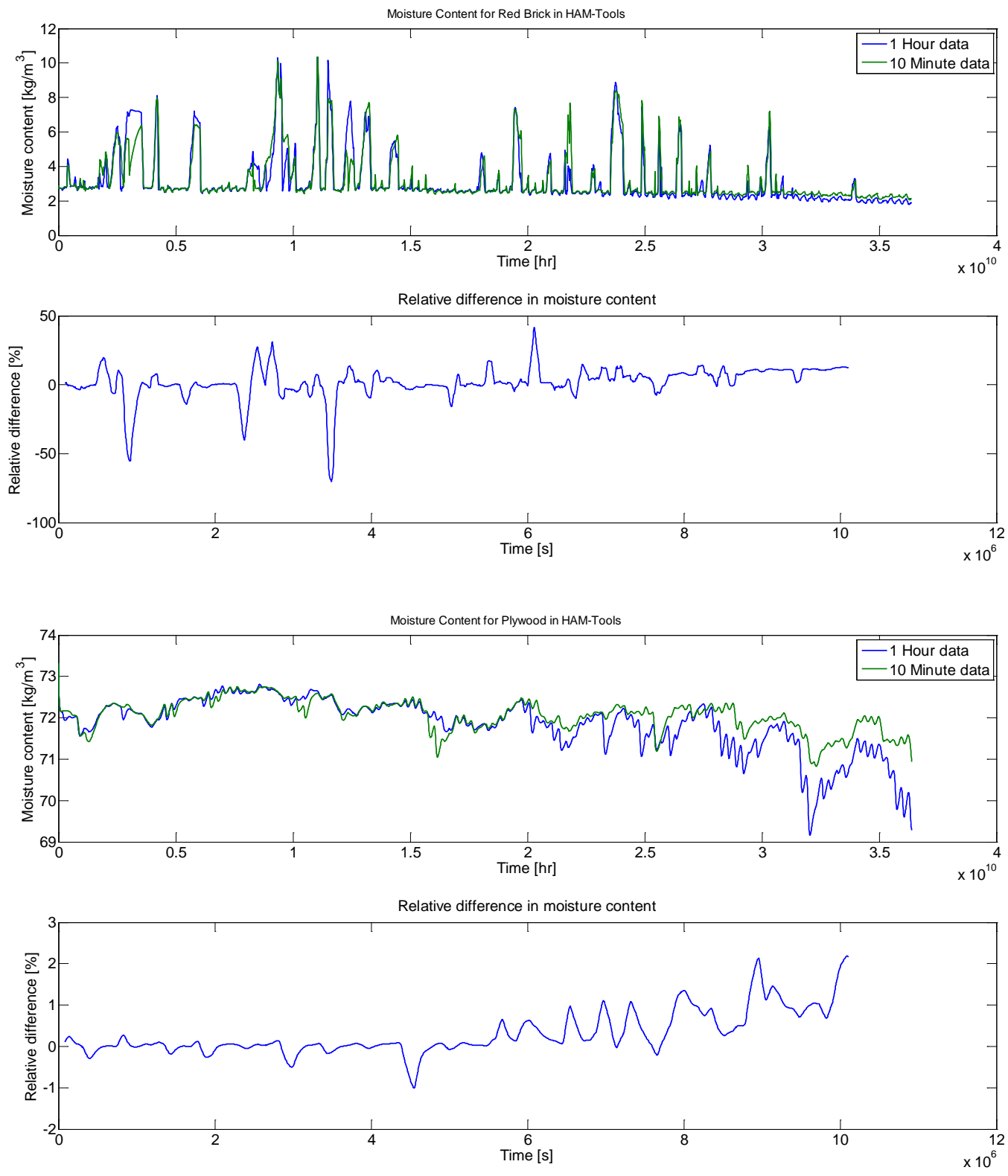
10 minute to 1 hour: Direction: Arithmetic Speed: Weighted Rain: Weighted
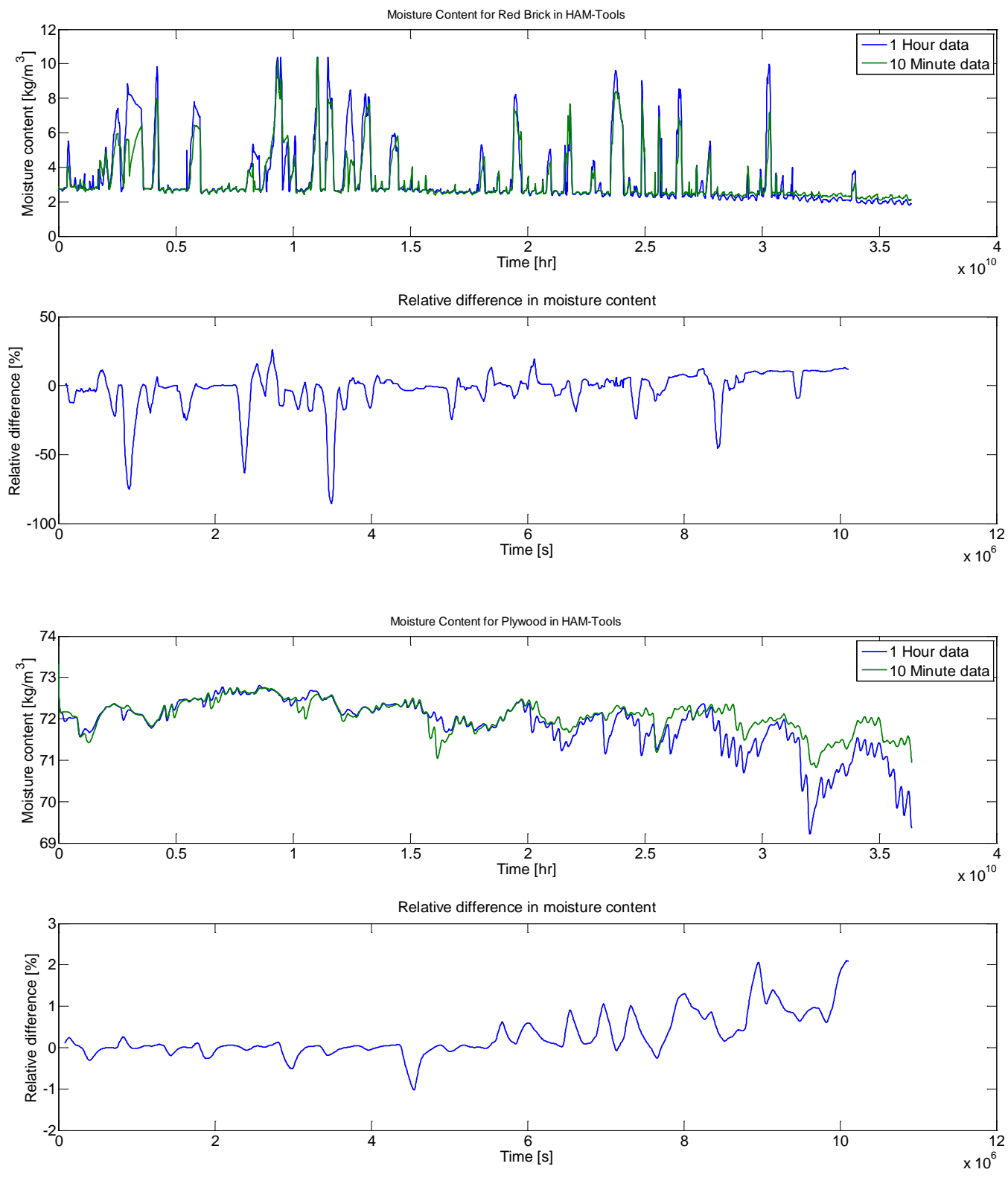


\section{Appendix F}

$\%$ This code calculates weighted average of speed and rain, with vector average for direction

$\%$ the matrix "num" contains all the weather data.

[num, txt $]=x l s r e a d(' m i n . x l s x ', ' 10 m i n u t e s ') ; \% 1 m i n u t e$ \%10minutes

$[$ row, column $]=\operatorname{size}($ num $)$;

[rowTxt, columnTxt] = size $(t x t)$;

$i=0$;

$j=0$;

count $=60$; \%put 60 to get $1 \mathrm{hr}$ data, 10 for $10 \mathrm{~min}$ data, 5 for 5 min, etc

while $i<$ row

$\mathrm{k}=0$ ；

while $k<$ count \&\& $i<$ row;

$\mathrm{k}=\mathrm{k}+1$;

$i=i+1$;

$x 1(k)=\operatorname{num}(i, 1) ; \%$ time

$x 2(k)=\operatorname{num}(i, 2) ; \%$ temperature

$x 3(k)=\operatorname{num}(i, 3) ; \%$ dew point

$x 4(k)=\operatorname{num}(i, 4) ; \%$ radiation

$x 5(k)=\operatorname{num}(i, 5) ; \%$ radiation

$x 6(k)=\operatorname{num}(i, 6) ; \%$ radiation

$x 7(k)=\operatorname{num}(i, 7) ; \%$ radiation

$x 8(k)=\operatorname{num}(i, 8) ; \quad \%$ lux

$x 9(k)=\operatorname{num}(i, 9) ; \quad \% \operatorname{lux}$

$x 10(k)=\operatorname{num}(i, 10) ; \%$ lux

$x 11(k)=\operatorname{num}(i, 11){ }^{*} \mathrm{pi} / 180 ; \%$ angle. change to rad for calculations

$x 12(k)=\operatorname{num}(i, 12)$;

$\%$ speed

$\cos x 11(k)=x 12(k){ }^{*} \cos (x 11(k)) ; \% y$ direction

$\sin \times 11(k)=x 12(k) * \sin (x 11(k)) ; \% x$ direction

$x 13(k)=\operatorname{num}(i, 13)$;

$\%$ rain

$R(k)=\operatorname{num}(i, 13) / 10 ; \quad \% R$ calculation for weighted average

$U(k)=\operatorname{num}(i, 12) / 10 ; \quad \%$ calculation for weighted average

$R j(k)=R(k){ }^{*} R(k) * 60 ; \% R j$ calculation for weighted average

$\mathrm{Uj}(\mathrm{k})=\mathrm{U}(\mathrm{k}){ }^{*} \mathrm{R}(\mathrm{k}) ; \quad \% \mathrm{Uj}$ calculation for weighted average

end

$\%$ create a matrix "mtrx" to put in new values in

$j=j+1$;

$\operatorname{mtrx}(j, 1)=x 1(1)$

$\operatorname{mtr} x(j, 2)=\operatorname{mean}(x 2)$;

$\operatorname{mtrx}(j, 3)=\operatorname{mean}(x 3)$;

$\operatorname{mtr} x(j, 4)=\operatorname{mean}(x 4) ;$

$\operatorname{mtr} x(j, 5)=\operatorname{mean}(x 5)$; 


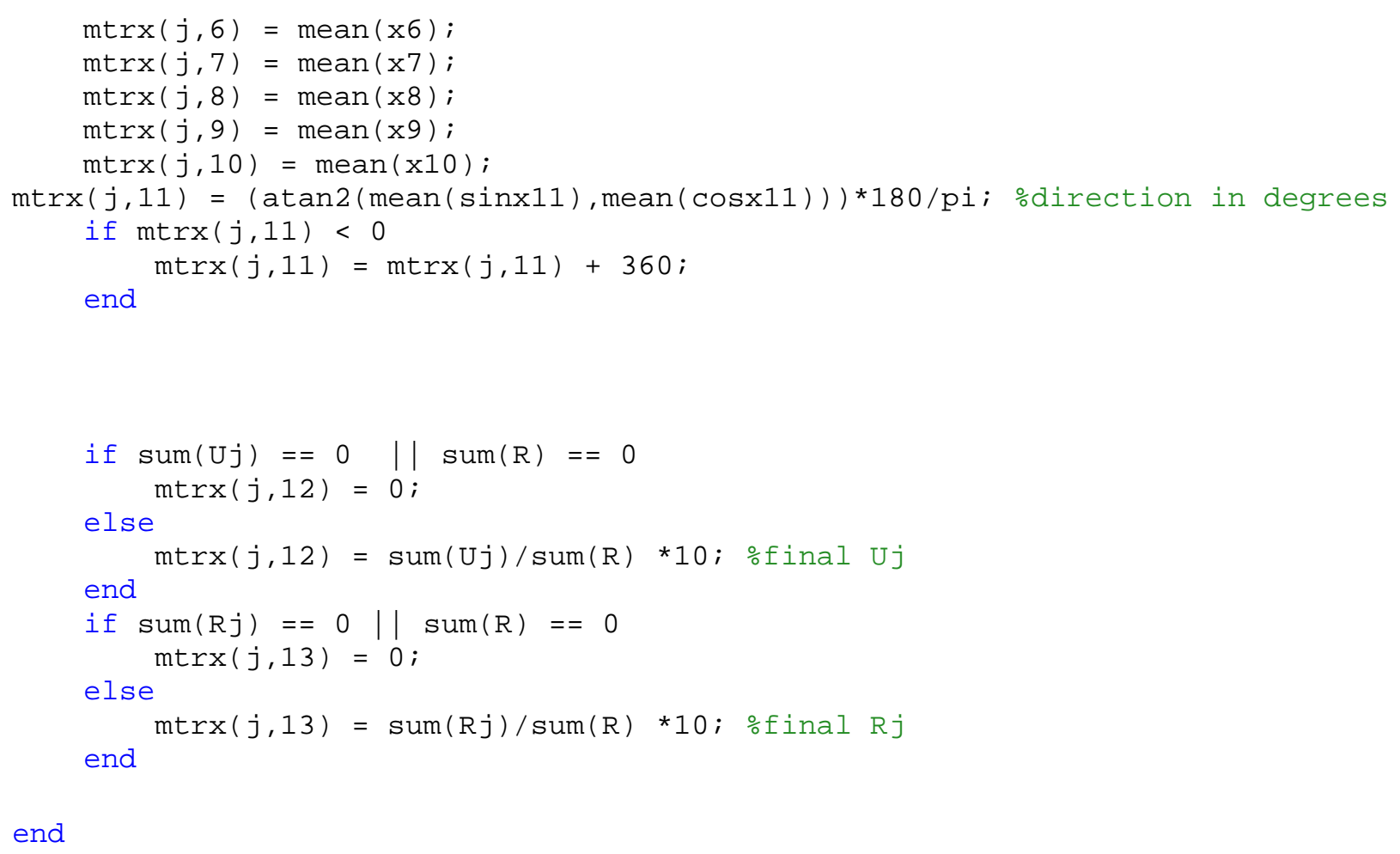

end 


\section{Appendix G}

$\%$ this code goes through the weather data and counts the missing minutes of $\%$ the weather data. The corrections were manually copied from the last given data. The sample of a part of the missing data is shown below

[num, txt $]=x l s r e a d(' m i n . x l s x ', ' 1$ minute'); \% 1 minute data $[$ row, column $]=\operatorname{size}($ num $)$;

$[$ rowTxt, columnTxt] = size $(t x t)$;

$[$ s1 ss $]=\operatorname{size}(\operatorname{num}(:, 4))$;

outp=0;

$j=1$;

$z=1$;

count $=1$;

state = true;

for $i=1: s 1$

$x=\operatorname{num}(i, 4)$;

if $x \sim=j$

$\operatorname{outp}(z, 1)=i$;

$\operatorname{outp}(z, 2)=x$;

$\operatorname{outp}(z, 3)=j$;

$\mathrm{z}=\mathrm{z}+1$;

$j=x$;

difference $=j-x$;

end

count = count - difference;

$j=j+1$;

if count $==59 \& x<60$ \& state $j=j+40$;

count $=0$;

end state $=$ false ;

if count $==60$

$j=j+40$;

end

count $=0$;

if $j>2400$

end

$j=1$;

end

count $=$ count +1 ; 


\begin{tabular}{|c|c|c|c|c|c|c|c|c|c|c|c|c|c|}
\hline 4 & 1 & 2 & 3 & 4 & 5 & 6 & 7 & 8 & 9 & 10 & 11 & 12 & 13 \\
\hline 1 & Time [s] & temp & dew point & radiation & radiation & radiation & radiation & lux & lux & $\operatorname{lux}$ & direction & speed & rain \\
\hline 2 & 804960 & 22.25 & 18.94 & 0 & 0.833333 & 0 & 0 & 100 & 100 & 0 & 78.3 & 1.764 & 0 \\
\hline 3 & 805020 & 20.91 & 17.60 & 0 & 0.833333 & 0 & 0 & 100 & 100 & 0 & 92 & 1.176 & 0 \\
\hline 4 & 805080 & 21.58 & 18.56 & 0 & 0.833333 & 0 & 0 & 100 & 100 & 0 & 135.7 & 0.588 & 0 \\
\hline 5 & 805140 & 20.91 & 17.75 & 0 & 0.833333 & 0 & 0 & 100 & 100 & 0 & 102.4 & 0.49 & 0 \\
\hline 6 & 805200 & 20.91 & 17.60 & 0 & 0.833333 & 0 & 0 & 100 & 100 & 0 & 118 & 1.078 & 0 \\
\hline 7 & 805260 & 21.58 & 18.27 & 0 & 0.833333 & 0 & 0 & 100 & 100 & 0 & 93.5 & 1.47 & 0 \\
\hline 8 & 805320 & 21.58 & 18.27 & 0 & 0.833333 & 0 & 0 & 100 & 100 & 0 & 100.6 & 1.078 & 0 \\
\hline 9 & 805380 & 21.58 & 18.27 & 0 & 0.833333 & 0 & 0 & 100 & 100 & 0 & 99.9 & 0.588 & 0 \\
\hline 10 & 805440 & 22.25 & 18.94 & 0 & 0.833333 & 0 & 0 & 100 & 100 & 0 & 109.7 & 0.098 & 0 \\
\hline 11 & 805500 & 21.58 & 18.27 & 0 & 0.833333 & 0 & 0 & 100 & 100 & 0 & 102.1 & 1.568 & 0 \\
\hline 12 & 805560 & 21.58 & 18.13 & 0 & 0.833333 & 0 & 0 & 100 & 100 & 0 & 102.1 & 1.372 & 0 \\
\hline 13 & 805620 & 21.58 & 18.42 & 0 & 0.833333 & 0 & 0 & 100 & 100 & 0 & 109.9 & 0.196 & 0 \\
\hline 14 & 805680 & 21.6 & 18.29 & 0 & 0.833333 & 0 & 0 & 100 & 100 & 0 & 180 & 0 & 0 \\
\hline 15 & 805740 & 21.6 & 18.29 & 0 & 0.833333 & 0 & 0 & 100 & 100 & 0 & 180 & 0 & 0 \\
\hline 16 & 805800 & 21.6 & 18.29 & 0 & 0.833333 & 0 & 0 & 100 & 100 & 0 & 113.2 & 0.392 & 0 \\
\hline 17 & 805860 & 21.59 & 18.14 & 0.196271 & 0.833333 & 0 & 0 & 100 & 100 & 0 & 118.2 & 0.392 & 1 \\
\hline 18 & 805920 & 22.26 & 18.95 & 0.196271 & 0.833333 & 0 & 0 & 100 & 100 & 0 & 110.1 & 0.784 & 0 \\
\hline 19 & 805980 & 22.26 & 18.80 & 0.294406 & 0.833333 & 0 & 0 & 100 & 100 & 0 & 109.1 & 0.294 & 0 \\
\hline 20 & 806040 & & & & & & & & & & & & \\
\hline 21 & 806100 & & & & & & & & & & & & \\
\hline 22 & 806160 & 1289 & 1712.62 & 0.294406 & 0.833333 & 0 & 0 & 100 & 100 & 0 & 180 & 0.294 & 0 \\
\hline 23 & 806220 & & & & & & & & & & & & \\
\hline 24 & 806280 & & & & & & & & & & & & \\
\hline 25 & 806340 & 0 & -1120.00 & 0 & 0.833333 & 0 & 0 & 100 & 100 & 0 & 152.8 & 0.294 & 0 \\
\hline 26 & 806400 & 22.26 & 18.80 & 0.294406 & 0.833333 & 0 & 0 & 100 & 100 & 0 & 127.6 & 0.196 & 0 \\
\hline 27 & 806460 & & & & & & & & & & & & \\
\hline 28 & 806520 & & & & & & & & & & & & \\
\hline 29 & 806580 & & & & & & & & & & & & \\
\hline 30 & 806640 & 0 & -1120.00 & 0 & 11.38889 & 0 & 60.27778 & 1300 & 1300 & 0 & 116.6 & 0.392 & 0 \\
\hline 31 & 806700 & 0 & -1120.00 & 0 & 11.38889 & 0 & 60.27778 & 1300 & 1300 & 0 & 134.2 & 0.196 & 0 \\
\hline 32 & 806760 & & & & & & & & & & & & \\
\hline 33 & 806820 & 21.58 & 17.98 & 0.981354 & 11.38889 & 0 & 60.27778 & 1300 & 1300 & 0 & 118.7 & 0.882 & 0 \\
\hline 34 & 806880 & 0 & -1120.00 & 0 & 11.38889 & 0 & 60.27778 & 1300 & 1300 & 0 & 180 & 0.196 & 0 \\
\hline 35 & 806940 & 0 & -1120.00 & 0 & 11.38889 & 0 & 60.27778 & 1300 & 1300 & 0 & 180 & 0 & 0 \\
\hline
\end{tabular}

